\title{
Faculdade de Engenharia da Universidade do Porto
}

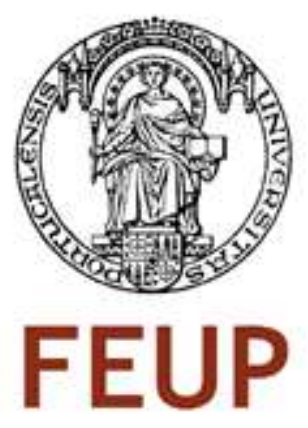

\section{A 2D Stress Analysis of Zirconia Dental Implants: A Comparison Study}

\author{
Leonor Gonçalves Piqueiro
}

\author{
PROVISIONAL VERSION
}

Thesis submitted to Faculdade de Engenharia da Universidade do Porto as a requirement to obtain the MSc Degree in Bioengineering

Under the supervision of:

Professor Jorge Américo Oliveira Pinto Belinha

Professor Renato Manuel Natal Jorge

June, 2016 
(c) Leonor Piqueiro, 2016 


\section{Resumo}

Ao longo dos anos, a saúde da boca, bem como o sorriso têm ganho importância, devido ao facto de ser uma das mais importantes capacidades de comunicação de uma pessoa. De facto, a frequência de próteses dentárias removíveis entre os adultos variou entre 13 e 29\%, enquanto a frequência das próteses dentárias fixas foi a maior na Suécia (45\%) e na Suíça (34\%). Ainda assim, os tratamentos de implantes dentários oferecem uma solução que poderá gerar resultados mais satisfatórios para pacientes que não se conseguem adaptar às dentaduras convencionais ou aqueles que já tenham comprometido o osso local.

Existem dois tipos de implantes dentários, que são as próteses dentárias removíveis (RDPs) e as próteses dentárias fixas (FDPs). Os tipos e restauração mencionados possuem nomes diferentes de acordo com a fixação (ou inexistência de fixação) ao osso. As próteses dentárias são aquelas que serão mais aprofundadas neste estudo. Estas próteses são constituídas por três elementos principais, que são a coroa, o abutment e o implante dentário propriamente dito.

A integridade biomecânica dos implantes compreende o comportamento mecânico dos materiais do implante, especialmente, Zircónia. As restaurações de zircónia possuem um papel importante nas FPDs, devido à sua vulnerabilidade mecânica.

Neste trabalho foram usadas técnicas avançadas de discretização numérica - meshless methods - mais especificamente, o Natural Neighbour Radial Point Interpolation Method (NNRPIM) e o Radial Point Interpolation Method (RPIM), mas também, o Método dos Elementos Finitos.

O principal objectivo deste trabalho foi compreender o comportamento mecânico dos implantes em zircónia e a resposta do tecido ósseo na presença destes implantes, bem como comparar os três métodos numéricos utilizados neste trabalho, FEM, RPIM e NNRPIM.

Os resultados obtidos mostram que os meshless methods são capazes de produzir campos de deslocamento e tensão mais precisos e suaves quando comparados com malhas de elementos finitos. 


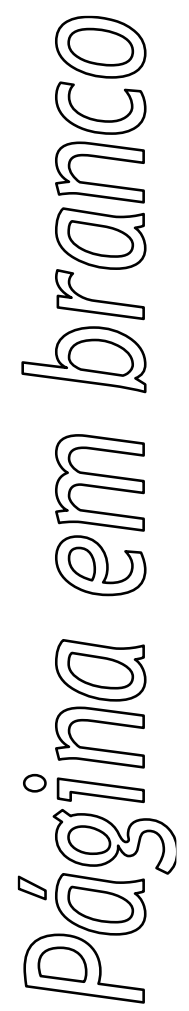




\section{Abstract}

Throughout the years, the health of the mouth and the smile have an increasing importance, due to the fact that is one of the most important interactive communication skills of a person. In fact, the frequency of removable dental prosthesis among adults varied between 13 and $29 \%$, while the frequency of fixed dental prosthesis was the highest in Sweden (45\%) and Switzerland (34\%). Yet, dental implant treatments offers a solution that may generate more satisfactory outcomes for patients who are not able to adapt to conventional dentures or who have already compromised local host bone.

There are two types of dental implants, which are the removable dental prosthesis (RDPs) and the fixed dental prosthesis (FDPs). The aforementioned types of restorations have different names according to the fixation (or absence of fixation) to the bone. Fixed dental prostheses are the ones that will be mainly focused in this study. These prostheses are constituted by three key elements, which are the crown, the abutment and the dental implant itself. The biomechanical integrity of implants comprises the mechanical behavior of implant materials, especially zirconia. Zirconia restorations have found their indications for FPDs supported by teeth implants due to its mechanical reliability.

It was used advanced discretization numerical techniques - meshless methods - more specifically, the Natural Neighbour Radial Point Interpolation Method (NNRPIM) and the Radial Point Interpolation Method (RPIM), and also the Finite Element Method (FEM)

.The main goal of this work was to understand the mechanical behavior of zirconia implants and the bone tissue response in the presence of such implants and also compare the three numerical methods used in this work, FEM, RPIM and NNRPIM.

The results obtained show that meshless methods are capable to produce more accurate and smooth displacement and stress fields when compared to finite element meshes. 


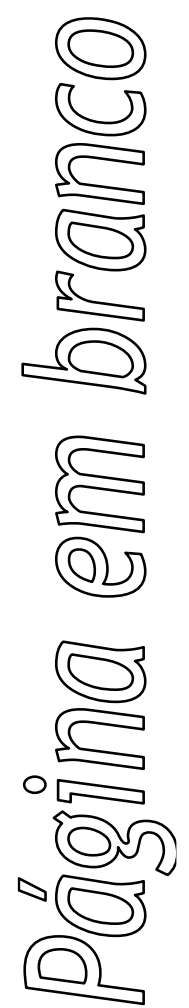




\section{Acknowledgements/Agradecimentos}

Em primeiro lugar, gostaria de agradecer ao Professor Jorge Belinha, pelo incansável apoio e por estar sempre disponível ao longo de todo este último semestre. Por todas as dúvidas esclarecidas, por todas as vezes que me ajudo a entender qual o melhor caminho a seguir após cada etapa.

Aos meus amigos Ana Faria, Ana Pereira, José Ribeiro, Madalena Peyroteo e Maria Magalhães por todos os almoços de quarta-feira, mas também por estes 5 anos incríveis que sem vocês não teriam sido a mesma coisa. Aprendi muito com vocês e espero continuar a aprender no futuro. Mas um obrigado especial à Madalena por me aturares 5 meses em Londres. Muito obrigado a todos.

Aos meus amigos do ginásio com quem passei uma boa parte da minha vida, são como uma segunda família para mim, sem dúvida. Por me ouvirem falar, mesmo que não vos interesse nada, por me animarem quando estou mais em baixo e por me terem permitido conquistar tanto. Quer ao nível pessoal, quer a nível técnico. Obrigada.

À Operação Tide 2014, só tenho a dizer 'Obrigada'. Obrigada por me terem deixado caminhar com vocês, aprender com vocês, viver com vocês, e tantas outras coisas que é difícil descrever por palavras. Muito Obrigada por me fazerem parte deste Caminho.

Ao meu irmão Henrique, por ser sempre o meu melhor amigo em todas as situações. Por me mostrar que vale sempre a pena lutar pelos nossos objetivos e que nada é impossível, basta querer e acreditar em nós mesmo. Obrigada por tudo.

Por fim, aos meus pais, muito obrigada, por me apoiarem sempre, em todas as situações e por acreditarem sempre em mim. Obrigada por me proporcionarem todas as aventuras que vivi até aqui, desde 5 meses em Londres, até uns dia na Colômbia. Obrigada por serem os meus maiores exemplos e por nunca me deixarem de desistir de nenhum sonho. Obrigada por tudo. 


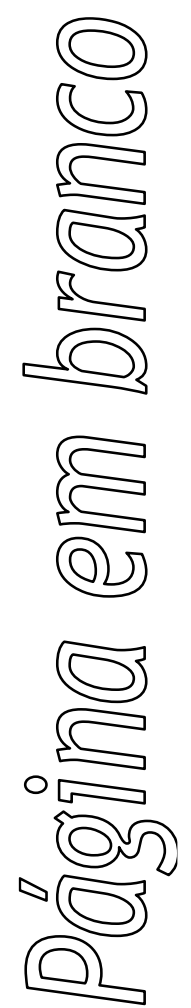




\section{Funding}

The author truly acknowledge the logistic conditions provided by Ministério da Educação e Ciência- Fundação para a Ciência e a Tecnologia (Portugal), under project funding UID/EMS/50022/2013 (funding provided by the inter-institutional projects from LAETA) and project NORTE-01-0145-FEDER-000022 - SciTech - Science and Technology for Competitive and Sustainable Industries, cofinanced by Programa Operacional Regional do Norte (NORTE2020), through Fundo Europeu de Desenvolvimento Regional (FEDER).

Additionally, the author truly acknowledge the work conditions provided by the department of Mechanical Engineering from FEUP and INEGI. 


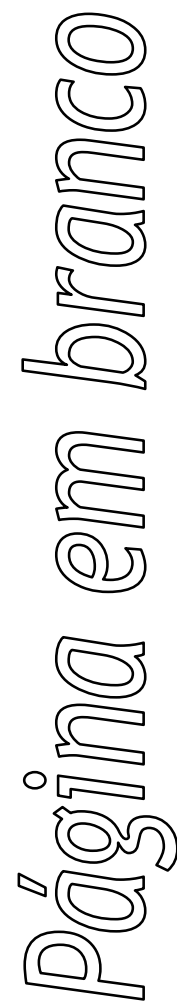




\section{Índice}

Chapter 1 .......................................................................... 1

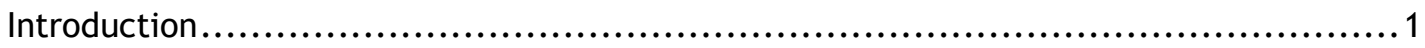

1.1 Meshless Methods ...................................................................

1.1.1. Radial Point Interpolation Method ...................................... 3

1.1.2. Natural Neighbour Radial Point Interpolation Method ..........................4

1.2 Objectives ...................................................................... 5

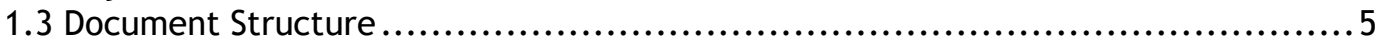

Chapter 2 ............................................................... 6

Meshless Methods ........................................................................6

2.1 General Meshless Method Procedure ..............................................6

2.2 RPIM Formulation .................................................................. 7

2.2.1. Influence-domains and nodal connectivity ...............................

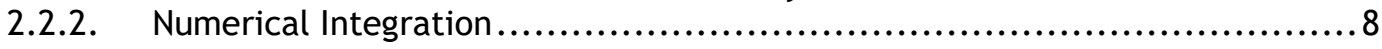

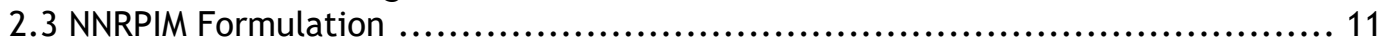

2.3.1. Natural Neighbours ................................................... 11

2.3.2. Influence-Cells and Nodal Connectivity ................................. 13

2.3.3. Numerical Integration ..................................................... 13

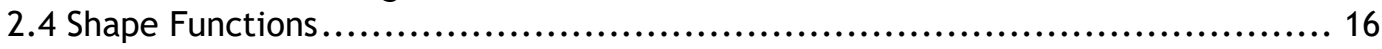

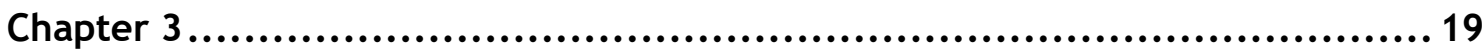

Solid Mechanics Fundamentals .................................................... 19

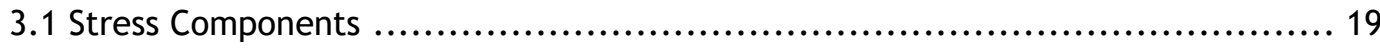

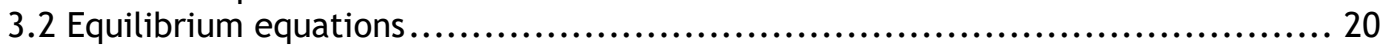

3.3 Components of strain ........................................................... 20

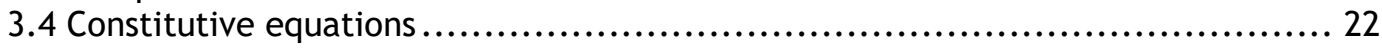

3.5 Strong form and weak form formulation ..................................... 23

3.5.1. Galerkin weak form ..................................................... 23

3.6 Discrete System Equations ................................................. 25

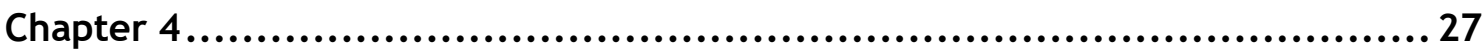

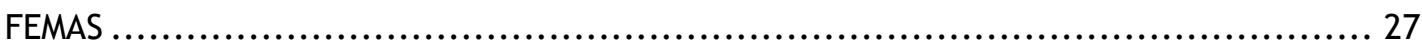

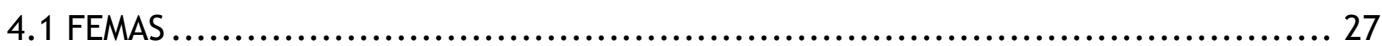

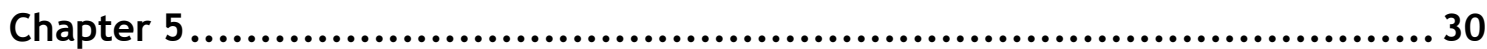

Dental Implants ............................................................... 30

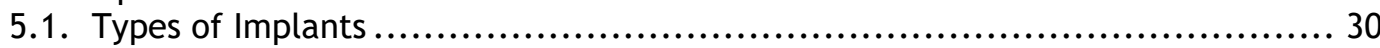

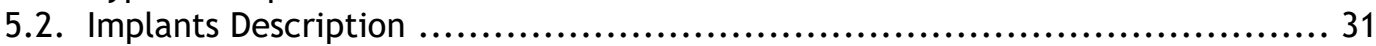

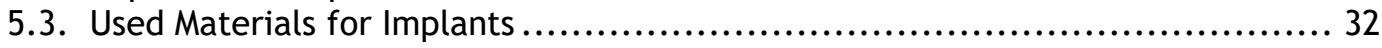

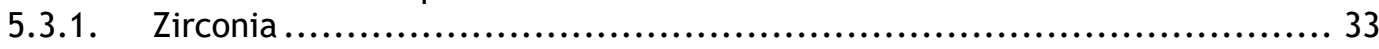

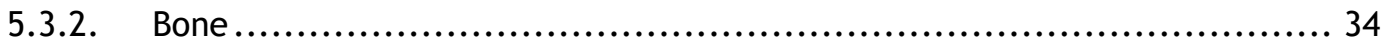

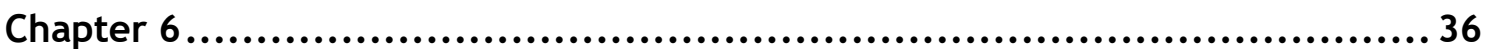

Numerical Examples ................................................................ 36

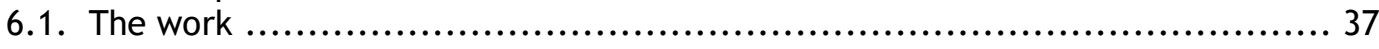

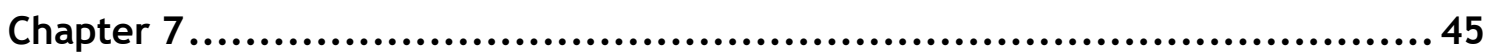

Conclusions and Future Work .......................................................... 45 
Appendix 1

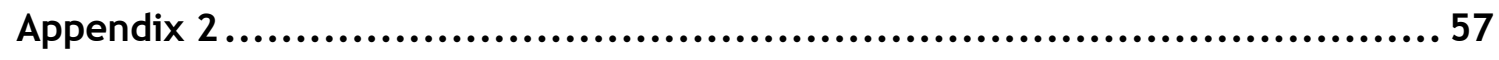

Appendix 3 ................................................................ 78

Appendix 4 .................................................................. 102 


\section{List of figures}

Figure 2.1 a.Problem domain with the essential and natural boundaries applied. b. Regular nodal discretization. c.Irregular nodal discretization ${ }^{3}$

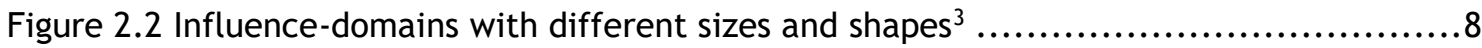

Figure 2.3 a.Fitted Gaussian background mesh. b.General Gaussian integration mesh. ${ }^{3} \ldots \ldots . . .9$

Figure 2.4 a.Initial grid-cell. b.Isoparametric square with integration points. c.Initial quadrature cell with integration points ${ }^{3}$

Figure 2.5 a.Initial nodal set. b.First trial plane. c.Second trial plane. d.Provisional Voronoï cell. e.Voronoï cell from node $n_{0}$. f.Voronoï diagram. ${ }^{3}$

Figure 2.6 a.First degree influence-cell. b.Second degree influence-cell. ${ }^{3}$

Figure 2.7 a.Voronoï cell and respective intersection points $\left(P_{l i}\right)$. b.Middle points $\left(M_{\mathrm{li}}\right)$ and the respective generated quadrilaterals. c.Quadilateral ${ }^{3}$

Figure 2.8 a.Voronoï cell and respective intersection points $\left(P_{l i}\right)$. b.Middle points $\left(M_{\mathrm{li}}\right)$ and the respective generated quadrilaterals. c.Quadilateral ${ }^{3}$

Figure 2.9 Triangular and quadrilateral shapes and the respective integration points. ${ }^{3} \ldots \ldots .15$

Figure 2.10 Division in quadrilaterals of the sub-cells ${ }^{3}$

Figure 2.11 Triangular and rectangular shape and respective integration points, $\mathrm{x}_{1}$, using the Gauss-Legendre integration scheme. ${ }^{3}$

Figure 3.1 Linear deformation of a virtual body ${ }^{3}$

Figure 4.1 FEMAS initial presentation

Figure 4.2 a.2D Model of a dental implant built in FEMAS b.Stress field of dental implant obtained in FEMAS.

Figure 5.1 Constitution of an Implant

Figure 6.1 a)3D model of the zirconia implant. b)2D view showing the minimum geometric dimensions. c) $2 \mathrm{D}$ view showing the maximum geometric dimensions.

Figure 6.2 a)3D model of the zirconia implant inserted in the bone block. b)2D section cut capturing the minimum geometric dimensions. c)2D section cut capturing the maximum geometric dimensions.

Figure 6.3 a.Model 1. b.Model 2

Figure 6.4 a.Model with essential boundary conditions b.Model with essential boundary conditions and applied load at $70^{\circ}$.

Figure 6.5 Stress map from type of bone 1, 'Model 1', angle $10^{\circ}$, analysed with FEM ........ 40

Figure 6.6 Model of a dental implant with the two lines selected 41 
Figure 6.7 a.Stress distribution from bone side, from 'Model 1', for an angle of $10^{\circ}$

b.Stress distribution from implant side, from 'Model 1', for an angle of $10^{\circ}$

Figure 6.8 Points of interest in the model of the dental implant

42

Figure 6.9 Discrete Stress Values for type of bone 4, 'Model 1' and from implant side (point 16)

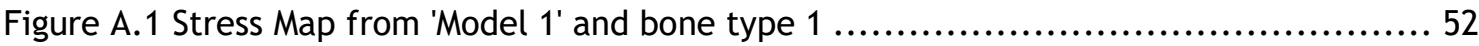

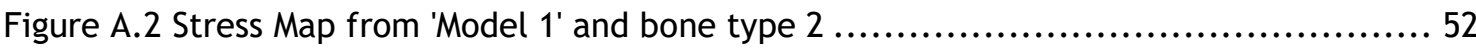

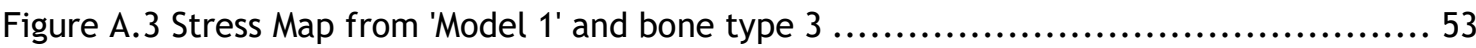

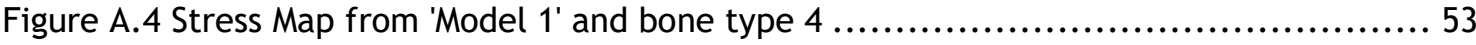

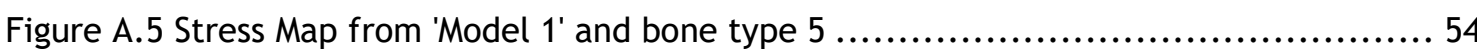

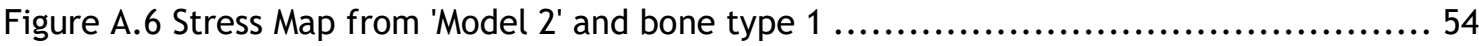

Figure A.7 Stress Map from 'Model 2' and bone type 2 ................................... 55

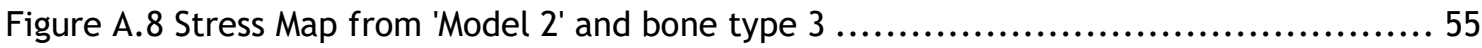

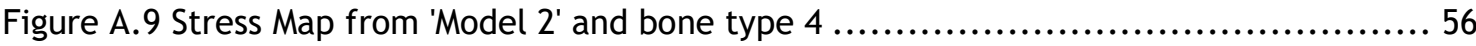

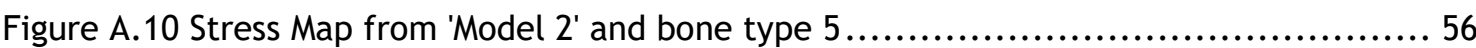

Figure A.11 Stress distribution from bone side, from 'Model 1', from bone type $1 \ldots \ldots \ldots \ldots . . .58$

Figure A.12 Stress distribution from bone side, from 'Model 1', from bone type 2 ........... 59

Figure A.13 Stress distribution from bone side, from 'Model 1', from bone type 3 ...........60

Figure A.14 Stress distribution from bone side, from 'Model 1', from bone type 4 ...........6 61

Figure A.15 Stress distribution from bone side, from 'Model 1', from bone type 5 ........... 62

Figure A.16 Stress distribution from bone side, from 'Model 2', from bone type $1 \ldots \ldots \ldots \ldots .63$

Figure A.17 Stress distribution from bone side, from 'Model 2', from bone type 2 ........... 64

Figure A.18 Stress distribution from bone side, from 'Model 2', from bone type 3 ........... 65

Figure A.19 Stress distribution from bone side, from 'Model 2', from bone type 4 ........... 66

Figure A.20 Stress distribution from bone side, from 'Model 2', from bone type 5 ...........67 67

Figure A.21 Stress distribution from implant side, from 'Model 1', from bone type $1 \ldots \ldots \ldots 68$

Figure A.22 Stress distribution from implant side, from 'Model 1', from bone type 2 ........69

Figure A.23 Stress distribution from implant side, from 'Model 1', from bone type $3 \ldots \ldots \ldots . .70$

Figure A.24 Stress distribution from implant side, from 'Model 1', from bone type $4 \ldots \ldots \ldots . . .71$

Figure A.25 Stress distribution from implant side, from 'Model 1', from bone type 5........ 72

Figure A.26 Stress distribution from implant side, from 'Model 2', from bone type $1 \ldots \ldots \ldots . .73$ 
Figure A.27 Stress distribution from implant side, from 'Model 2', from bone type $2 \ldots \ldots \ldots . .74$

Figure A.28 Stress distribution from implant side, from 'Model 2', from bone type $3 \ldots \ldots \ldots .75$

Figure A.29 Stress distribution from implant side, from 'Model 2', from bone type $4 \ldots \ldots \ldots . .76$

Figure A.30 Stress distribution from implant side, from 'Model 2', from bone type $5 \ldots \ldots \ldots . .77$

Figure A.31 Discrete stress values for type of bone 1, 'Model 1' and from bone side..........103

Figure A.32 Discrete stress values for type of bone 1, for 'Model 1' and from implant side..104

Figure A.33 Discrete stress values for type of bone 1, 'Model 2' and from bone side..........105

Figure A.34 Discrete stress values for type of bone 1, for 'Model 2' and from implant side..106

Figure A.35 Discrete stress values for type of bone 2, 'Model 1' and from bone side..........107

Figure A.36 Discrete stress values for type of bone 2, 'Model 1' and from implant side .......108

Figure A.37 Discrete stress values for type of bone 2, 'Model 2' and from bone side.........109

Figure A.38 Discrete stress values for type of bone 2, 'Model 2' and from implant side .......110

Figure A.39 Discrete stress values for type of bone 3, 'Model 1 ' and from bone side..........111

Figure A.40 Discrete stress values for type of bone 3, 'Model 1' and from implant side ......112

Figure A.41 Discrete stress values for type of bone 3, 'Model 2' and from bone side..........113

Figure A.42 Discrete stress values for type of bone 3, 'Model 2' and from implant side .......114

Figure A.43 Discrete stress values for type of bone 4, 'Model 1' and from bone side..........115

Figure A.44 Discrete stress values for type of bone 4, 'Model 1' and from implant side .......116

Figure A.45 Discrete stress values for type of bone 4, 'Model 2' and from bone side..........117

Figure A.46 Discrete stress values for type of bone 4, 'Model 2' and from implant side .......118

Figure A.47 Discrete stress values for type of bone 5, 'Model 1' and from bone side..........119

Figure A.48 Discrete stress values for type of bone 5, 'Model 1' and from implant side .......120

Figure A.49 Discrete stress values for type of bone 5, 'Model 2' and from bone side..........121

Figure A.50 Discrete stress values for type of bone 5, 'Model 2' and from implant side .......122 


\section{List of tables}

Table 2.1 Integration points coordinates and weights for quadrilateral 'cells'. ............... 10

Table 2.2 Integration points coordinates and weights for triangular 'cells' . ................ 10

Table 5.1 Mechanical Properties of bone cases ............................................. 35

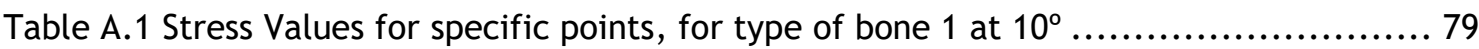

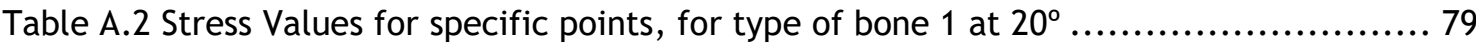

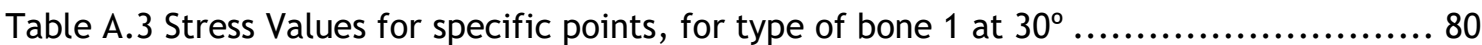

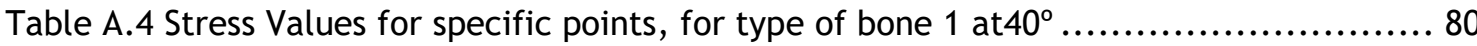

Table A.5 Stress Values for specific points, for type of bone 1 at $50^{\circ} \ldots \ldots \ldots \ldots \ldots \ldots \ldots \ldots . \ldots 1$

Table A.6 Stress Values for specific points, for type of bone 1 at $60^{\circ} \ldots \ldots \ldots \ldots \ldots \ldots \ldots \ldots . \ldots 1$

Table A.7 Stress Values for specific points, for type of bone 1 at $70^{\circ} \ldots \ldots \ldots \ldots \ldots \ldots \ldots \ldots . \ldots . \ldots 2$

Table A.8 Stress Values for specific points, for type of bone 1 at $80^{\circ} \ldots \ldots \ldots \ldots \ldots \ldots \ldots \ldots . \ldots . \ldots 2$

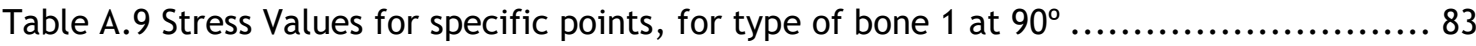

Table A.10 Stress Values for specific points, for type of bone 2 at $10^{\circ} \ldots \ldots \ldots \ldots \ldots \ldots \ldots . . . . . . . . . .83$

Table A.11 Stress Values for specific points, for type of bone 2 at $20^{\circ} \ldots \ldots \ldots \ldots \ldots \ldots \ldots \ldots . \ldots . \ldots . \ldots$

Table A.12 Stress Values for specific points, for type of bone 2 at $30^{\circ} \ldots \ldots \ldots \ldots \ldots \ldots \ldots . \ldots . \ldots 4$

Table A.13 Stress Values for specific points, for type of bone 2 at $40^{\circ} \ldots \ldots \ldots \ldots \ldots \ldots \ldots \ldots . \ldots 5$

Table A.14 Stress Values for specific points, for type of bone 2 at $50^{\circ} \ldots \ldots \ldots \ldots \ldots \ldots \ldots \ldots . . .15$

Table A.15 Stress Values for specific points, for type of bone 2 at $60^{\circ} \ldots \ldots \ldots \ldots \ldots \ldots \ldots . . . . . . . .66$

Table A.16 Stress Values for specific points, for type of bone 2 at $70^{\circ} \ldots \ldots \ldots \ldots \ldots \ldots \ldots \ldots \ldots . . . .66$

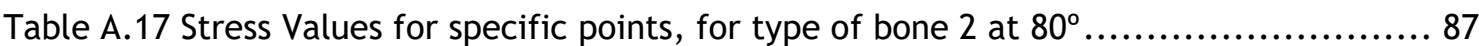

Table A.18 Stress Values for specific points, for type of bone 2 at $90^{\circ} \ldots \ldots \ldots \ldots \ldots \ldots \ldots \ldots . \ldots . \ldots . \ldots 1$

Table A.19 Stress Values for specific points, for type of bone 3 at $10^{\circ} \ldots \ldots \ldots \ldots \ldots \ldots \ldots \ldots . \ldots . \ldots . \ldots . \ldots$

Table A.20 Stress Values for specific points, for type of bone 3 at $20^{\circ} \ldots \ldots \ldots \ldots \ldots \ldots \ldots \ldots . . . \ldots 8$

Table A.21 Stress Values for specific points, for type of bone 3 at $30^{\circ} \ldots \ldots \ldots \ldots \ldots \ldots \ldots \ldots . \ldots . \ldots . \ldots$

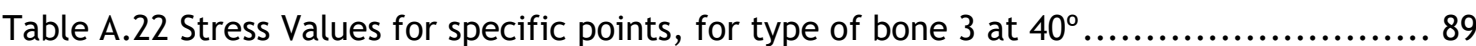

Table A.23 Stress Values for specific points, for type of bone 3 at $50^{\circ} \ldots \ldots \ldots \ldots \ldots \ldots \ldots . . . \ldots 9$ 
Table A.24 Stress Values for specific points, for type of bone 3 at $60^{\circ}$

Table A. 25 Stress Values for specific points, for type of bone 3 at $70^{\circ}$ 91

Table A.26 Stress Values for specific points, for type of bone 3 at $80^{\circ}$. 91

Table A.27 Stress Values for specific points, for type of bone 3 at $90^{\circ}$...... 92

Table A.28 Stress Values for specific points, for type of bone 4 at $10^{\circ}$...... 92

Table A.29 Stress Values for specific points, for type of bone 4 at $20^{\circ}$ 93

Table A.30 Stress Values for specific points, for type of bone 4 at $30^{\circ}$. 93

Table A.31 Stress Values for specific points, for type of bone 4 at $40^{\circ}$ 94

Table A.32 Stress Values for specific points, for type of bone 4 at $50^{\circ}$ 94

Table A.33 Stress Values for specific points, for type of bone 4 at $60^{\circ}$ 95

Table A.34 Stress Values for specific points, for type of bone 4 at $70^{\circ}$ 95

Table A.35 Stress Values for specific points, for type of bone 4 at $80^{\circ}$. 96

Table A.36 Stress Values for specific points, for type of bone 4 at $90^{\circ}$ 96

Table A.37 Stress Values for specific points, for type of bone 5 at $10^{\circ}$ 97

Table A.38 Stress Values for specific points, for type of bone 5 at $20^{\circ}$. 97

Table A.39 Stress Values for specific points, for type of bone 5 at $30^{\circ}$ 98

Table A.40 Stress Values for specific points, for type of bone 5 at $40^{\circ}$ 98

Table A.41 Stress Values for specific points, for type of bone 5 at $50^{\circ}$ 99

Table A.42 Stress Values for specific points, for type of bone 5 at $60^{\circ}$ 99

Table A.43 Stress Values for specific points, for type of bone 5 at $70^{\circ}$ 100

Table A.44 Stress Values for specific points, for type of bone 5 at $80^{\circ}$ 100

Table A.45 Stress Values for specific points, for type of bone 5 at $90^{\circ}$ 101 


\section{Abbreviations}

$\begin{array}{ll}\text { DEM } & \text { Diffuse Element Method } \\ \text { EFGM } & \text { Element-Free Galerkin Method } \\ \text { FEM } & \text { Finite Element Method } \\ \text { GUI } & \text { Graphical User Interface } \\ \text { MFEM } & \text { Meshless Finite Element Method } \\ \text { MLPG } & \text { Meshless Local Petrov-Galerkin } \\ \text { MLS } & \text { Moving Least Square } \\ \text { NEM } & \text { Natural Element Method } \\ \text { NNFEM } & \text { Natural Neighbour Finite Element Method } \\ \text { NNRPIM } & \text { Natural Neighbour Radial Point Interpolation Method } \\ \text { PIM } & \text { Point Interpolation Method } \\ \text { RBF } & \text { Radial Basis Functions } \\ \text { RKPM } & \text { Reproducing Kernel Particle Method } \\ \text { RPIM } & \text { Radial Point Interpolation Method } \\ \text { SED } & \text { Strain Energy Density } \\ \text { SPH } & \text { Smooth Particle Hydrodynamics }\end{array}$




\section{Chapter 1}

\section{Introduction}

Throughout the years, the importance of the health of the mouth and smile have increased, being one of the most important interactive communication skills of a person. Patients and consumers, now demand, not only a healthy mouth, but also a perfect smile. However, the main purpose of dental restorations is to replace missing teeth and, in addition, restore teeth that have been hardly damaged or, for any reason, are not aesthetic, either because of colour, form or contour. ${ }^{1}$ In order to determine if a single missing tooth can be replaced, it is necessary in the first instance, to analyse if the tooth in question can be restored or not. ${ }^{2}$

\subsection{Meshless Methods}

There is a vast quantity of numerical methods, and they can be defined and classified by three fundamental modules: the field approximation (or interpolation) function, the used formulation and the integration. ${ }^{3}$ From this point of view, it is possible to define the Finite Element Method (FEM) and the Meshless Methods as numerical methods.

The Finite Element Method was firstly developed to solve structural problems in the aerospace industry, in the early 1960s and, ever since, has been extended to solve a wide range of problems, from heat transfer to electromagnetics. ${ }^{4}$

The Finite Element Method is a very recognized and optimized method, often applied to a widespread variety of engineering fields, as well as to distinct sciences. According to this method, a more complex problem can be simplified by dividing the problem's domain into smaller elements, which are, usually, triangles. This means that the domain of the problem is discretized, and the field function is obtained by means of consecutive interpolations by simple functions, so called shape functions. In other words, instead of seeking a solution function for the entire domain, FEM intends to formulate the solution function for each element previously created and after combines them properly to obtain the solution for the whole domain. This method requires a mesh to divide the whole domain into smaller elements. The discretization 
of the problem domain includes the process of creating the mesh, elements, their respective nodes and defining boundary conditions. ${ }^{4,5}$

This method is very effective and successful due to the local character of approximations, the ability to deal with complex geometrical domains and the existence of a large set of approximation schemes adapted to various problems but embedded in a unified formulation. ${ }^{6}$

Yet, FEM presents two major drawbacks. First, FEM's approximate solutions present limited regularity, by way of, the solution itself, in most cases, is continuous, but some of its derivatives are discontinuous at elements boundaries leading to difficulties of interpretation and the use of unsatisfactory smoothing techniques. Second, generating adequate discretization meshes is a difficult task, in particular, in complex three-dimensional domains. For example, as a result of the lack of efficient mesh generators able to dynamically adjust the size of each individual element, the development of auto-adaptive methods is limited. ${ }^{6}$

Thus, when analysing more complex geometries, FEM can easily generate highly distorted elements, causing shape functions to have low quality and compromising the performance of it. $^{5}$

Considering the issues mentioned before, and with the intention to create new solutions that would fulfil the existing problems, meshless methods were created. Moreover, the stress and displacement fields produced with meshless methods, relating the analysis of structural problems, are, usually, much more uniform and close to the analytical solution than those created by low order element meshes (three and four nodes). On the contrary of Finite Element Methods, which uses the element mesh to obtain the approximation, meshless methods build the approximation based on nothing but an arbitrary nodal set, without any knowledge of the relation between nodes, at first instance. ${ }^{7}$

It was only in the middle 90s that meshless methods came into focus of interest for numerically solving partial differential equations, especially in the computational mechanics community. ${ }^{3,8}$ Despite this fact, this methods have rapidly evolved, solving many of their initial problems, such as accuracy, imposition of essential boundary conditions, numerical integration, stability and many others. ${ }^{9}$ The type of functions used initially for meshless methods were approximation functions, since the implementation of the influence-domain concept was easier and the background integration scheme was nodal independent. ${ }^{3}$

One of the first meshless method is the Smooth Particle Hydrodynamics (SPH) method, which was created to solve problems in astrophysics and, later on, fluid dynamics. Although SPH and their corrected versions were based on a strong form, other methods were based on a weak form. One of the first meshless methods based on a global weak form and one of the most popular, developed in 1994, was the Element-Free Galerkin method (EFGM). ${ }^{7}$ This method was developed having in mind the concept created in the Diffuse Element Method (DEM), which, by its turn was the first meshless method using the Moving Least Square(MLS) approximants in the construction of the shape functions. ${ }^{6}$ The Reproducing Kernel Particle Method (RKPM) was also 
a very successful method and it was developed one year later than EFG, but this method has its origin in wavelets on the contrary to the Element-Free Galerkin method and was based in two different methods, the SPH and the Meshless Local Petrov-Galerkin (MLPG). ${ }^{7}$ Meshless Methods have some major advantages such as (i) h-adaptivity is simpler to incorporate in Meshless Methods than in mesh-based methods (ii) problems with moving discontinuities such as crack propagation, shear bands and phase transformation can be treated with ease (iii) large deformation can be handled more robustly (iv) higher-order continuous shape functions $(v)$ nonlocal interpolation character (vi) no mesh alignment sensitivity. Besides these improvements, there also some disadvantages, in particular, the fact that approximation Meshless Methods do not satisfy the Kronecker delta property, making the imposition of essential and natural boundary conditions difficult. ${ }^{7}$ This is the immediate consequence, in the referred meshless methods, of using approximation functions instead of interpolation functions. ${ }^{5}$

Meanwhile, this obstacle was solved by exploring the advantages of both mesh-free methods and finite element methods, by means, hybrid methods, also called interpolation meshless methods. ${ }^{7}$ Some of this newly developed meshless methods were the Point Interpolation Method (PIM), the Point Assembly Method, the Natural Neighbour Finite Element Method (NNFEM) or Natural Element Method (NEM) and the Meshless Finite Element Method (MFEM). ${ }^{5}$ As a consequence of the evolution of the first meshless method, PIM, which initially used the original polynomial basis function, it was possible to start using a radial basis function for solving partial differential equations. This combination allows the generation of the Radial Point Interpolation Method (RPIM). The radial basis functions used in the first works done with this method were the Gaussian and the multiquadric radial basis functions. ${ }^{5}$ Recently, having RPIM and the natural neighbours geometric concept as starting point, it was developed a new concept, the Natural Neighbour Radial Point Interpolation Method (NNRPIM).

\subsubsection{Radial Point Interpolation Method}

The Radial Point Interpolation Method started with the Point Interpolation Method. ${ }^{10}$

Having in mind that methods that uses MLS approximation for the construction of shape functions have issues related with the imposition of essential and natural boundary conditions, PIM was proposed. ${ }^{10}$ Starting with only a group of arbitrarily distributed points, this technique consisted in constructing polynomial interpolants that possessed the Kronecker delta property as shape functions. This means that they pass through every single node, which fixes the issue of the essential and natural boundary imposition. However, this method has too many numerical problems. For instance, the perfect alignment of the nodes produces singular solutions in the interpolation function construction process. As a result, this technique evolved and originated the Radial Point Interpolation Method (RPIM). ${ }^{3,11}$ 
In order to stabilize the procedure, the Radial Basis Function (RBF) was added in the construction process of the interpolation function. In addition to the benefit mentioned before, the RBF allowed the removal of the possible singularities existent in PIM. Moreover, since the RPIM uses the concept of 'influence-domain', it creates sparse and banded stiffness matrices, which are more adequate to complex geometries problems. ${ }^{3}$

Due to all of the aforementioned advantages, together with the high convergence of the method, it is still used nowadays.

\subsubsection{Natural Neighbour Radial Point Interpolation Method}

The NNRPIM is one of the most recent developments in Radial Point Interpolators (RPI) and it uses the natural neighbour concept, which was firstly introduced by Sibson for data fitting and field smoothing. ${ }^{12}$ This method results from the combination of the RPI and the Natural Neighbours geometric concept. ${ }^{3}$

The major difference between this method and the one described before, RPIM, is the way the nodal connectivity is enforced. In RPIM it was used the concept of 'influence-domain' and it is replaced by the 'influence-cell' concept, when considering the NNRPIM method. ${ }^{3}$

Having in mind the influence-cells, the NNRPIM relies on both geometrical (Voronoi diagrams ${ }^{13}$ ) and mathematical (Delaunay tessellation ${ }^{14}$ ) constructions. Hence, considering Voronoï cells, departing from an arbitrary set of nodes, a set of influence-cells are created. The Delaunay triangles, which are the dual of the Voronoï cells, are applied to create a nodedepending background mesh used in numerical integration of the interpolation functions of the method in question. ${ }^{3}$

Due to the fact that NNRPIM interpolation functions, used in the Galerkin weak form, are constructed in a similar manner to the RPIM, it also possess the Kronecker delta property. ${ }^{3}$ As a result of the way nodal connectivity is imposed, NNRPIM possesses smoother and more accurate displacements and stress fields when compared to results obtained with other methods, especially, FEM. Moreover, considering that the integration mesh is total dependent from the initial nodal distribution, NNRPIM can be considered a truly meshless method.

Even though NNRPIM is a recent developed meshless method, it already has been extended to numerous fields, such as the static analysis of isotropic and orthotropic plates, the functionally graded material plate analysis, the 3D shell-like approach for laminated plates and shells. ${ }^{3}$

Also, this method was already applied to biomechanics, with highlights to bone structures, since the non-convex boundaries and the material discontinuities in the bone structure, are easily handled by the NNRPIM. Because of this characteristics, meshless methods were already applied to bone tissue analysis and, more recently, Belinha and co-workers presented a new bone tissue remodelling algorithm relying on the meshless method accuracy. ${ }^{3}$ 


\subsection{Objectives}

The main purposes of this thesis are:

- Perform an elasto-static analysis of a dental implant, applying a concentrated load, using three numerical methods: FEM, RPIM and NNRPIM

- Compare the performance of all three methods, especially FEM, against the two meshless methods.

- Understand the mechanical behaviour of zirconia implants and the bone tissue response in the presence of such implants.

\subsection{Document Structure}

This thesis is composed by 7 main chapters, which are: Introduction, Meshless Methods, Solid Mechanics Fundamentals, FEMAS, Dental Implants, Numerical Examples and Conclusions and Future Work.

In the first chapter, Introduction, is presented a brief state-of-the-art regarding the origin of numerical methods, in particular, meshless methods in general and specifically the RPIM and NNRPIM. Also, the objectives of this work are defined.

In the second chapter, Meshless Methods, the two highlighted meshless methods are carefully presented, as well as their formulation.

In the third chapter, Solid Mechanics Fundamentals, it is presented and explained the basic notions of solid mechanics which are important to better understand some aspects of this work.

In the fourth chapter, FEMAS, it is presented and explained the software used in this thesis.

In the fifth chapter, Dental Implants, it is presented a state-of-the-art regarding dental implants, mainly considering their constitution, the materials and also the bone.

In the sixth chapter, Numerical Examples, are presented some works already done about the numerical problems solved along the development of this thesis. Also, using the software described in chapter 4, a dental implant is analysed and all the results obtained are presented.

In seventh chapter, Conclusions and Future Work, it is presented the conclusions about the work done and suggestions for possible works based on this one. 


\section{Chapter 2}

\section{Meshless Methods}

The work here presented was developed having in mind two of the most recently developed meshless methods: the RPIM and the NNRPIM. After a brief description of the procedure of meshless methods in general and an overall presentation of RPIM and NNRPIM, it is now possible to present a thoroughly explanation of them both.

\subsection{General Meshless Method Procedure}

The outline respected by most meshless methods and the majority of other nodal dependent discretization numerical methods is as follows: first, it is necessary to study the problem geometry and establish the solid domain and the contour. Then, the essential and natural boundary conditions are identified, as it is possible to see in Figure 2.1a. Afterwards, as it is shown in Figure $2.1 \mathrm{~b}$ and c, the problem domain and boundary is numerically discretized by a nodal set following a regular or irregular distribution. ${ }^{3}$
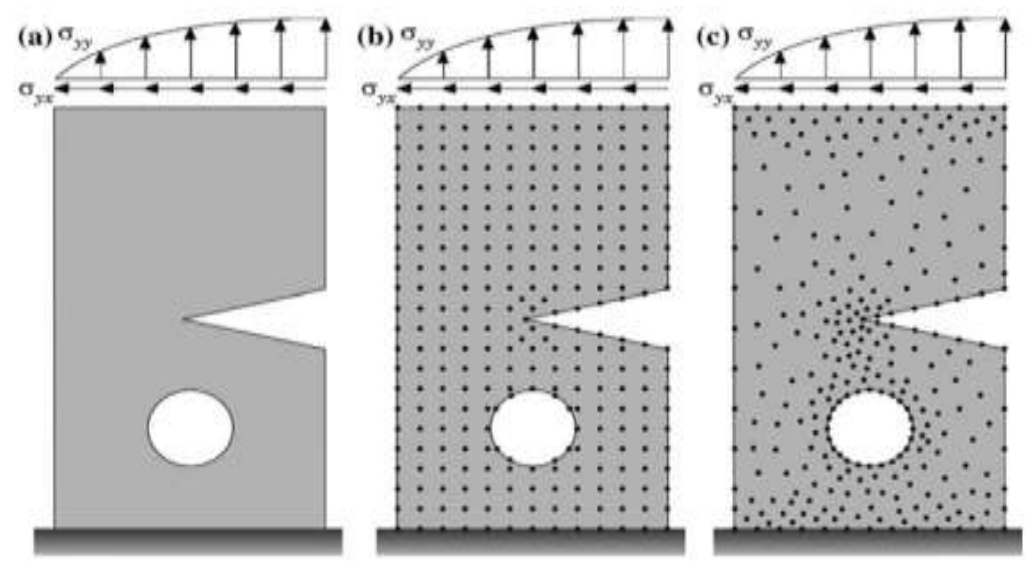

Figure 2.1 a.Problem domain with the essential and natural boundaries applied. b.Regular nodal discretization. c.Irregular nodal discretization ${ }^{3}$ 
Considering that it is not required, for meshless methods, any kind of previous information about the relation between the nodes towards the construction of the approximation (or interpolation) functions of the unknown variable field functions, the nodal distribution do not form a mesh. In fact, the only information necessary by truly meshless methods is the spatial location of each node discretized in the problem domain. The nodal discretization has a direct effect on the numerical analysis outcome and consequently, affects the method performance. An even nodal distribution as seen in Figure $2.1 \mathrm{~b}$ leads, generally, to more accurate results and on the opposite, an uneven discretization of the nodes, Figure 2.1c, can often present lower accuracy. Despite this fact, locations with predictable stress concentrations, such as: domain discontinuities, crack tips, as seen in Figure 2.1, among others, should present a higher nodal density when compared with locations in which smooth stress distributions are expected. In pursuance of solving both issues named before, it is possible to add extra nodes, only on the locations with predictable stress concentrations while maintaining a regular mesh on the rest of the problem domain, therefore, not increasing the computational cost significantly. ${ }^{3}$

Once it is obtained the problem domain discretization, it is now possible to get the nodal connectivity. While in FEM this is obtained using a predefined finite element mesh, in which it is known a priori which nodes belong to the same element and, consequently, interact directly between themselves. The boundary nodes interact with boundary nodes of nearby elements. On the other hand, in meshless methods, such connectivity is ensured by overlapping the influence-domains, when it comes to RPIM and influence-cells, when regarding NNRPIM.

Subsequently, it is created a background integration mesh, which can either be nodal dependent or independent, the later having a higher accuracy. The integration mesh can, at least, have the size of the problem domain, but in the cases in which it is larger, it cannot affect too much the final results. Afterwards, it is possible to obtain the field variables under study by using either approximation or interpolation shape functions, based on the combination of Radial Basis Functions (RBF) with polynomial basis functions. ${ }^{3}$

\subsection{RPIM Formulation}

\subsubsection{Influence-domains and nodal connectivity}

After the initial nodal discretization of the problem domain, it is necessary to impose the nodal connectivity between each and every node.

In order to find the nodal connectivity it is necessary to overlap the influence-domain of each node. The influence-domains are obtained through a process in which, firstly, it is settled an area (in case the problem is 2D) or a volume (in case the problem is 3D). Then, it is necessary to search for a specified number of nodes inside the previously established zone. As it is possible 
to observe in Figure 2.2, there are influence-domains with different size and shape. Yet, the variation of this parameters along the problem domain affects the performance and the final solution of the meshless method. This said, it is important that all the influence-domains in the problem contain approximately the same number of nodes. Irregular domain boundaries or node clusters in the nodal distribution can lead to unbalanced influenced-domains. Regardless the used meshless technique, according to the literature, it is recommended using between $n=[9,16]$ nodes for $2 D$ problems and $n=[27,70]$ nodes for $3 D$ problems. ${ }^{7,11,15-17}$

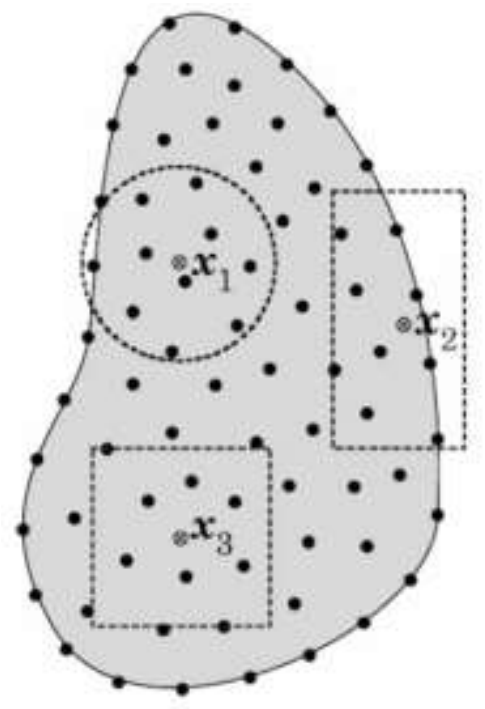

Figure 2.2 Influence-domains with different sizes and shapes ${ }^{3}$

The number of nodes inside each influence-domain does not depend on the density of the nodal discretization and once selected, the value is valid for all domain discretization within the same analysis.

\subsubsection{Numerical Integration}

Based on the RPIM, a new meshless method has recently proven better results than other meshless RPIM approaches based on Gauss-Legendre integration schemes. Even though using a stabilized nodal integration, the extra time spent in this process does not pay the increased accuracy of the final solution. ${ }^{11,18}$ This said, in RPIM, the differential equations are integrated using the Gauss-Legendre integration scheme. In order to ensure this, firstly, a background mesh is created. The connection of the nodes discretizing the problem domain gives origin to cells. These are the ones that will later compose the background mesh. 

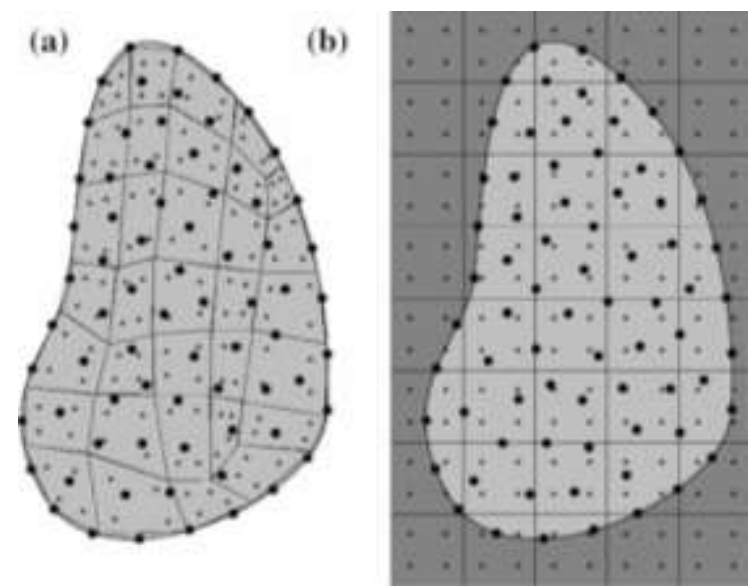

Figure 2.3 a.Fitted Gaussian background mesh. b.General Gaussian integration mesh. ${ }^{3}$

This mesh can either fit the solid-domain, as seen in Figure 2.3a, where no pos-treatment is needed, or, as it is possible to see in Figure 2.3b, be larger than the solid domain. In the latter case, the points outside the solid domain have to be removed. ${ }^{3}$

After all the solid domain is divided in a regular grid, each grid-cell is filled with integration points respecting the Gauss-Legendre quadrature rule. Taking as example Figure $2.4 \mathrm{a}$, it is represented one grid-cell of the total background mesh. The initial quadrilateral is transformed in an isoparametric square, as seen in Figure 2.4b. Then, the Gauss-Legendre quadrature points are distributed inside the isoparametric square, and, in this case, it was used a $2 \times 2$ quadrature, Figure 2.4b. ${ }^{19,20}$

(a)

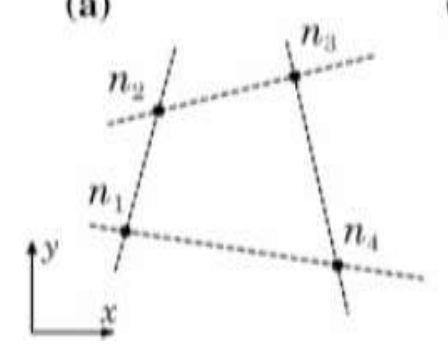

(b)

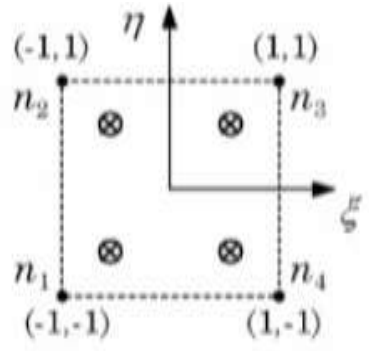

(c)

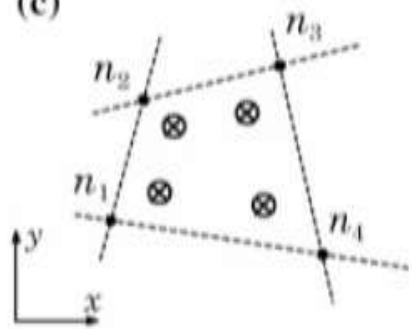

Figure 2.4 a.Initial grid-cell. b.Isoparametric square with integration points. c.Initial quadrature cell with integration points ${ }^{3}$

Later, with the intention to obtain the Cartesian coordinates of the quadrature points, isoparametric interpolation functions were used, and the results is the one presented in Figure 2.4c. The integration weight of the quadrature point is obtained multiplying the isoparametric weight of the quadrature point with the inverse of the Jacobian matrix determinant of the respective grid-cell. ${ }^{3}$ The following tables display the location and the weights of the isoparametric integration points for quadrilateral and triangular element background meshes, respectively. 
Table 2.1 Integration points coordinates and weights for quadrilateral 'cells'.

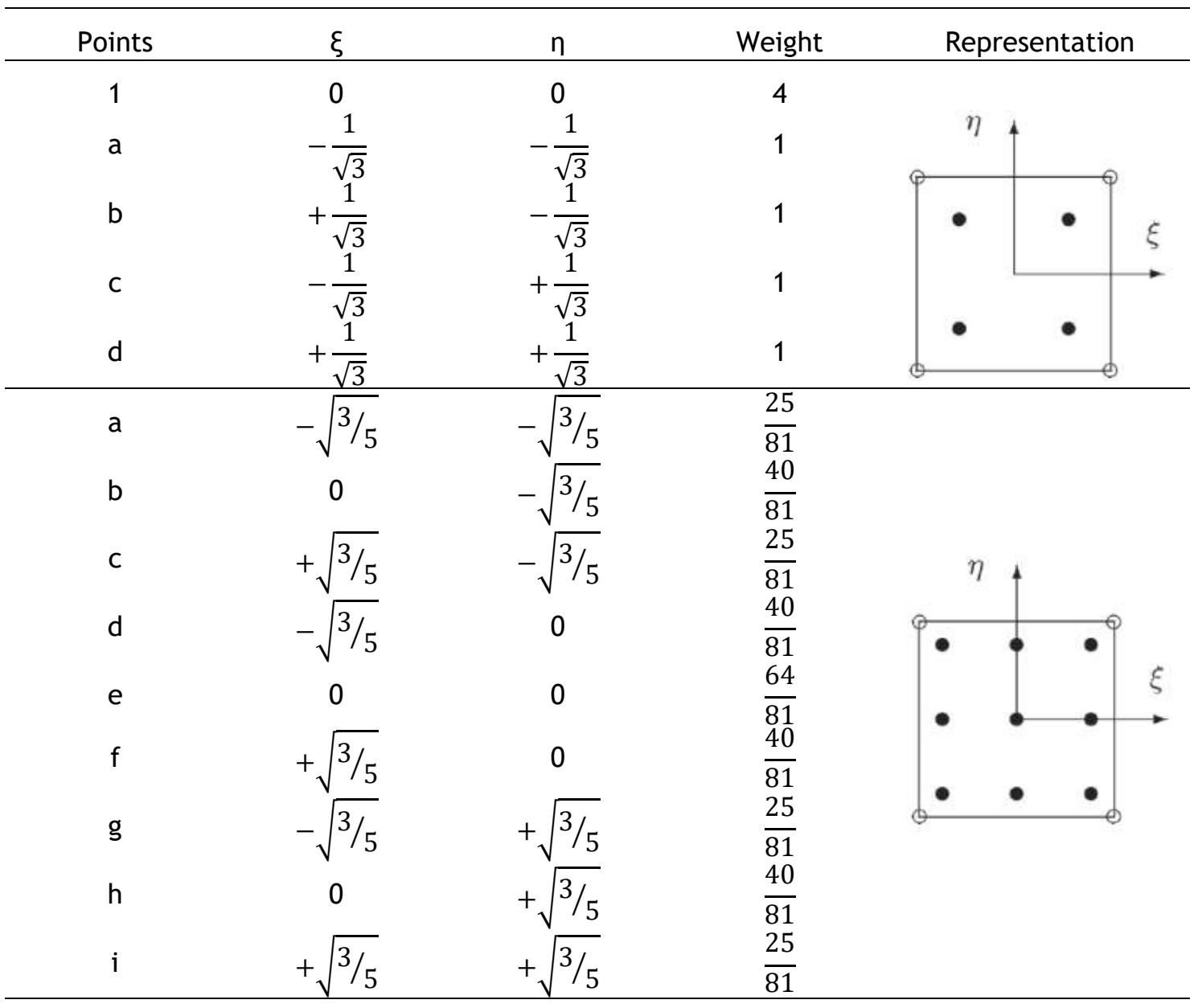

Table 2.2 Integration points coordinates and weights for triangular 'cells'.

\begin{tabular}{|c|c|c|c|c|}
\hline Points & $\xi$ & $\eta$ & Weight & Representation \\
\hline a & $\frac{1}{3}$ & $\frac{1}{3}$ & $\frac{1}{2}$ & \\
\hline $\mathrm{a}$ & $\frac{1}{6}$ & $\frac{1}{6}$ & $\frac{1}{6}$ & t \\
\hline$b$ & $\frac{2}{3}$ & $\frac{1}{6}$ & $\frac{1}{6}$ & OR \\
\hline C & $\frac{1}{6}$ & $\frac{2}{3}$ & $\frac{1}{6}$ & \\
\hline
\end{tabular}




\begin{tabular}{cccc}
\hline a & $\frac{1}{3}$ & $\frac{1}{3}$ & $-\frac{27}{96}$ \\
$\mathrm{~b}$ & $\frac{1}{5}$ & $\frac{1}{5}$ & $\frac{25}{96}$ \\
$\mathrm{c}$ & $\frac{3}{5}$ & $\frac{1}{5}$ & $\frac{25}{96}$ \\
$\mathrm{~d}$ & $\frac{1}{5}$ & $\frac{3}{5}$ & $\frac{25}{96}$ \\
\hline
\end{tabular}

\subsection{NNRPIM Formulation}

\subsubsection{Natural Neighbours}

First introduced in 1980, as a way to obtain influence-cells, the concept of natural neighbours was created and is used by the NNRPIM, in order to determine the nodal connectivity. In opposition to the RPIM, which relies on the use of influence-domains. ${ }^{21}$ The influence-cells are determined based on the geometric and spatial relations between the Voronoï cells, obtained from the Voronoï diagram of the nodal distribution. This concept was firstly introduced by Sibson for data fitting and field smoothing. ${ }^{12}$

Initially it is necessary to consider a nodal set, $N$, discretized in the space domain $\Omega \in \mathbb{R}^{2}$, $N=\left\{n_{1}, n_{2}, \ldots, n_{N}\right\}$, and also $X=\left\{x_{1}, x_{2}, \ldots, x_{X}\right\}$. The Voronoï diagram of $N$ is the assembly of $i$ sub-regions $V_{i}$, closed and convex, in which, each sub-region is associated to the node $n_{i}$ in a way that any point in the interior of $V_{i}$ is closer to $n_{i}$ than any other node $n_{j}{ }^{3}$

$$
V_{i}=\left\{x_{I} \in \mathbb{R}^{2}:\left\|x_{I}-x_{i}\right\|<\left\|x_{I}-x_{j}\right\|, \forall i \neq j\right\}
$$

being $\|$.$\| the distance between x_{l}$, an interest point and the nodes with coordinates defined by $x_{i}$ e $x_{j}$. Thus, the Voronoï diagram is defined by:

$$
V=\left\{V_{1}, V_{2}, \ldots, V_{N}\right\}
$$

In Figure 2.5a, it is represented a nodal set in a two-dimensional space. Considering that the purpose is to determine the Voronoï cell $V_{0}$ of the node $n_{0}$, initially, it is necessary to choose the potential neighbours. ${ }^{3}$ 


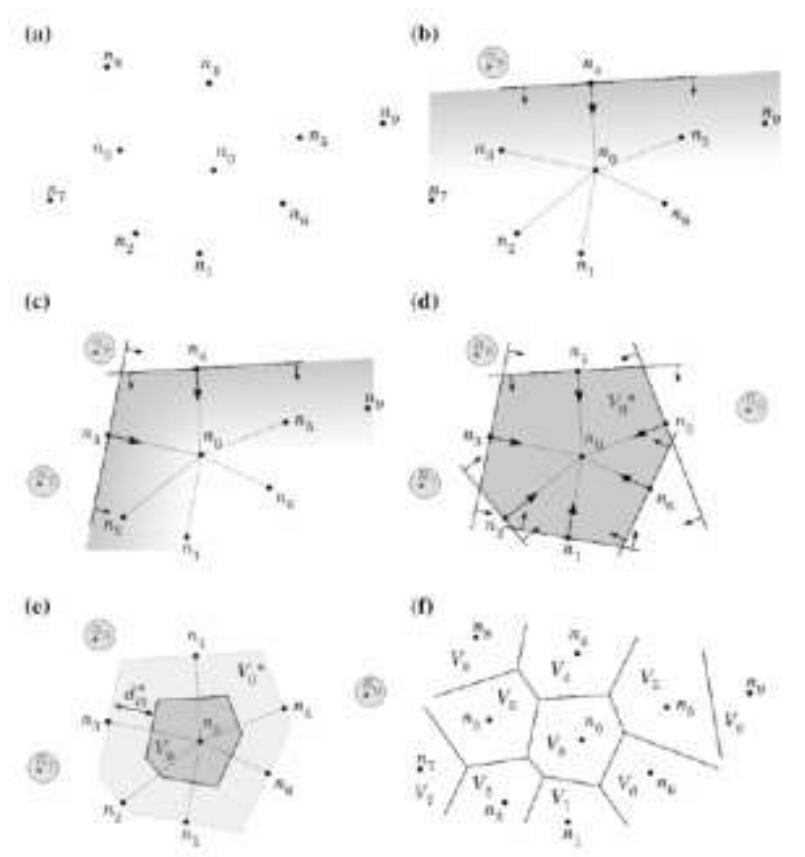

Figure 2.5 a.Initial nodal set. b.First trial plane. c.Second trial plane. d.Provisional Voronoï cell. e.Voronoï cell from node $\mathrm{n}_{0}$. f. Voronoï diagram. ${ }^{3}$

The nodes that are not included in the provisional selection are discarded. After this step, one of the nodes is selected as potential neighbour, for instance node $n_{4}$, as seen in Figure $2.5 \mathrm{~b}$, it determined a vector $u_{40}$.

$$
u_{40}=\frac{\left(x_{0}-x_{4}\right)}{\left\|x_{0}-x_{4}\right\|}
$$

In which $u_{40}=\left\{u_{40}, v_{40}, w_{40}\right\}$. Afterwards a plane is defined. All the nodes that do not respect the following condition are discarded:

$$
u_{40} x+v_{40} y+w_{40} z \geq\left(u_{40} x_{4}+v_{40} y_{4}+w_{40} z_{4}\right)
$$

This procedure is repeated for each and every node of the initial set of nodes, as it is possible to observe in Figure 2.5c. In Figure 2.5d, it is represented all of the 6 natural neighbours of node $n_{0}$, and it is possible to see that nodes $n_{7}, n_{8}$ and $n_{9}$ does not belong to the referred cluster, because they do not respect the equation 2.4, mentioned before. ${ }^{3}$

Having already obtained the provisional Voronoï cell, it is now possible to obtain a definitive one, as shown in Figure 2.5e. The distance between node $n_{0}$ and the boundary of the Voronoï cell, $V_{0}$ is half of node's $n_{0}$ and the neighbour node in question Euclidian norm. So, this distance is given by the following equation:

$$
d_{0 i}^{*}=\frac{d_{0 i}}{2}=\frac{\left\|x_{0}-x_{i}\right\|}{2}
$$


In order to obtain the remaining Voronoi cells, a similar procedure is applied, as seen in Figure 2.5f. ${ }^{3}$

\subsubsection{Influence-Cells and Nodal Connectivity}

As mentioned before in this work, in meshless methods, the nodal connectivity is obtained by overlapping the influence-domains of each interest point. In order to respond to difficulties that can affect the efficiency of the meshless methods when using blind influence-domains, the concept of influence-cells was created. ${ }^{22}$

(a)

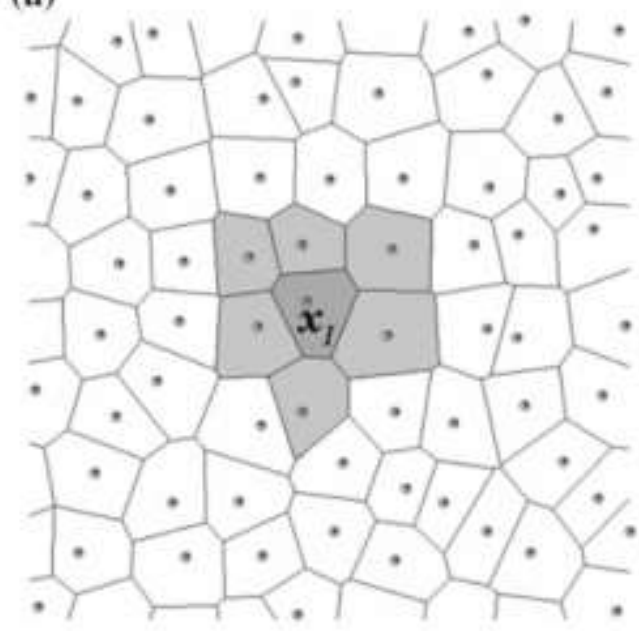

(b)

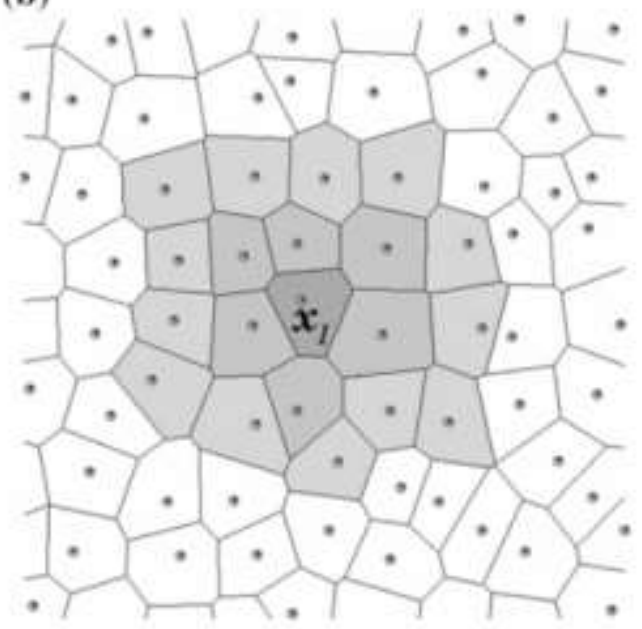

Figure 2.6 a.First degree influence-cell. b.Second degree influence-cell. ${ }^{3}$

Regarding the level of nodal connectivity, influence-cells can be either "First degree influence-cells" or "Second degree influence-cells", as seen in Figure 2.6a and 2.6b, respectively. According to the literature, "First degree influence-cells" are composed by only these natural neighbours and "Second degree influence-cells" contain, not only the first degree natural neighbour of a certain point of interest, but also, the natural neighbours of all the nodes belonging to the first degree of influence cells. Thus, the first degree influence-cell is naturally smaller than the second degree influence-cell. Therefore, as expected, the use of second degree influence-cells generally leads to better numerical results.

\subsubsection{Numerical Integration}

The Natural Neighbour Radial Point Interpolation Method (NNRPIM) uses a nodal based integration scheme proposed by Belinha and co-workers ${ }^{3}$ The most important advantage of this scheme is that the background integration scheme is constructed using uniquely the nodal distribution spatial information. Since there is no information besides the spatial location of 
the nodes discretizing the problem domain, is also necessary to: establish the nodal connectivity, determine the integration points and construct the shape functions. Hence, following the construction of the Voronoï diagram, it is possible to obtain a nodal dependent integration mesh based purely on the nodal distribution spatial information.

In order for this to be done, it is necessary to divide each of the Voronoï cells of the previously obtained Voronoï diagram and divide them into smaller sub-cells.
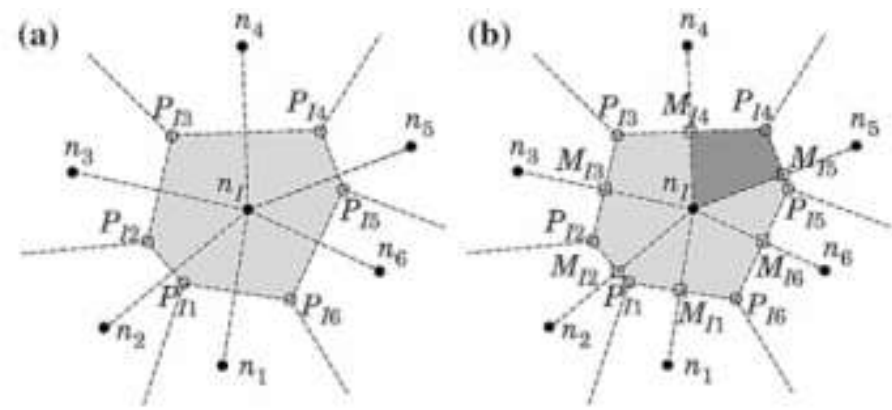

(c)

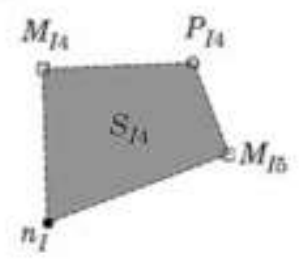

Figure 2.7 a.Voronoï cell and respective intersection points $\left(P_{l i}\right)$. b.Middle points $\left(M_{\mathrm{li}}\right)$ and the respective generated quadrilaterals. c. Quadilateral ${ }^{3}$

In Figure $2.7 a$ is possible to observe a constructed Voronoï cell, $V_{1}$, of node $n_{1}$, based on its natural neighbours. Afterwards, the corners $\mathrm{P}_{\mathrm{li}}$ of the polygonal shape defined by $\mathrm{V}_{\mathrm{l}}$ are determined, Figure $2.7 a$. Then, the middle points, $M_{\mathrm{li}}$, between $n_{1}$ and each neighbour node, $n_{i}$ are obtained, Figure 2.7b. Hence, the Voronoï cells are divided in $\mathrm{n}$ quadrilateral sub-cells, $\mathrm{S}_{\mathrm{li}}$, in which $\mathrm{n}$ is the number of natural neighbours of node $\mathrm{n}_{\mathrm{l}}$, as seen in both Figure $2.7 \mathrm{~b}$ and $2.7 \mathrm{c}$.

If the $\mathrm{N}$ nodes discretizing the problem domain are irregularly scattered, the sub-cells that are originated are quadrilateral, on the other hand, if the field nodes $\mathrm{N}$ discretizing the problem domain are scattered in a regular nodal distribution, the Voronoï cells are divided in triangles, as sub-cells, instead of quadrilateral, as seen in Figure 2.8.
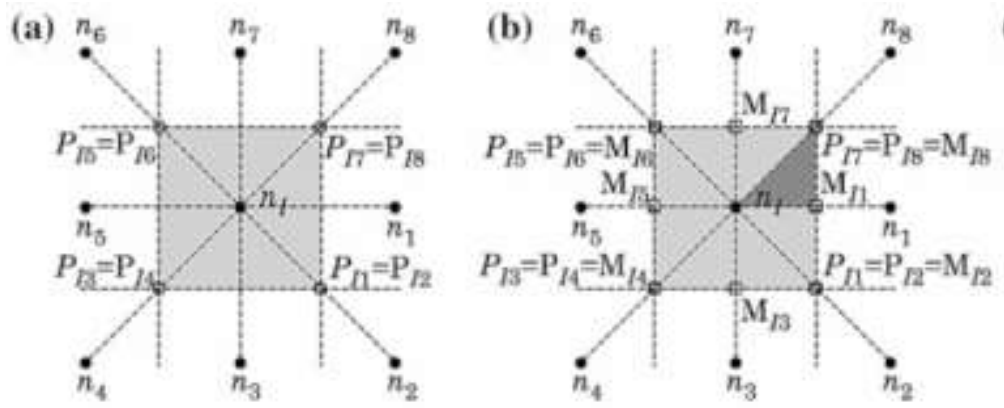

(c)

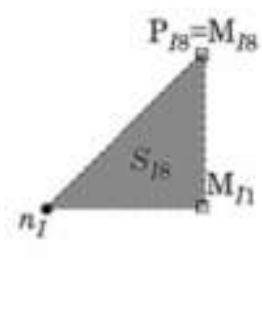

Figure 2.8 a.Voronoï cell and respective intersection points $\left(P_{l i}\right)$. b.Middle points $\left(M_{\mathrm{li}}\right)$ and the respective generated quadrilaterals. c. Quadilateral ${ }^{3}$

The procedure to obtain sub-cells in case of a regular discretization of the problem domain is the same mentioned previously for the case of an irregular discretization of the problem domain. Due to the fact that it is always possible to divide a Voronoï cell, $\mathrm{V}_{\mathrm{l}}$, in $\mathrm{n}$ sub-cells, $\mathrm{S}_{\mathrm{li}}$, 
being $n$ the total number of natural neighbours of $n_{i}$, therefore, the area of the Voronoï cell, $V_{1}$, can be determined using the area of the $n$ sub-cells $S_{1 i}$ :

$$
A_{V_{I}}=\sum_{i=1}^{n} A_{S_{I i}}, \forall A_{S_{I i}} \geq 0
$$

In which, $A_{V_{I}}$ is the area of the Voronoï cell $V_{I}$ and $A_{S_{I i}}$ is the area of the sub-cell $\mathrm{S}_{\mathrm{li}}$.

In order to obtain the simplest integration scheme that can be established, using sub-cells with either triangular or quadrilateral shape, a single integration point is placed in the barycentre of the sub-cells. Consequently, spatial location of each integration point is determined on each sub-cell, Figure 2.9, being the weight of each integration point the area of the respective sub-cell.

The example pictured below only uses 1 integration point in each cell. However, it is possible to add more integration points.
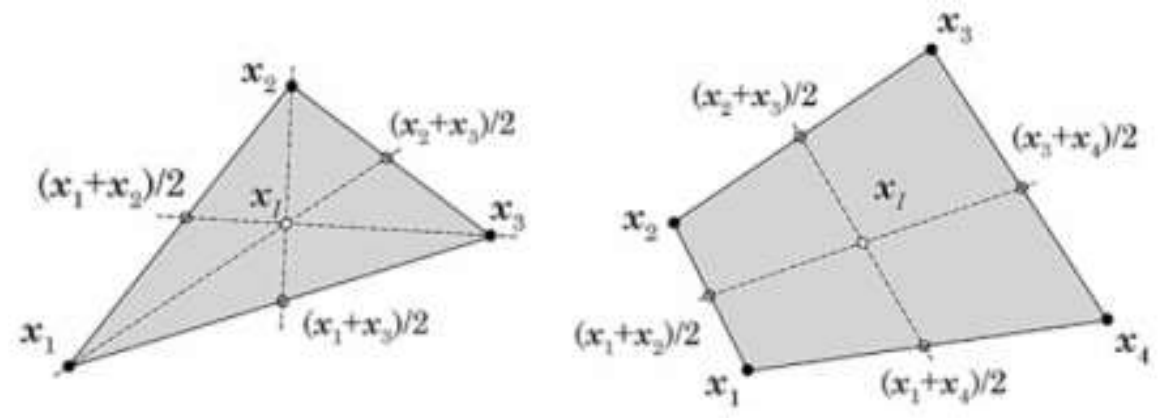

Figure 2.9 Triangular and quadrilateral shapes and the respective integration points. ${ }^{3}$

Regarding this subject, initially, the sub-cell is divided again, although this time only as quadrilaterals, as seen in Figure 2.10, then, it is possible to apply the Gauss-Legendre quadrature to the obtained sub-quadrilaterals in order to obtain the integration points. ${ }^{19,20}$
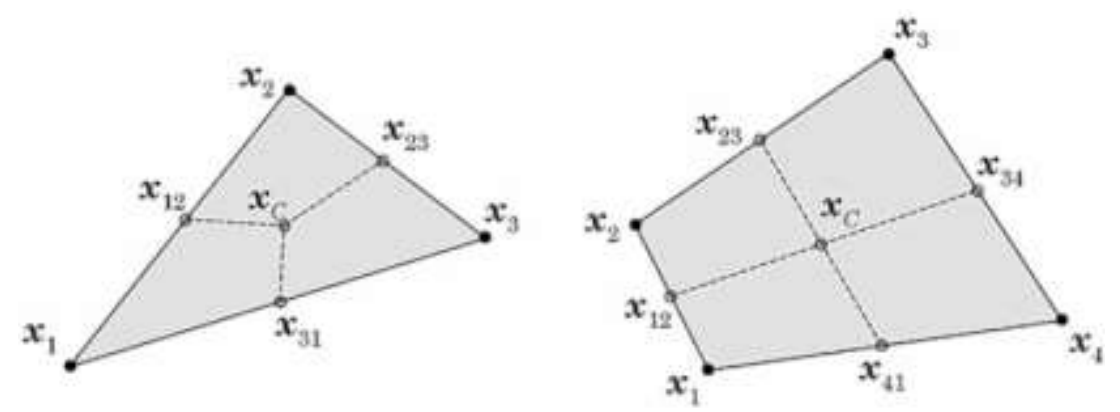

Figure 2.10 Division in quadrilaterals of the sub-cells ${ }^{3}$

Afterwards, the process follows as it was described, in section 2.2.2, for the RPIM using quadrilateral integration. The resultant integration is as follows, in Figure 2.11. 

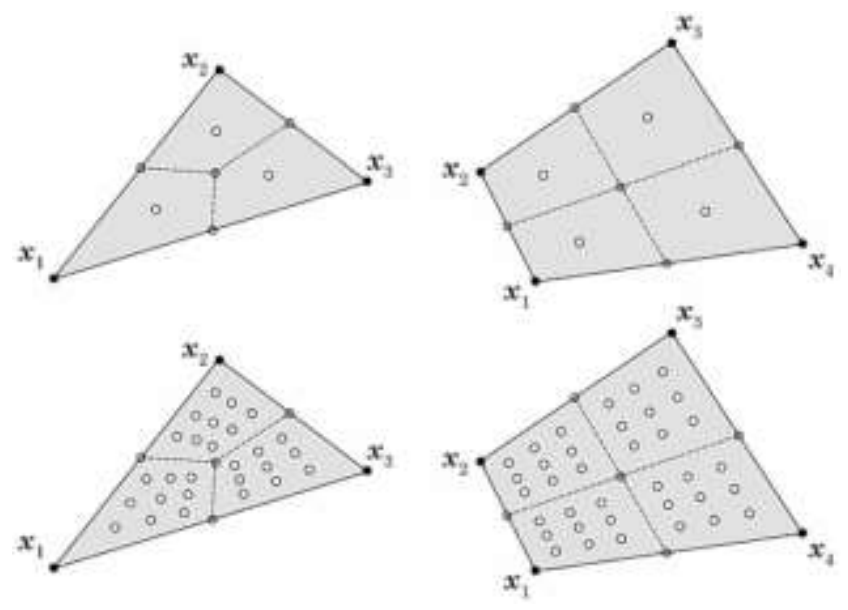

Figure 2.11 Triangular and rectangular shape and respective integration points, $x_{1}$, using the Gauss-Legendre integration scheme. ${ }^{3}$

In Figure 2.11 are shown distinct integration schemes for the triangular and the quadrilateral sub-cells. Nevertheless, adding more integration points does not increase significantly the solution accuracy and, in addition, greatly increases the computational cost. ${ }^{3}$ Therefore, this work follows the suggestion from Belinha ${ }^{3}$ and only uses one integration point per sub-cell. The domain integration mesh is obtained by repeating this process for the remaining Voronoï cells.

\subsection{Shape Functions}

Since the shape functions construction methodology should be able to use only the nodes discretizing the domain without the need of any pre-established mesh providing the nodal connectivity, its construction and development assume great importance in meshless methods. ${ }^{7}$

Both RPIM and NNRPIM use the same shape functions, based on a combination of radial basis functions with polynomial functions. The combination of these functions eliminates some issues such as the possible singularities created by methods that only use polynomial functions. ${ }^{11,18}$

One of the biggest advantages of both these method's shape functions is that they possess the Kronecker delta property, meaning that they are interpolating shape functions.

First of all, it is necessary to consider an influence domain that has a set of arbitrarily distributed nodes $P_{i}\left(x_{i}\right)(i=1,2, \ldots, n)$, being $n$ the number of nodes in the influence domain of $\boldsymbol{x}$ and consider, also, a shape function (in this case, approximation function) $u(\boldsymbol{x})$ in the referred influence domain. Radial PIM constructs the approximation functions $u(x)$ to pass through all these node points using radial basis function $(\mathrm{RBF}), B_{i}(\boldsymbol{x})$, and polynomial basis function, $P_{j}(x) .{ }^{11,18}$

Thus,

$$
u(x)=\sum_{i=1}^{n} B_{i}(x) a_{i}+\sum_{j=1}^{m} P_{j}(x) b_{j}=B^{T}(x) a+P^{T}(x) b
$$


In equation 2.7, $a_{i}$ is the coefficient for $B_{i}(\mathbf{x})$, and $b_{j}$ is the coefficient for $P_{j}(\mathbf{x})$. Moreover, $n$ is the number of nodes in an domain of $\mathbf{x}, m$ is the polynomial term which is usually $m<n$.

In equation 2.8 are defined the vectors

$$
\begin{gathered}
a=\left[a_{1}, a_{2}, a_{3}, \ldots, a_{n}\right]^{T}, \\
b=\left[b_{1}, b_{2}, b_{3}, \ldots, b_{m}\right]^{T} \\
B^{T}=\left[B_{1}(x), B_{2}(x), B_{3}(x), \ldots, B_{n}(x)\right], \\
P^{T}=\left[P_{1}(x), P_{2}(x), P_{3}(x), \ldots, P_{m}(x)\right],
\end{gathered}
$$

Above is defined the radial basis function, which is a function of distance $r$ :

$$
\begin{gathered}
B_{i}(x)=B_{i}\left(r_{i}\right) \\
r_{i}=\sqrt{\left[\left(x-x_{i}\right)^{2}+\left(y-y_{i}\right)^{2}\right]}
\end{gathered}
$$

The monomial terms of the polynomial basis functions are as follows:

$$
P^{T}(x)=\left[1, x, y, x^{2}, x y, y^{2}, \ldots\right]
$$

The radial term transforms a multidimension into one-dimension, and the polynomial term improves the polynomial accuracy of the interpolation. According to Wang et $\mathrm{al}^{18}$ and his research, addition of polynomial terms does not improve greatly the accuracy for nonpolynomial functions, but it was revealed that there was no guarantee that the interpolating condition could be satisfied without the addition of polynomial terms.

Additionally, the coefficients should be constrained in order to assure the uniqueness of the interpolation. Constrains presented in equation 2.11 are usually imposed:

$$
\sum_{i=1}^{n} P_{j}\left(x_{i}, y_{i}\right) a_{i}=0, j=1,2, \ldots, m
$$

It can be expressed in matrix form, as follows:

$$
\left[\begin{array}{cc}
B_{0} & P_{0} \\
P_{0}^{T} & 0
\end{array}\right]\left\{\begin{array}{l}
a \\
b
\end{array}\right\}=\left\{\begin{array}{c}
u^{e} \\
0
\end{array}\right\} \quad \text { or } \quad G\left\{\begin{array}{l}
a \\
b
\end{array}\right\}=\left\{\begin{array}{c}
u^{e} \\
0
\end{array}\right\}
$$

The distance is directionless, $B_{k}\left(x_{i}, y_{i}\right)=B_{i}\left(x_{k}, y_{k}\right)$. If the inverse of the matrix $\mathbf{G}$ exists, consequently, it is possible to obtain a unique solution:

$$
\left\{\begin{array}{l}
a \\
b
\end{array}\right\}=G^{-1}\left\{\begin{array}{c}
u^{e} \\
0
\end{array}\right\}
$$


As result, the interpolation is expressed as:

$u(x)=\left[B^{T}(x) P^{T}(x)\right] G^{-1}\left\{\begin{array}{c}u^{e} \\ 0\end{array}\right\}=\varphi(x) u^{e}$

Being $\varphi(x)$ the shape function defined by:

$\varphi(x)=\left[\Phi_{1}(x), \Phi_{2}(x), \ldots, \Phi_{i}(x), \ldots, \Phi_{n}(x)\right]$

Since shape functions from both RPIM and NNRPIM, as already said, respect the Kronecker delta property,

$$
\varphi_{i}\left(x_{j}\right)= \begin{cases}1, & i=j, \quad j=1,2, \ldots, n \\ 0, & i \neq j, \quad j=1,2, \ldots, n\end{cases}
$$

This means they pass through every single node within the influence-domain (or influencecell), in opposition to approximation shape functions which do not. When comparing approximation shape functions to interpolation shape function, the latter ones have reduced computational costs associated, due to using direct imposition methods, which allows to easily impose the essential and natural boundary conditions. ${ }^{11,18}$ 


\section{Chapter 3}

\section{Solid Mechanics Fundamentals}

Solids and structures subjected to loads or forces become stressed. The stresses lead to strains, which can be interpreted as deformations or relative displacements. Solid mechanics aim is to understand the relationship between stress and strain, as well as, the relationship between strain and displacements. ${ }^{3}$ Depending on the solid material stress-strain curve, solids can show different behaviours.

In the present work, all solids were considered as being linear-elastic, it means that the relationship between stress and strain is assumed to be linear and after the removal of the applied load, the solid returns to its undeformed shape. Additionally, since this is a static study, only static loads were applied and considered, meaning that stresses, strains and displacements are not considered as a function of time.

Also, there are anisotropic and isotropic materials. The first ones are materials in which the properties varies with the directions. On this type of materials the deformation caused by a load applied in a certain direction is different from the deformation caused by the same load applied in a different direction. Isotropic materials are a special case of anisotropic materials, since only two independent material properties need to be known, the Young modulus $(E)$ and the Poisson ratio (v). In this work, only isotropic material were used. ${ }^{3}$

\subsection{Stress Components}

Due to the application of external loads, internal forces are produced. As represented in equation 3.1, these internal forces are defined by the variation of force per unit of area and are entitled stress.

$$
T=\lim _{\Delta A \rightarrow 0} \frac{\Delta F}{\Delta A}
$$


On a certain point, the stress a body is under is given by the following stress tensor:

$$
\tau=\left[\begin{array}{lll}
\sigma_{x x} & \tau_{x y} & \tau_{x z} \\
\tau_{y x} & \sigma_{y y} & \tau_{y z} \\
\tau_{z x} & \tau_{z y} & \sigma_{z z}
\end{array}\right]
$$

This tensor can also be written as a vector:

$$
\sigma=\left\{\sigma_{x x} \sigma_{y y} \sigma_{z z} \tau_{x y} \tau_{y z} \tau_{z x}\right\}^{\top}
$$

Stress can be divided into two categories, normal stress, which is perpendicular to the plane in question, denotes by the letter $\sigma$ and shear stress, which is tangential to the plane in which it acts, denoted by the letter $\tau .^{23}$

\subsection{Equilibrium equations}

Although stresses vary according to the volume of the body, these cannot vary randomly between two given points. An infinitesimal element is characterized by three dimensional equilibrium equation, which are:

$$
\begin{aligned}
& \frac{\partial_{\sigma_{x x}}}{\partial_{x}}+\frac{\partial_{\tau_{y x}}}{\partial_{y}}+\frac{\partial_{\tau_{z x}}}{\partial_{z}}+F_{x}=0 \\
& \frac{\partial_{\tau_{x y}}}{\partial_{x}}+\frac{\partial_{\sigma_{y y}}}{\partial_{y}}+\frac{\partial_{\tau_{z y}}}{\partial_{z}}+F_{y}=0 \\
& \frac{\partial_{\tau_{x z}}}{\partial_{x}}+\frac{\partial_{\tau_{y z}}}{\partial_{y}}+\frac{\partial_{\sigma_{z z}}}{\partial_{z}}+F_{z}=0
\end{aligned}
$$

And must be verified for every point throughout the volume of the body. ${ }^{23}$

\subsection{Components of strain}

Due to the fact that no material is perfectly rigid, when subject to external loads, a body will become deformed. Regarding the deformable body presented in Figure 3.1, prior to applying any external loads, point $\mathrm{Q}$ was in a certain space location, but as soon as external loads are applied, this leads to a change on the location giving origin to any point location, q. 


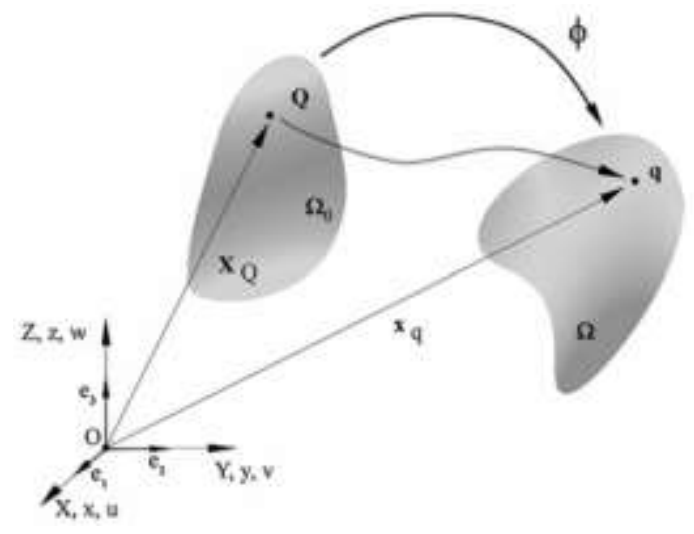

Figure 3.1 Linear deformation of a virtual body ${ }^{3}$

The equation that defines the displacement field, for any given point of the solid is:

$u(u, v, w)=\left\{\begin{array}{l}u(x, y, z) \\ v(x, y, z) \\ w(x, y, z)\end{array}\right\}$

Strain and displacements are related according to the following equations,

$\begin{array}{ll}\varepsilon_{x x} \frac{\partial u}{\partial x} & Y_{x y}=\frac{\partial v}{\partial x}+\frac{\partial u}{\partial y} \\ \varepsilon_{y y} \frac{\partial v}{\partial y} & Y_{y z}=\frac{\partial w}{\partial y}+\frac{\partial v}{\partial z} \\ \varepsilon_{z z} \frac{\partial w}{\partial z} & Y_{z x}=\frac{\partial u}{\partial z}+\frac{\partial w}{d x}\end{array}$

Similarly to what happens in stress, there is also two types of strain. The normal strain, which can be represented by the letter $\varepsilon$, and represents the relative change of length of a certain line segment. On the other hand, the shear strain is represented by the letter $\gamma$ and refers to the change in angle of two previously perpendicular line segments. ${ }^{23}$

The strain tensor comes:

$\varepsilon=\left[\begin{array}{lll}\varepsilon_{x x} & \gamma_{x y} & \gamma_{x z} \\ \gamma_{y x} & \gamma_{y y} & \gamma_{y z} \\ \gamma_{z x} & \gamma_{z y} & \varepsilon_{z z}\end{array}\right]$

The equations presented in 3.6 can be represented in matrix form as the product of the partial differential equation operator matrix $L$ and the displacement field $u$.

$\varepsilon=\boldsymbol{L u}$

Where $L$ is given by, 


$$
\boldsymbol{L}=\left[\begin{array}{cccccc}
\frac{\partial}{\partial x} & 0 & 0 & \frac{\partial}{\partial y} & 0 & \frac{\partial}{\partial z} \\
0 & \frac{\partial}{\partial y} & 0 & \frac{\partial}{\partial x} & \frac{\partial}{\partial z} & 0 \\
0 & 0 & \frac{\partial}{\partial z} & 0 & \frac{\partial}{\partial y} & \frac{\partial}{\partial x}
\end{array}\right]^{T}
$$

\subsection{Constitutive equations}

Due to all solids considered in this work were isotropic, besides the fact that not only is the material completely defined by just its Elastic Modulus and Poisson's ratio, but also, by the components of stress and strain relation, which is given by the generalized Hooke's Law. ${ }^{23}$

$$
\sigma=c \varepsilon
$$

In which, $\mathrm{c}$ is the constitutive matrix of the material, defined by:

$$
\boldsymbol{c}=\frac{E}{(1+v)(1-2 v)}\left[\begin{array}{cccccc}
1-v & v & v & 0 & 0 & 0 \\
v & 1-v & v & 0 & 0 & 0 \\
v & v & 1-v & 0 & 0 & 0 \\
0 & 0 & 0 & (1-2 v) & 0 & 0 \\
0 & 0 & 0 & 0 & (1-2 v) & 0 \\
0 & 0 & 0 & 0 & 0 & (1-2 v)
\end{array}\right]
$$

This constitutive matrix can also be obtained by inverting the compliance elasticity matrix, $c=s^{-1}$. In equations 3.12 and 3.13 are defined the plane stress and plane strain, respectively, for the general anisotropic material case, the compliance elasticity matrix $s$.

$$
\begin{aligned}
& S_{\text {plane stress }}=\left[\begin{array}{ccc}
\frac{1}{E_{11}} & -\frac{v_{21}}{E_{22}} & 0 \\
-\frac{v_{12}}{E_{11}} & \frac{1}{E_{22}} & 0 \\
0 & 0 & \frac{1}{G_{12}}
\end{array}\right] \\
& S_{\text {plane strain }}=\left[\begin{array}{ccc}
\frac{1-v_{31} v_{13}}{E_{11}} & -\frac{v_{12}+v_{31} v_{23}}{E_{22}} & 0 \\
-\frac{v_{12}+v_{32} v_{13}}{E_{11}} & \frac{1-v_{32} v_{23}}{E_{22}} & 0 \\
0 & 0 & \frac{1}{G_{12}}
\end{array}\right]
\end{aligned}
$$

being $E_{i j}$ the elastic modulus, $v_{i j}$ the material Poisson coefficient and $G_{i j}$ the distortion modulus in material direction $i$ and $j$. It is possible to align the constitutive matrix $c$ with a new material referential $O x^{\prime} y^{\prime}$ defined by $i^{\prime}=\left\{i_{x}^{\prime}, i_{y}^{\prime}\right\}$ and $j^{\prime}=\left\{-i_{y}^{\prime}, i_{x}^{\prime}\right\}$, which are versors of the new material referential. Hence,

$$
c^{\prime}=T^{T} c T
$$


where the transformation matrix $\mathrm{T}$ is defined by,

$$
T=\left[\begin{array}{ccc}
\cos ^{2} \alpha & \sin ^{2} \alpha & -\sin 2 \alpha \\
\sin ^{2} \alpha & \cos ^{2} \alpha & \sin 2 \alpha \\
\sin \alpha \cdot \cos \alpha & -\sin \alpha \cdot \cos \alpha & \cos ^{2} \alpha-\sin ^{2} \alpha
\end{array}\right]
$$

the angle $\alpha$ is the angle between the original material axis $O x$ and the new material axis $O_{x}^{\prime}: \alpha=\cos ^{-1}\left(i \cdot i^{\prime}\right)$.

\subsection{Strong form and weak form formulation}

The partial differential system equations are strong forms of the governing system of equations for solids. The strong form, in contrast to a weak form, requires strong continuity on the dependent field variables. Whatsoever functions that define these field variables have to be differentiable up to the order of the partial differential equations that exist in the strong form of the system. On the other hand, the weak form requires a weaker consistency on the adopted approximation (or interpolation) functions.

By reason of the weaker requirements on the field variables, and the integral operation, a formulation based on a weak form, usually produces a set of discretized system equations that give much more accurate results, especially for problems of complex geometry. These are the reasons why so many prefer the weak form to obtain the approximated solution. However, accuracy is dependent on the density of the mesh discretizing the problem domain. ${ }^{3,24}$

\subsubsection{Galerkin weak form}

The Galerkin weak form is a variational principle based on the energy principle. Between all possible displacement configurations satisfying the compatibility conditions, the essential boundary conditions and the initial and final time conditions, the real solution correspondent configuration in the one that minimizes the Lagrangian functional $L$,

$$
L=T-U+W_{f}
$$

Where $T$ is the kinetic energy, $U$ is the strain energy and $W_{f}$ is the work produced by the external forces.

The variables above can be replaced by the equations that defines them, which can be written as,

$$
L=\frac{1}{2} \int_{\Omega} \rho \mathrm{o}^{T} \stackrel{\mathrm{u}}{ } d \Omega-\frac{1}{2} \int_{\Omega} \varepsilon^{T} \sigma d \Omega+\int_{\Omega} u^{T} b d \Omega+\int_{\Gamma_{t}} u^{T} f d \Gamma
$$




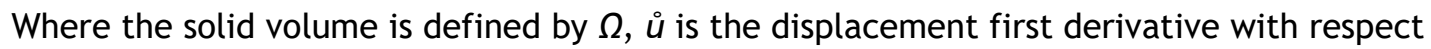
to time and $\rho$ is the solid mass density. $\varepsilon$ is the strain vector and $\sigma$ is the stress vector. Lastly, $u$ represents the displacement, $b$ the body forces and $\Gamma_{t}$ the traction boundary where the external forces $f$ are applied.

Minimizing equation 3.17, the following is obtained:

$$
\delta \int_{t_{1}}^{t_{2}}\left[\frac{1}{2} \int_{\Omega} \rho \stackrel{\circ}{\mathrm{u}}^{T} \stackrel{\mathrm{u}}{\mathrm{u}} d \Omega-\frac{1}{2} \int_{\Omega} \varepsilon^{T} \sigma d \Omega+\int_{\Omega} u^{T} b d \Omega+\int_{\Gamma_{t}} u^{T} f d \Gamma\right] d t=0
$$

Moving the variation operator $\delta$ inside the integrals,

$$
\int_{t_{1}}^{t_{2}}\left[\frac{1}{2} \int_{\Omega} \delta\left(\rho \stackrel{\mathrm{u}}{ }^{T} \stackrel{\circ}{\mathrm{u}}\right) d \Omega-\frac{1}{2} \int_{\Omega} \delta\left(\varepsilon^{T} \sigma\right) d \Omega+\int_{\Omega} \delta u^{T} b d \Omega+\int_{\Gamma_{t}} \delta u^{T} f d \Gamma\right] d t=0
$$

Due to the fact that in this work only static problems were considered, the first term of the equation 3.19 can be discard, which leads to:

$$
\int_{t_{1}}^{t_{2}}\left[-\frac{1}{2} \int_{\Omega} \delta\left(\varepsilon^{T} \sigma\right) d \Omega+\int_{\Omega} \delta u^{T} b d \Omega+\int_{\Gamma_{t}} \delta u^{T} f d \Gamma\right] d t=0
$$

Considering the equation 3.20 , there are some simplifications that can be made to the first term of the integral. The integrand function can be written as:

$$
\delta\left(\varepsilon^{T} \sigma\right)=\delta \varepsilon^{T} \sigma+\varepsilon^{T} \delta \sigma
$$

Since both terms are scalars, in equation 3.21 ,

$$
\varepsilon^{T} \delta \sigma=\left(\varepsilon^{T} \delta \sigma\right)^{T}=\delta \sigma^{T} \varepsilon
$$

According to the generalized Hooke's law shown in 3.10, and the symmetric property of material shown in $3.11, c^{T}=c$, it is possible to write:

$\delta \sigma^{T} \varepsilon=\delta \varepsilon^{T} \sigma$

Hence, by replacing equation 3.23 in equation 3.21 ,

$\delta\left(\varepsilon^{T} \sigma\right)=2\left(\delta \varepsilon^{T} \sigma\right)$

Substituting equation 3.24 in equation 3.20

$\int_{t_{1}}^{t_{2}}\left[-\int_{\Omega} \delta\left(\varepsilon^{T} \sigma\right) d \Omega+\int_{\Omega} \delta u^{T} b d \Omega+\int_{\Gamma_{t}} \delta u^{T} f d \Gamma\right] d t=0$ 
If it is pretended for the time integration to be valid for any pair of initial and final time, $t_{1}$ and $t_{2}$, respectively, the integrand from equation 3.25 must be null. This leads to the "Galerkin weak form" equation,

$$
-\int_{\Omega} \delta \varepsilon^{T} \sigma d \Omega+\int_{\Omega} \delta u^{T} b d \Omega+\int_{\Gamma_{t}} \delta u^{T} f d \Gamma=0
$$

Replacing equations 3.8 and 3.10 In equation 3.26, the generic Galerkin weak form written in terms of displacement is obtained,

$$
\int_{\Omega} \delta(\boldsymbol{L} \boldsymbol{u})^{T} \boldsymbol{c}(\boldsymbol{L} \boldsymbol{u}) d \Omega-\int_{\Omega} \delta u^{T} b d \Omega-\int_{\Gamma_{t}} \delta u^{T} f d \Gamma=0
$$

\subsection{Discrete System Equations}

Having as base the principle of virtual work, the discrete equations for meshless methods are obtained by using the meshless shape functions as trial and test functions. The meshless trial function $u\left(x_{I}\right)$ Is given by,

$$
u\left(x_{i}\right)=\sum_{i=1}^{n} \varphi_{i}\left(x_{I}\right) u_{i}
$$

in which $\varphi_{i}\left(x_{I}\right)$ is the meshless approximation or interpolation function and $u_{i}$ are the nodal displacements of the $n$ nodes belonging to the influence-domain of interest node $x_{i}$.

It is known that the NNRPIM interpolation function satisfies the condition,

$$
\varphi_{i}\left(x_{j}\right)=\delta_{i j}
$$

Where $\delta_{i j}$ is the Kronecker delta, being $\delta_{i j}=1$ if $i=j$ and $\delta_{i j}=0$ if $i \neq j$.

Following equation 3.24, the test function (or virtual displacements) are defined as,

$$
d u\left(x_{i}\right)=\sum_{i=1}^{n} \varphi_{i}\left(x_{I}\right) d u_{i}
$$

Where $d u_{i}$ are the nodal values for the test function.

Since that in the presented work it was studied only two-dimensional problems considering the plane strain or the plane stress assumptions, each node $x_{i}$ discretizing the problem domain has two degrees of freedom: $u_{i}=\left\{u_{i}, v_{i}\right\}$. Thus, in order to interpolate the virtual displacement at the interest point $x_{l}$, it is possible to write: 
$\delta u\left(x_{I}\right)=\delta u_{I}=I\left\{\begin{array}{l}\phi_{I} \\ \phi_{I}\end{array}\right\} \delta u_{s}=\left[\begin{array}{ccccc}\varphi_{1}\left(x_{I}\right) & 0 & \ldots & \varphi_{n}\left(x_{I}\right) & 0 \\ 0 & \varphi_{1}\left(x_{I}\right) & \ldots & 0 & \varphi_{n}\left(x_{I}\right)\end{array}\right]\left\{\begin{array}{c}\delta u_{1} \\ \delta v_{1} \\ \ldots \\ \delta u_{n} \\ \delta v_{n}\end{array}\right\}=H_{I} \delta u_{s}$ (eq. 3.31) being I a 2x2 identity matrix. Equation 3.27 can be re-written as follows:

$$
\delta L=\delta u^{T} \int_{\Omega} B_{I}^{T} c B_{I} d \Omega u-\delta u_{s}^{T} \int_{\Omega} H_{I}^{T} b d \Omega-\delta u_{s}^{T} \int_{\Gamma_{i}} H_{I}^{T} \bar{t} d \Gamma_{t}=0
$$

The equation system can be presented in the matrix form: $K u=f$. Being $\mathrm{K}$ the stiffness matrix (first term of eq. 3.32), $u$ the displacement field vector and $f=f_{b}+f_{t}$ the vector of applied forces ( $f_{b}$ is the second term of eq. 3.32 and $f_{t}$ is the third term of eq. 3.32). Since the RPI shape function possesses the delta Kronecker property, the essential boundary conditions can be directly applied in the stiffness matrix. In order to determine the stress field, it is necessary to determine: the displacement field by solving the linear equation system $K^{-1} f=$ $u$, the strain in an interest point, $x_{I} \in \Omega$, which can be obtained using $\varepsilon\left(x_{I}\right)=\operatorname{Lu}\left(x_{I}\right)$, and lastly, considering the Hooke Law, to solve the equation 3.33.

$$
\sigma\left(x_{I}\right)=c\left(x_{I}\right) \varepsilon\left(x_{I}\right)
$$

Afterwards, the strain energy density (SED) field for the considered load case is determined using stress field and the strain field. The SED for an interest point $x_{I}$ is obtained through equation 3.34

$$
U\left(x_{I}\right)=\frac{1}{2} \int_{\Omega_{I}} \sigma\left(x_{I}\right)^{T} \varepsilon\left(x_{I}\right) d \Omega_{I}
$$

Additionally, it is possible to obtain the three principal stresses $\sigma\left(x_{I}\right)$, for each interest point $x_{I}, \operatorname{det}\left(\Lambda\left(x_{I}\right)-\sigma\left(x_{I}\right)_{i} I\right)=0$, and the three principal directions $n\left(x_{I}\right)_{i}:\left(\Lambda\left(x_{I}\right)-\right.$ $\left.\sigma\left(x_{I}\right)_{i} I\right) n\left(x_{I}\right)_{i}=0$, being $\Lambda\left(x_{I}\right)$ the Cauchy stress tensor obtained for the interest point and I a 2x2 identity matrix. Using the three principal stresses $\sigma\left(x_{I}\right)_{i}$ and the following expression (eq. 3.35)

$$
\bar{\sigma}\left(x_{I}\right)=\sqrt{\frac{1}{2}\left(\left(\sigma\left(x_{I}\right)_{1}-\sigma\left(x_{I}\right)_{2}\right)^{2}+\left(\sigma\left(x_{I}\right)_{2}-\sigma\left(x_{I}\right)_{3}\right)^{2}+\left(\sigma\left(x_{I}\right)_{3}-\sigma\left(x_{I}\right)_{1}\right)^{2}\right)}
$$

The Von Mises effective stress of the interest point $x_{I}$ is obtained. 


\section{Chapter 4}

\section{FEMAS}

This chapter contains a brief introduction to the software used throughout this work and the standard parameters used in both meshless methods, RPIM and NNRPIM.

\subsection{FEMAS}

Developed at FEUP and implemented in the commercial software Matlab, FEMAS, is a meshless computational framework that uses the formulation presented in Chapter 2 . This program possesses a graphical user interface (GUI), allowing to build the numerical model and analyse it using several numerical discretization techniques. In Figure 4.1 is an image from the program here described.

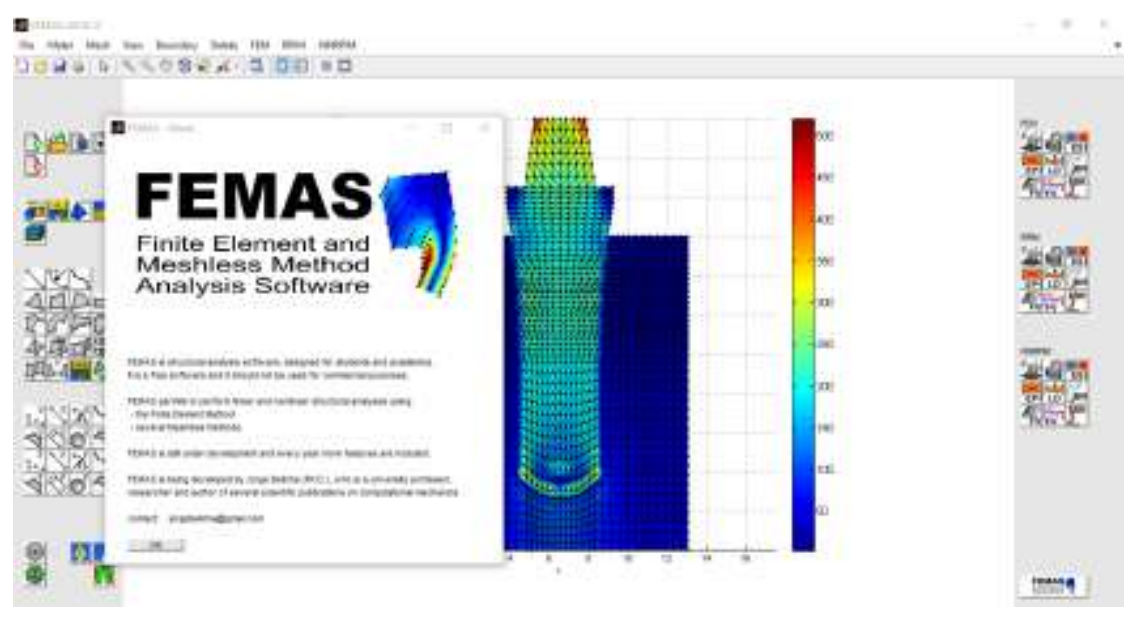

Figure 4.1 FEMAS initial presentation

For comparison purposes, FEMAS can perform numerical analysis using the RPIM, NNRPIM and FEM and can, currently, execute the following analyses: 
- Static linear-elastic

- Elasto-plastic

- Crack opening path

- Bone tissue remodelling

- Free vibration

○ Buckling

- Fluid Flow (low velocities)

Using this software is possible to work in both 2D and 3D problems. So, the software allows to build autonomously the 2D or 3D numerical model, in which the user controls the nodal discretization, the material disposition and the location of both essential an natural boundary conditions. All these tasks can be executed in the program without usage of any external CAD software. Nevertheless, meshless generated in other CAD programs can also be imported and used in FEMAS. Besides this, the computational framework uses the classical three-dimensional deformation theory (when talking about 3D problems) and the plane stress and plane strain two-dimensional deformation theory (for 2D problems) and also allows the use of both isotropic and anisotropic materials, which the user can choose. The workflow of the elastic-static analysis performed by FEMAS is constituted by three steps, the pre-process, the process and the post-process.
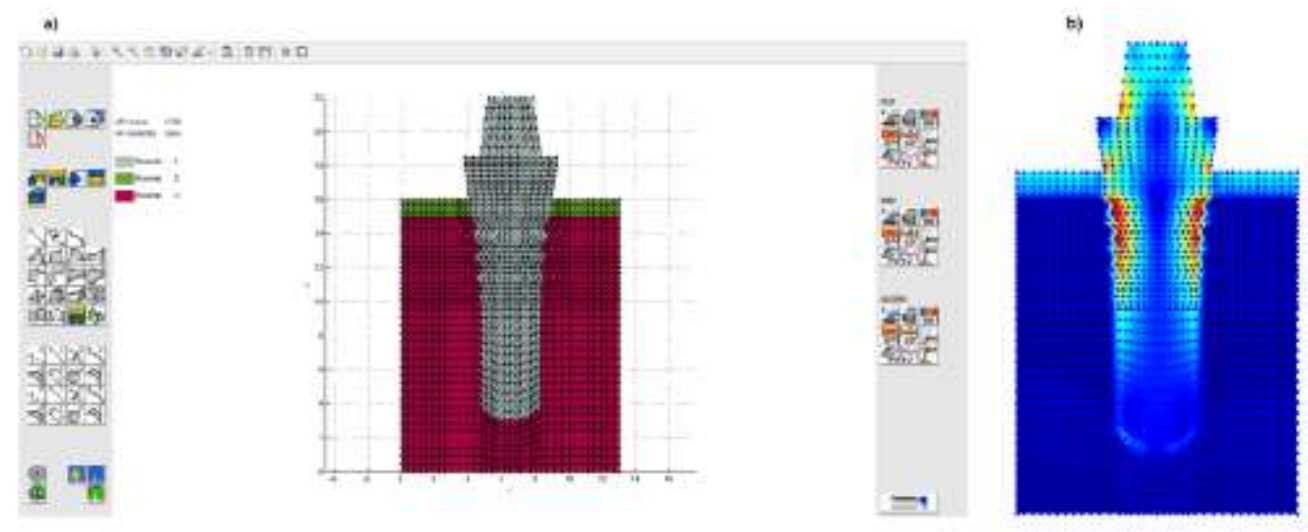

Figure 4.2 a.2D Model of a dental implant built in FEMAS b.Stress field of dental implant obtained in FEMAS

Moreover, FEMAS allows to present the displacement, stress and strain fields along with the solid domain using both figures and arrays, which permits further data analyses. In Figure 4.2, it is presented a model built in FEMAS and also a stress field obtained with an analysis in FEMAS.

The following parameters were also used in all RPIM and NNRPIM analysis throughout this work, as recommended by the literature. ${ }^{3}$ 
Table 4.1 RPIM Parameters

RPIM

2D

3D

Nodes in the influence-domain: 16

Nodes in the influence-domain: 70

$\begin{array}{ll}C=0.0001 & C=0.0001 \\ P=0.9999 & P=0.9999\end{array}$

Polynomial Basis: Constant

Polynomial Basis: Constant

Integration Points: 1 per triangle

Integration Points: 1 per triangle

Table 4.2 NNRPIM Parameters

NNRPIM

\begin{tabular}{cc}
\hline 2D & 3D \\
\hline$C=0.0001$ & $C=0.0001$ \\
\hline$P=0.9999$ & $P=0.9999$ \\
\hline Influence-cell: $2^{\text {nd }}$ Order & Influence-cell: 2 $^{\text {nd }}$ Order \\
\hline Polynomial Basis: Constant & Polynomial Basis: Constant \\
\hline Integration Points: 1 per sub-cell & Integration Points: 1 per sub-cell
\end{tabular}




\section{Chapter 5}

\section{Dental Implants}

At least half of the population from Switzerland and UK have some kind of dental restoration by the year of 1993. In fact, the frequency of removable dental prosthesis (RDPs) among adults varied between 13 and 29\%, while the frequency of fixed dental prosthesis (FDP) was the highest in Sweden (45\%) and Switzerland (34\%). ${ }^{1}$

According to Zitzmann et $\mathrm{al}^{1}$, the proportion of adults using dental restorations is strongly linked with the age, in which, older patients are the ones where the use of this ones is higher. As well, sociodemographic and economic factors have high influence in the usage of dental restorations, since people living in rural areas, with limited access to education, lower social levels and lower incomes have presented a higher prevalence of dental prosthesis than people living in more centre and urbanized areas, with higher education and social levels. It is assumed that this difference is related to an easy access to dental services by the latter ones. ${ }^{1}$

Dental Implant Treatments offers a solution that may generate more satisfactory outcomes for patients who are not able to adapt to conventional dentures or who have already compromised local host bone. The reported 10-year survival rate is approximately $90 \%$, making it a fairly predictable modality of treatment. ${ }^{25}$

Since there is a high impact on society from the lack of teeth, as it was possible to observe from the data shown previously, it is important to address some time on this topic and observe what happens to both implant and bone when a FDP is made, and an implant is placed in the mouth.

\subsection{Types of Implants}

Dental prosthesis can be from two types, either removable or fixed and are termed removable dental prosthesis (RDPs) and fixed dental prosthesis (FDPs), respectively. In this work it will be mainly studied the latter ones. 
Fixed restorations can be sustained, by its term, for dental implants or not. Fixed restorations can also be subdivided into two main types, crowns and fixed dental prosthesis, also called bridges. However, single crowns are not considered a subdivision, since, by definition, fixed prosthesis are replacing one or more teeth and are associated with alveolar structures. Fixed prosthesis are often applied in cases where the soft tissue is fragile and there is gag reflex from the point of view from the patient. ${ }^{1}$

The number of patients using fixed dental prosthesis instead of RDPs have been increasing, due to a recent widespread availability of osseointegrated dental implants, yet, the price of this implants is, sometimes, still a limiting factor.

Due to the preservation of the structure of adjacent teeth and better comfort, aesthetic outcome, functions and stability, osseointegrated dental implants are, most of the time, preferable to conventional dentures. ${ }^{25}$

\subsection{Implants Description}

The dental implant was designed to be placed in the jawbone and it is used to replace a missing tooth. Its localization allows the creation of a strong and solid foundation for replacement teeth, by merging with the existent natural bone. There are three main elements in the composition of a dental implant, which are the crown, the abutment and the dental implant itself, seen from the exterior to the interior of it. As it is possible to observe from Fig. 5.1 , the crown is the most exterior part of the implant and it is the part which is actually visible. It is a replacement tooth and it is custom made, in order to match the natural teeth and look as similar as the original one. The second component is the abutment, which is a connector placed between the crown and the dental implant. It is important because it will maintain the implant solid. Finally, the last component, which is the dental implant itself, serves as substitute for the tooth root and it has a cylindrical shape, slightly tapered with a rough surface. ${ }^{26}$

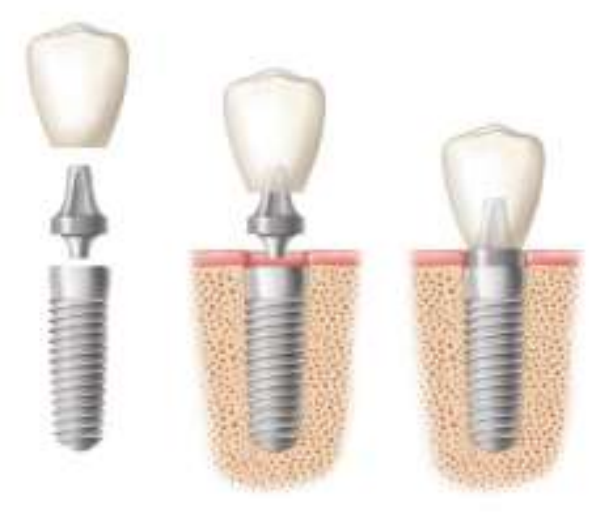

Figure 5.1 Constitution of an Implant 
The implant's surface has to be rough enough towards an easier attachment and stability, and simultaneously, minimizing bone loss associated with site preparation, and slightly minimizing implant volume. In other words, it is supposed to improve the anchoring capacity with bone maintenance, no loss in bone contact area, and no reduction in mechanical strength of the implant. Implants with roughened surfaces have been recommended for single-stage treatment procedures in aesthetic zone and have been proven successful. According to several authors, bone healing and apposition adjacent to dental implants have improved because of the characteristics of surfaces such as the ones here described. ${ }^{27}$

Improvements in implants surface, may improve the prospects of implant survival and reduce the probability of implant failure, for any given healing period.

Many all-ceramic systems have been proposed in the search for the ultimate aesthetic restorative material. In pursuance of an improvement aesthetical outcome of FPD restorations, dental researchers are nowadays directed towards metal-free prosthetic restorations, giving more consistence look of soft tissue in contact with FPD, being these influenced by two factors: mucosal thickness and typology of restorative material. Instead of porcelain fused to metal restorations and restorations, which are more commonly used, it can be adopted metal-free restorations. This permits to preserve soft tissue colour more similar to the natural one. Ceramics such as spinel, alumina and ceramic reinforced with lithium disilicate, have been proposed for the construction of metal free restorations having precise indications for fixed partial dentures. ${ }^{28}$

\subsection{Used Materials for Implants}

The biomechanical integrity of implants comprises the mechanical behaviour of implant materials, surface/induced bone micromechanics, and adaptive bone remodelling. Once implants are placed with intimate apposition of bone at the surgical site, there is an immediate response at the interface which involves adsorption of tissue fluid and cell binding proteins. ${ }^{29,30}$ The existent critical gap between host bone and the implant surface is likely filled by newly formed bone and non-collagenous protein-rich cement line. ${ }^{31-34}$

Many all-ceramic systems have been proposed in the search for the ultimate aesthetic restorative material. In order to improve this outcome of FPD restorations, dental research is nowadays directed towards metal-free prosthetic restorations, which (as already mentioned) allow to preserve soft tissue colour more similar to the natural one than porcelain fused to metal restorations. The natural look of soft tissue in contact with fixed partial dentures is influenced by two factors: musical thickness and typology of restorative material. ${ }^{28}$

Many ceramic, such as spinel, alumina and ceramic reinforced with lithium disilicate have been proposed for the construction of metal-free restorations, however, this reinforced ceramics can only be used to replace anterior teeth with single crown restorations or maximum with three units FPDs. On the other hand, $\mathrm{ZrO}_{2}$ restorations have a wider application field and 
can also be used on molars. Other ceramic technologies only allow the construction of structures that are resistant to chewing stresses on an anterior teeth. ${ }^{28,35}$

\subsubsection{Zirconia}

The height of the abutment is fundamental to obtain $\mathrm{ZrO}_{2}$ frameworks with correct shape and dimension to ensure mechanical resistance of restoration.

Zirconia is a crystalline dioxide of zirconium having analogous mechanical properties to those of metals and its colour is very similar to tooth colour. A volumetric change in the crystal is due to $\mathrm{a}$ force on the zirconia surface caused by a transition between the different crystalline reticulations and it is where the stress is applied. This crystalline modification is followed by an expansion that seals the crack. Zirconia Dioxide $\left(\mathrm{ZrO}_{2}\right)$ can be stabilized with Yttrium Oxide $\left(\mathrm{Y}_{2} \mathrm{O}_{3}\right)$ which will guarantee better mechanical properties than other combinations. Although its sintering is much more difficult, this is the principal kind of zirconia considered for current medical applications. ${ }^{28}$

The first use of zirconia oxide for medical purposes was in an orthopaedic application, in which the research was focused on the mechanical behaviour of zirconia, as well as, on its wear and the integration with bone and muscle. Zirconium oxide creates less flogistic reaction in tissue than other restorative material, such as titanium. Inflammatory infiltrate, micro-vessel density, and vascular endothelial growth factor expression were found to be higher around the titanium caps than around the zirconium oxide ones. ${ }^{28}$

Regarding the zirconia mechanical properties, they are similar to those of stainless steel, in which the resistance to traction can be as high as 900-1200 MPa and its compression resistance is about $2000 \mathrm{MPa}$. Cyclical stresses are also well tolerated by this kind of material. According to Cales, it was necessary around 50 billion cycles to break the samples, when applying an intermittent force of $28 \mathrm{kN}$ to zirconia substrates. Despite this, with a force in excess of $90 \mathrm{kN}$, the same author found that structure failure of the samples occurred after just 15 cycles. It is also known that surface treatments can modify the physical properties of zirconia and the exposure to wetness for an extended period of time can have a detrimental effect on its properties. Tinschert et al. reported a fracture load for $\mathrm{ZrO}_{2}$ of over $2000 \mathrm{~N}$. Sundh et al. measured fracture loads in the range of 2700-4100 N, and whereas Luthy et al. asserted that zirconia core could fracture under a load of $706 \mathrm{~N}$. However, these results are not directly compatible because the methods of measurement were not standardized between studies. 28,36

Zirconia restorations have found their indications for FPDs supported by teeth or implants. Due to the mechanical reliability of this material, single tooth restorations and fixed partial dentures with a single pontic element are possible on both anterior and posterior elements. Ageing Zirconia can have detrimental effects on its mechanical properties. Mechanical stresses and wetness exposure are critical to accelerate this process. Nowadays, effects of ageing 
zirconium oxide used for oral rehabilitation are not yet well known. Resistance values decrease into clinical acceptable values, although ageing reduce mechanical features of Zirconia. It has not only a colour similar to teeth but it is also opaque, being an advantage for the technician. ${ }^{28}$

Even though many types of zirconia-containing ceramic systems are currently available, only three are used to date in dentistry. These are yttrium cation-doped tetragonal zirconia polycristals (3Y-TZP), magnesium cation-doped partially stabilized zirconia (Mg-PSZ) and zirconia-toughened alumina (ZTA).

The mechanical properties of 3Y-TZP strongly depend on its grain size. While above a critical grain size, this system is less stable and more susceptible to spontaneous transformations induced by stress, whereas smaller grain sizes $(<1 \mu \mathrm{m})$ are associated with a lower transformation rate. Moreover, below a certain grain size $(\approx 0.2 \mu \mathrm{m})$, the transformation is not possible, leading to reduced fracture toughness. These are well above those of all other available dental ceramics, with a flexural strength in the 800-1000 $\mathrm{MPa}$ and a fracture toughness in the 6-8 $\mathrm{MPa} \sqrt{\mathrm{m}}$ range. ${ }^{37}$

One of the main advantages of zirconia-toughened alumina is that there is a very limited shrinkage having, yet, a greater amount of porosity than that of sintered 3Y-TZP, which was seen previously. The In-Ceram ${ }^{\circledR}$ and Zirconia $^{\circledR}$ processed by slip-casting, both of them commercially available dental products, have a significantly higher flexural strength $(630 \pm 58$ $\mathrm{MPa})$, when compared to the machined material $(476 \pm 50 \mathrm{MPa})$ and have no significant difference in fracture toughness. In some of the newly developed ZTA for biomedical applications, excellent mechanical properties are obtained by promoting a fine and uniform dispersion of zirconia grains in an alumina matrix. ${ }^{37}$

Although a considerable amount of research has been dedicated to magnesia partially stabilized zirconia (Mg-PSZ) for possible biomedical applications, this material has not been successful mainly due to the presence of porosity, associated with large grain size (30-60 $\mu \mathrm{m})$ that can induce wear. ${ }^{37}$

Since this work will mainly focus on the implant materials, it is important to know the Poisson's coefficient, as well as the elasticity modulus $(\mathrm{E})$. For the specific case of zirconia, the coefficient of Poisson (v) is 0.25 and the Young's modulus is $245 \mathrm{GPa}$. Having in mind that the bone's elastic modulus is presumed to be $10-30 \mathrm{GPa}$, the zirconia flexural modulus is approximately 16 times higher than that. 38,39

Moreover, since this is a biomechanical analysis it is important to know the value of the Maximum Compressive Strength of the Zirconia. The literature reports a value of $900 \mathrm{MPa}$ for the Maximum Compressive Strength of the Zirconia. ${ }^{40,41}$

\subsubsection{Bone}

Over a long period of human evolution and adaptation, hard tissues such as bone and teeth have developed desirable mechanical properties along with their own hierarchical structures. 
Bone is still functional as a supporting tissue for much harder and stiffer implants, which allows to conclude that intact bone enables remarkable adaptation associated with strain energy dissipation in the human body. ${ }^{34}$

Bone consists of directional structural features across several hierarchical scales, ranging from nanoscale crystals and molecules to the microscopic range. ${ }^{42,43} \mathrm{~A}$ two-phase arrangement of an anisometric bone mineral called hydroxyl apatite, preferentially oriented in a collagen matrix is the foundational unit. ${ }^{44,45}$ According to Griffith's ${ }^{46}$ theory of brittle fracture, the smaller the individual sample, the higher the strength is, because smaller samples contain less and smaller defects. Having this in mind, nanoscale bone apatite crystals enable a higher strength than bulk sintered apatite block. ${ }^{34}$

Many experimental studies show that the bone mechanical properties depend on the bone composition and on the bone porosity (directly related with the bone density).

At the macrostructure level, bone can be distinguished in two types: cortical (or compact), highly densified bone tissue, and cancellous (or trabecular), which shows a considerably smaller apparent density. Even though types of bone (cortical and trabecular) are most easily wellknown by their degree of porosity or density, true differentiation comes from histological evaluation of the tissue's microstructure. And the mechanical behaviour is also different. ${ }^{3,42,47-}$ 52

In cortical bone the mechanical properties are influenced greatly by the porosity, the mineralisation level and the organization of the solid matrix. In opposition to cortical bone, the mechanical properties of cancellous bone vary significantly. ${ }^{42}$

From the literature it was possible to assemble in Table 5.1 the properties of five cases of different types of bone. Despite all of this five cases have different Young Modulus for both Cortical and Trabecular Bone, all of them have the same Poisson's coefficient: $v=0.3$. All of this five cases were used in the presented study.

As it was already mentioned in section 5.3.1, it is important for this study to know the value of the Compressive stress of the bone. According to Belinha ${ }^{3}$, the bone Maximum Compression Stress for the density used in this study is about $50 \mathrm{MPa} .^{3}$

Table 5.1 Mechanical Properties of bone cases

\begin{tabular}{cccc}
\hline Case & $\begin{array}{c}\text { Cortical Bone } \\
\text { Young Modulus (MPa) }\end{array}$ & $\begin{array}{c}\text { Trabecular Bone } \\
\text { Young Modulus (MPa) }\end{array}$ & Ref \\
\hline 1 & 10000 & 250 & 53 \\
\hline 2 & 11500 & 2130 & 54 \\
\hline 3 & 13400 & 790 & 4 \\
\hline 4 & 13700 & 1000 & 55 \\
\hline 5 & 14800 & 1850 & 56 \\
\hline
\end{tabular}




\section{Chapter 6}

\section{Numerical Examples}

Throughout the years there have been many works studying the numerical analysis in implants, especially dental implants. Due to the fact that components in a dental implant bone system are extremely complex geometrically, the most common analysis performed has been finite element analysis. ${ }^{4}$

FEM has been used in implant dentistry since 1976 (Weinstein at al. ${ }^{57}$ ) after Atmaram and Mohamed $^{58-60}$, studied the distribution of stress alongside a single tooth implant. This allowed a better understanding of the effect of elastic parameters and the geometry of the implant, as well as implant length variation and pseudo-periodontal ligament incorporation. Borchers and Reichart ${ }^{61}$ and Cook et al. ${ }^{62}$ performed a 3D finite element analysis of an implant at different stages of bone interface development and applied the method to porous rooted dental implants, respectively. Meroueh et al. ${ }^{63}$ performed the same analysis for an osseointegrated cylindrical implant. Williams et al. ${ }^{64}$ carried out an FEA on a cantilevered prostheses on dental implants, and Akpinar et al. ${ }^{65}$ used FEA to simulate the combination of a natural tooth and implant. ${ }^{4}$

Towards making the modelling and solving process possible, certain assumptions needed to be done, since the principal difficulty in simulating the mechanical behaviour of dental implants is the modelling of human bone tissue and its response to applied mechanical force. Due to the complexity of the mechanical characterization of bone and its interaction with implant systems, the assumption made include a detailed geometry of the bone and implant to be modelled, material properties, boundary conditions and interface between bone and implant. $4,66,67$

If the goal is to obtain more accurate stress predictions, advanced digital imaging techniques can be applied to model the bone geometry more realistically. Also, the anisotropic and non-homogeneous nature of the material must be considered and the boundary conditions must be carefully treated with the use of computational modelling techniques. Moreover, 
modelling of the bone-implant interface should incorporate the actual osseointegration contact area in cortical bone and the detailed trabecular bone contact pattern through the use of contact algorithms in FEM. ${ }^{4}$

More recently, studies considering the FEM model done by Chou et al. ${ }^{68}$ analysed a twodimensional four-node finite element. Furthermore, Lian et al. ${ }^{69}$ proposed a FEM model having in consideration a two-dimensional three-node element. In the first of these two works, the implant system was submitted to an occlusal load, $F_{0}=100 \mathrm{~N}$ applied directly in the crown, inclined $11^{\circ}$ in relation to the implant longitudinal axis and it is suggested a second load condition referring an uniform distributed pressure along the outer surface of the cortical bone $(500 \mathrm{kPa})$ which intend to simulate the effect of the mandibular flexure. In this same analysis, the model is constrained in the basis along $x$ and $y$ direction. ${ }^{3}$

Meshless methods have also been applied in this field, becoming more effective and used throughout the years. As shown by Belinha and co-workers, the proposed algorithm for bone remodelling presented by them, combined with the NNRPIM is capable of reproducing trabecular distributions very close to the clinical results and much better predictions when compared with the FEM. Under the implant is possible to observe high-density horizontally oriented regions connecting the cortical layers on the bone periphery and a closer look allows to verify that using a meshless approach is likely to achieve results that resembles much more real trabecular structures when compared with results obtained with FEM. $3,68,69$

\subsection{The work}

The numerical model analysed in this work was built based on 3D images provided by zirconia implant manufacturer (Ceraroot ${ }^{\circledR}$, Barcelona, Spain), are presented in Figure 6.1a. From the 3D geometry, two section views were obtained. Since the provided zirconia implant is not perfectly cylindrical, the two section views optimized the minimum and maximum 2D geometries that can be obtained from the 3D model, Figure 6.1b and Figure 6.1c.

a)

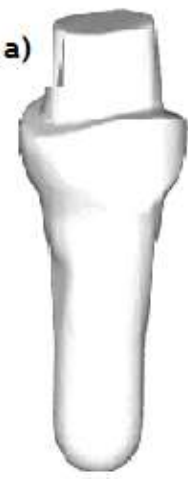

b)

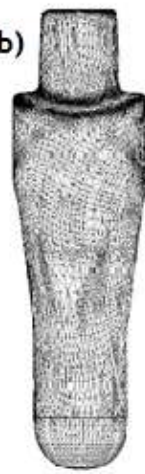

c)

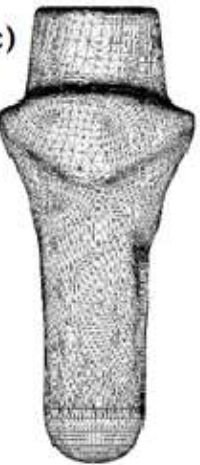

Figure 6.1 a)3D model of the zirconia implant. b)2D view showing the minimum geometric dimensions. C) $2 \mathrm{D}$ view showing the maximum geometric dimensions. 
In order to study the mechanical behaviour of the zirconia implant and the corresponding bone response, the implant was inserted in a cubic block of bone, as Figure 6.2a shows. Then, 2D section cuts were performed, respecting the optimized geometries previously presented, Figure $6.2 \mathrm{~b}$ and $6.2 \mathrm{c}$. In the end, 2D dental implant system, respecting dimensions suggested in other research works ${ }^{69}$, were obtained.
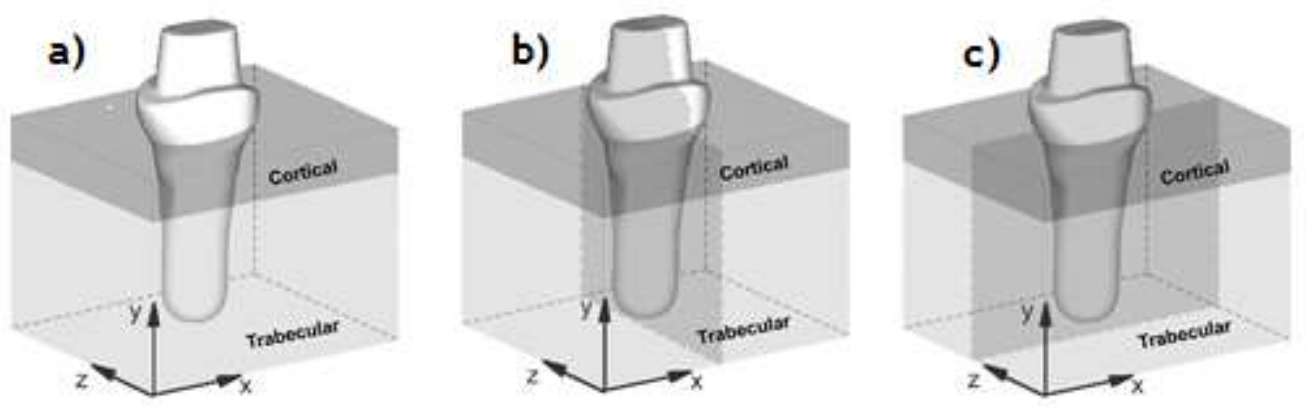

Figure 6.2 a)3D model of the zirconia implant inserted in the bone block. b)2D section cut capturing the minimum geometric dimensions. c)2D section cut capturing the maximum geometric dimensions.

There were created two models, one which was called 'Model 1' having $2.6 \mathrm{~mm}$ in $\mathrm{x}$ direction and another which was called 'Model 2' being slightly thicker, having $3.5 \mathrm{~mm}$, as it is possible to observe in Figure $6.3 \mathrm{a}$ and Figure $6.3 \mathrm{~b}$, respectively. Both view had $12 \mathrm{~mm}$ length.
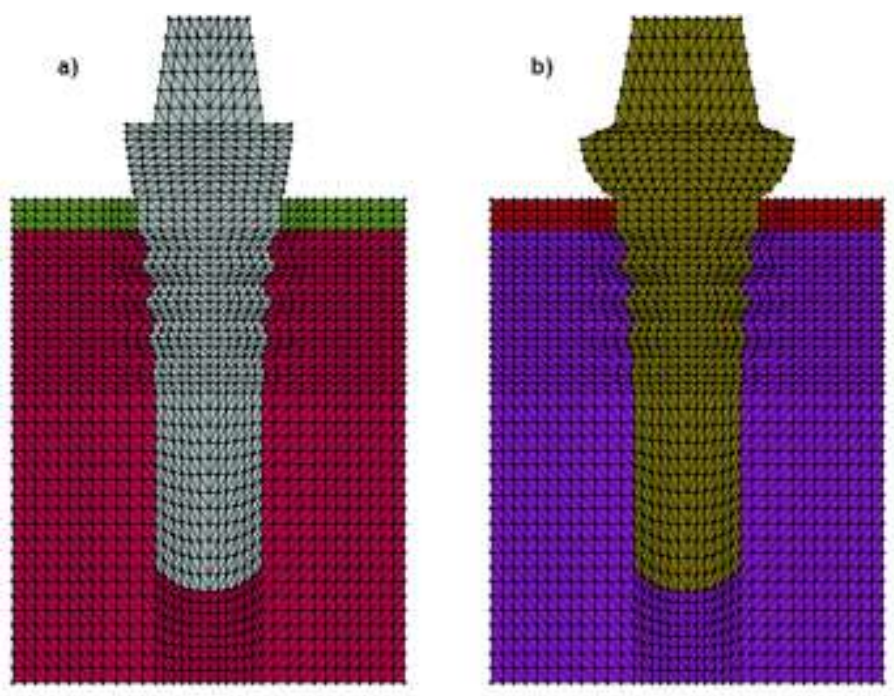

Figure 6.3 a.Model 1. b.Model 2

As it is possible to observe in Figure 6.3, there are three diverse materials, in each model: the zirconia, the cortical bone and the trabecular bone. The first one is the material from which the implant is made (grey in Model 1 and green in Model 2). The second one is a cortical bone layer (green in Model 1 and red in Model 2), and the latter one is a trabecular bone layer (Bordeaux in Model 1 and purple in Model 2). The mechanical properties of the distinct 
materials presented were shown previously in this work, in sections 5.3.1 and 5.3.2, respectively. In this work, there were used five different types of bone, where the Young modulus of both Cortical and Trabecular bone varied, according to Table 5.1. ${ }^{70}$

One of the main purposes of the present study is to compare the results obtained with the proposed numerical approach with other algorithms, such as the finite element method. Due to the fact that there were two different models, which had different meshes, the number of nodes in each one was also different. The 'Model 1' mesh had 1725 nodes and 'Model 2' mesh had 1758 nodes.

After each mesh was constructed, the essential and natural boundary conditions were applied as suggested in the work of Chou et al. ${ }^{68}$ with some adjustments. The load applied, as in the mentioned work, was $100 \mathrm{~N}$, and were tested all inclinations from $90^{\circ}$ to $10^{\circ}$ with intervals of $10^{\circ}$, instead just the $11^{\circ}$ angle suggested in the literature ${ }^{68}$. Also, the uniform distributed pressure along the outer surface was not applied. The movement of the model was blocked in $x$ direction in the lateral faces and along $y$ in the basis, as shown in Figure 6.4a, constituting the essential boundary conditions. In Figure 6.4b, is an example of a model with an applied load at an inclination of $70^{\circ}$.

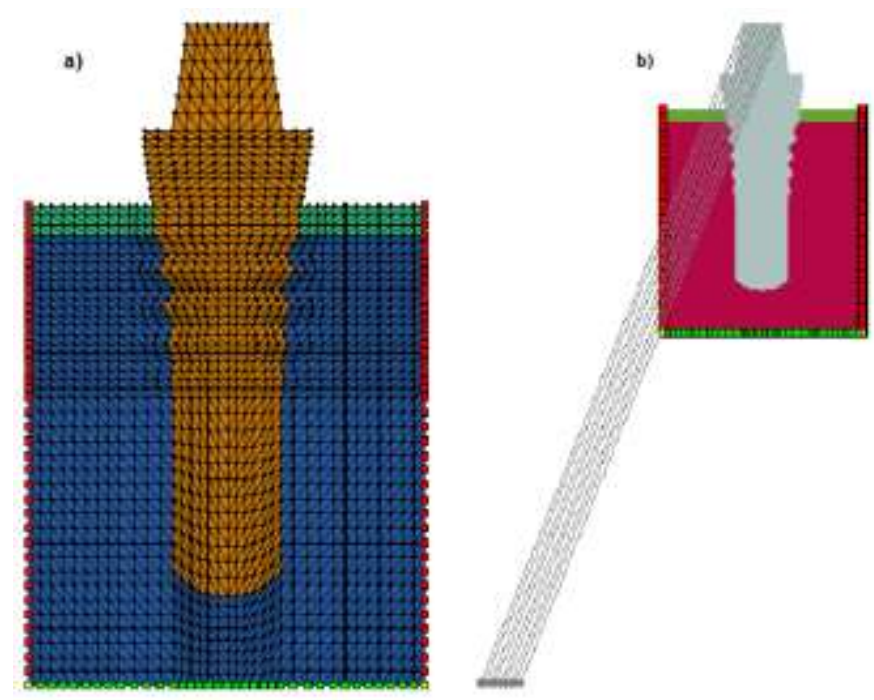

Figure 6.4 a.Model with essential boundary conditions b.Model with essential boundary conditions and applied load at $70^{\circ}$

Once all the parameters are settled, it is possible to perform a static linear-elastic analysis. With this analysis it is possible to obtain, for instance, the Von Mises stress map of each model. The maps for all the models are presented in appendix 1 FigureA.1, FigureA.2, FigureA.3, FigureA.4, FigureA.5, FigureA.6, FigureA.7, FigureA.8, FigureA.9 and FigureA.10. Each figure represent a stress map for one model and one type of bone that is why there are 10 different. In each one, the first line corresponds to FEM analysis, the second line to RPIM analysis and the third line to NNRPIM analysis. Besides, each column represents an angle from $10^{\circ}$ to $90^{\circ}$ from 
left to right, respectively. In Figure 6.5 it is represented an example of this tension maps from 'Model 1', type of bone 1 , at an angle of $10^{\circ}$ and that was analysed with FEM. As it is possible to observe, the areas where the stress is higher are inside the implant, where the colour is red and correspond to higher values of stress. The dark blue is the place where the stress is lower and corresponds essentially to the trabecular bone.

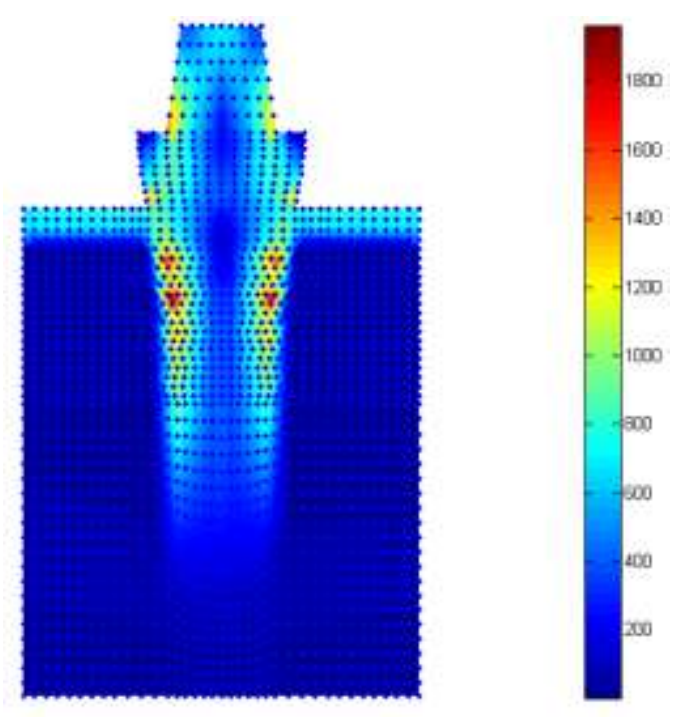

Figure 6.5 Stress map from type of bone 1 , 'Model 1', angle $10^{\circ}$, analysed with FEM

The interface between the implant and the bone is the zone with greater interest for this study. In order to study the stress created by the applied load in this area, after each stress map was obtained, it was chosen a line of points on the implant side and a line of points on the bone side, as Figure 6.6 shows. The line was obtained based on Matlab script created by the author, through reading the Excel files that were extracted from each of the results originated by FEMAS. 


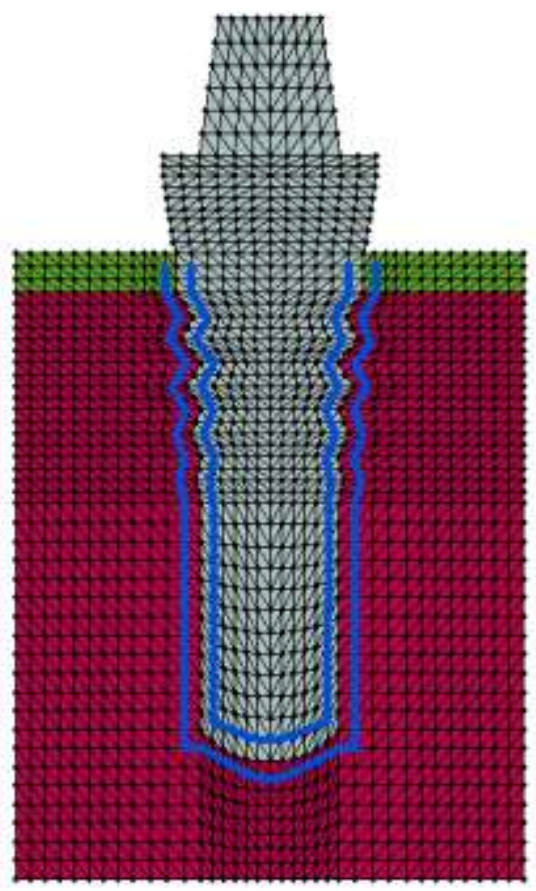

Figure 6.6 Model of a dental implant with the two lines selected

The main purpose for this analysis is comparing the three methods mentioned before, FEM, RPIM and NNRPIM, for each model, on the perspective of both bone and implant, for each type of bone and for all angles, pointed out previously. Having this comparison in mind, for each case, it was built a graph which are presented in appendix 2 . The graphics allow to analyse how the stress vary along the selected line. In Figure $6.7 \mathrm{a}$ and $6.7 \mathrm{~b}$ are examples of these graphs. The first one (Figure 6.7a) is in respect of bone side and the other one (Figure 6.7b) is in respect of implant side.

a)

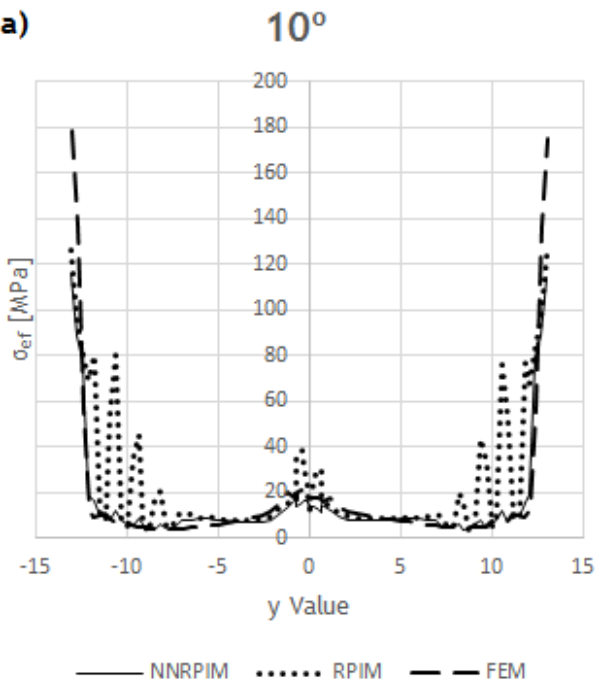

b)

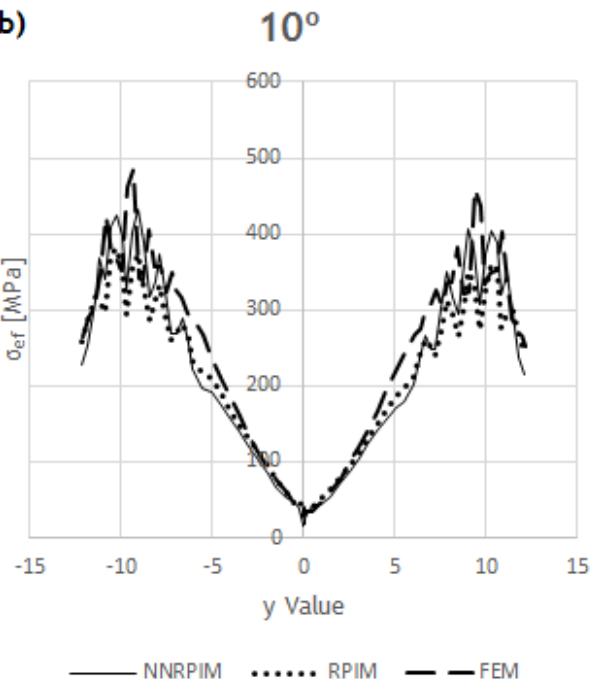

Figure 6.7 a.Stress distribution from bone side, from 'Model 1 ', for an angle of $10^{\circ}$ b.Stress distribution from implant side, from 'Model 1 ', for an angle of $10^{\circ}$ 
Although there weren't negative values on the initial model, in interest of a better visualization of the results, it was performed a normalization of the results. Regarding this topic, the value corresponding to the lowest value of $y$ from the line obtained previously (points 5 and 14 from Figure 6.8), corresponds to zero in the graphics, and the other values became symmetric. Thus, the values from the left side of the model ( $x$ value lower than point 5 for bone side and 14 for implant side) are negative in the graphics and values from the right side of the model ( $x$ value higher than point 5 for bone side and 14 for implant side) are positive in the graphics.

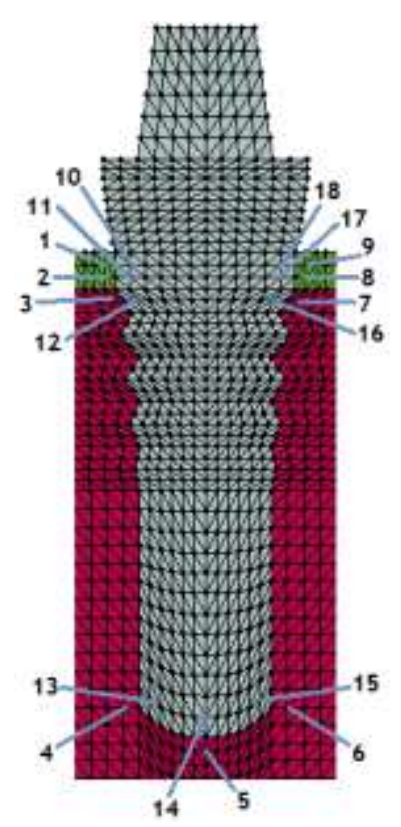

Figure 6.8 Points of interest in the model of the dental implant

Since the produced line-graphics only allow to analyse variation of data, 18 points were chosen to analyse their individual values and are indicated in Figure 6.4. Points 1 to 9 , inclusive, regards to the bone side, where points 1, 2, 8 and 9 corresponds to cortical bone and the others to trabecular bone. Points 10 to 18 , inclusive regards the implant. Their individual values of stress were obtained and gathered in the Tables from appendix 3, where M1 corresponds to 'Model 1' and M2 resembles to 'Model 2'. Each one of this tables has a dashed line separating the points that corresponds to the bone side and the implant side.

Afterwards, in order to better understand how stress varies in function of the angle for each method, FEM, RPIM and NNRPIM, it was constructed a graph, having this relation as a base, for each point of Figure 6.8. An example is presented below in Figure 6.9, where it is presented discrete stress values for type of bone 4, 'Model 1', and seen from implant perspective, more specially, point 16 (Figure 6.8). The values correspondent to $x$ are the values of the tested angles, meaning, $10^{\circ}, 20^{\circ}, 30^{\circ}, 40^{\circ}, 50^{\circ}, 60^{\circ}, 70^{\circ}, 80^{\circ}$ and $90^{\circ}$, and the values correspondent to the $y$ are the effective stress values. In this graphic are represented all the three methods tested 
16

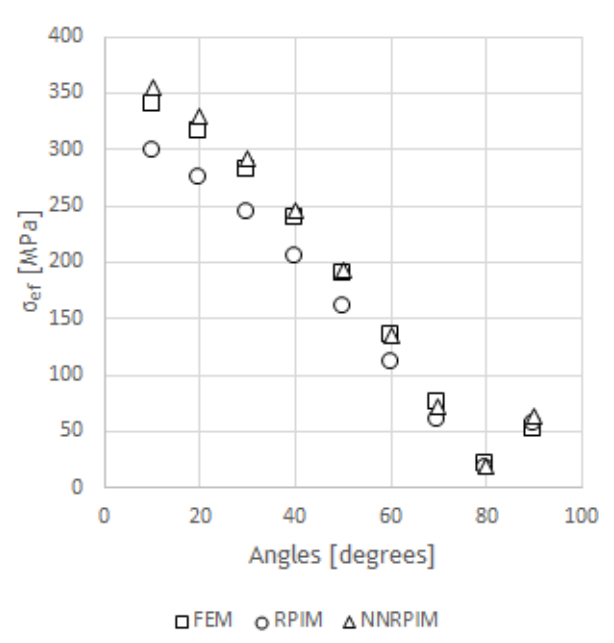

Figure 6.9 Discrete Stress Values for type of bone 4, 'Model 1' and from implant side (point 16)

All the obtained graphs are in appendix 4. The angles represented in the graphs are the angles mentioned before, from $10^{\circ}$ to $90^{\circ}$ with intervals of $10^{\circ}$.

Through the observation of the results obtained for each of the presented cases, it is possible to notice that even though the results obtained with the three methods tested (FEM, RPIM and NNRPIM) lead to quite similar stress distributions, there are some differences intrinsic to each method.

Firstly, looking to the stress maps from appendix 1 , it is possible to observe that there are higher stress values from the left side of the implant, probably due to the fact that the load is applied down with inclination to the left. Despite the differences of the meshes from 'Model 1 ' and 'Model 2', the results obtained in both cases were similar between each other, for all types of bones, except for the type of bone 1 , for higher angles $\left(80^{\circ}\right.$ and $\left.90^{\circ}\right)$. In this case, the results obtained with FEM were slightly different from the ones obtained with meshless methods, where FEM had higher stress values.

Looking, now, for the graphs created having as base the selected line (appendix 2), in order to study the interface implant-bone, it is possible to see that NNRPIM and FEM have quite similar results, but, RPIM has constantly results higher than the other two referred methods, even though this results are more dissimilar for higher values of the angles. From the graphs is also possible to notice that FEM has higher values of stress than meshless methods for the points in which the absolute value of $y$ is higher. Furthermore, the values of stress from the bone side are, generally, lower than the same ones from the side of the implant. From the bone perspective, an increasing value of the angle results in an increasing value of stress of the $y$ values near zero. The same happens for the implant perspective, even though for lower values 
of angles, in this case, the stress values for higher absolute values of $y$ are higher than from bone side.

Regarding the results from the tables from appendix 3 , although very similar, the values from 'Model 2' are all higher than the ones obtained for 'Model 1', and as it was expected, from the previous analysis, the stress values from the implant are higher than the ones from the bone, because Zirconia has a higher Young's Modulus than the bone. Regarding the two different types of bones, it is possible to observe that points 1, 2, 8 and 9 have higher values of stress than points 3, 4, 5, 6 and 7, even though all of them correspond to bone. This occurs because the first four here mentioned correspond to cortical bone and the others correspond to trabecular bone and the latter one has lower values of Young's Modulus in all five bone types than the first one.

Lastly, analysing the results obtained from the graphics which relate the stress with the angle, it is possible to say that for all cases, the best results are in points $10,11,12,16,17$ and 18 and the poorest results are points, 3 and 7 . The latter ones must be due to the fact that are in the interface with both the implant and with cortical bone, leading to poorer results.

Once analysed all the results through the graphs, it is important to see the results from the perspective of both bone and zirconia implant. Considering the worst cases studied from the perspective of Zirconia implant, which occurred for point 12 (Figure 6.6), for all types of bone except type 2, for angles $10^{\circ}$ and $20^{\circ}$, for methods FEM and NNRPIM, for 'Model 2', the values varied around $600 \mathrm{MPa}$. Since the Maximum Compressive Strength of the Zirconia is 900MPa, the obtained value was lower, even for the minimum value of the interval cited in the literature, becoming, the value acquired in this study, $600 \mathrm{MPa}$ below from the mentioned value.

Regarding the bone perspective, the value of Maximum Compression Stress (50MPa) was higher only from points 3 to 7 and the worst results were from points 1 and 9 (Figure 6.6).

Even though points 3 to 7 (Figure 6.6) were the ones which fits the most the value presented in literature, a considerable number of values are above 50MPa, especially in 'Model 2', because, as it was already referred, it has higher values than 'Model 1'. The results presented in this study don't have a good agreement with the value presented in Belinha ${ }^{3}$, probably due to the fact that the value extracted from the literature was based on the density of the bone, and the Elastic Modulus used in Belinha's work was approximately 10 times lower than the ones used in this work. As the latter parameter has influence in the results, perhaps, if it was used Elastic Modulus suggested in Belinha, the results would be better. 


\section{Chapter 7}

\section{Conclusions and Future Work}

This study is a comparative study between the Finite Element Method (FEM), the Radial Point Interpolation Method (RPIM) and the Natural Neighbour Radial Point Interpolation Method (NNRPIM) on the analysis of dental implants.

From this work, the main conclusions that can be drawn were:

$\checkmark$ Meshless methods converge much faster than FEM. When compared with FEM, the convergence rate is similar.

$\checkmark$ Considering the same number of nodes, even though meshless methods require a higher computational time, the same solution can be achieved using fewer nodes than FEM, which means that the same accuracy in results can be obtained through a smaller mesh

$\checkmark$ The stress values obtained for Zirconia are very distant from the maximum compressive strength of Zirconia (900MPa).

$\checkmark$ The difference of stress between FEM and the meshless methods is due to the fact that the influence-domain from meshless methods is bigger than the influencedomain from FEM (a single element). This leads to softer mechanical properties on the integration point, where the stress value is read.

$\checkmark$ This work shows that meshless methods are an alternative numerical tool to analyse dental implants structures using 2D formulations.

$\checkmark$ Form this work it is possible to say that Zirconia implants are suitable, because the Maximum Compressive Strength is never reached, even though bone has stress values near the value of Maximum Compression.

In the beginning, this work had three main goals, being the first one, perform an elastostatic analysis of a dental implant, applying a concentrated load, using three numerical 
method: FEM, RPIM and NNRPIM. The second one, was to compare the performance of all three methods, especially FEM, against the two meshless methods. And the third one was to understand the mechanical behaviour of zirconia implants and the bone tissue response, in the presence of such implants. Regarding this purposes, it is possible to observe that all of them were fulfilled, which can be observed from the analysis of the results, which were obtained by an elasto-static analysis performed with FEMAS, with a concentrated load of $100 \mathrm{~N}$ in each case. The results for FEM, RPIM and NNRPIM were obtained, which allowed a performance analysis between all of them. In order to analyse the mechanical behaviour of zirconia implants and the bone response to them, graphs were done that corroborate this behaviour, and which is analysed in section 6.1 .

In the future, it would be interesting to continue this work, by testing different approaches to the same problem, for instance:

$\checkmark$ Test with implants with the mechanical properties of titanium and PEEK.

$\checkmark$ Perform the same analysis in a 3D model of a dental implant.

$\checkmark$ Perform an elasto-plastic analysis.

$\checkmark$ Analyse the bone remodelling created by dental implants.

$\checkmark$ Compare the results obtained numerically with similar ones obtained by experimental testing 


\section{References}

1. Zitzmann NU. What is the prevalence of various types of prosthetic dental restorations in Europe ? 2007:20-33. doi:10.1111/j.1600-0501.2007.01435.x.

2. Salinas TJ, Block MS, Sadan A. Fixed Partial Denture or Single-Tooth Implant Restoration ? Statistical Considerations for Sequencing. 2004:2-16. doi:10.1016/j.joms.2004.06.001.

3. Belinha J. Meshless Methods in Biomechanics: Bone Tissue Remodelling Analysis.; 2012. doi:10.1007/978-94-007-4174-4.

4. Geng JP, Tan KB, Liu GR. Application of finite element analysis in implant dentistry: a review of the literature. J Prosthet Dent. 2001;85(6):585-598. doi:10.1067/mpr.2001.115251.

5. Dinis LMJS, Natal Jorge RM, Belinha J. Analysis of plates and laminates using the natural neighbour radial point interpolation method. Eng Anal Bound Elem. 2008;32(3):267-279. doi:10.1016/j.enganabound.2007.08.006.

6. Nayroles B, Touzot G, Villon P. Computational Mechanics Generalizing the finite element method : Diffuse approximation and diffuse elements. 1992:307-318.

7. Phu V, Rabczuk T, Duflot M. Meshless methods : A review and computer implementation aspects. 2008;79:763-813. doi:10.1016/j.matcom.2008.01.003.

8. Belinha J, Dinis LMJS, Jorge RMN. The Meshless Methods in the Bone Tissue Remodelling Analysis. Procedia Eng. 2015;110:51-58. doi:10.1016/j.proeng.2015.07.009.

9. Doblaré M, Cueto E, Calvo B, Martínez M a., Garcia JM, Cegoñino J. On the employ of meshless methods in biomechanics. Comput Methods Appl Mech Eng. 2005;194(68):801-821. doi:10.1016/j.cma.2004.06.031.

10. LIU GR, GU YT. A point interpolation method for two dimensional solids. Int J Numer Methods Eng. 2001;50(4):937-951. doi:10.1002/1097-0207(20010210)50.

11. Wang JG, Liu GR. A point interpolation meshless method based on radial basis functions. Int J Numer Methods Eng. 2002;54(11):1623-1648. doi:10.1002/nme.489.

12. Sibson R. A brief description of natural neighbour interpolation. Interpret Multivar data. 1981.

https://scholar.google.pt/scholar?q=A+brief+description+of+natural+neighbor+interpol ation\&btnG=\&hl=pt-PT\&as_sdt=0\%2C5\#0. Accessed February 1, 2016.

13. Voronoi G. Nouvelles applications des paramètres continus à la théorie des formes quadratiques. Deuxième mémoire. Recherches sur les parallélloèdres primitifs. $J$ für die reine und Angew Math. 134:198-287. https://eudml.org/doc/149291. Accessed February 1, 2016.

14. Delaunay B. Sur la sphere vide. Izv Akad Nauk SSSR, Otd Mat i .... 1934. http://galiulin.narod.ru/delaunay_.pdf. Accessed February 1, 2016.

15. Belytschko T, Lu YY, Gu L. Element-free Galerkin methods. Int J Numer Methods Eng. 
1994;37(2):229-256. http://www.scopus.com/inward/record.url?eid=2-s2.0$0028259955 \&$ partnerID=tZOtx3y1.

16. Wing Kam Liu, Sukky Jun, Yi Fei Zhang. Reproducing kernel particle methods. Int J Numer Methods Fluids. 1995;20(8-9):1081-1106.

http: / / www.scopus.com/inward/record.url?eid=2-s2.0-

$0029102512 \&$ partnerID=tZOtx3y1.

17. Atluri SN, Zhu T. A new Meshless Local Petrov-Galerkin (MLPG) approach in

computational mechanics. Comput Mech. 1998;22(2):117-127.

http: / / www.scopus.com/inward/record.url?eid=2-s2.0-

$0032136132 \&$ fartnerID=tZOtx3y1.

18. Wang JG, Liu GR. On the optimal shape parameters of radial basis functions used for 2-D meshless methods. Comput Methods Appl Mech Eng. 2002;191(23-24):2611-2630. doi:10.1016/S0045-7825(01)00419-4.

19. Zienkiewicz O, Taylor R. The finite element method. 1977. http://civil.dept.shef.ac.uk/current/module/CIV4135.pdf. Accessed June 3, 2016.

20. Bathe K-J. Finite element procedures. 1996.

https: / / dialnet.unirioja.es/servlet/libro?codigo=370662. Accessed June 3, 2016.

21. Sibson R. A vector identity for the Dirichlet tessellation. Math Proc Cambridge Philos Soc. 2008;87(01):151. doi:10.1017/S0305004100056589.

22. Dinis LMJS, Natal Jorge RM, Belinha J. Analysis of 3D solids using the natural neighbour radial point interpolation method. Comput Methods Appl Mech Eng. 2007;196(13-

16):2009-2028. doi:10.1016/j.cma.2006.11.002.

23. Liu GR, Quek SS, Liu GR, Quek SS. 2 - Introduction to mechanics for solids and structures. In: Finite Element Method. ; 2003:12-34. doi:10.1016/B978-0750658669/50003-7.

24. Liu GR, Quek SS, Liu GR, Quek SS. 3 - Fundamentals for finite element method. In: Finite Element Method. ; 2003:35-66. doi:10.1016/B978-075065866-9/50004-9.

25. Wang G, Gao X, Lo ECM. Public perceptions of dental implants: a qualitative study. J Dent. 2015;43(7):798-805. doi:10.1016/j.jdent.2015.04.012.

26. What are Dental Implants, Abutments and Crowns? | AAID | American Academy of Implant Dentistry. http://www.aaid-implant.org/about-dental-implants/what-aredental-implants/. Accessed February 1, 2016.

27. Morton D, Martin WC, Ruskin JD. Single-Stage Straumann Dental Implants in the Aesthetic Zone : Considerations and. 2004:57-66. doi:10.1016/j.joms.2004.06.043.

28. Manicone PF, lommetti PR, Raffaelli L. An overview of zirconia ceramics : Basic properties and clinical applications. 2007;35:819-826.

doi:10.1016/j.jdent.2007.07.008.

29. Puleo DA, Nanci A. Understanding and controlling the bone-implant interface. Biomaterials. 1999;20(23-24):2311-2321. doi:10.1016/S0142-9612(99)00160-X.

30. Shibata Y, Hosaka M, Kawai H, Miyazaki T. Glow Discharge Plasma Treatment of Titanium Plates Enhances Adhesion of Osteoblast-like Cells to the Plates Through the Integrin-Mediated Mechanism. Int J Oral Maxillofac Implant. 2002;17(6):771-777. http: / / www.scopus.com/inward/record.url?eid=2-s2.0$0036836152 \&$ partnerID=tZOtx3y1.

31. Ayukawa $Y$, Takeshita F, Inoue T, et al. An immunoelectron microscopic localization of noncollagenous bone proteins (osteocalcin and osteopontin) at the bone-titanium interface of rat tibiae. J Biomed Mater Res. 1998;41(1):111-119. http://www.ncbi.nlm.nih.gov/pubmed/9641631. Accessed February 1, 2016.

32. Linder L. High-resolution microscopy of the implant-tissue interface. Acta Orthop. 1985;56(3):269-272. doi:10.3109/17453678508993011.

33. Murai K, Takeshita F, Ayukawa Y, Kiyoshima T, Suetsugu T, Tanaka T. Light and electron microscopic studies of bone-titanium interface in the tibiae of young and mature rats. J Biomed Mater Res. 1996;30(4):523-533. doi:10.1002/(SICI)10974636(199604)30:4\&lt;523::AID-JBM11\&gt;3.0.CO;2-I.

34. Shibata $Y$, Tanimoto $Y$, Maruyama N, Nagakura M. A review of improved fixation methods for dental implants. Part II: Biomechanical integrity at bone-implant interface. J Prosthodont Res. 2015;59(2):84-95. doi:10.1016/j.jpor.2015.01.003.

35. Raigrodski AJ. Concepts of Design for Contemporary Anterior All-Ceramic Restorations. 
2013;28(4):46-59.

36. Cales B, Stefani Y. Mechanical Properties and Surface Analysis of Retrieved Zirconia Hip Joint Heads after an Implantation Time of Two to Three Years. J Mater Sci. 1994;5(6-7):376-380. doi:10.1007/BF00058967.

37. Denry I, Kelly JR. State of the art of zirconia for dental applications. 2007;4:299-307. doi:10.1016/j.dental.2007.05.007.

38. Della Bona A, Donassollo TA, Demarco FF, Barrett AA, Mecholsky JJ. Characterization and surface treatment effects on topography of a glass-infiltrated alumina/zirconiareinforced ceramic. Dent Mater. 2007;23(6):769-775.

doi:10.1016/j.dental.2006.06.043.

39. Ryan G, Pandit A, Apatsidis DP. Fabrication methods of porous metals for use in orthopaedic applications. Biomaterials. 2006;27(13):2651-2670.

doi:10.1016/j.biomaterials.2005.12.002.

40. Vs FZ, Units S. Full Zirconia Vs. e.max Single Units. 2012;(August):48-50.

41. Zirconia - ZrO2, Zirconium Dioxide Properties.

http://www.azom.com/properties.aspx?ArticlelD=133.

42. Rho JY, Kuhn-Spearing L, Zioupos P. Mechanical properties and the hierarchical structure of bone. Med Eng Phys. 1998;20(2):92-102.

http://www.ncbi.nlm.nih.gov/pubmed/9679227. Accessed June 14, 2016.

43. Weiner $\mathrm{S}$, Wagner HD. The material bone: structure-mechanical function relations. Annu Rev Mater Sci. 1998;28:271-298.

44. Asefa T, Yoshina-Ishii C, MacLachlan MJ, Ozin GA. New nanocomposites: putting organic function "inside" the channel walls of periodic mesoporous silica. J Mater Chem. 2000;10(8):1751-1755. doi:10.1039/b000950o.

45. Zimmermann EA, Gludovatz B, Schaible E, Busse B, Ritchie RO. Fracture resistance of human cortical bone across multiple length-scales at physiological strain rates. Biomaterials. 2014;35(21):5472-5481. doi:10.1016/j.biomaterials.2014.03.066.

46. Griffith1921fracture.pdf.

47. Carter DR, Hayes WC. The compressive behavior of bone as a two-phase porous structure. J Bone Joint Surg Am. 1977;59(7):954-962.

http://www.ncbi.nlm.nih.gov/pubmed/561786. Accessed June 9, 2016.

48. Carter DR, Spengler DM. Mechanical properties and composition of cortical bone. Clin Orthop Relat Res. 1978;(135):192-217.

http://www.ncbi.nlm.nih.gov/pubmed/361320. Accessed June 9, 2016.

49. Gibson LJ, Ashby MF, Behrens JC, et al. The mechanical behaviour of cancellous bone. J Biomech. 1985;18(5):317-328. doi:10.1016/0021-9290(85)90287-8.

50. Goldstein SA. The mechanical properties of trabecular bone: dependence on anatomic location and function. J Biomech. 1987;20(11-12):1055-1061.

http://www.ncbi.nlm.nih.gov/pubmed/3323197. Accessed June 9, 2016.

51. Rice JC, Cowin SC, Bowman JA. On the dependence of the elasticity and strength of cancellous bone on apparent density. J Biomech. 1988;21(2):155-168.

http://www.ncbi.nlm.nih.gov/pubmed/3350829. Accessed June 9, 2016.

52. Martin RB. Determinants of the mechanical properties of bones. J Biomech. 1991;24 Suppl 1:79-88. http://www.ncbi.nlm.nih.gov/pubmed/1842337. Accessed June 9, 2016.

53. Lin D, Li Q, Li W, Swain M. Dental implant induced bone remodeling and associated algorithms. J Mech Behav Biomed Mater. 2009;2(5):410-432. doi:10.1016/j.jmbbm.2008.11.007.

54. Kayabașı O, Yüzbasıoğlu E, Erzincanlı F. Static, dynamic and fatigue behaviors of dental implant using finite element method. Adv Eng Softw. 2006;37(10):649-658. doi:10.1016/j.advengsoft.2006.02.004.

55. Bozkaya D, Muftu S, Muftu A. Evaluation of load transfer characteristics of five different implants in compact bone at different load levels by finite elements analysis. $J$ Prosthet Dent. 2004;92(6):523-530. doi:10.1016/j.prosdent.2004.07.024.

56. Meri?? G, Erkmen E, Kurt A, Eser A, ??elik G. Biomechanical evaluation of a fiberreinforced composite prosthesis supported by implants with and without a microthread collar design. J Dent Sci. 2010;5(4):201-208. doi:10.1016/j.jds.2010.11.010. 
57. Weinstein AM, Klawitter JJ, Anand SC, Schuessler R. Stress analysis of porous rooted dental implants. J Dent Res. 1976;55(5):772-777.

http: / / www.scopus.com/inward/record.url?eid=2-s2.0-

$0017093130 \&$ partnerID=tZOtx3y1.

58. Mohammed H, Atmaram GH, Schoen FJ. Dental implant design: a critical review. J Oral Implantol. 1979;8(3):393-410. http://www.scopus.com/inward/record.url?eid=2s2.0-0018556657\&partnerID=tZOtx3y1.

59. Atmaram $\mathrm{GH}$, Mohammed $\mathrm{H}$. Stress analysis of single-tooth implants. I. Effect of elastic parameters and geometry of implant. Implantologist. 1983;3(1):24-29. http: / / www. scopus.com/inward/record.url?eid=2-s2.0$0020933362 \&$ partnerlD=tZOtx3y1.

60. Atmaram GH, Mohammed $\mathrm{H}$. Stress analysis of single-tooth implants. II. Effect of implant root-length variation and pseudo periodontal ligament incorporation. Implantologist. 1983;3(1):58-62. http://www.scopus.com/inward/record.url?eid=2s2.0-0020898298\&partnerID=tZOtx3y1.

61. Borchers $L$, Reichart $P$. Three-dimensional stress distribution around a dental implant at different stages of interface development. J Dent Res. 1983;62(2):155-159. http: / / www.scopus.com/inward/record.url?eid=2-s2.0$0020711801 \&$ partnerID=tZOtx3y1.

62. Cook SD, Weinstein AM, Klawitter JJ. A three-dimensional finite element analysis of a porous rooted Co-Cr-Mo alloy dental implant. J Dent Res. 1982;61(1):25-29. http: / / www.scopus.com/inward/record.url?eid=2-s2.0$0020020445 \&$ partnerID=tZOtx3y1.

63. Meroueh K. Finite element analysis of partially edentulous mandible rehabilitated with an osteointegrated cylindrical implant. J oral .... 1987. http://www.ncbi.nlm.nih.gov/pubmed/3077414. Accessed February 1, 2016.

64. Williams KR, Watson CJ, Murphy WM, Scott J, Gregory M, Sinobad D. Finite element analysis of fixed prostheses attached to osseointegrated implants. Quintessence Int (Berl). 1990;21(7):563-570. http: / /www.scopus.com/inward/record.url?eid=2-s2.0$0025463278 \&$ partnerlD=tZOtx3y1.

65. Akpinar I, Demirel F, Parnas L, Sahin S. A comparison of stress and strain distribution characteristics of two different rigid implant designs for distal-extension fixed prostheses. Quintessence Int (Berl). 1996;27(1):11-17. http: / / www.scopus.com/inward/record.url?eid=2-s2.00029678751 \&partnerlD=tZOtx3y1.

66. Korioth T, Versluis A. Modeling the mechanical behavior of the jaws and their related structures by finite element (FE) analysis. Crit Rev Oral Biol .... 1997. http://cro.sagepub.com/content/8/1/90.short. Accessed February 1, 2016.

67. Oosterwyck $\mathrm{H}$ Van. The influence of bone mechanical properties and implant fixation upon bone loading around oral implants. Clin Oral .... 1998.

http://onlinelibrary.wiley.com/doi/10.1034/j.1600-0501.1996.090606.x/full. Accessed February 1, 2016.

68. Chou H-Y, Jagodnik JJ, Müftü S. Predictions of bone remodeling around dental implant systems. J Biomech. 2008;41(6):1365-1373. doi:10.1016/j.jbiomech.2008.01.032.

69. Lian Z, Guan H, Ivanovski S, Loo Y-C, Johnson NW, Zhang H. Effect of bone to implant contact percentage on bone remodelling surrounding a dental implant. Int J Oral Maxillofac Surg. 2010;39(7):690-698. doi:10.1016/j.ijom.2010.03.020.

70. JBelinha_Book_Chap_2013e.pdf. 


\section{Appendix 1}

In this appendix is presented all the maps that corresponds to the Von Mises stress maps.

In each one, the first line corresponds to the Finite Element Method analysis, the second line corresponds to the Radial Point Interpolation Method analysis, and the third one corresponds to the analysis with Natural Neighbour Radial Point Interpolation Method.

For each one, the columns correspond to the angles, where, from left to right it is, $10^{\circ}$, $20^{\circ}, 30^{\circ}, 40^{\circ}, 50^{\circ}, 60^{\circ}, 70^{\circ}, 80^{\circ}$ and $90^{\circ}$. 


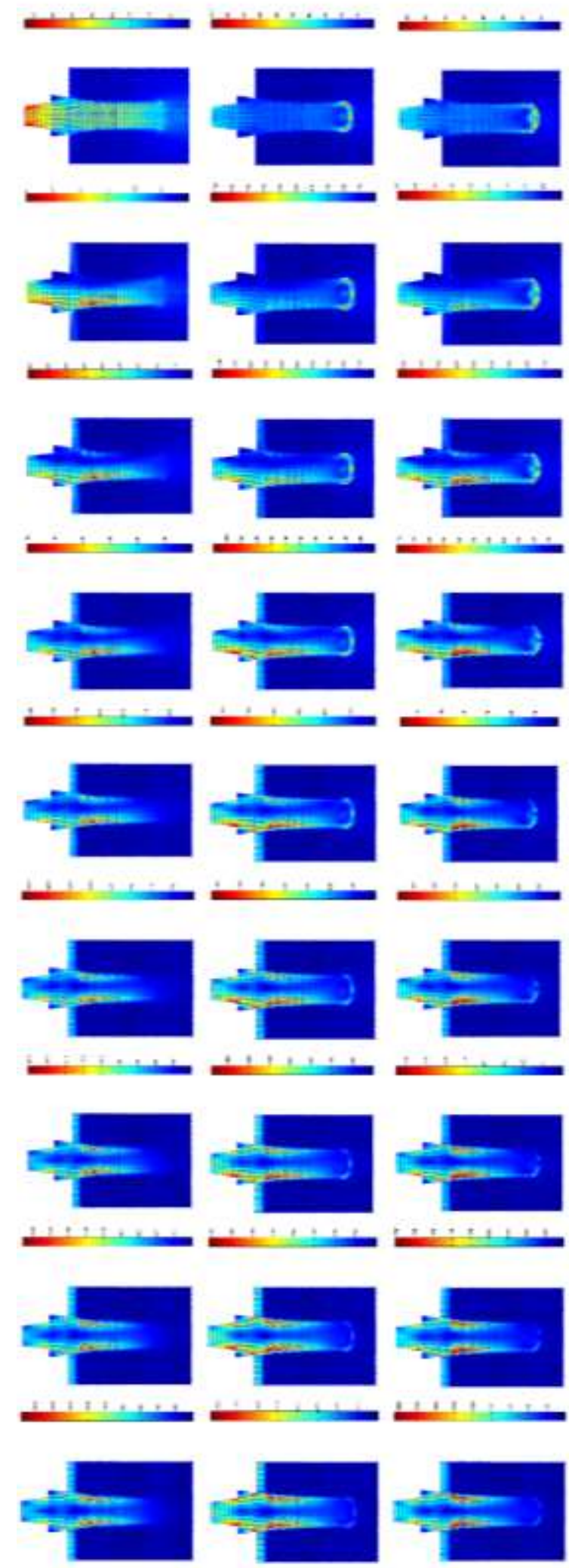

Figure A.1 Stress Map from 'Model 1' and bone type 1

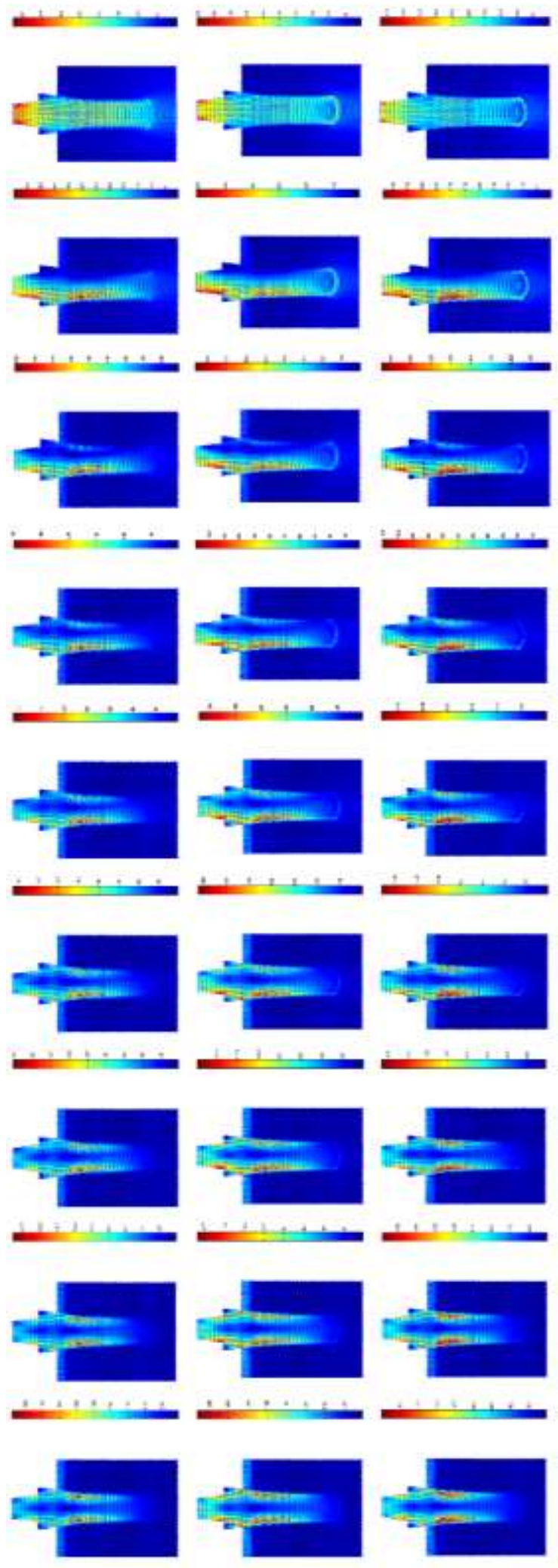

Figure A.2 Stress Map from 'Model 1' and bone type 2 


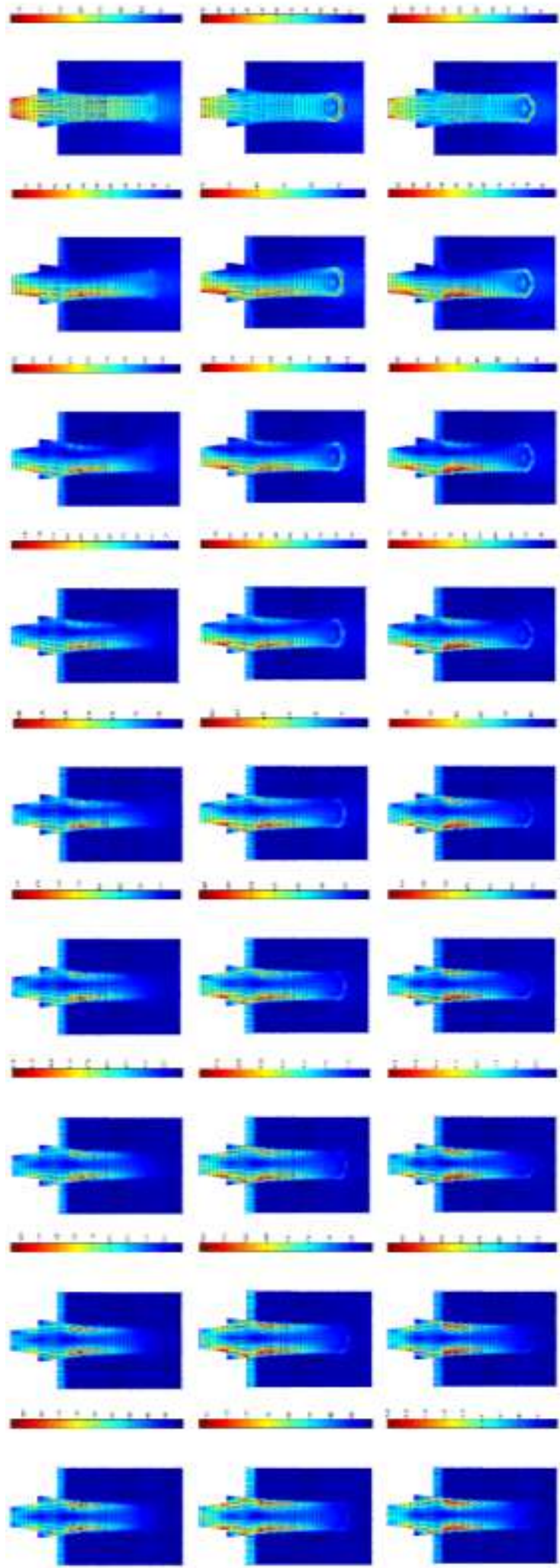

Figure A.3 Stress Map from 'Model 1' and bone type 3

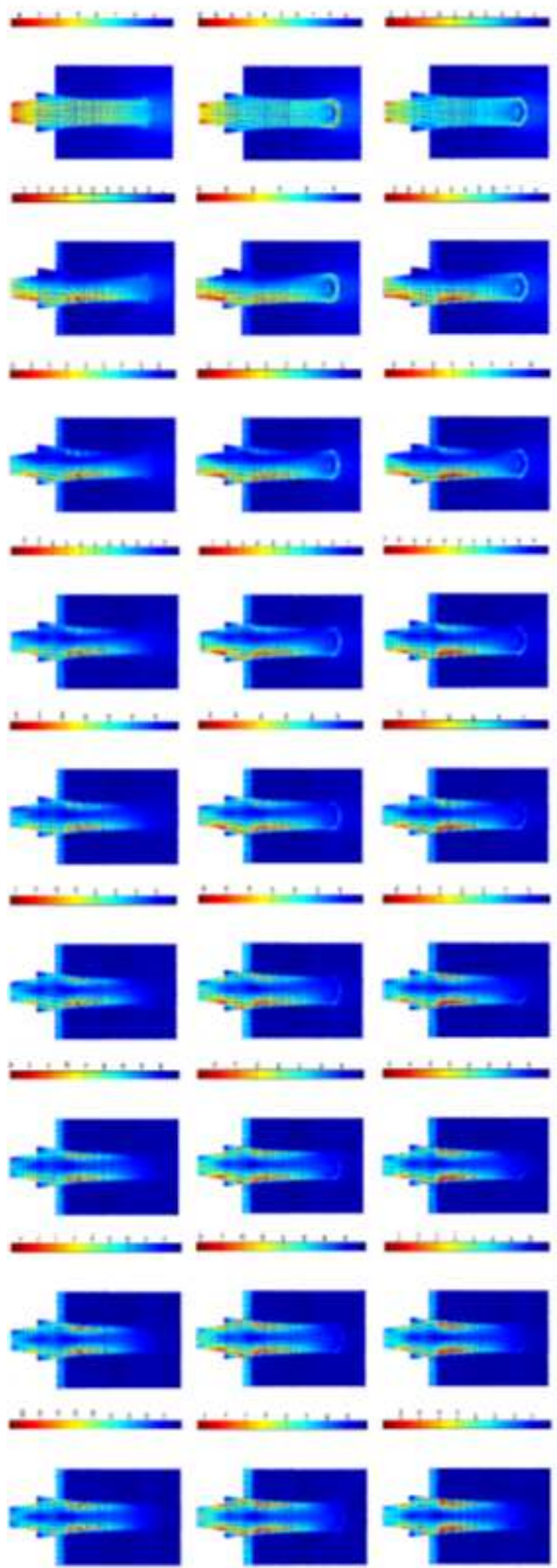

Figure A.4 Stress Map from 'Model 1' and bone type 4 


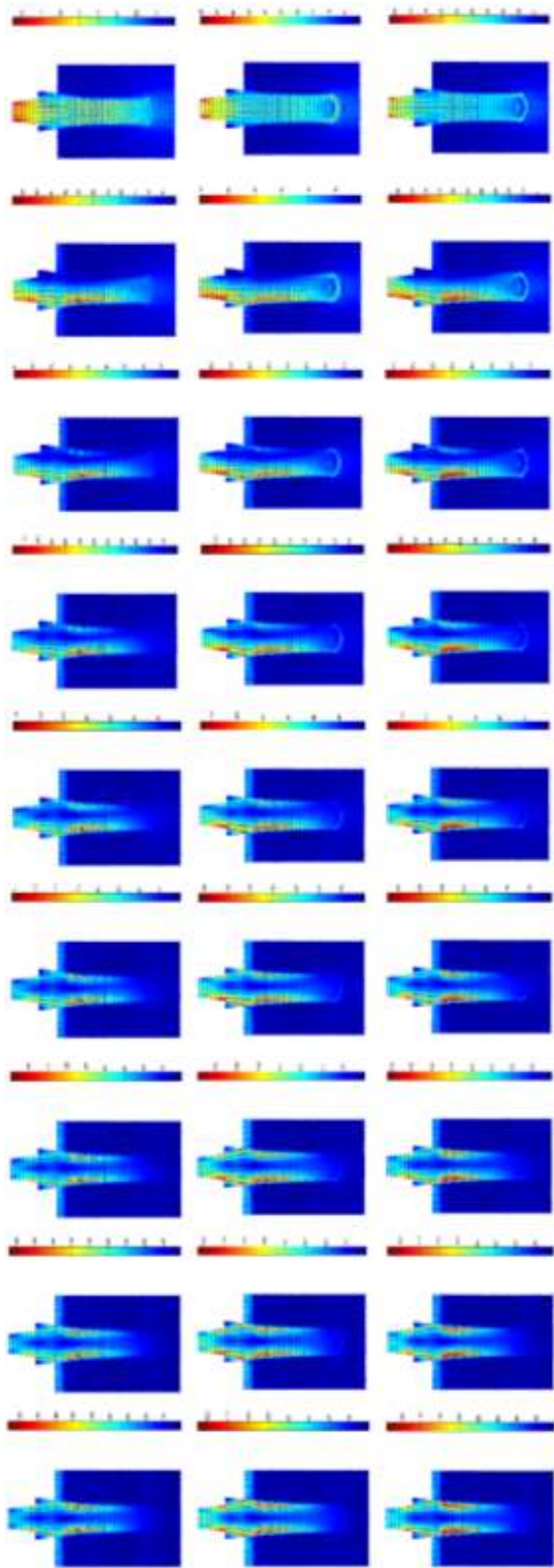

Figure A.5 Stress Map from 'Model 1' and bone type 5

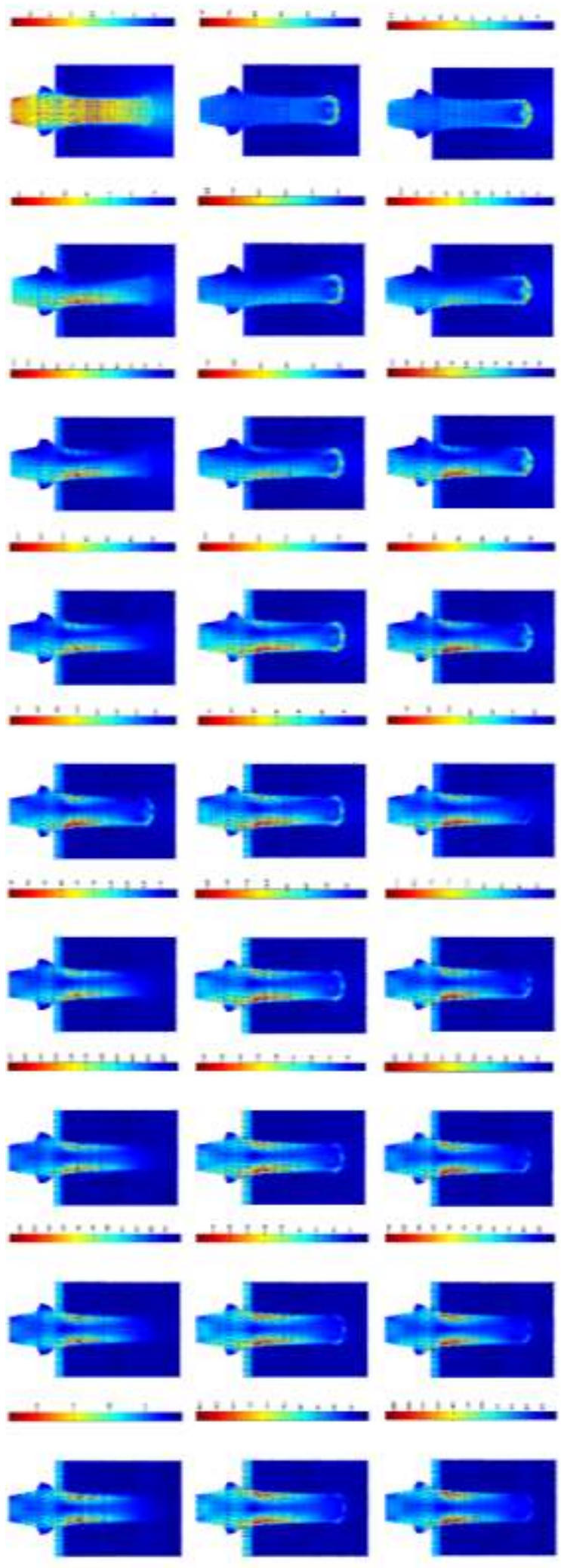

Figure A.6 Stress Map from 'Model 2' and bone type 1 


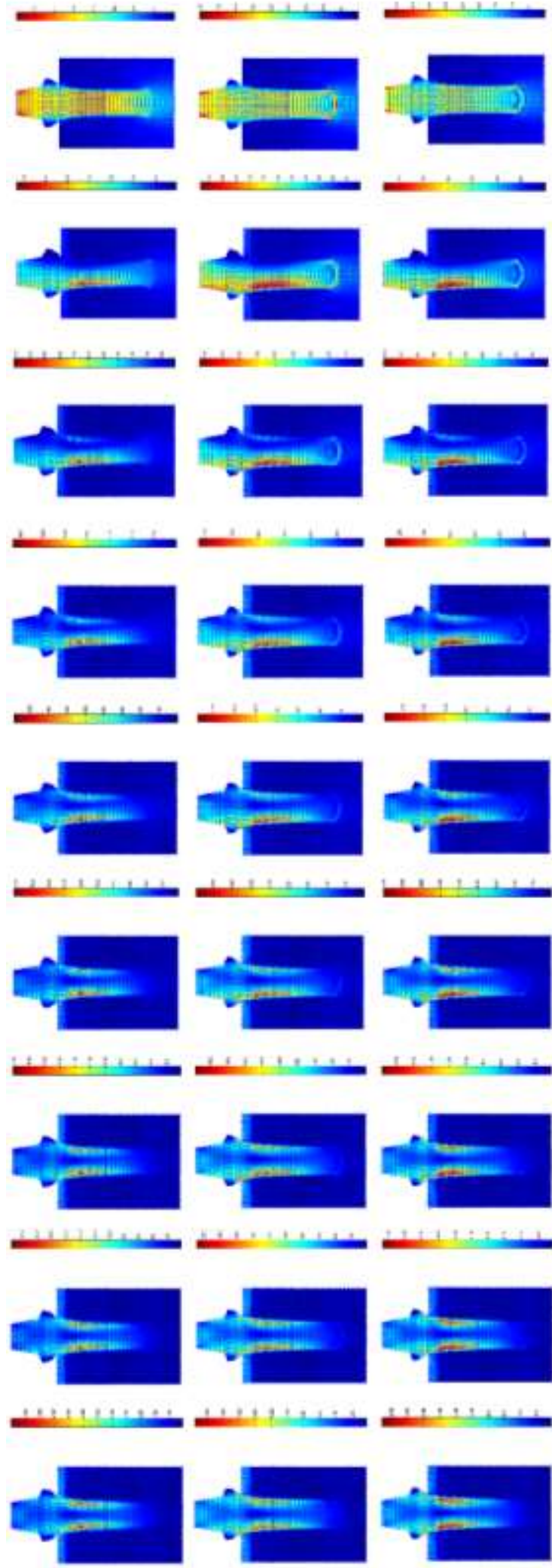

Figure A.7 Stress Map from 'Model 2' and bone type 2
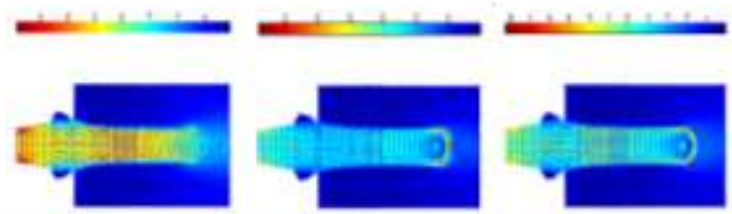

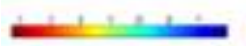
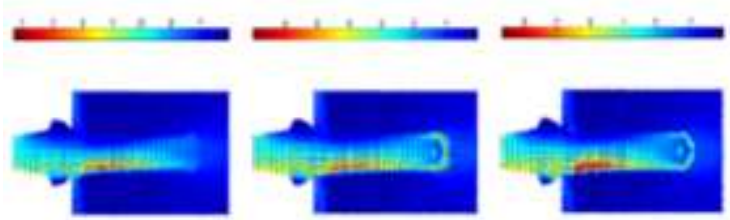

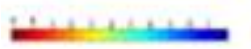
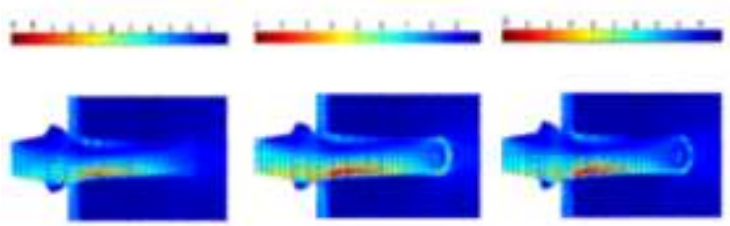

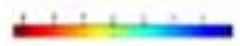
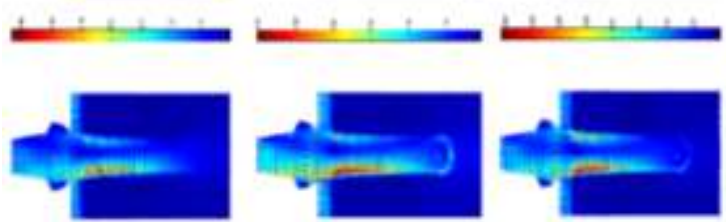

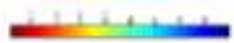
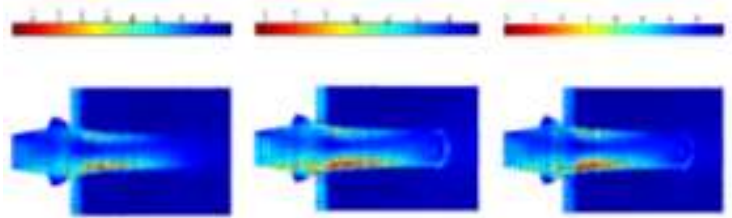

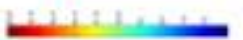
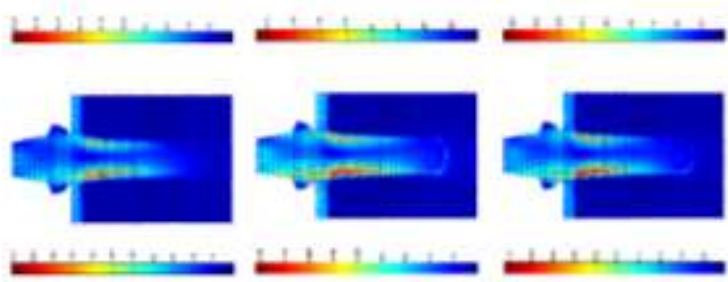

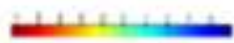
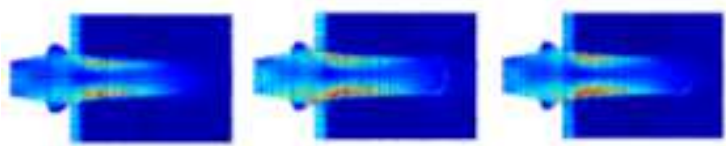

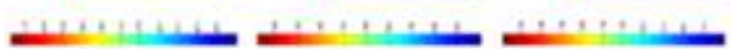
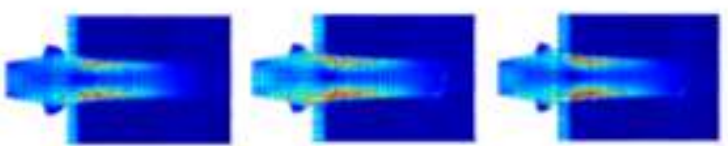

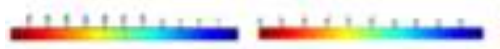
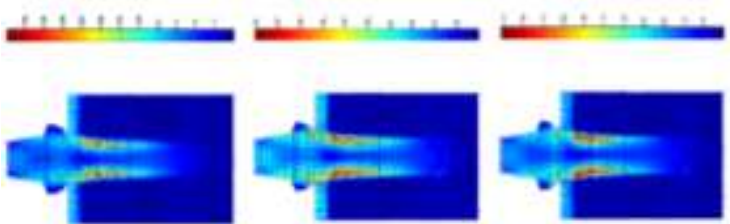

Figure A.8 Stress Map from 'Model 2' and bone type 3 


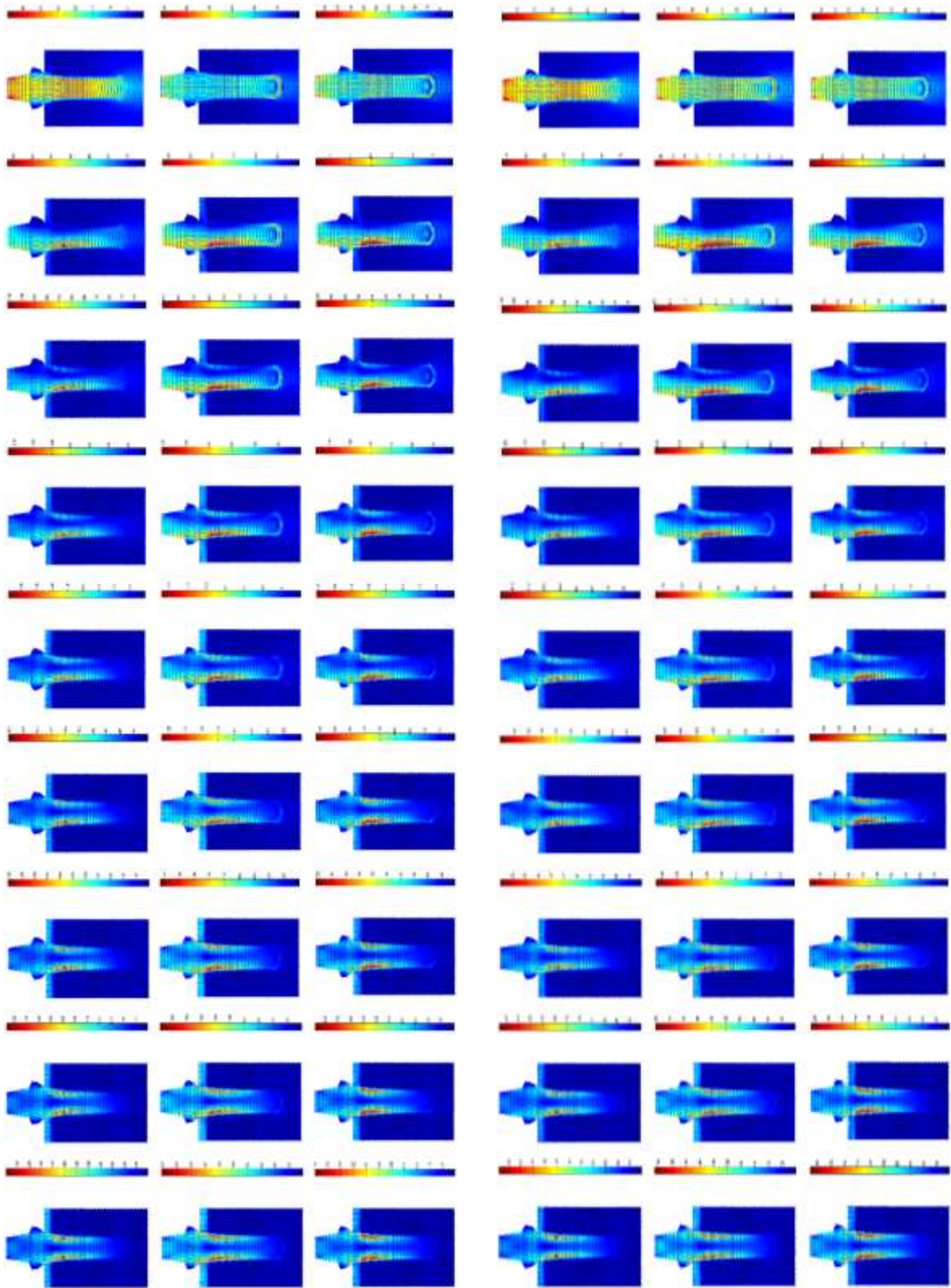

Figure A.9 Stress Map from 'Model 2' and bone type 4

Figure A.10 Stress Map from 'Model 2' and bone type 5 


\section{Appendix 2}

In this appendix, it is presented all the results, in this case graphics, relative to the analysis of the stress near the interface between implant and bone, for all the studied angles and for all the types of bones. 

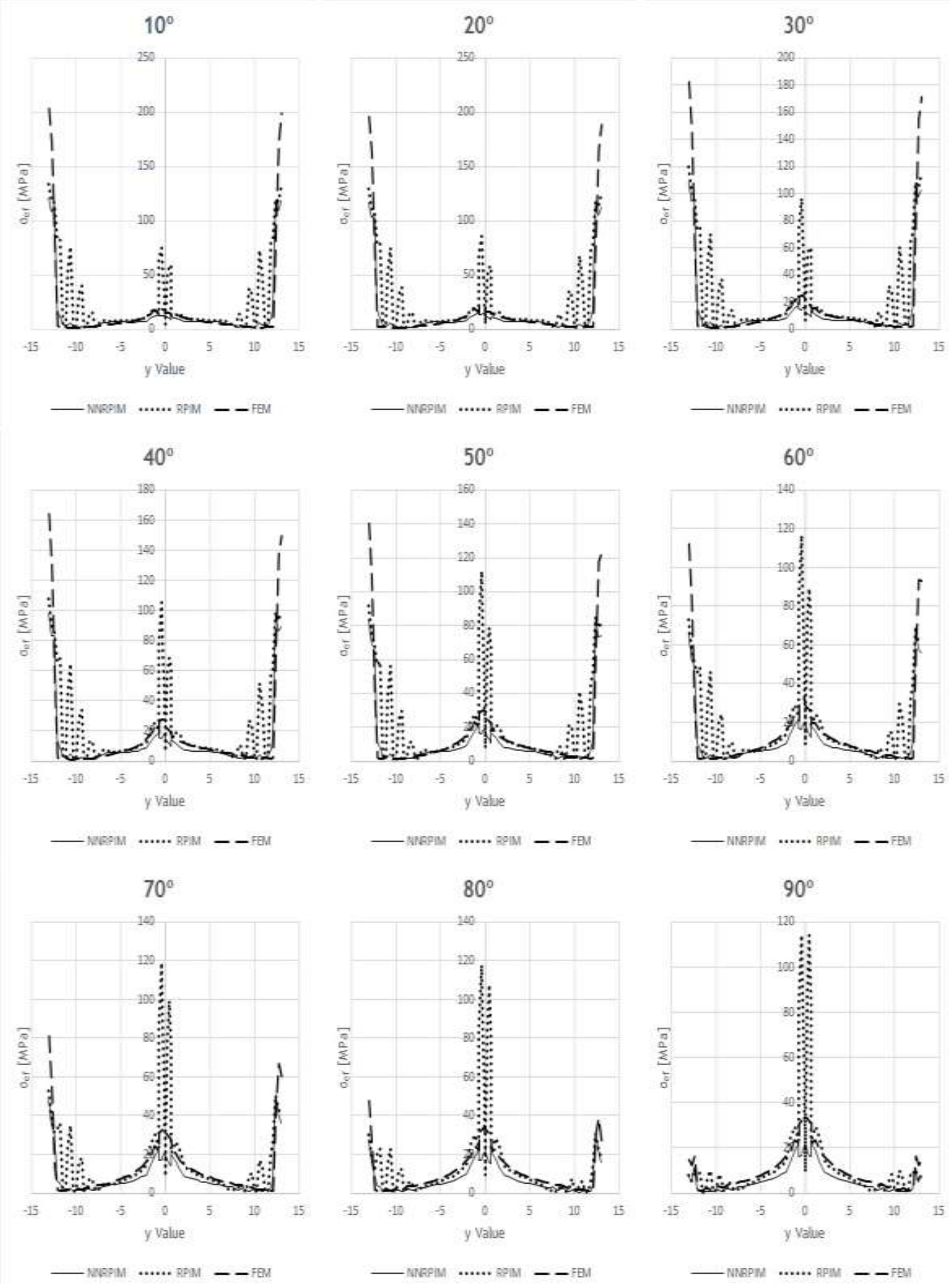

Figure A.11 Stress distribution from bone side, from 'Model 1', from bone type 1 

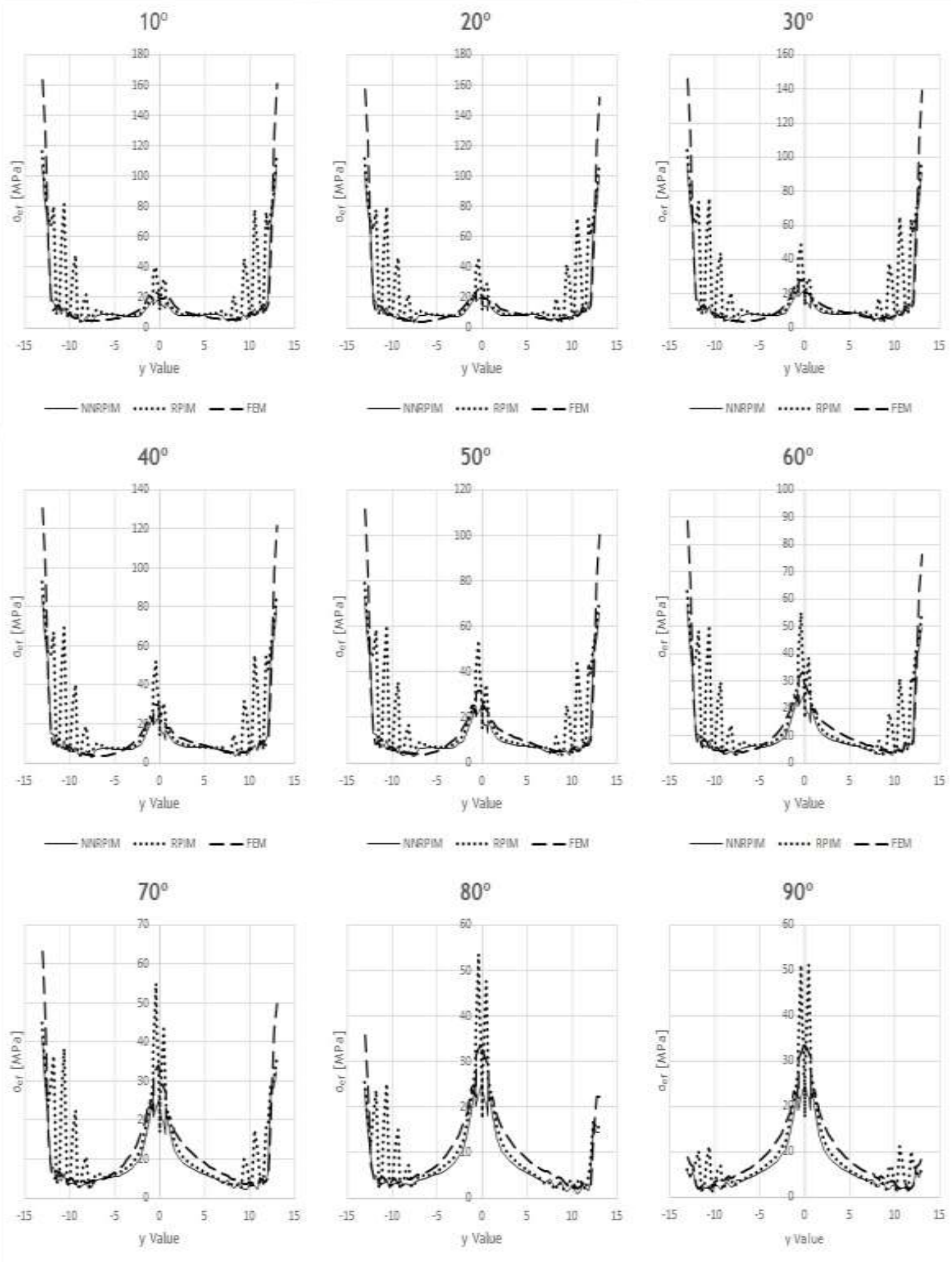

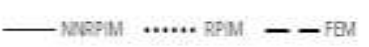
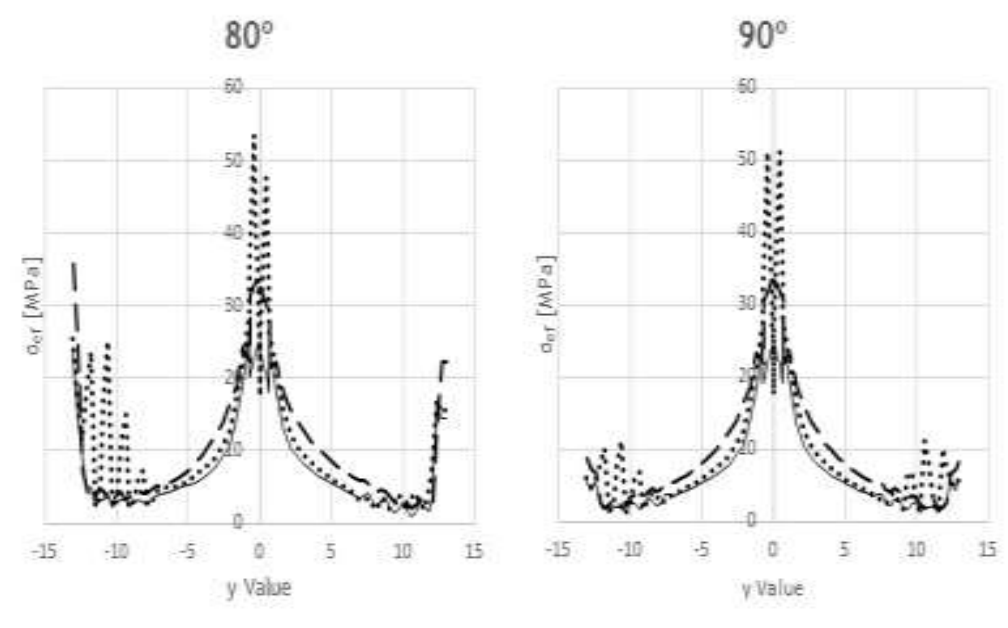

Figure A.12 Stress distribution from bone side, from 'Model 1', from bone type 2 

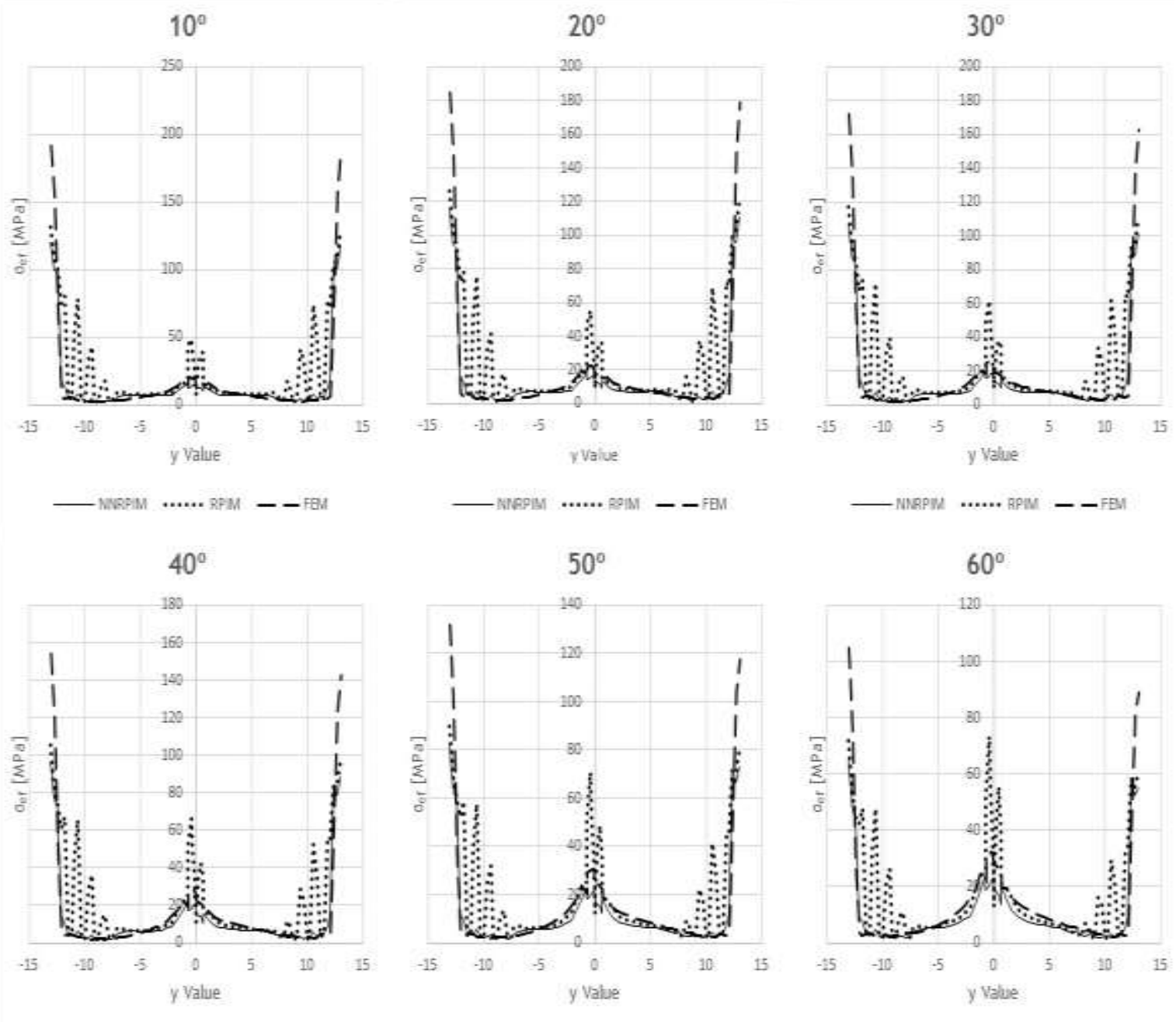

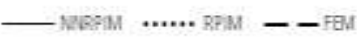
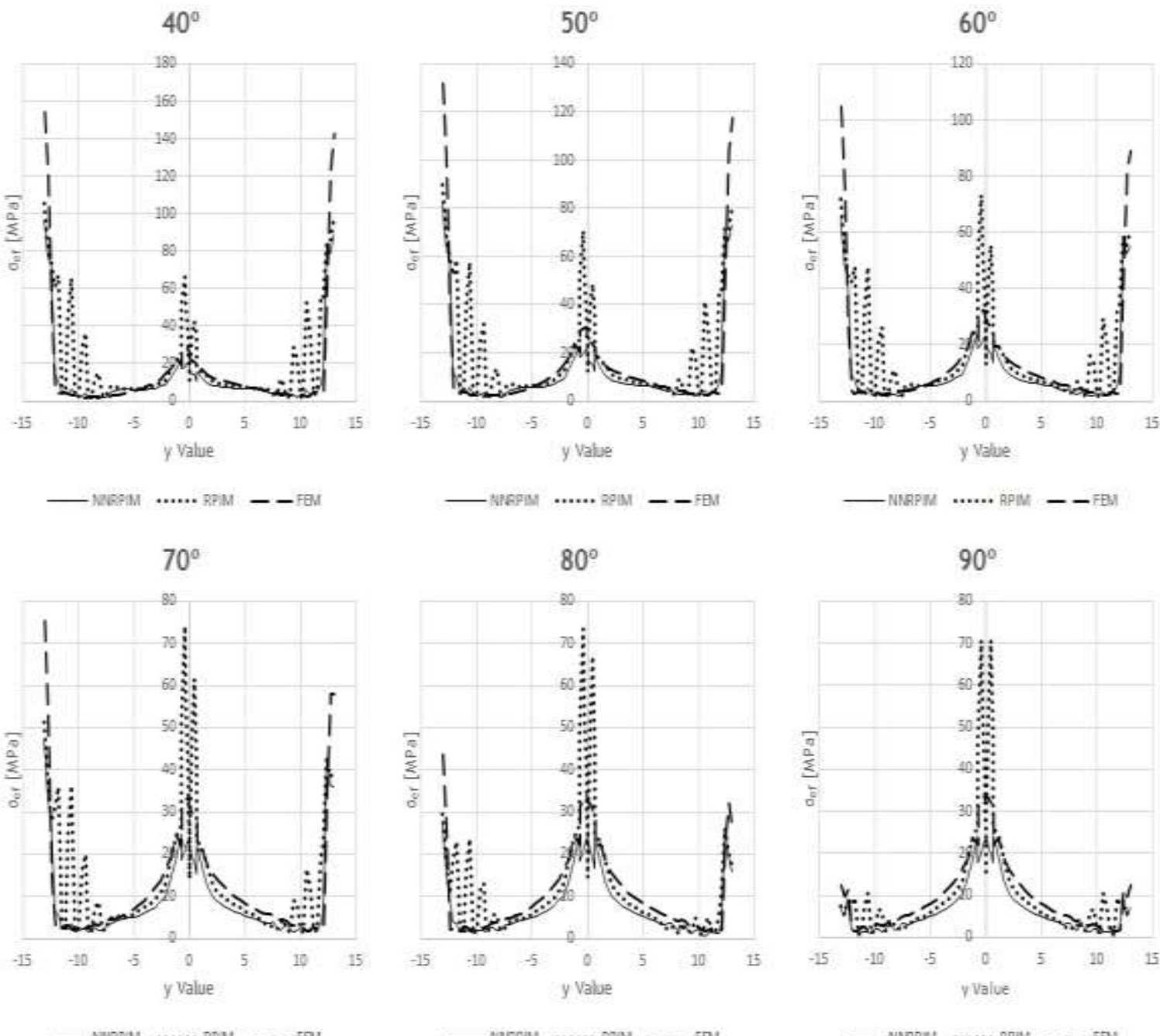

Figure A.13 Stress distribution from bone side, from 'Model 1', from bone type 3 

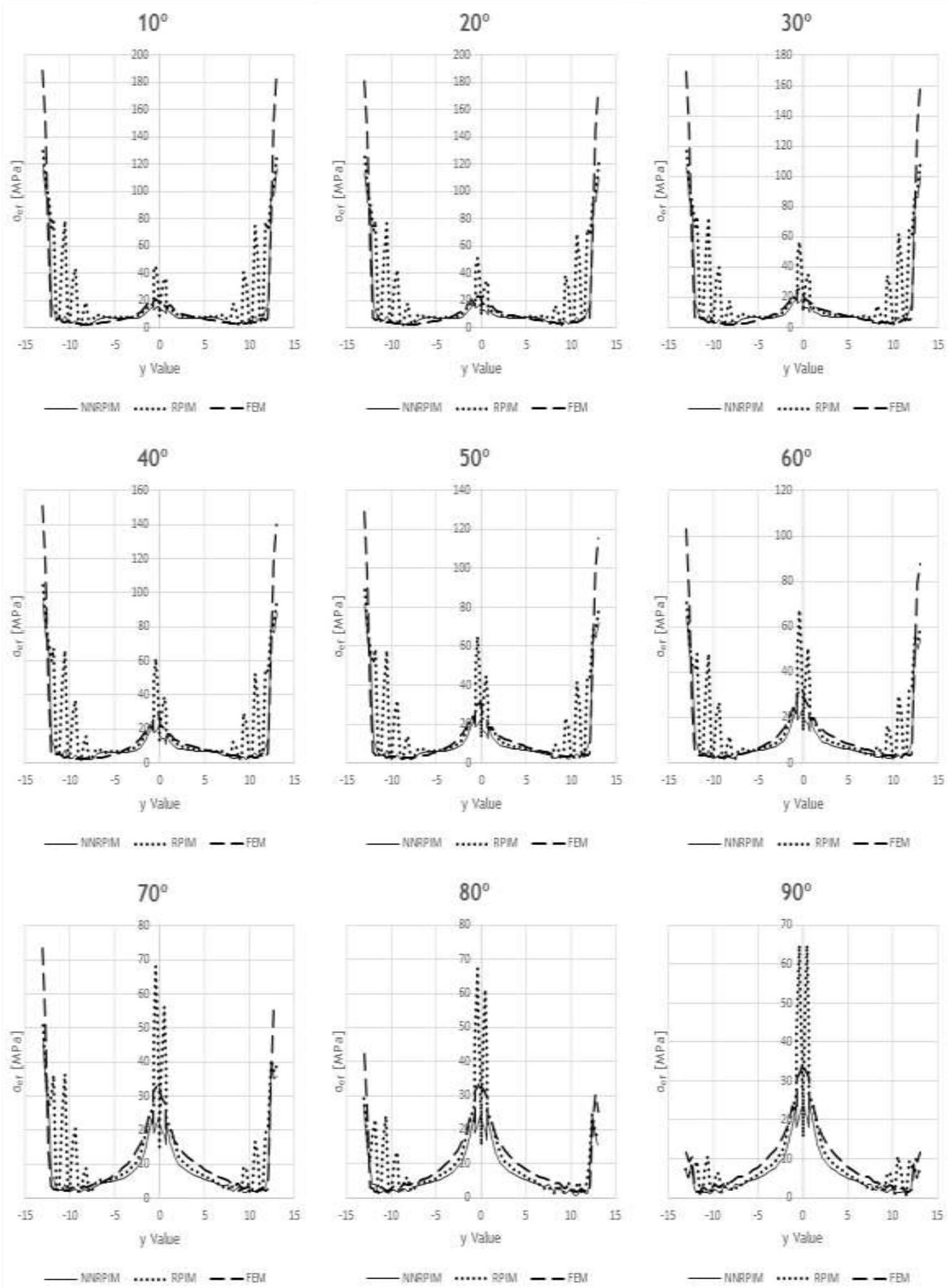

Figure A.14 Stress distribution from bone side, from 'Model 1', from bone type 4 

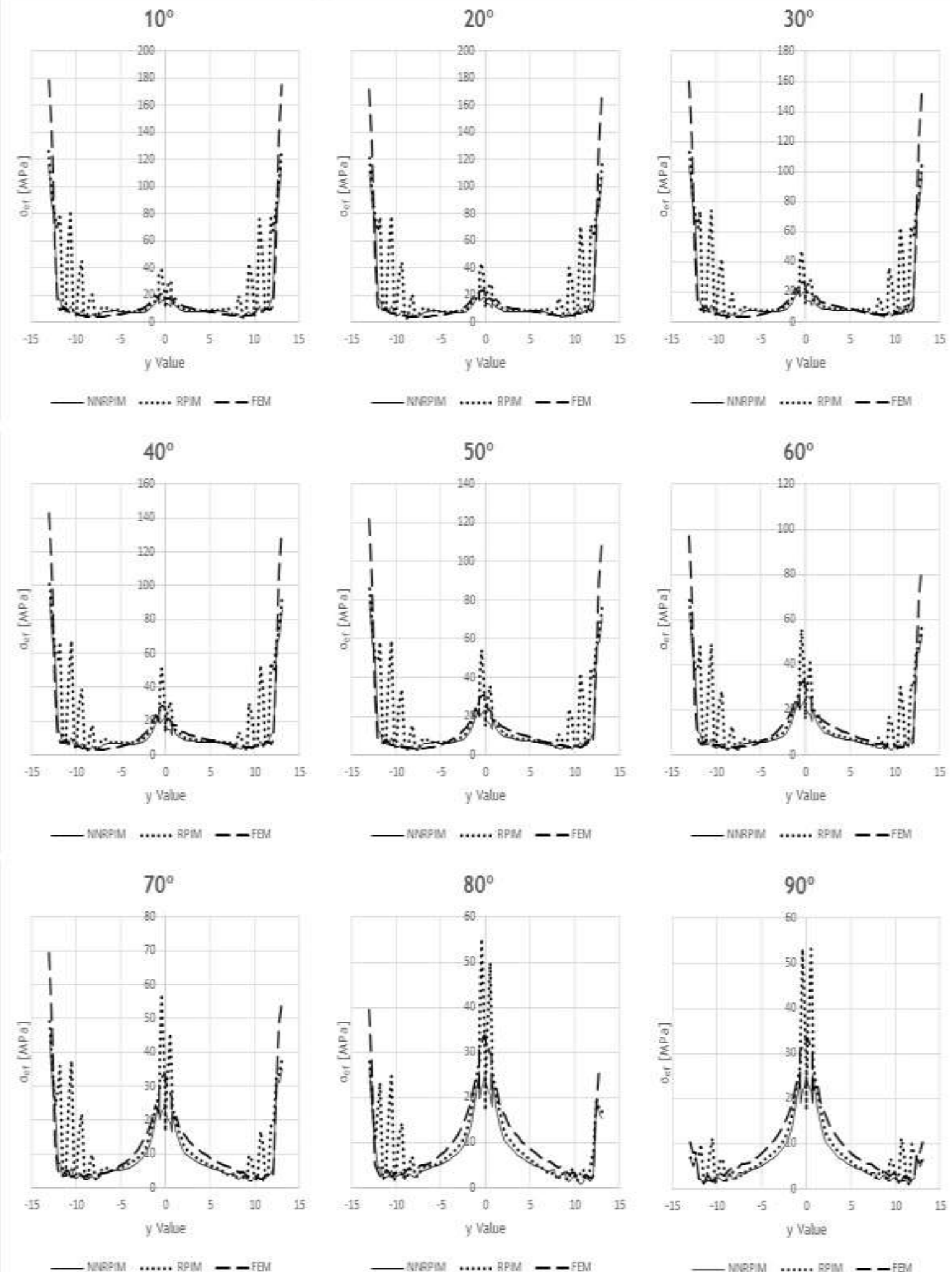

Figure A.15 Stress distribution from bone side, from 'Model 1', from bone type 5 

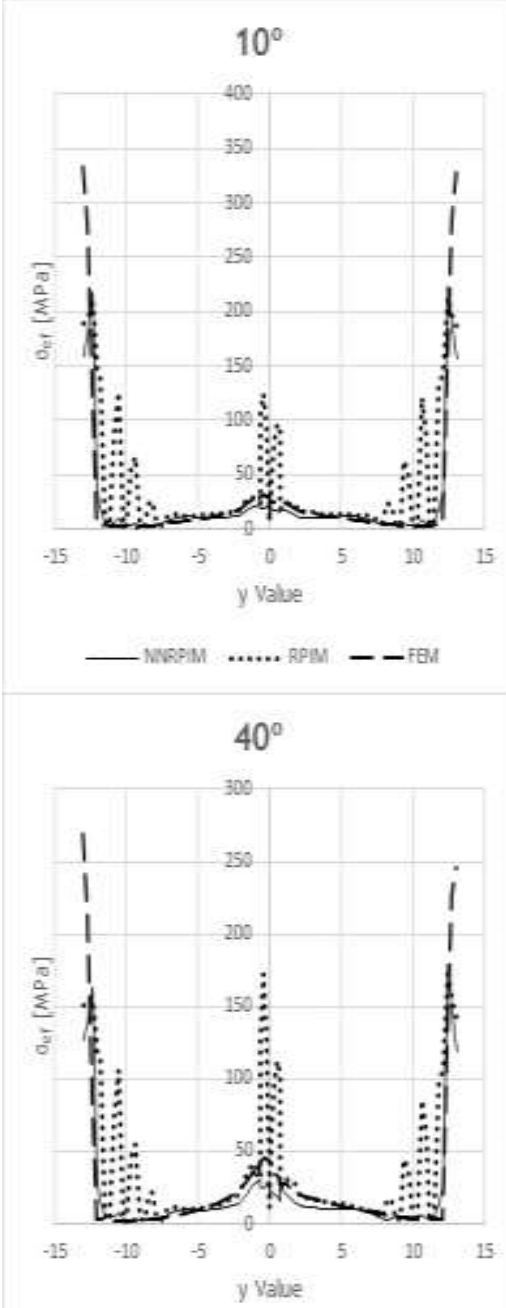

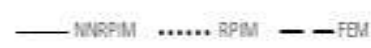

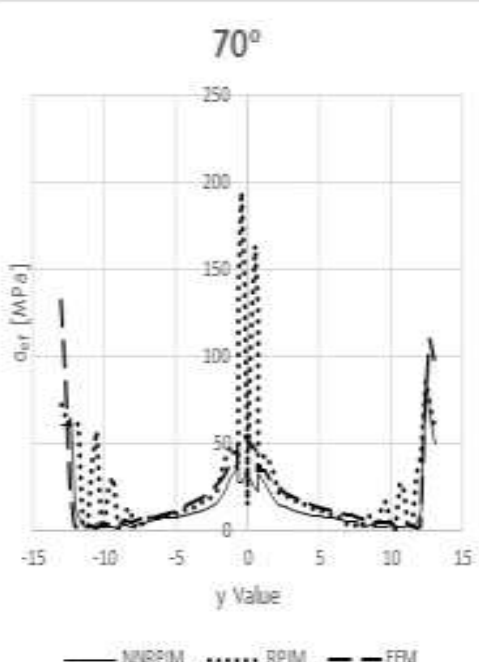

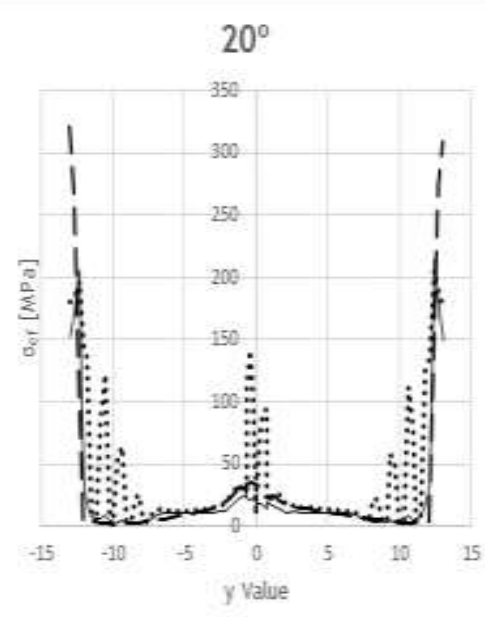

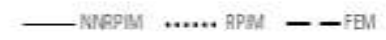

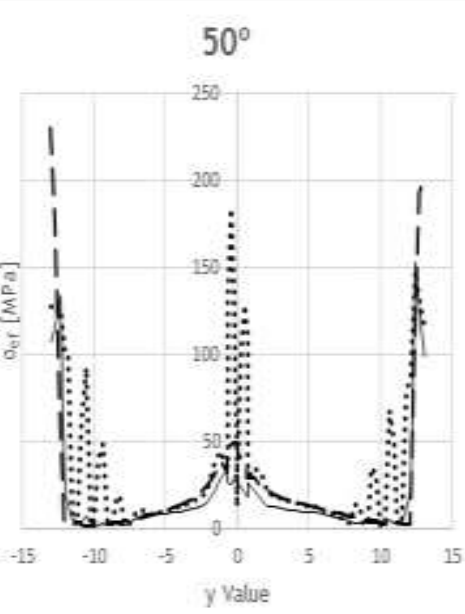

— миямМ …… ври - ввМ

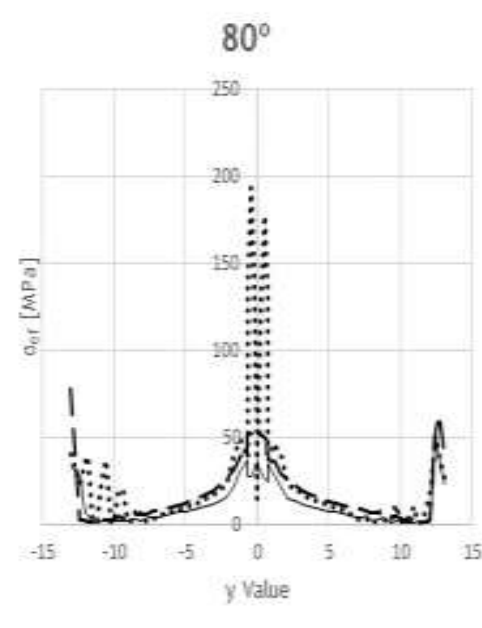

- wapes

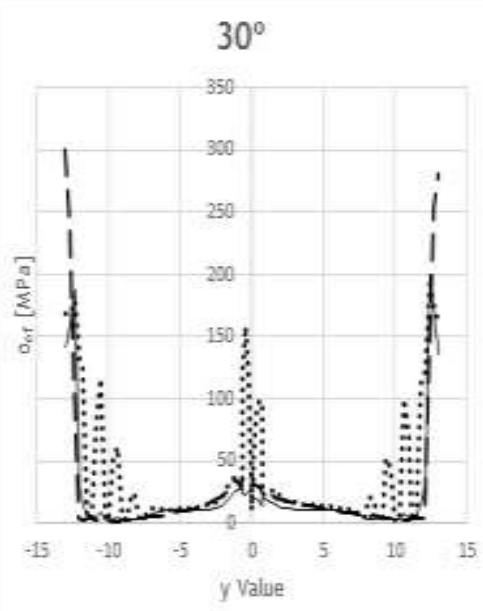

- NMPPU $\quad$....... PFM -- FEY

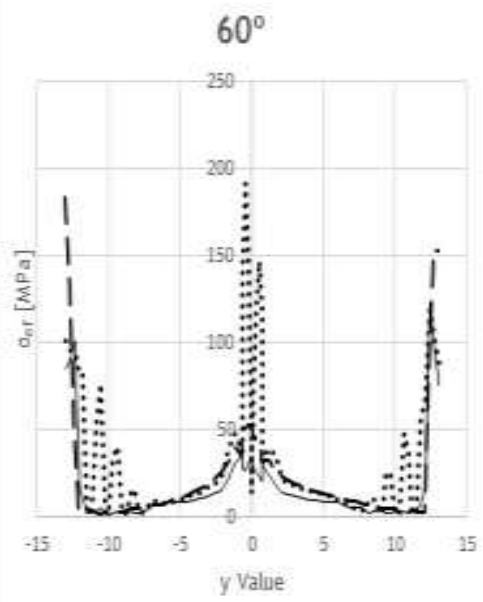

— MRPM ...... RPM - - FEM

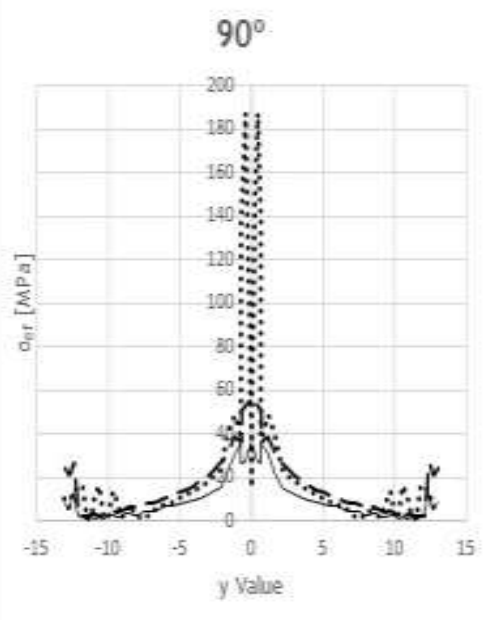

- MNAPU $\ldots . . . .$. APM - -FEM

Figure A.16 Stress distribution from bone side, from 'Model 2', from bone type 1 

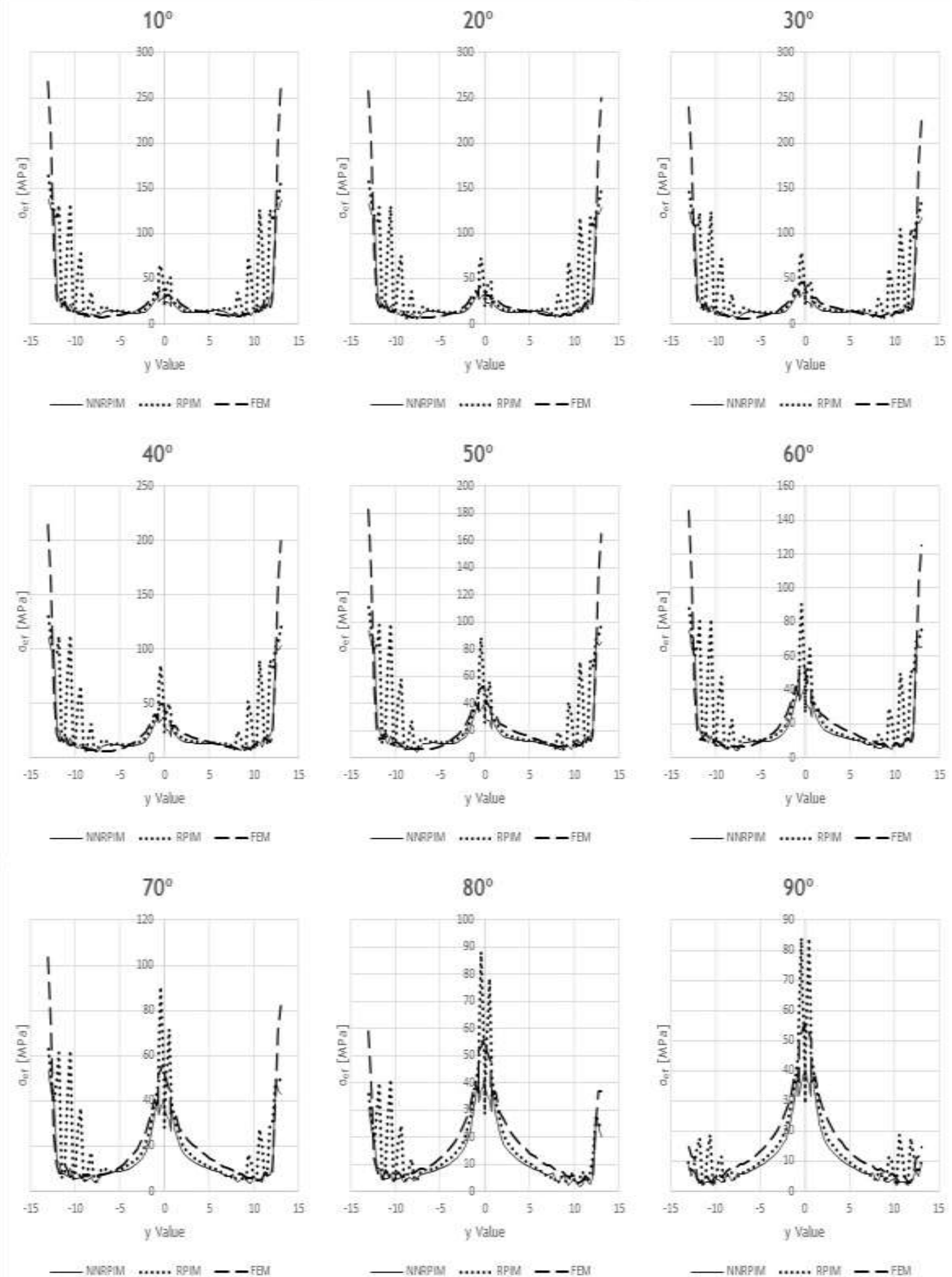

Figure A.17 Stress distribution from bone side, from 'Model 2', from bone type 2 

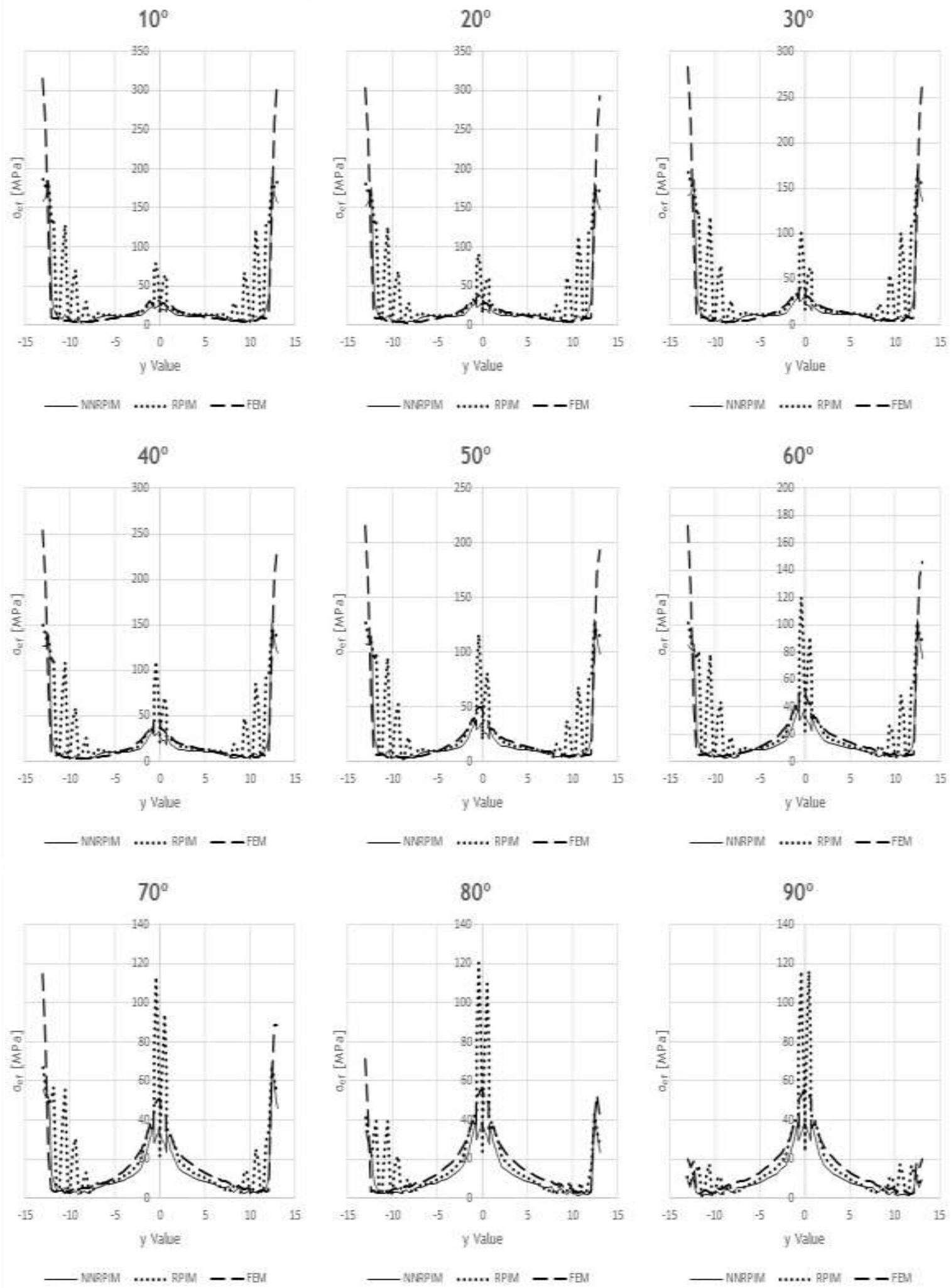

Figure A.18 Stress distribution from bone side, from 'Model 2', from bone type 3 

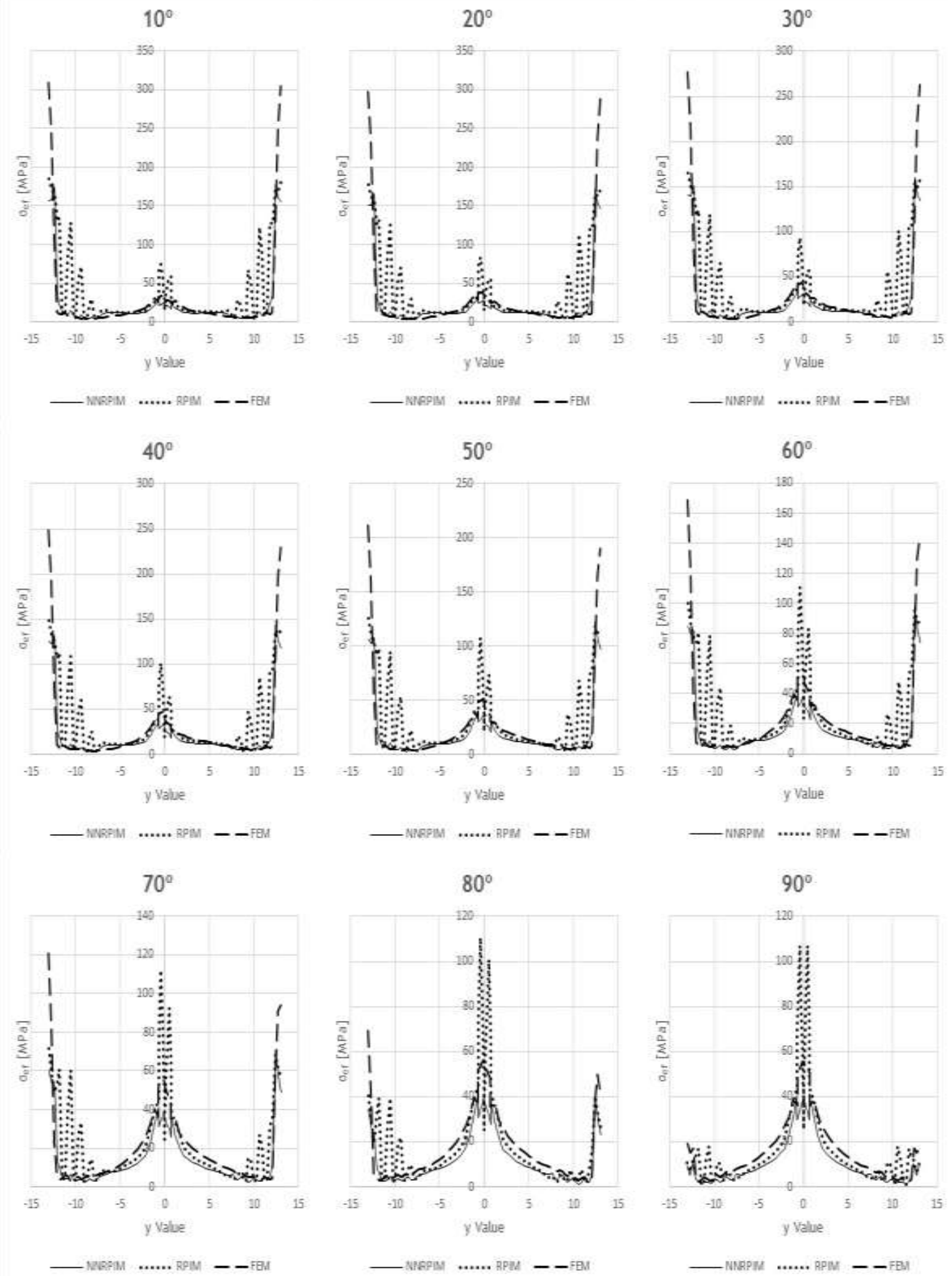

Figure A.19 Stress distribution from bone side, from 'Model 2', from bone type 4 


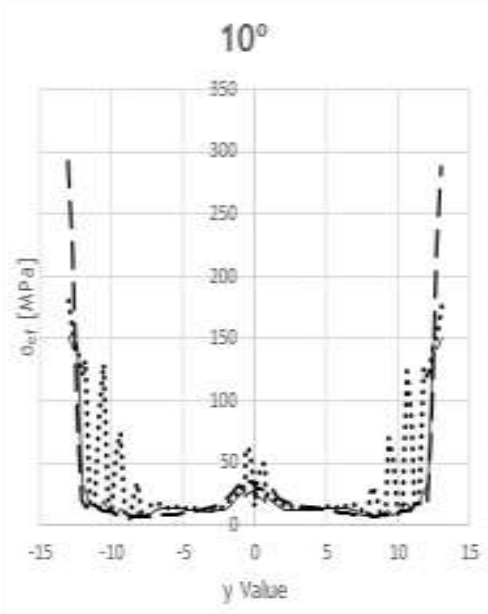

- WNPM ...... RPM -- Fe日

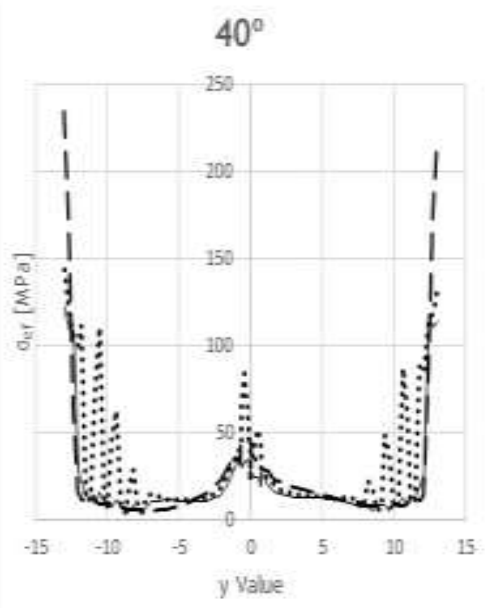

— NaVPM ....... RPM - FEM

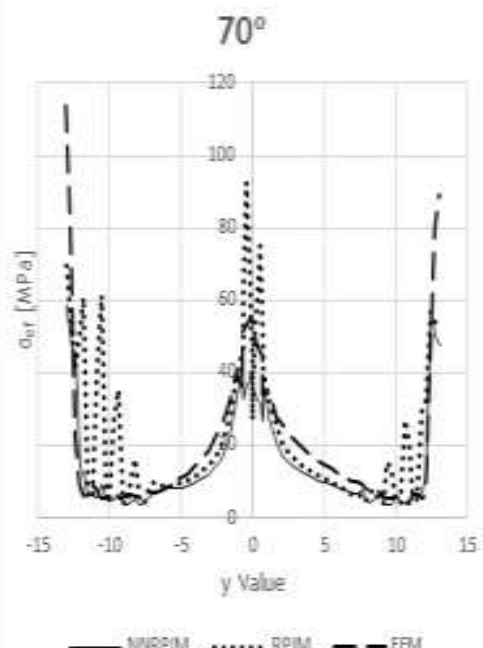

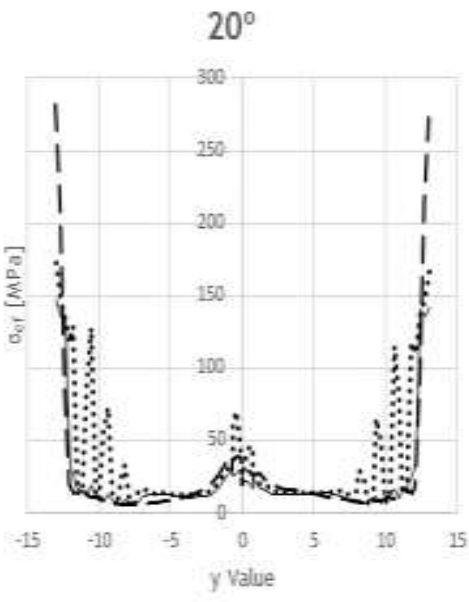

— MPPM ...... APAA - FEM

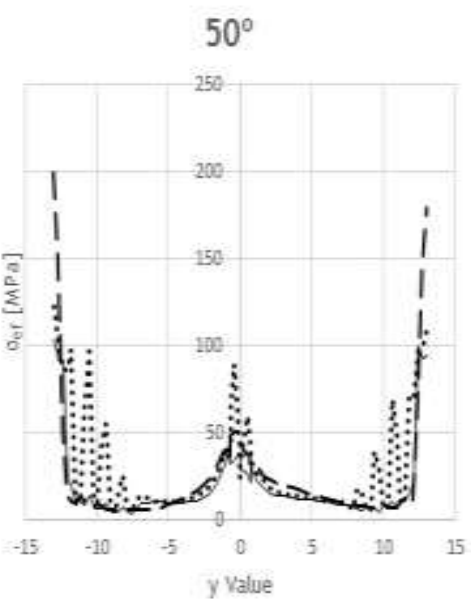

— NRAPM..... BPM - -

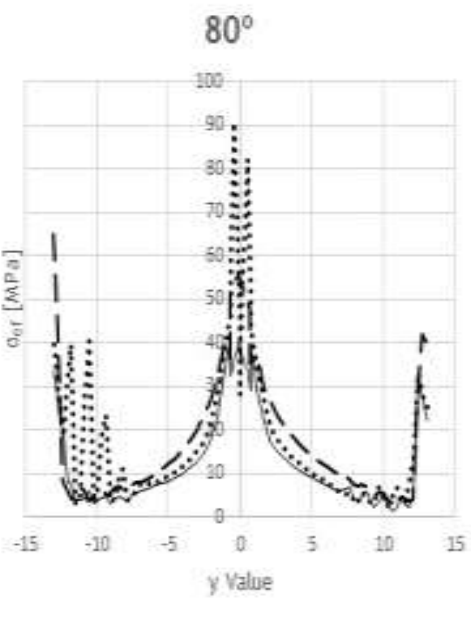

- Nrapis

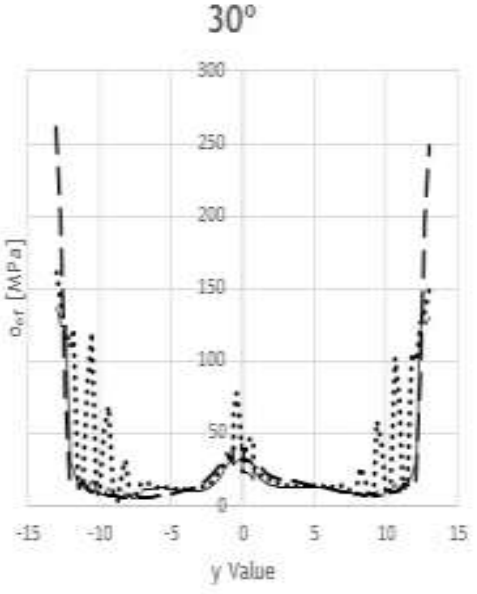

- NNPPW..... PFM -- FEV

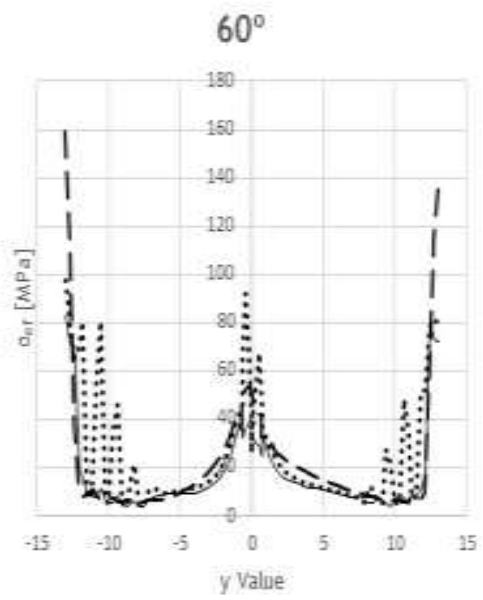

- MIRPM ...... RPM - FEM

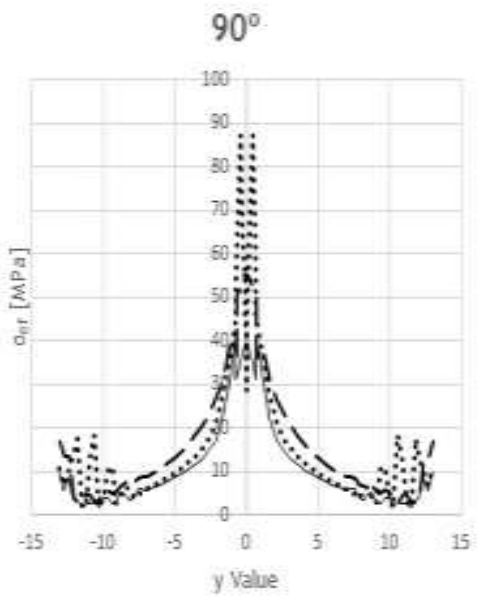

- MNRPH ...... RPM - FEM

Figure A.20 Stress distribution from bone side, from 'Model 2', from bone type 5 

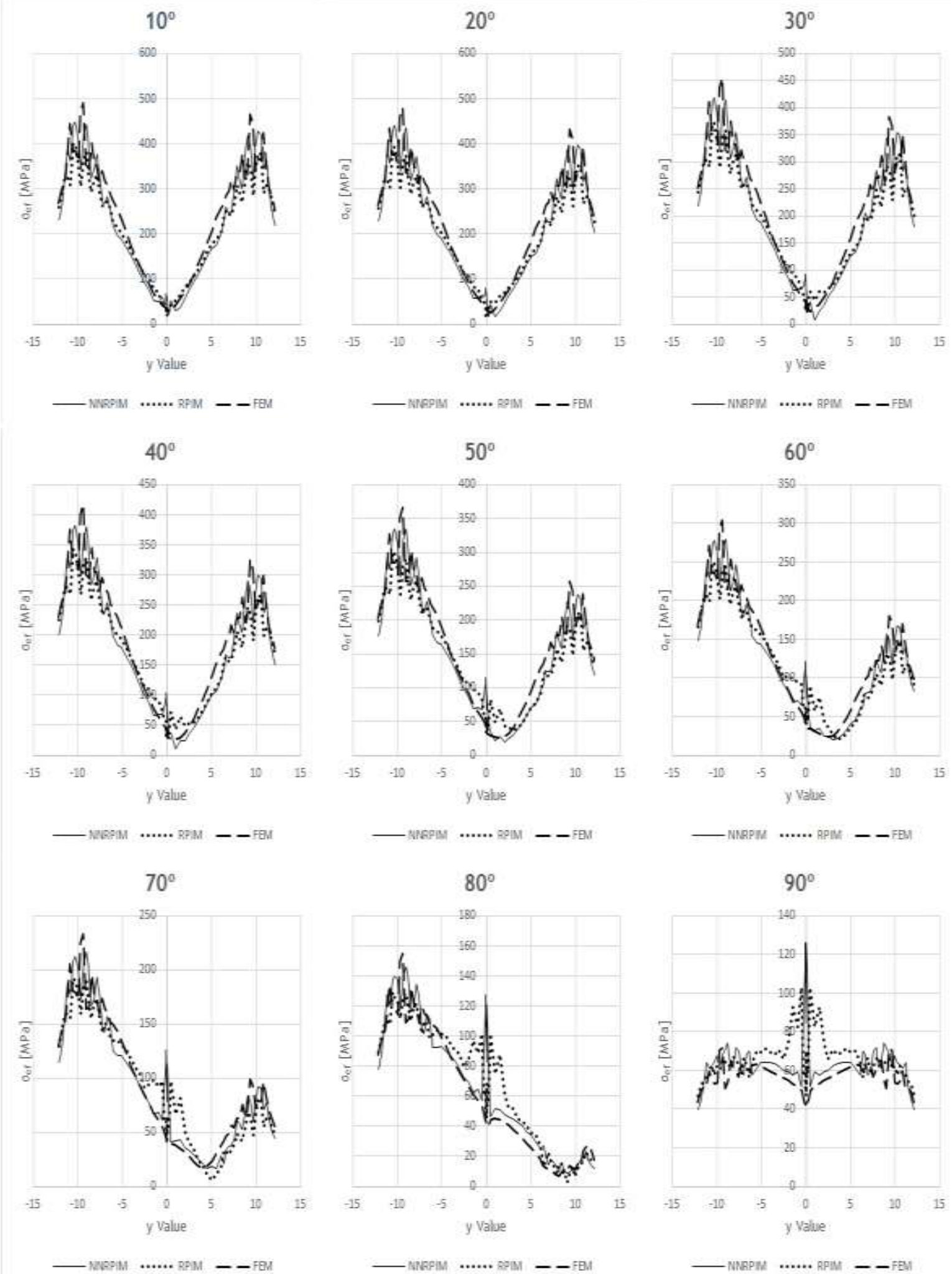

Figure A.21 Stress distribution from implant side, from 'Model 1', from bone type 1 

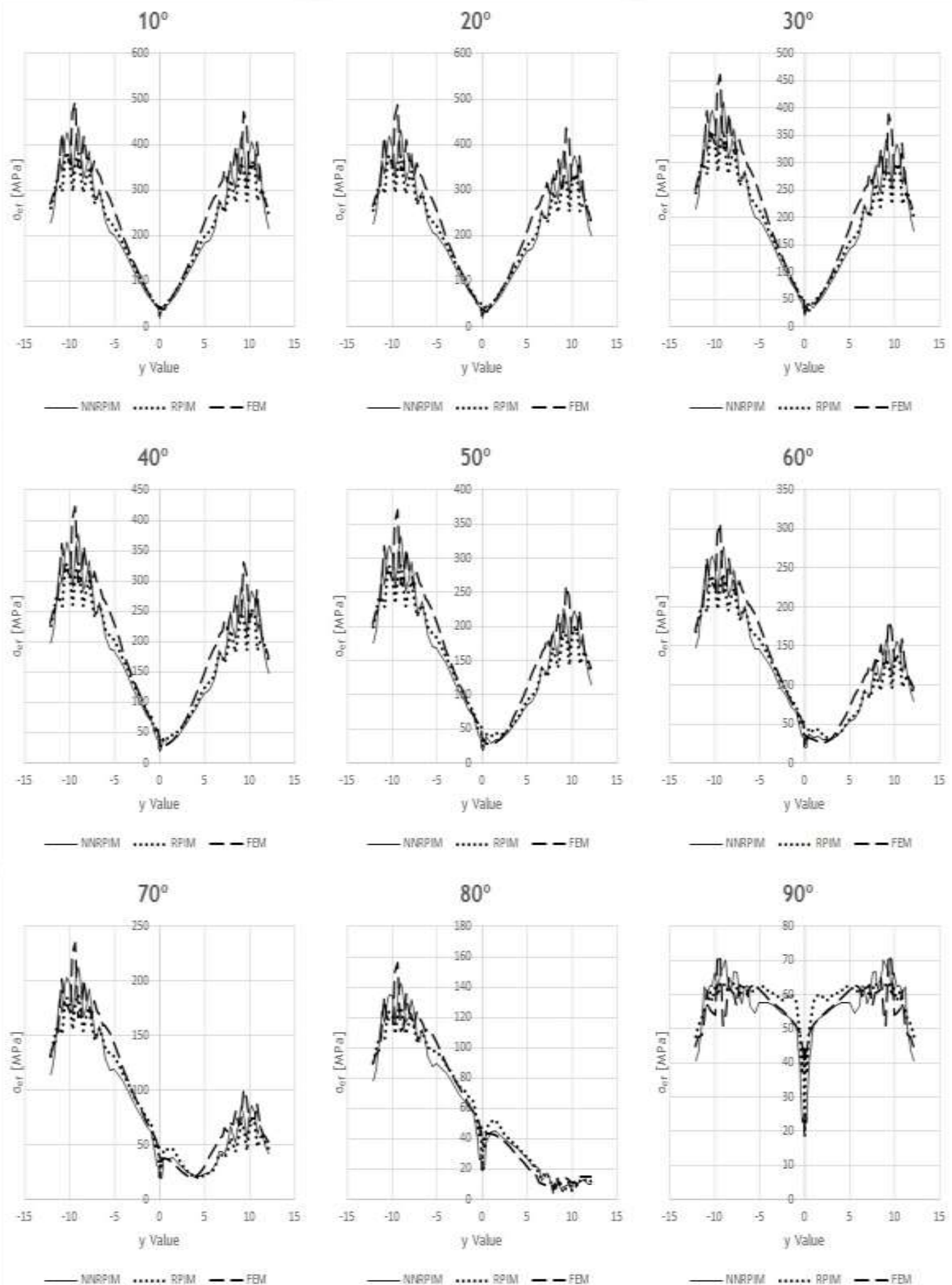

Figure A.22 Stress distribution from implant side, from 'Model 1', from bone type 2 

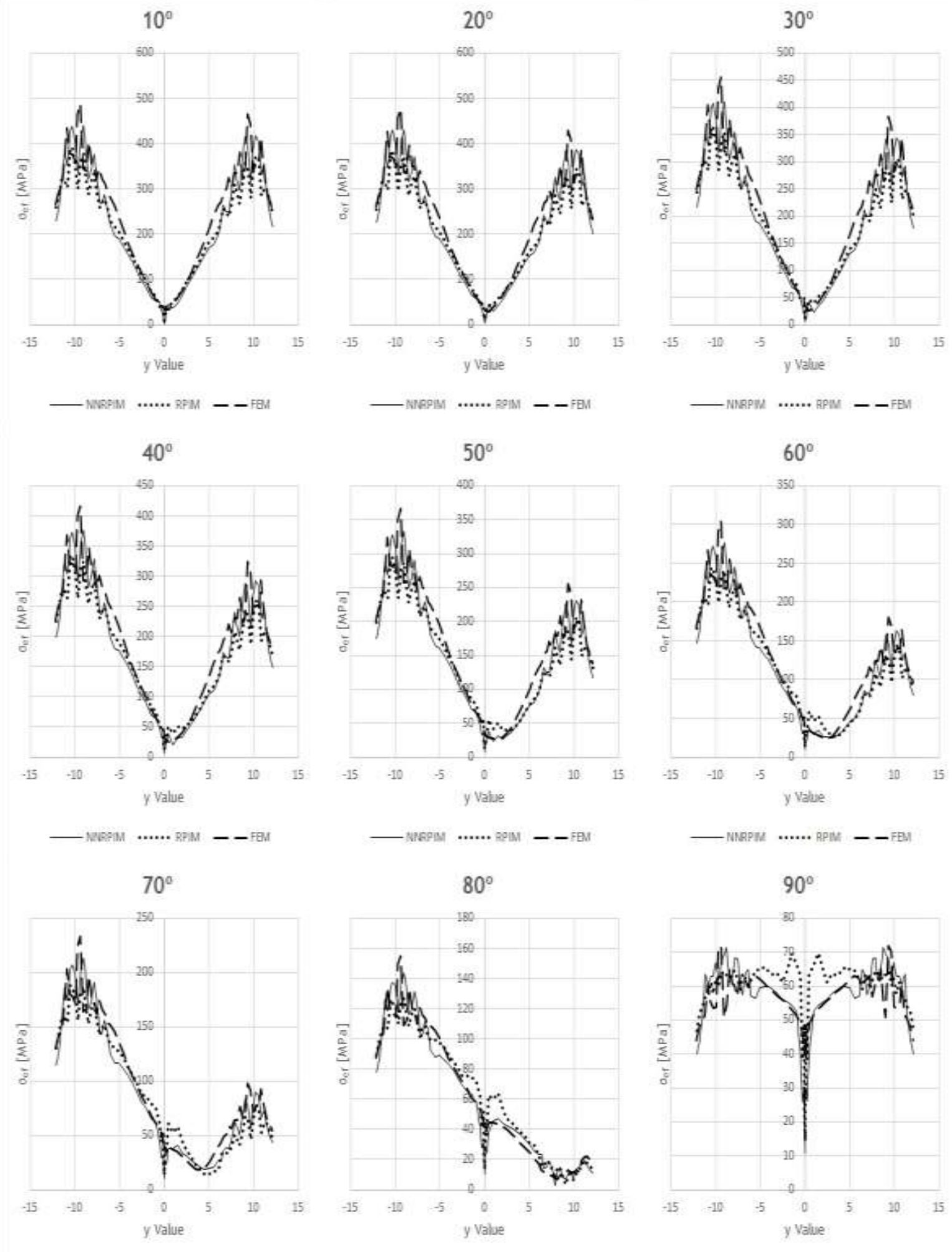

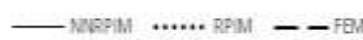

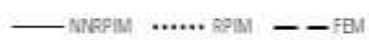

— NMAPNA ....... APMM - - FEV

Figure A.23 Stress distribution from implant side, from 'Model 1', from bone type 3 

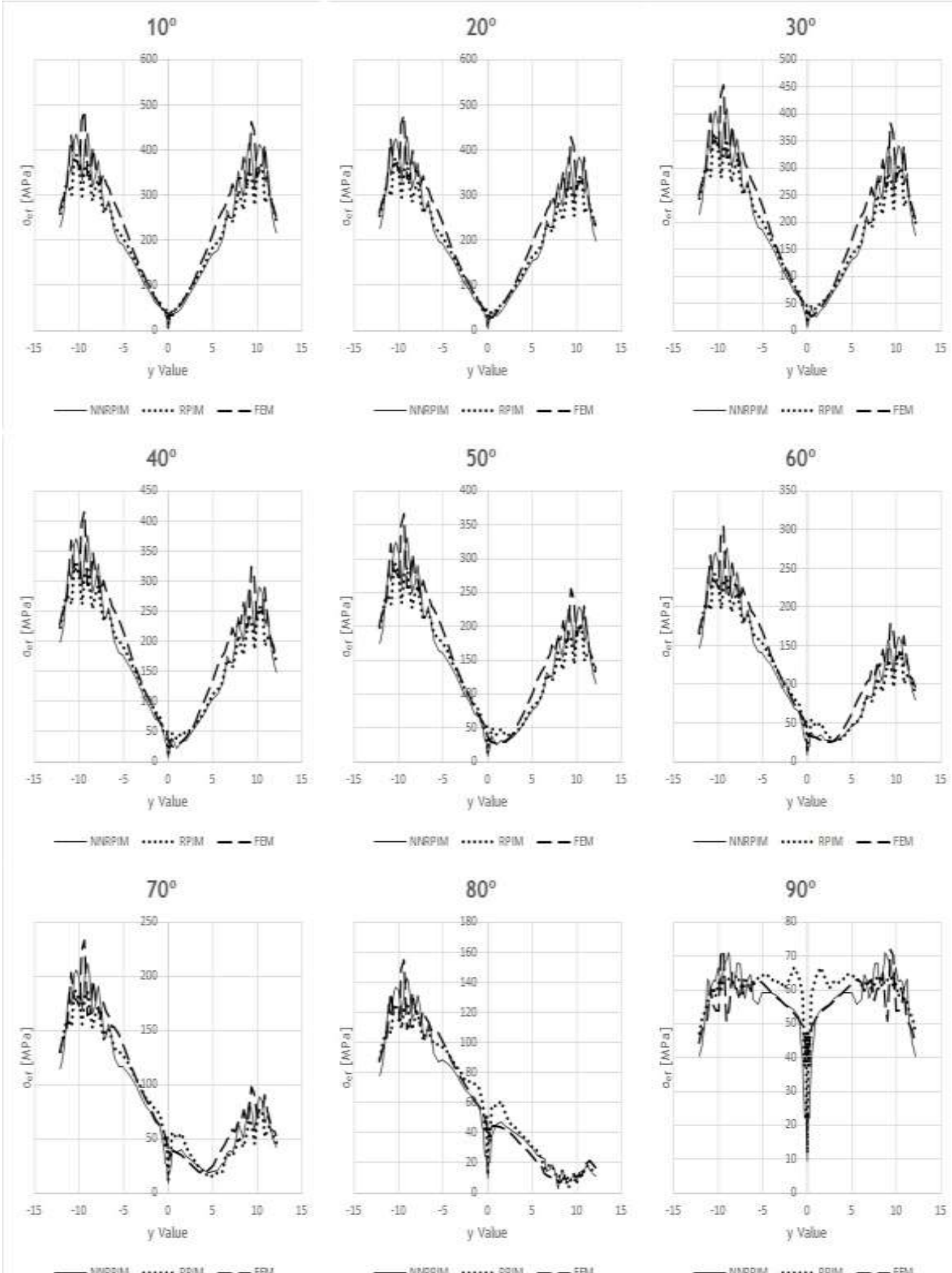

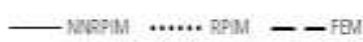

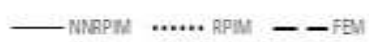

Figure A.24 Stress distribution from implant side, from 'Model 1', from bone type 4 

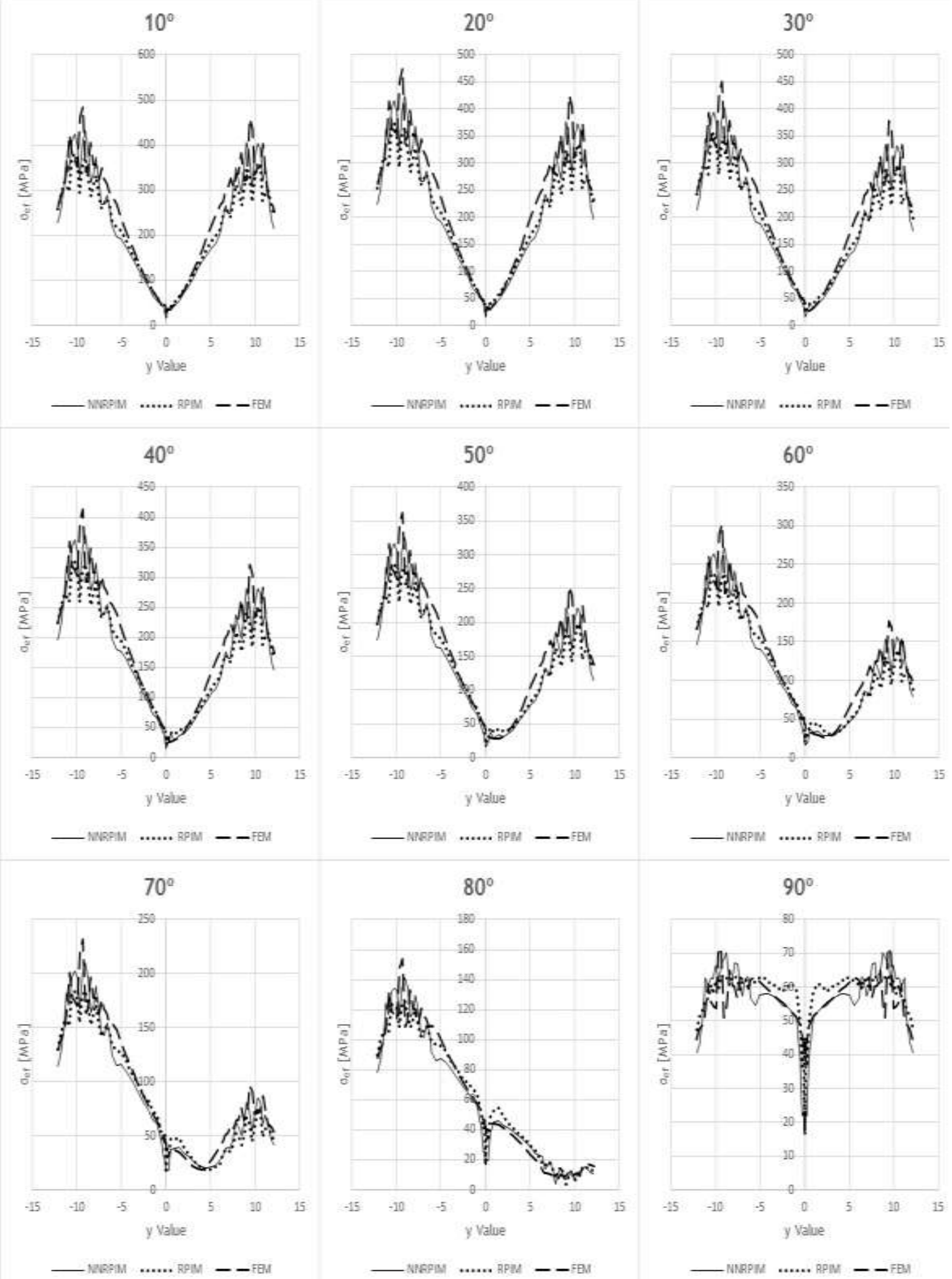

Figure A.25 Stress distribution from implant side, from 'Model 1', from bone type 5 

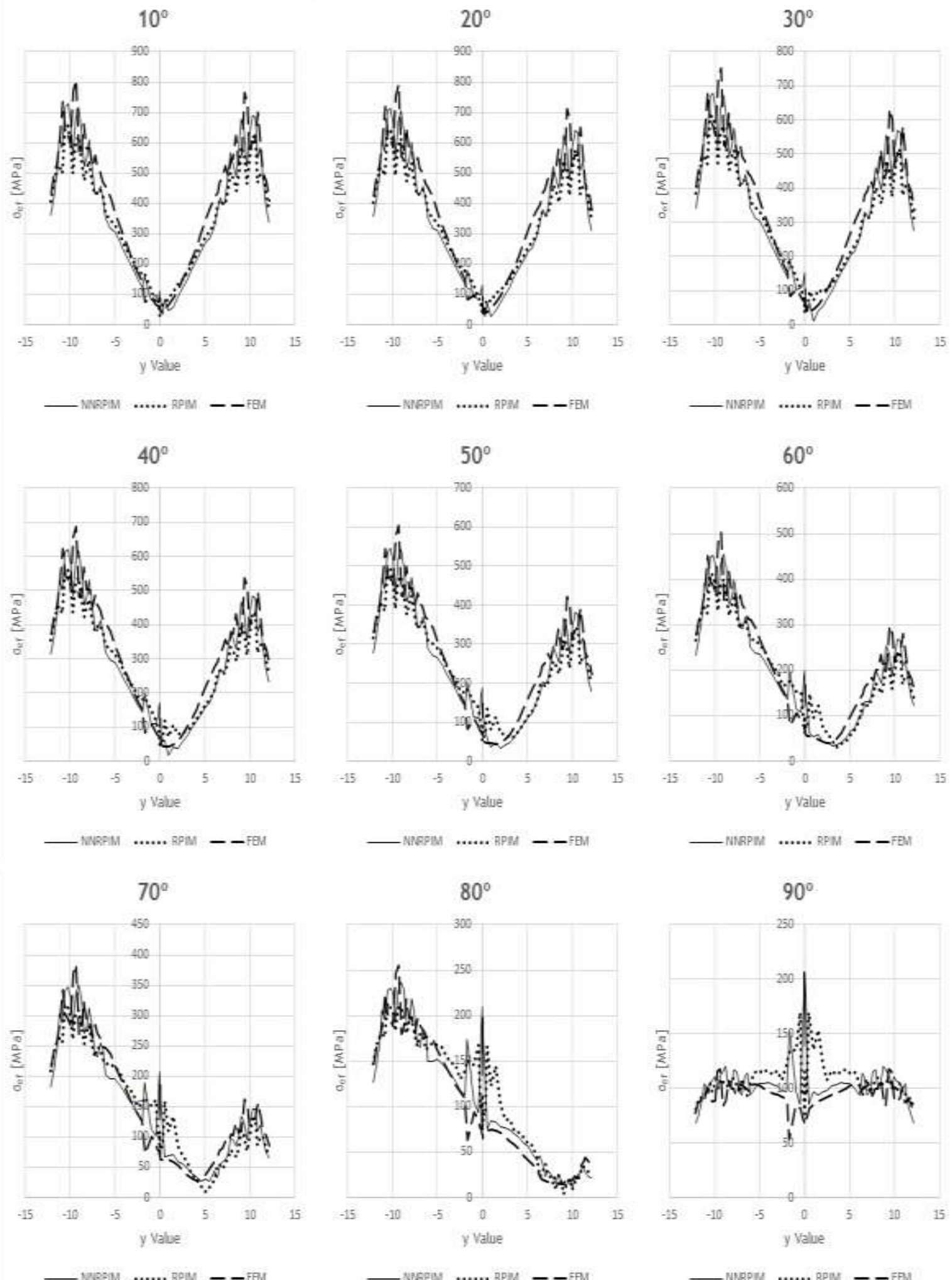

Figure A.26 Stress distribution from implant side, from 'Model 2', from bone type 1 

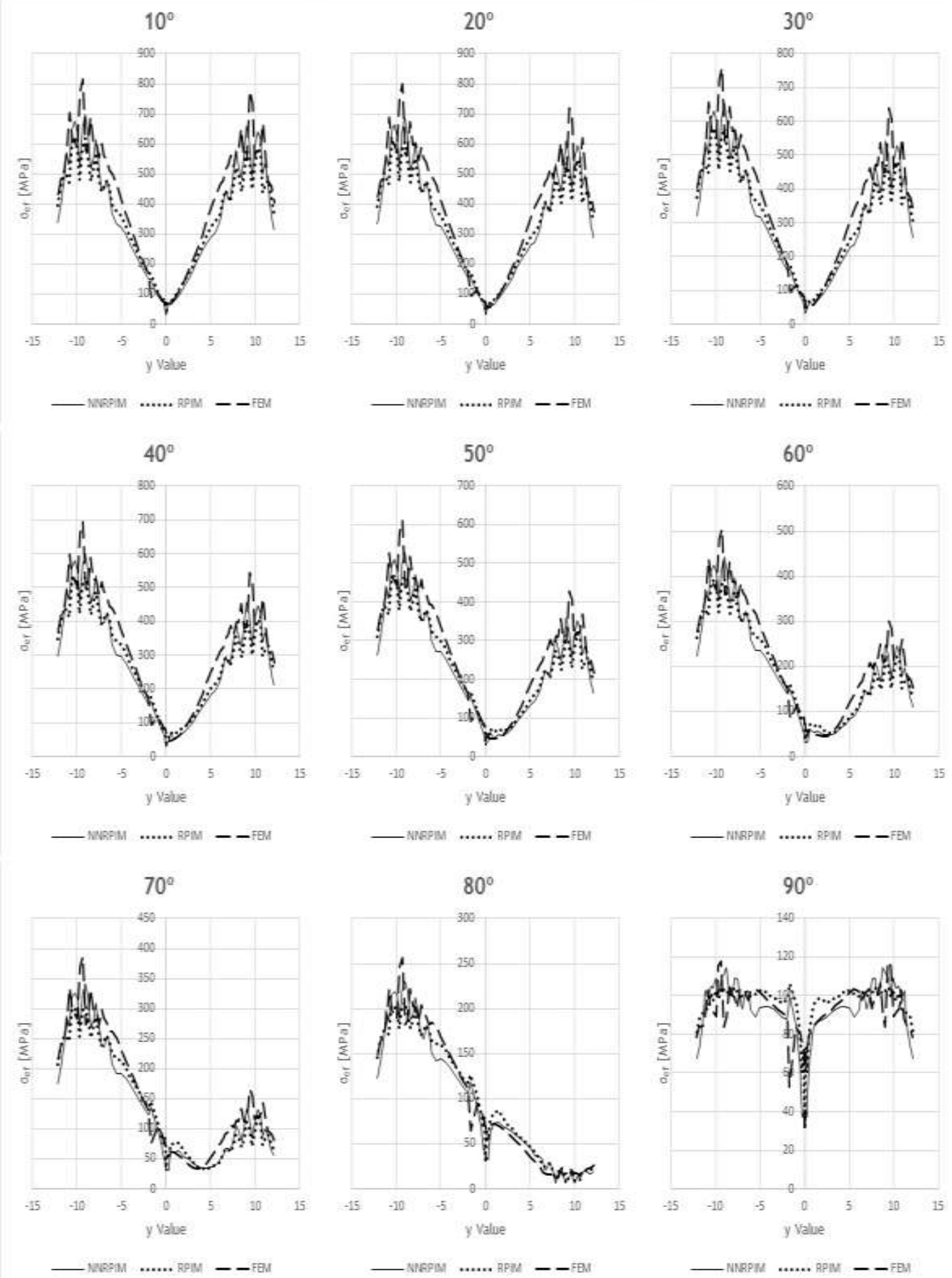

Figure A.27 Stress distribution from implant side, from 'Model 2', from bone type 2 

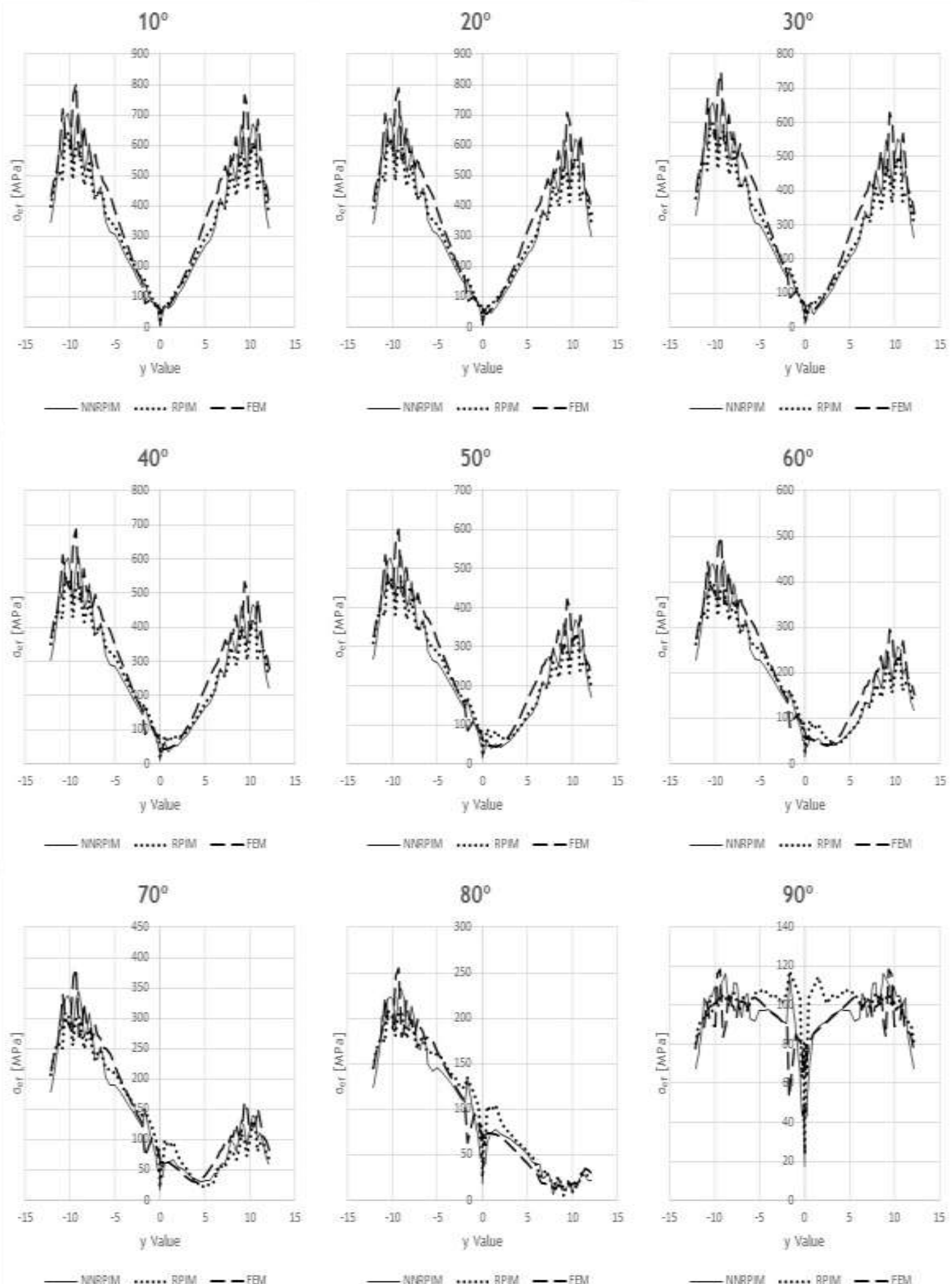

Figure A.28 Stress distribution from implant side, from 'Model 2', from bone type 3 

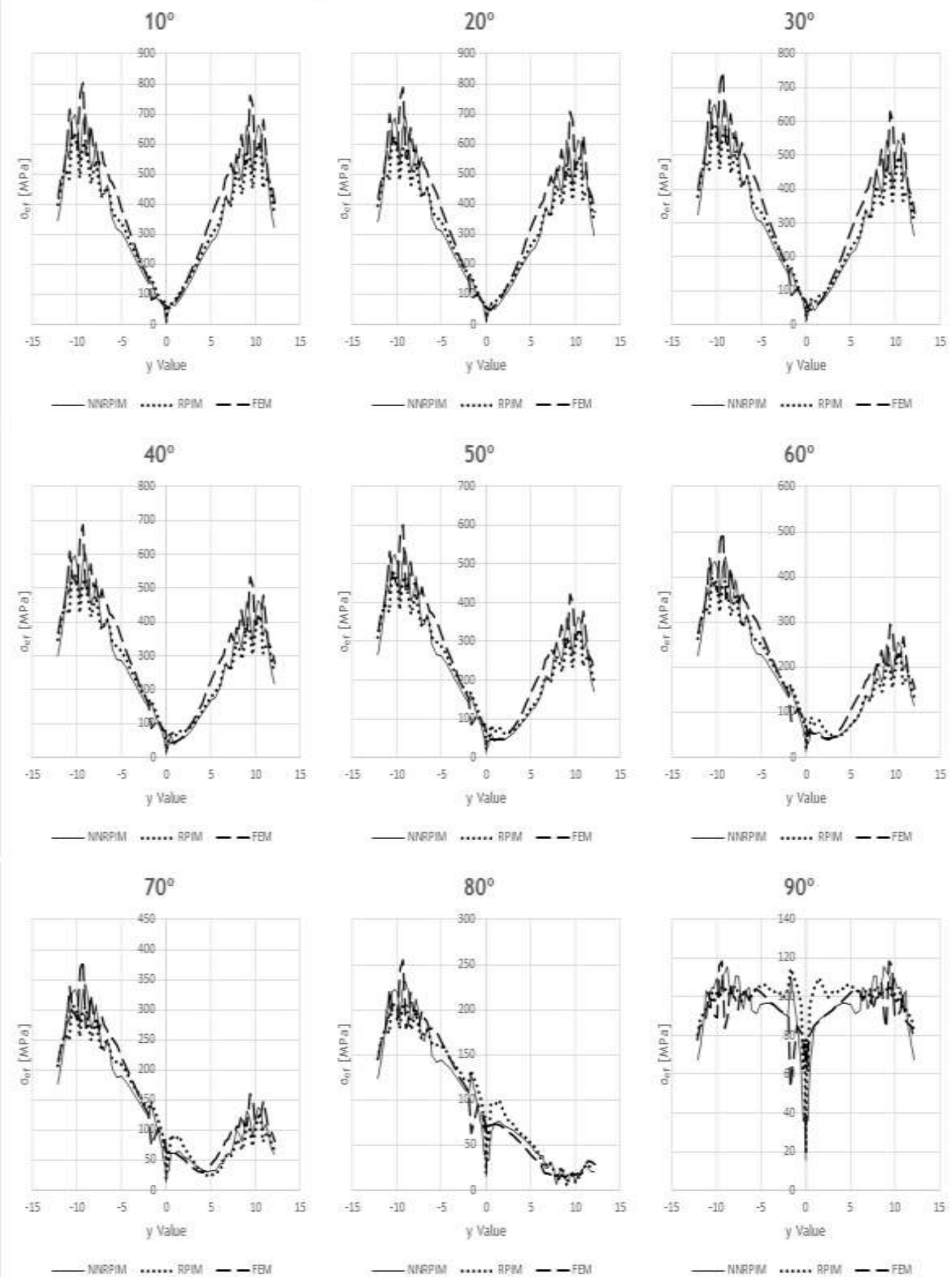

Figure A.29 Stress distribution from implant side, from 'Model 2', from bone type 4 

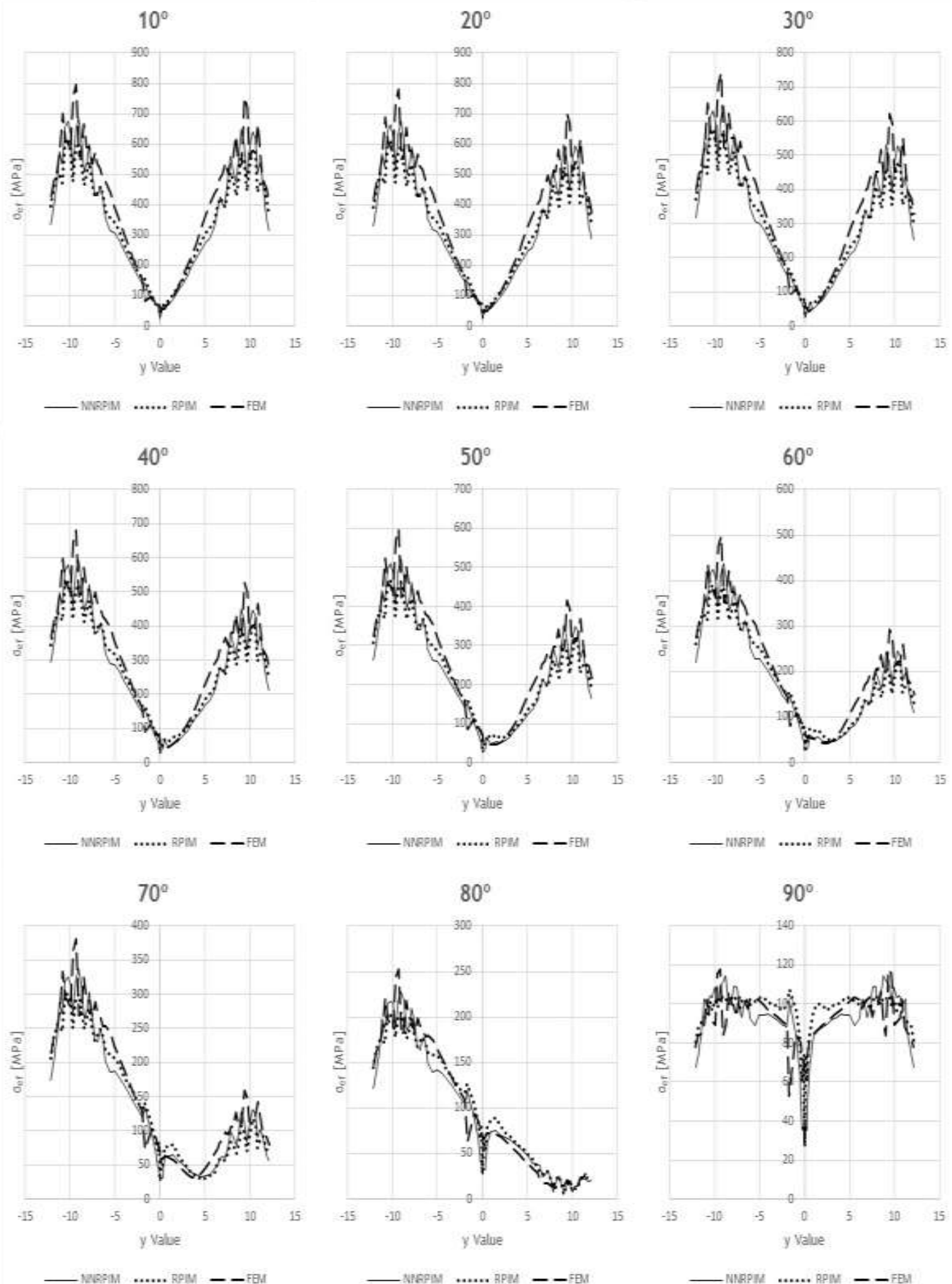

Figure A.30 Stress distribution from implant side, from 'Model 2', from bone type 5 


\section{Appendix 3}

In this appendix are presented all the tables with the specified values of the points acquired and that are identified in section 6.1 of this work. The dotted line in each table helps to separate the points that correspond to the bone side (first 9) and the ones that corresponds to the implant side. 
Table A.1 Stress Values for specific points, for type of bone 1 at $10^{\circ}$

\begin{tabular}{ccccccc}
\hline \multirow{2}{*}{ Points } & \multicolumn{2}{c}{ FEM } & \multicolumn{2}{c}{ RPIM } & \multicolumn{2}{c}{ NNRPIM } \\
\cline { 2 - 7 } & $M 1$ & $M 2$ & $M 1$ & $M 2$ & $M 1$ & $M 2$ \\
\hline 1 & 203.346 & 334.016 & 133.980 & 188.487 & 121.317 & 158.992 \\
2 & 170.691 & 280.490 & 117.591 & 193.656 & 108.414 & 182.463 \\
3 & 2.693 & 4.437 & 82.621 & 146.296 & 18.064 & 34.127 \\
4 & 17.632 & 29.009 & 17.206 & 28.195 & 12.322 & 20.007 \\
5 & 14.844 & 24.424 & 4.602 & 7.547 & 9.692 & 15.765 \\
6 & 15.173 & 24.964 & 13.790 & 22.620 & 10.251 & 16.664 \\
7 & 2.655 & 4.377 & 81.242 & 143.283 & 18.116 & 33.937 \\
8 & 173.147 & 284.589 & 118.263 & 194.699 & 109.418 & 183.528 \\
9 & 199.446 & 327.669 & 131.671 & 185.920 & 119.145 & 157.105 \\
10 & 269.316 & 434.560 & 260.001 & 407.439 & 232.401 & 360.455 \\
11 & 296.538 & 496.288 & 289.178 & 465.666 & 259.673 & 412.683 \\
12 & 368.712 & 612.971 & 325.452 & 526.610 & 386.687 & 615.872 \\
13 & 40.559 & 66.731 & 42.666 & 69.892 & 61.324 & 99.643 \\
14 & 31.226 & 51.376 & 23.037 & 37.840 & 60.504 & 98.355 \\
15 & 29.730 & 48.914 & 42.067 & 69.094 & 51.283 & 83.243 \\
16 & 352.282 & 584.571 & 307.181 & 496.168 & 365.782 & 581.529 \\
17 & 281.364 & 469.186 & 271.964 & 435.813 & 245.042 & 387.577 \\
18 & 255.297 & 409.954 & 244.708 & 381.302 & 219.186 & 338.150 \\
\hline
\end{tabular}

Table A. 2 Stress Values for specific points, for type of bone 1 at $20^{\circ}$

\begin{tabular}{ccccccc}
\hline \multirow{2}{*}{ Points } & \multicolumn{2}{c}{ FEM } & \multicolumn{2}{c}{ RPIM } & \multicolumn{2}{c}{ NNRPIM } \\
\cline { 2 - 7 } & $M 1$ & $M 2$ & $M 1$ & $M 2$ & $M 1$ & $M 2$ \\
\hline 1 & 196.037 & 321.980 & 129.023 & 181.170 & 116.873 & 152.683 \\
2 & 161.656 & 265.611 & 111.873 & 184.263 & 102.947 & 173.571 \\
3 & 2.620 & 4.315 & 79.569 & 141.168 & 17.221 & 32.672 \\
4 & 19.285 & 31.730 & 19.978 & 32.755 & 13.857 & 22.517 \\
5 & 17.333 & 28.519 & 5.204 & 8.543 & 11.495 & 18.730 \\
6 & 14.842 & 24.419 & 14.146 & 23.246 & 10.206 & 16.629 \\
7 & 2.546 & 4.197 & 76.852 & 135.235 & 17.323 & 32.298 \\
8 & 166.493 & 273.684 & 113.198 & 186.318 & 104.924 & 175.669 \\
9 & 188.355 & 309.477 & 124.475 & 176.113 & 112.593 & 148.966 \\
10 & 264.148 & 427.253 & 255.902 & 402.153 & 228.498 & 355.338 \\
11 & 290.742 & 487.460 & 284.721 & 459.583 & 255.244 & 406.594 \\
12 & 360.221 & 599.394 & 319.901 & 518.062 & 379.659 & 605.198 \\
13 & 45.651 & 75.108 & 51.264 & 84.029 & 64.909 & 105.540 \\
14 & 32.150 & 52.897 & 30.348 & 49.887 & 66.803 & 108.721 \\
15 & 25.556 & 42.047 & 50.325 & 82.778 & 45.690 & 74.167 \\
16 & 327.857 & 543.451 & 283.915 & 458.104 & 338.482 & 537.552 \\
17 & 260.859 & 434.083 & 250.814 & 400.783 & 226.425 & 357.141 \\
18 & 236.535 & 378.793 & 225.779 & 350.675 & 202.467 & 311.404 \\
\hline
\end{tabular}


Table A.3 Stress Values for specific points, for type of bone 1 at $30^{\circ}$

\begin{tabular}{ccccccc}
\hline \multirow{2}{*}{ Points } & \multicolumn{2}{c}{ FEM } & \multicolumn{2}{c}{ RPIM } & \multicolumn{2}{c}{ NNRPIM } \\
\cline { 2 - 7 } & $M 1$ & $M 2$ & $M 1$ & $M 2$ & $M 1$ & $M 2$ \\
\hline 1 & 182.778 & 300.173 & 120.145 & 168.346 & 108.877 & 141.736 \\
2 & 147.725 & 242.686 & 102.759 & 169.267 & 94.353 & 159.400 \\
3 & 2.489 & 4.097 & 74.117 & 131.776 & 15.861 & 30.230 \\
4 & 20.914 & 34.410 & 22.810 & 37.421 & 15.406 & 25.057 \\
5 & 20.570 & 33.845 & 6.012 & 9.876 & 13.808 & 22.528 \\
6 & 15.267 & 25.119 & 15.879 & 26.130 & 10.908 & 17.814 \\
7 & 2.383 & 3.929 & 70.149 & 123.106 & 16.010 & 29.684 \\
8 & 154.793 & 254.485 & 104.696 & 172.271 & 97.242 & 162.467 \\
9 & 171.550 & 281.899 & 113.497 & 160.954 & 102.621 & 136.303 \\
10 & 250.973 & 407.011 & 244.042 & 384.693 & 217.660 & 339.448 \\
11 & 276.153 & 463.889 & 271.628 & 439.567 & 243.069 & 388.170 \\
12 & 340.802 & 567.623 & 304.665 & 493.820 & 361.120 & 576.165 \\
13 & 49.918 & 82.130 & 62.030 & 101.764 & 67.180 & 109.314 \\
14 & 33.516 & 55.143 & 38.973 & 64.092 & 75.439 & 122.916 \\
15 & 23.749 & 39.074 & 60.984 & 100.374 & 40.612 & 65.979 \\
16 & 293.500 & 485.856 & 252.081 & 406.204 & 300.942 & 477.300 \\
17 & 232.489 & 385.901 & 222.072 & 353.636 & 200.947 & 315.893 \\
18 & 210.619 & 336.199 & 200.019 & 309.475 & 179.613 & 275.242 \\
\hline
\end{tabular}

Table A.4 Stress Values for specific points, for type of bone 1 at $40^{\circ}$

\begin{tabular}{ccccccc}
\hline \multirow{2}{*}{ Points } & \multicolumn{2}{c}{ FEM } & \multicolumn{2}{c}{ RPIM } & \multicolumn{2}{c}{ NNRPIM } \\
\cline { 2 - 7 } & $M 1$ & $M 2$ & $M 1$ & $M 2$ & $M 1$ & $M 2$ \\
\hline 1 & 163.989 & 269.284 & 107.624 & 150.420 & 97.583 & 126.497 \\
2 & 129.338 & 212.442 & 90.533 & 149.136 & 82.901 & 140.394 \\
3 & 2.308 & 3.798 & 66.443 & 118.420 & 14.029 & 26.882 \\
4 & 22.348 & 36.769 & 25.395 & 41.685 & 16.804 & 27.355 \\
5 & 23.951 & 39.407 & 6.874 & 11.299 & 16.200 & 26.453 \\
6 & 16.343 & 26.890 & 18.439 & 30.360 & 12.156 & 19.880 \\
7 & 2.177 & 3.589 & 61.349 & 107.287 & 14.221 & 26.181 \\
8 & 138.420 & 227.601 & 93.022 & 152.997 & 86.614 & 144.337 \\
9 & 149.560 & 245.801 & 99.079 & 140.918 & 89.541 & 119.515 \\
10 & 230.212 & 374.486 & 224.803 & 355.624 & 200.233 & 313.296 \\
11 & 253.239 & 426.336 & 250.318 & 406.263 & 223.537 & 358.001 \\
12 & 311.073 & 518.670 & 280.233 & 454.666 & 331.664 & 529.702 \\
13 & 53.100 & 87.365 & 73.023 & 119.887 & 68.007 & 110.745 \\
14 & 35.119 & 57.781 & 47.460 & 78.064 & 84.842 & 138.355 \\
15 & 25.047 & 41.211 & 72.015 & 118.546 & 36.991 & 60.219 \\
16 & 250.295 & 413.601 & 212.696 & 342.124 & 254.351 & 402.678 \\
17 & 197.167 & 326.190 & 186.650 & 295.872 & 169.414 & 265.139 \\
18 & 178.370 & 283.537 & 168.245 & 259.024 & 151.345 & 230.814 \\
\hline
\end{tabular}


Table A.5 Stress Values for specific points, for type of bone 1 at $50^{\circ}$

\begin{tabular}{ccccccc}
\hline \multirow{2}{*}{ Points } & \multicolumn{2}{c}{ FEM } & \multicolumn{2}{c}{ RPIM } & \multicolumn{2}{c}{ NNRPIM } \\
\cline { 2 - 7 } & $M 1$ & $M 2$ & $M 1$ & $M 2$ & $M 1$ & $M 2$ \\
\hline 1 & 140.261 & 230.285 & 91.852 & 127.950 & 83.342 & 107.445 \\
2 & 107.082 & 175.841 & 75.580 & 124.497 & 68.950 & 117.144 \\
3 & 2.089 & 3.436 & 56.796 & 101.530 & 11.788 & 22.735 \\
4 & 23.463 & 38.604 & 27.530 & 45.212 & 17.933 & 29.220 \\
5 & 27.088 & 44.567 & 7.685 & 12.637 & 18.406 & 30.070 \\
6 & 17.838 & 29.348 & 21.283 & 35.045 & 13.675 & 22.376 \\
7 & 1.944 & 3.205 & 50.742 & 88.293 & 12.015 & 21.901 \\
8 & 117.891 & 193.884 & 78.545 & 129.098 & 73.373 & 121.841 \\
9 & 123.081 & 202.324 & 81.672 & 116.633 & 73.764 & 99.129 \\
10 & 202.521 & 330.709 & 198.790 & 315.869 & 176.766 & 277.708 \\
11 & 222.732 & 376.000 & 221.463 & 360.721 & 197.262 & 317.039 \\
12 & 271.970 & 454.073 & 247.382 & 401.838 & 292.219 & 467.274 \\
13 & 55.024 & 90.530 & 83.079 & 136.472 & 67.342 & 109.752 \\
14 & 36.747 & 60.460 & 55.068 & 90.589 & 93.814 & 153.077 \\
15 & 28.903 & 47.554 & 82.194 & 135.296 & 35.754 & 58.372 \\
16 & 199.623 & 328.982 & 167.054 & 267.958 & 200.214 & 316.085 \\
17 & 156.059 & 256.931 & 145.688 & 229.370 & 132.832 & 206.512 \\
18 & 140.830 & 222.536 & 131.481 & 200.995 & 118.566 & 179.561 \\
\hline
\end{tabular}

Table A.6 Stress Values for specific points, for type of bone 1 at $60^{\circ}$

\begin{tabular}{ccccccc}
\hline \multirow{2}{*}{ Points } & \multicolumn{2}{c}{ FEM } & \multicolumn{2}{c}{ RPIM } & \multicolumn{2}{c}{ NNRPIM } \\
\cline { 2 - 7 } & $M 1$ & $M 2$ & $M 1$ & $M 2$ & $M 1$ & $M 2$ \\
\hline 1 & 112.305 & 184.346 & 73.294 & 101.604 & 66.577 & 85.146 \\
2 & 81.644 & 134.016 & 58.348 & 96.078 & 52.917 & 90.335 \\
3 & 1.851 & 3.043 & 45.482 & 81.633 & 9.212 & 17.920 \\
4 & 24.177 & 39.779 & 29.082 & 47.782 & 18.719 & 30.523 \\
5 & 29.737 & 48.926 & 8.377 & 13.778 & 20.263 & 33.113 \\
6 & 19.499 & 32.082 & 24.033 & 39.567 & 15.233 & 24.923 \\
7 & 1.706 & 2.812 & 38.680 & 66.740 & 9.466 & 16.983 \\
8 & 93.831 & 154.358 & 61.695 & 101.276 & 57.911 & 95.643 \\
9 & 92.918 & 152.794 & 61.796 & 88.821 & 55.761 & 75.758 \\
10 & 168.733 & 277.008 & 166.783 & 266.634 & 147.956 & 233.750 \\
11 & 185.564 & 314.418 & 185.926 & 304.307 & 165.027 & 266.505 \\
12 & 224.665 & 375.759 & 207.108 & 336.932 & 243.971 & 390.746 \\
13 & 55.597 & 91.473 & 91.483 & 150.344 & 65.223 & 106.389 \\
14 & 38.215 & 62.876 & 61.368 & 100.959 & 101.530 & 165.731 \\
15 & 34.105 & 56.114 & 90.778 & 149.407 & 37.285 & 61.011 \\
16 & 143.076 & 234.639 & 116.696 & 186.189 & 140.285 & 220.299 \\
17 & 110.566 & 180.515 & 100.514 & 156.340 & 92.364 & 141.908 \\
18 & 99.216 & 155.257 & 90.926 & 137.404 & 82.315 & 123.176 \\
\hline
\end{tabular}


Table A.7 Stress Values for specific points, for type of bone 1 at $70^{\circ}$

\begin{tabular}{ccccccc}
\hline \multirow{2}{*}{ Points } & \multicolumn{2}{c}{ FEM } & \multicolumn{2}{c}{ RPIM } & \multicolumn{2}{c}{ NNRPIM } \\
\cline { 2 - 7 } & $M 1$ & $M 2$ & $M 1$ & $M 2$ & $M 1$ & $M 2$ \\
\hline 1 & 81.030 & 132.962 & 52.538 & 72.217 & 47.823 & 60.322 \\
2 & 53.929 & 88.450 & 39.400 & 64.773 & 35.323 & 60.811 \\
3 & 1.620 & 2.661 & 32.917 & 59.427 & 6.412 & 12.617 \\
4 & 24.442 & 40.213 & 29.964 & 49.251 & 19.111 & 31.186 \\
5 & 31.734 & 52.211 & 8.901 & 14.642 & 21.660 & 35.401 \\
6 & 21.113 & 34.737 & 26.435 & 43.510 & 16.655 & 27.241 \\
7 & 1.497 & 2.465 & 25.664 & 43.492 & 6.681 & 11.615 \\
8 & 67.048 & 110.351 & 43.019 & 70.406 & 40.726 & 66.564 \\
9 & 60.108 & 98.913 & 40.091 & 58.383 & 36.124 & 50.174 \\
10 & 129.943 & 215.145 & 129.811 & 209.529 & 114.723 & 182.841 \\
11 & 142.975 & 243.641 & 144.847 & 238.839 & 127.861 & 208.019 \\
12 & 170.682 & 286.232 & 160.733 & 262.065 & 188.479 & 302.576 \\
13 & 54.791 & 90.148 & 97.756 & 160.709 & 61.774 & 100.856 \\
14 & 39.373 & 64.779 & 66.062 & 108.685 & 107.413 & 175.376 \\
15 & 39.639 & 65.217 & 97.267 & 160.059 & 41.115 & 67.334 \\
16 & 82.846 & 134.146 & 64.080 & 100.744 & 77.157 & 119.374 \\
17 & 62.912 & 100.857 & 53.124 & 80.339 & 49.670 & 74.180 \\
18 & 55.318 & 85.007 & 48.389 & 71.756 & 44.077 & 64.327 \\
\hline
\end{tabular}

Table A. 8 Stress Values for specific points, for type of bone 1 at $80^{\circ}$

\begin{tabular}{ccccccc}
\hline \multirow{2}{*}{ Points } & \multicolumn{2}{c}{ FEM } & \multicolumn{2}{c}{ RPIM } & \multicolumn{2}{c}{ NNRPIM } \\
\cline { 2 - 7 } & $M 1$ & $M 2$ & $M 1$ & $M 2$ & $M 1$ & $M 2$ \\
\hline 1 & 47.574 & 78.005 & 30.273 & 40.786 & 27.718 & 33.860 \\
2 & 25.444 & 41.629 & 19.483 & 31.639 & 16.855 & 29.564 \\
3 & 1.433 & 2.354 & 19.731 & 35.908 & 3.603 & 7.111 \\
4 & 24.237 & 39.877 & 30.129 & 49.540 & 19.087 & 31.166 \\
5 & 32.971 & 54.247 & 9.227 & 15.179 & 22.524 & 36.817 \\
6 & 22.511 & 37.038 & 28.318 & 46.593 & 17.820 & 29.133 \\
7 & 1.360 & 2.237 & 12.779 & 20.419 & 3.854 & 6.136 \\
8 & 38.623 & 63.633 & 23.200 & 37.497 & 22.420 & 35.550 \\
9 & 26.315 & 43.416 & 17.412 & 26.503 & 15.680 & 23.453 \\
10 & 87.495 & 147.318 & 89.124 & 146.557 & 78.167 & 126.703 \\
11 & 96.542 & 166.271 & 99.604 & 166.526 & 86.999 & 143.527 \\
12 & 111.875 & 188.501 & 109.906 & 179.849 & 127.645 & 205.732 \\
13 & 52.642 & 86.612 & 101.581 & 167.047 & 57.215 & 93.502 \\
14 & 40.109 & 65.990 & 68.952 & 113.441 & 111.081 & 181.389 \\
15 & 44.834 & 73.764 & 101.331 & 166.714 & 46.290 & 75.785 \\
16 & 25.878 & 39.016 & 22.812 & 34.793 & 23.718 & 34.697 \\
17 & 23.485 & 38.462 & 16.167 & 28.619 & 13.579 & 22.545 \\
18 & 17.345 & 30.388 & 14.986 & 29.385 & 11.921 & 21.701 \\
\hline
\end{tabular}


Table A. 9 Stress Values for specific points, for type of bone 1 at $90^{\circ}$

\begin{tabular}{ccccccc}
\hline \multirow{2}{*}{ Points } & \multicolumn{2}{c}{ FEM } & \multicolumn{2}{c}{ RPIM } & \multicolumn{2}{c}{ NNRPIM } \\
\cline { 2 - 7 } & $M 1$ & $M 2$ & $M 1$ & $M 2$ & $M 1$ & $M 2$ \\
\hline 1 & 14.979 & 24.536 & 7.970 & 9.845 & 7.726 & 8.623 \\
2 & 12.487 & 20.577 & 5.255 & 5.735 & 5.052 & 5.404 \\
3 & 1.336 & 2.195 & 8.359 & 14.426 & 1.967 & 2.895 \\
4 & 23.579 & 38.795 & 29.571 & 48.640 & 18.648 & 30.469 \\
5 & 33.390 & 54.937 & 9.338 & 15.362 & 22.817 & 37.296 \\
6 & 23.579 & 38.795 & 29.571 & 48.640 & 18.648 & 30.469 \\
7 & 1.336 & 2.195 & 8.359 & 14.426 & 1.967 & 2.895 \\
8 & 12.487 & 20.577 & 5.255 & 5.735 & 5.052 & 5.404 \\
9 & 14.979 & 24.536 & 7.970 & 9.845 & 7.726 & 8.623 \\
10 & 43.561 & 77.155 & 46.590 & 80.847 & 39.874 & 67.900 \\
11 & 49.141 & 86.893 & 52.226 & 90.610 & 44.236 & 75.849 \\
12 & 51.325 & 87.276 & 57.362 & 94.456 & 64.460 & 104.681 \\
13 & 49.263 & 81.052 & 102.792 & 169.081 & 51.890 & 84.884 \\
14 & 40.362 & 66.407 & 69.928 & 115.048 & 112.328 & 183.433 \\
15 & 49.263 & 81.052 & 102.792 & 169.081 & 51.890 & 84.884 \\
16 & 51.325 & 87.276 & 57.362 & 94.456 & 64.460 & 104.681 \\
17 & 49.141 & 86.893 & 52.226 & 90.610 & 44.236 & 75.849 \\
18 & 43.561 & 77.155 & 46.590 & 80.847 & 39.874 & 67.900 \\
\hline
\end{tabular}

Table A.10 Stress Values for specific points, for type of bone 2 at $10^{\circ}$

\begin{tabular}{ccccccc}
\hline \multirow{2}{*}{ Points } & \multicolumn{2}{c}{ FEM } & \multicolumn{2}{c}{ RPIM } & \multicolumn{2}{c}{ NNRPIM } \\
\cline { 2 - 7 } & $M 1$ & $M 2$ & $M 1$ & $M 2$ & $M 1$ & $M 2$ \\
\hline 1 & 163.310 & 268.243 & 115.947 & 163.355 & 106.762 & 138.473 \\
2 & 126.659 & 207.886 & 89.213 & 139.595 & 81.922 & 126.919 \\
3 & 16.867 & 27.725 & 67.221 & 116.979 & 19.207 & 35.455 \\
4 & 21.368 & 35.158 & 16.920 & 27.579 & 14.923 & 24.017 \\
5 & 18.502 & 30.443 & 11.545 & 18.851 & 15.975 & 25.784 \\
6 & 19.000 & 31.262 & 14.069 & 22.965 & 12.595 & 20.314 \\
7 & 16.475 & 27.087 & 65.234 & 113.253 & 18.958 & 34.970 \\
8 & 126.257 & 207.287 & 88.813 & 139.371 & 81.713 & 126.978 \\
9 & 160.854 & 264.260 & 114.208 & 161.062 & 105.114 & 136.534 \\
10 & 268.985 & 431.163 & 259.922 & 396.758 & 228.824 & 337.818 \\
11 & 291.467 & 485.256 & 288.901 & 458.021 & 253.885 & 392.071 \\
12 & 345.175 & 572.971 & 313.182 & 497.598 & 370.751 & 573.473 \\
13 & 48.851 & 80.378 & 47.165 & 76.939 & 49.143 & 79.175 \\
14 & 38.520 & 63.380 & 30.554 & 49.797 & 18.875 & 30.360 \\
15 & 38.216 & 62.881 & 44.425 & 72.521 & 47.020 & 75.781 \\
16 & 327.651 & 542.852 & 294.271 & 466.096 & 349.514 & 538.505 \\
17 & 275.739 & 457.311 & 271.569 & 427.951 & 239.275 & 366.922 \\
18 & 254.179 & 405.391 & 243.936 & 369.867 & 215.115 & 315.199 \\
\hline
\end{tabular}


Table A.11 Stress Values for specific points, for type of bone 2 at $20^{\circ}$

\begin{tabular}{ccccccc}
\hline \multirow{2}{*}{ Points } & \multicolumn{2}{c}{ FEM } & \multicolumn{2}{c}{ RPIM } & \multicolumn{2}{c}{ NNRPIM } \\
\cline { 2 - 7 } & $M 1$ & $M 2$ & $M 1$ & $M 2$ & $M 1$ & $M 2$ \\
\hline 1 & 157.087 & 257.996 & 111.524 & 157.053 & 102.715 & 133.133 \\
2 & 121.081 & 198.702 & 85.343 & 133.329 & 78.287 & 121.086 \\
3 & 16.310 & 26.807 & 65.172 & 113.546 & 18.467 & 34.096 \\
4 & 22.599 & 37.183 & 18.626 & 30.381 & 16.287 & 26.241 \\
5 & 20.262 & 33.339 & 12.214 & 19.971 & 17.034 & 27.563 \\
6 & 18.194 & 29.936 & 13.447 & 22.013 & 12.034 & 19.494 \\
7 & 15.539 & 25.551 & 61.258 & 106.206 & 17.978 & 33.141 \\
8 & 120.290 & 197.520 & 84.553 & 132.888 & 77.875 & 121.201 \\
9 & 152.249 & 250.150 & 108.100 & 152.535 & 99.469 & 129.314 \\
10 & 264.222 & 424.580 & 256.165 & 392.314 & 225.328 & 333.881 \\
11 & 286.139 & 477.281 & 284.496 & 452.359 & 249.697 & 386.920 \\
12 & 338.286 & 562.051 & 308.471 & 490.849 & 364.579 & 565.004 \\
13 & 53.226 & 87.576 & 48.526 & 79.193 & 49.299 & 79.477 \\
14 & 38.655 & 63.602 & 29.694 & 48.411 & 18.918 & 30.473 \\
15 & 33.052 & 54.384 & 43.393 & 70.924 & 45.241 & 72.994 \\
16 & 303.764 & 502.718 & 271.220 & 428.794 & 322.746 & 496.120 \\
17 & 255.157 & 422.234 & 250.353 & 393.126 & 220.917 & 337.380 \\
18 & 235.058 & 373.818 & 224.676 & 339.348 & 198.323 & 289.327 \\
\hline
\end{tabular}

Table A.12 Stress Values for specific points, for type of bone 2 at $30^{\circ}$

\begin{tabular}{ccccccc}
\hline \multirow{2}{*}{ Points } & \multicolumn{2}{c}{ FEM } & \multicolumn{2}{c}{ RPIM } & \multicolumn{2}{c}{ NNRPIM } \\
\cline { 2 - 7 } & $M 1$ & $M 2$ & $M 1$ & $M 2$ & $M 1$ & $M 2$ \\
\hline 1 & 146.089 & 239.907 & 103.710 & 145.980 & 95.546 & 123.755 \\
2 & 111.833 & 183.493 & 78.884 & 123.014 & 72.277 & 111.575 \\
3 & 15.269 & 25.094 & 61.153 & 106.679 & 17.176 & 31.712 \\
4 & 23.672 & 38.948 & 20.226 & 33.025 & 17.556 & 28.333 \\
5 & 22.695 & 37.341 & 13.173 & 21.573 & 18.540 & 30.084 \\
6 & 17.840 & 29.353 & 13.612 & 22.360 & 12.079 & 19.673 \\
7 & 14.145 & 23.261 & 55.434 & 95.955 & 16.462 & 30.319 \\
8 & 110.676 & 181.766 & 77.730 & 122.370 & 71.676 & 111.743 \\
9 & 139.016 & 228.438 & 98.705 & 139.377 & 90.801 & 118.172 \\
10 & 251.441 & 405.125 & 244.631 & 375.976 & 214.987 & 319.812 \\
11 & 272.124 & 454.817 & 271.447 & 432.957 & 237.921 & 370.015 \\
12 & 321.112 & 534.040 & 294.389 & 469.189 & 347.327 & 539.362 \\
13 & 56.527 & 93.006 & 49.667 & 81.121 & 48.814 & 78.782 \\
14 & 38.860 & 63.939 & 28.325 & 46.204 & 18.982 & 30.643 \\
15 & 29.158 & 47.976 & 42.792 & 70.058 & 43.196 & 69.820 \\
16 & 270.647 & 447.304 & 239.940 & 378.482 & 286.175 & 438.667 \\
17 & 226.839 & 374.359 & 221.541 & 346.377 & 195.852 & 297.601 \\
18 & 208.817 & 330.940 & 198.605 & 298.572 & 175.514 & 254.695 \\
\hline
\end{tabular}


Table A.13 Stress Values for specific points, for type of bone 2 at $40^{\circ}$

\begin{tabular}{ccccccc}
\hline \multirow{2}{*}{ Points } & \multicolumn{2}{c}{ FEM } & \multicolumn{2}{c}{ RPIM } & \multicolumn{2}{c}{ NNRPIM } \\
\cline { 2 - 7 } & $M 1$ & $M 2$ & $M 1$ & $M 2$ & $M 1$ & $M 2$ \\
\hline 1 & 130.663 & 214.546 & 92.751 & 130.487 & 85.481 & 110.633 \\
2 & 99.206 & 162.743 & 70.040 & 108.977 & 64.083 & 98.684 \\
3 & 13.779 & 22.643 & 55.294 & 96.599 & 15.377 & 28.383 \\
4 & 24.487 & 40.289 & 21.571 & 35.263 & 18.611 & 30.094 \\
5 & 25.363 & 41.730 & 14.261 & 23.390 & 20.235 & 32.915 \\
6 & 18.008 & 29.631 & 14.519 & 23.912 & 12.720 & 20.805 \\
7 & 12.340 & 20.296 & 47.951 & 82.828 & 14.461 & 26.596 \\
8 & 97.720 & 160.524 & 68.557 & 108.149 & 63.310 & 98.900 \\
9 & 121.571 & 199.804 & 86.317 & 122.001 & 79.381 & 103.459 \\
10 & 231.052 & 373.424 & 225.688 & 348.270 & 198.132 & 296.064 \\
11 & 249.869 & 418.582 & 250.172 & 400.435 & 218.934 & 341.896 \\
12 & 294.200 & 489.828 & 271.388 & 433.308 & 319.542 & 497.363 \\
13 & 58.564 & 96.358 & 50.472 & 82.524 & 47.731 & 77.155 \\
14 & 39.111 & 64.350 & 26.549 & 43.345 & 19.061 & 30.852 \\
15 & 27.624 & 45.451 & 42.715 & 70.060 & 41.115 & 66.622 \\
16 & 229.335 & 378.337 & 201.412 & 316.734 & 240.944 & 367.942 \\
17 & 191.677 & 315.194 & 186.033 & 289.171 & 164.866 & 248.832 \\
18 & 176.285 & 278.120 & 166.544 & 248.834 & 147.405 & 212.399 \\
\hline
\end{tabular}

Table A.14 Stress Values for specific points, for type of bone 2 at $50^{\circ}$

\begin{tabular}{ccccccc}
\hline \multirow{2}{*}{ Points } & \multicolumn{2}{c}{ FEM } & \multicolumn{2}{c}{ RPIM } & \multicolumn{2}{c}{ NNRPIM } \\
\cline { 2 - 7 } & $M 1$ & $M 2$ & $M 1$ & $M 2$ & $M 1$ & $M 2$ \\
\hline 1 & 111.289 & 182.704 & 78.988 & 111.059 & 72.833 & 94.183 \\
2 & 83.602 & 137.107 & 59.091 & 91.658 & 53.964 & 82.818 \\
3 & 11.892 & 19.540 & 47.783 & 83.630 & 13.130 & 24.219 \\
4 & 24.974 & 41.090 & 22.556 & 36.917 & 19.367 & 31.380 \\
5 & 27.922 & 45.940 & 15.334 & 25.179 & 21.894 & 35.680 \\
6 & 18.665 & 30.711 & 15.946 & 26.291 & 13.803 & 22.626 \\
7 & 10.190 & 16.764 & 39.052 & 67.252 & 12.044 & 22.097 \\
8 & 81.832 & 134.466 & 57.326 & 90.672 & 53.043 & 83.074 \\
9 & 100.459 & 165.144 & 71.323 & 100.952 & 65.567 & 85.642 \\
10 & 203.696 & 330.475 & 199.931 & 310.072 & 175.291 & 263.384 \\
11 & 220.073 & 369.714 & 221.335 & 355.814 & 193.329 & 303.442 \\
12 & 258.388 & 430.791 & 240.186 & 384.330 & 282.093 & 440.320 \\
13 & 59.230 & 97.453 & 50.861 & 83.262 & 46.145 & 74.738 \\
14 & 39.375 & 64.786 & 24.521 & 40.081 & 19.145 & 31.072 \\
15 & 29.008 & 47.727 & 43.174 & 70.927 & 39.263 & 63.808 \\
16 & 181.123 & 297.975 & 156.859 & 245.509 & 188.477 & 286.170 \\
17 & 150.790 & 246.627 & 144.953 & 223.328 & 128.937 & 192.618 \\
18 & 138.505 & 217.071 & 129.515 & 191.758 & 114.886 & 163.800 \\
\hline
\end{tabular}


Table A.15 Stress Values for specific points, for type of bone 2 at $60^{\circ}$

\begin{tabular}{ccccccc}
\hline \multirow{2}{*}{ Points } & \multicolumn{2}{c}{ FEM } & \multicolumn{2}{c}{ RPIM } & \multicolumn{2}{c}{ NNRPIM } \\
\cline { 2 - 7 } & $M 1$ & $M 2$ & $M 1$ & $M 2$ & $M 1$ & $M 2$ \\
\hline 1 & 88.541 & 145.324 & 62.827 & 88.276 & 57.977 & 74.899 \\
2 & 65.493 & 107.367 & 46.368 & 71.576 & 42.225 & 64.449 \\
3 & 9.676 & 15.895 & 38.854 & 68.169 & 10.512 & 19.356 \\
4 & 25.095 & 41.288 & 23.115 & 37.878 & 19.773 & 32.102 \\
5 & 30.130 & 49.574 & 16.278 & 26.752 & 23.347 & 38.097 \\
6 & 19.689 & 32.395 & 17.621 & 29.052 & 15.122 & 24.795 \\
7 & 7.782 & 12.808 & 29.032 & 49.740 & 9.299 & 16.977 \\
8 & 63.498 & 104.388 & 44.377 & 70.463 & 41.186 & 64.738 \\
9 & 76.308 & 125.489 & 54.167 & 76.865 & 49.770 & 65.262 \\
10 & 170.189 & 277.570 & 168.125 & 262.525 & 147.141 & 222.746 \\
11 & 183.621 & 309.666 & 185.790 & 300.414 & 161.863 & 255.791 \\
12 & 214.733 & 358.667 & 201.707 & 323.703 & 236.084 & 369.915 \\
13 & 58.490 & 96.235 & 50.797 & 83.264 & 44.204 & 71.760 \\
14 & 39.623 & 65.193 & 22.447 & 36.748 & 19.224 & 31.278 \\
15 & 32.802 & 53.970 & 44.098 & 72.529 & 37.909 & 61.788 \\
16 & 127.464 & 208.623 & 107.665 & 167.016 & 130.368 & 195.845 \\
17 & 105.457 & 170.818 & 99.571 & 150.911 & 89.168 & 130.707 \\
18 & 96.677 & 149.799 & 88.687 & 129.254 & 78.969 & 110.480 \\
\hline
\end{tabular}

Table A.16 Stress Values for specific points, for type of bone 2 at $70^{\circ}$

\begin{tabular}{ccccccc}
\hline \multirow{2}{*}{ Points } & \multicolumn{2}{c}{ FEM } & \multicolumn{2}{c}{ RPIM } & \multicolumn{2}{c}{ NNRPIM } \\
\cline { 2 - 7 } & $M 1$ & $M 2$ & $M 1$ & $M 2$ & $M 1$ & $M 2$ \\
\hline 1 & 63.140 & 103.592 & 44.777 & 62.871 & 41.383 & 53.415 \\
2 & 45.493 & 74.528 & 32.296 & 49.390 & 29.259 & 44.172 \\
3 & 7.227 & 11.870 & 28.814 & 50.747 & 7.636 & 13.985 \\
4 & 24.840 & 40.869 & 23.212 & 38.081 & 19.801 & 32.212 \\
5 & 31.818 & 52.351 & 17.010 & 27.969 & 24.468 & 39.961 \\
6 & 20.913 & 34.408 & 19.305 & 31.808 & 16.481 & 27.001 \\
7 & 5.263 & 8.668 & 18.314 & 31.023 & 6.362 & 11.465 \\
8 & 43.342 & 71.319 & 30.148 & 48.187 & 28.139 & 44.485 \\
9 & 49.899 & 82.125 & 35.397 & 50.539 & 32.500 & 43.020 \\
10 & 131.605 & 216.414 & 131.277 & 207.157 & 114.568 & 175.444 \\
11 & 141.674 & 240.347 & 144.655 & 235.980 & 125.524 & 200.442 \\
12 & 164.599 & 275.703 & 157.166 & 253.335 & 182.956 & 288.350 \\
13 & 56.383 & 92.767 & 50.286 & 82.531 & 42.111 & 68.533 \\
14 & 39.824 & 65.524 & 20.603 & 33.790 & 19.288 & 31.445 \\
15 & 37.927 & 62.401 & 45.353 & 74.633 & 37.278 & 60.896 \\
16 & 70.201 & 113.297 & 55.742 & 84.322 & 68.701 & 100.256 \\
17 & 57.453 & 90.834 & 51.614 & 74.876 & 47.032 & 65.536 \\
18 & 52.529 & 79.413 & 45.740 & 64.508 & 41.052 & 54.903 \\
\hline
\end{tabular}


Table A.17 Stress Values for specific points, for type of bone 2 at $80^{\circ}$

\begin{tabular}{|c|c|c|c|c|c|c|}
\hline \multirow{2}{*}{ Points } & \multicolumn{2}{|c|}{ FEM } & \multicolumn{2}{|c|}{ RPIM } & \multicolumn{2}{|c|}{ NNRPIM } \\
\hline & M1 & $M 2$ & M1 & $M 2$ & M1 & $M 2$ \\
\hline 1 & 35.936 & 58.911 & 25.427 & 35.747 & 23.607 & 30.546 \\
\hline 2 & 24.450 & 39.994 & 17.446 & 25.953 & 15.603 & 22.738 \\
\hline 3 & 4.718 & 7.748 & 18.087 & 32.069 & 4.700 & 8.425 \\
\hline 4 & 24.228 & 39.863 & 22.840 & 37.514 & 19.449 & 31.701 \\
\hline 5 & 32.872 & 54.085 & 17.470 & 28.735 & 25.172 & 41.130 \\
\hline 6 & 22.168 & 36.473 & 20.816 & 34.265 & 17.725 & 28.996 \\
\hline 7 & 3.035 & 5.004 & 7.994 & 13.057 & 3.550 & 6.071 \\
\hline 8 & 22.275 & 36.749 & 15.264 & 24.721 & 14.465 & 23.060 \\
\hline 9 & 22.253 & 36.737 & 15.700 & 23.105 & 14.427 & 19.994 \\
\hline 10 & 89.235 & 149.088 & 90.587 & 145.824 & 78.623 & 123.030 \\
\hline 11 & 95.613 & 164.035 & 99.245 & 164.577 & 85.474 & 139.160 \\
\hline 12 & 109.573 & 184.494 & 107.993 & 175.470 & 124.390 & 198.197 \\
\hline 13 & 53.017 & 87.230 & 49.376 & 81.129 & 40.113 & 65.435 \\
\hline 14 & 39.954 & 65.737 & 19.304 & 31.710 & 19.329 & 31.553 \\
\hline 15 & 43.415 & 71.431 & 46.765 & 76.951 & 37.482 & 61.285 \\
\hline 16 & 14.677 & 20.759 & 13.236 & 20.772 & 13.314 & 19.964 \\
\hline 17 & 14.848 & 23.808 & 11.637 & 21.086 & 10.037 & 16.662 \\
\hline 18 & 14.734 & 25.833 & 12.297 & 25.487 & 9.779 & 19.128 \\
\hline
\end{tabular}

Table A.18 Stress Values for specific points, for type of bone 2 at $90^{\circ}$

\begin{tabular}{|c|c|c|c|c|c|c|}
\hline \multirow{2}{*}{ Points } & \multicolumn{2}{|c|}{ FEM } & \multicolumn{2}{|c|}{ RPIM } & \multicolumn{2}{|c|}{ NNRPIM } \\
\hline & M1 & $M 2$ & M1 & $M 2$ & M1 & $M 2$ \\
\hline 1 & 8.910 & 14.618 & 6.008 & 9.541 & 5.920 & 9.022 \\
\hline 2 & 7.188 & 11.845 & 4.815 & 6.243 & 4.349 & 4.935 \\
\hline 3 & 2.707 & 4.450 & 7.816 & 13.913 & 2.495 & 3.985 \\
\hline 4 & 23.311 & 38.354 & 22.024 & 36.214 & 18.741 & 30.604 \\
\hline 5 & 33.231 & 54.675 & 17.628 & 28.997 & 25.413 & 41.529 \\
\hline 6 & 23.311 & 38.354 & 22.024 & 36.214 & 18.741 & 30.604 \\
\hline 7 & 2.707 & 4.450 & 7.816 & 13.913 & 2.495 & 3.985 \\
\hline 8 & 7.188 & 11.845 & 4.815 & 6.243 & 4.349 & 4.935 \\
\hline 9 & 8.910 & 14.618 & 6.008 & 9.541 & 5.920 & 9.022 \\
\hline 10 & 45.000 & 78.729 & 47.698 & 81.184 & 40.715 & 67.652 \\
\hline 11 & 47.433 & 83.955 & 51.300 & 88.916 & 43.248 & 74.249 \\
\hline 12 & 51.719 & 88.304 & 56.101 & 93.045 & 62.555 & 102.729 \\
\hline 13 & 48.596 & 79.955 & 48.160 & 79.203 & 38.486 & 62.890 \\
\hline 14 & 40.000 & 65.812 & 18.832 & 30.956 & 19.344 & 31.591 \\
\hline 15 & 48.596 & 79.955 & 48.160 & 79.203 & 38.486 & 62.890 \\
\hline 16 & 51.719 & 88.304 & 56.101 & 93.045 & 62.555 & 102.729 \\
\hline 17 & 47.433 & 83.955 & 51.300 & 88.916 & 43.248 & 74.249 \\
\hline 18 & 45.000 & 78.729 & 47.698 & 81.184 & 40.715 & 67.652 \\
\hline
\end{tabular}


Table A.19 Stress Values for specific points, for type of bone 3 at $10^{\circ}$

\begin{tabular}{ccccccc}
\hline \multirow{2}{*}{ Points } & \multicolumn{2}{c}{ FEM } & \multicolumn{2}{c}{ RPIM } & \multicolumn{2}{c}{ NNRPIM } \\
\cline { 2 - 7 } & $M 1$ & $M 2$ & $M 1$ & $M 2$ & $M 1$ & $M 2$ \\
\hline 1 & 192.236 & 315.622 & 131.282 & 187.167 & 119.508 & 158.629 \\
2 & 155.527 & 255.351 & 107.873 & 175.316 & 99.694 & 164.797 \\
3 & 6.358 & 10.469 & 75.374 & 132.795 & 18.041 & 34.128 \\
4 & 18.655 & 30.694 & 15.182 & 24.835 & 12.953 & 20.969 \\
5 & 15.857 & 26.091 & 8.006 & 13.115 & 12.663 & 20.548 \\
6 & 16.226 & 26.698 & 12.304 & 20.157 & 10.691 & 17.337 \\
7 & 6.226 & 10.255 & 73.758 & 129.527 & 18.000 & 33.851 \\
8 & 156.656 & 257.285 & 108.128 & 175.937 & 100.217 & 165.522 \\
9 & 188.997 & 310.374 & 129.078 & 184.481 & 117.477 & 156.552 \\
10 & 266.977 & 429.841 & 259.340 & 400.601 & 229.960 & 347.271 \\
11 & 292.778 & 489.239 & 288.478 & 461.171 & 255.853 & 401.183 \\
12 & 359.088 & 596.726 & 318.888 & 512.925 & 378.803 & 597.653 \\
13 & 42.861 & 70.519 & 40.702 & 66.609 & 48.876 & 79.191 \\
14 & 33.259 & 54.721 & 9.916 & 16.195 & 5.500 & 8.964 \\
15 & 32.086 & 52.792 & 40.626 & 66.596 & 45.886 & 74.347 \\
16 & 342.159 & 567.529 & 300.359 & 482.065 & 357.818 & 563.137 \\
17 & 277.444 & 461.896 & 271.234 & 431.299 & 241.261 & 376.162 \\
18 & 252.737 & 404.934 & 243.798 & 374.332 & 216.575 & 325.022 \\
\hline
\end{tabular}

Table A.20 Stress Values for specific points, for type of bone 3 at $20^{\circ}$

\begin{tabular}{ccccccc}
\hline \multirow{2}{*}{ Points } & \multicolumn{2}{c}{ FEM } & \multicolumn{2}{c}{ RPIM } & \multicolumn{2}{c}{ NNRPIM } \\
\cline { 2 - 7 } & $M 1$ & $M 2$ & $M 1$ & $M 2$ & $M 1$ & $M 2$ \\
\hline 1 & 185.093 & 303.859 & 126.395 & 179.973 & 115.074 & 152.436 \\
2 & 147.857 & 242.715 & 102.816 & 166.982 & 94.873 & 156.888 \\
3 & 6.157 & 10.135 & 72.767 & 128.409 & 17.246 & 32.720 \\
4 & 20.186 & 33.211 & 17.276 & 28.276 & 14.483 & 23.466 \\
5 & 18.126 & 29.823 & 8.812 & 14.451 & 14.159 & 23.021 \\
6 & 15.754 & 25.920 & 12.238 & 20.096 & 10.449 & 17.003 \\
7 & 5.898 & 9.716 & 69.586 & 121.974 & 17.167 & 32.174 \\
8 & 150.080 & 246.526 & 103.317 & 168.205 & 95.902 & 158.316 \\
9 & 178.712 & 293.521 & 122.054 & 174.681 & 111.073 & 148.343 \\
10 & 262.027 & 422.899 & 255.393 & 395.686 & 226.253 & 342.726 \\
11 & 287.216 & 480.821 & 284.062 & 455.291 & 251.577 & 395.572 \\
12 & 351.277 & 584.276 & 313.750 & 505.190 & 372.159 & 587.880 \\
13 & 47.747 & 78.559 & 43.243 & 70.784 & 49.544 & 80.314 \\
14 & 33.947 & 55.853 & 10.810 & 17.685 & 7.324 & 11.939 \\
15 & 27.601 & 45.413 & 43.108 & 70.762 & 43.840 & 71.080 \\
16 & 317.929 & 526.762 & 277.254 & 444.405 & 330.823 & 519.891 \\
17 & 257.015 & 426.968 & 250.094 & 396.453 & 222.832 & 346.287 \\
18 & 233.979 & 373.845 & 224.779 & 343.947 & 199.887 & 298.905 \\
\hline
\end{tabular}


Table A.21 Stress Values for specific points, for type of bone 3 at $30^{\circ}$

\begin{tabular}{ccccccc}
\hline \multirow{2}{*}{ Points } & \multicolumn{2}{c}{ FEM } & \multicolumn{2}{c}{ RPIM } & \multicolumn{2}{c}{ NNRPIM } \\
\cline { 2 - 7 } & $M 1$ & $M 2$ & $M 1$ & $M 2$ & $M 1$ & $M 2$ \\
\hline 1 & 172.327 & 282.866 & 117.666 & 167.311 & 107.143 & 141.615 \\
2 & 135.706 & 222.726 & 94.639 & 153.574 & 87.173 & 144.209 \\
3 & 5.784 & 9.521 & 67.965 & 120.141 & 15.936 & 30.325 \\
4 & 21.657 & 35.633 & 19.367 & 31.723 & 15.983 & 25.927 \\
5 & 21.135 & 34.773 & 9.921 & 16.286 & 16.185 & 26.363 \\
6 & 15.951 & 26.245 & 13.220 & 21.754 & 10.952 & 17.884 \\
7 & 5.409 & 8.912 & 63.316 & 110.739 & 15.819 & 29.528 \\
8 & 138.955 & 228.294 & 95.372 & 155.361 & 88.677 & 146.298 \\
9 & 163.000 & 267.756 & 111.320 & 159.576 & 101.294 & 135.633 \\
10 & 249.135 & 403.152 & 243.697 & 378.789 & 215.677 & 327.791 \\
11 & 272.953 & 457.839 & 271.025 & 435.602 & 239.663 & 377.958 \\
12 & 332.799 & 554.078 & 299.100 & 482.135 & 354.220 & 560.262 \\
13 & 51.744 & 85.134 & 46.845 & 76.736 & 49.564 & 80.411 \\
14 & 34.973 & 57.542 & 12.052 & 19.751 & 9.459 & 15.420 \\
15 & 25.144 & 41.370 & 46.678 & 76.708 & 41.700 & 67.693 \\
16 & 284.056 & 470.008 & 245.764 & 393.300 & 293.804 & 460.887 \\
17 & 228.819 & 379.142 & 221.379 & 349.610 & 197.650 & 305.926 \\
18 & 208.144 & 331.470 & 198.954 & 303.186 & 177.141 & 263.749 \\
\hline
\end{tabular}

Table A.22 Stress Values for specific points, for type of bone 3 at $40^{\circ}$

\begin{tabular}{ccccccc}
\hline \multirow{2}{*}{ Points } & \multicolumn{2}{c}{ FEM } & \multicolumn{2}{c}{ RPIM } & \multicolumn{2}{c}{ NNRPIM } \\
\cline { 2 - 7 } & $M 1$ & $M 2$ & $M 1$ & $M 2$ & $M 1$ & $M 2$ \\
\hline 1 & 154.343 & 253.307 & 105.369 & 149.580 & 95.964 & 126.508 \\
2 & 119.460 & 196.014 & 83.599 & 135.512 & 76.835 & 127.158 \\
3 & 5.257 & 8.650 & 61.120 & 108.258 & 14.152 & 27.023 \\
4 & 22.921 & 37.712 & 21.240 & 34.819 & 17.302 & 28.104 \\
5 & 24.322 & 40.018 & 11.132 & 18.288 & 18.368 & 29.959 \\
6 & 16.774 & 27.599 & 14.945 & 24.619 & 12.053 & 19.726 \\
7 & 4.781 & 7.878 & 55.152 & 96.183 & 14.003 & 25.999 \\
8 & 123.635 & 203.169 & 84.542 & 137.809 & 78.769 & 129.842 \\
9 & 142.355 & 233.887 & 97.212 & 139.638 & 88.446 & 118.822 \\
10 & 228.711 & 371.234 & 224.628 & 350.456 & 198.571 & 302.945 \\
11 & 250.446 & 421.031 & 249.784 & 402.735 & 220.493 & 348.906 \\
12 & 304.243 & 507.091 & 275.409 & 444.500 & 325.559 & 515.679 \\
13 & 54.609 & 89.848 & 50.904 & 83.459 & 48.938 & 79.477 \\
14 & 36.194 & 59.550 & 13.419 & 22.022 & 11.551 & 18.832 \\
15 & 25.620 & 42.154 & 50.729 & 83.429 & 39.734 & 64.612 \\
16 & 241.604 & 399.047 & 206.889 & 330.371 & 247.927 & 387.984 \\
17 & 193.756 & 319.946 & 185.994 & 292.256 & 166.507 & 256.354 \\
18 & 176.052 & 279.166 & 167.141 & 253.355 & 149.052 & 220.674 \\
\hline
\end{tabular}


Table A.23 Stress Values for specific points, for type of bone 3 at $50^{\circ}$

\begin{tabular}{ccccccc}
\hline \multirow{2}{*}{ Points } & \multicolumn{2}{c}{ FEM } & \multicolumn{2}{c}{ RPIM } & \multicolumn{2}{c}{ NNRPIM } \\
\cline { 2 - 7 } & $M 1$ & $M 2$ & $M 1$ & $M 2$ & $M 1$ & $M 2$ \\
\hline 1 & 131.702 & 216.107 & 89.888 & 127.335 & 81.888 & 107.591 \\
2 & 99.634 & 163.430 & 70.046 & 113.361 & 64.186 & 106.266 \\
3 & 4.597 & 7.562 & 52.455 & 93.138 & 11.956 & 22.920 \\
4 & 23.868 & 39.269 & 22.748 & 37.317 & 18.336 & 29.819 \\
5 & 27.307 & 44.929 & 12.289 & 20.201 & 20.435 & 33.360 \\
6 & 18.046 & 29.691 & 17.019 & 28.041 & 13.495 & 22.102 \\
7 & 4.044 & 6.665 & 45.362 & 78.779 & 11.780 & 21.704 \\
8 & 104.603 & 171.946 & 71.168 & 116.097 & 66.488 & 109.463 \\
9 & 117.426 & 192.979 & 80.171 & 115.494 & 72.933 & 98.437 \\
10 & 201.402 & 328.159 & 198.786 & 311.584 & 175.472 & 268.974 \\
11 & 220.410 & 371.563 & 221.008 & 357.727 & 194.669 & 309.329 \\
12 & 266.503 & 444.786 & 243.424 & 393.472 & 287.077 & 455.533 \\
13 & 56.187 & 92.445 & 54.882 & 90.058 & 47.717 & 77.592 \\
14 & 37.448 & 61.614 & 14.735 & 24.204 & 13.423 & 21.885 \\
15 & 28.832 & 47.438 & 54.719 & 90.030 & 38.222 & 62.278 \\
16 & 191.918 & 316.121 & 161.891 & 257.652 & 194.659 & 303.508 \\
17 & 152.966 & 251.312 & 145.073 & 226.243 & 130.397 & 199.165 \\
18 & 138.738 & 218.648 & 130.361 & 196.097 & 116.518 & 171.080 \\
\hline
\end{tabular}

Table A.24 Stress Values for specific points, for type of bone 3 at $60^{\circ}$

\begin{tabular}{ccccccc}
\hline \multirow{2}{*}{ Points } & \multicolumn{2}{c}{ FEM } & \multicolumn{2}{c}{ RPIM } & \multicolumn{2}{c}{ NNRPIM } \\
\cline { 2 - 7 } & $M 1$ & $M 2$ & $M 1$ & $M 2$ & $M 1$ & $M 2$ \\
\hline 1 & 105.080 & 172.375 & 71.680 & 101.237 & 65.331 & 85.429 \\
2 & 76.838 & 125.974 & 54.388 & 87.779 & 49.607 & 82.150 \\
3 & 3.838 & 6.311 & 42.242 & 75.252 & 9.423 & 18.149 \\
4 & 24.425 & 40.187 & 23.792 & 39.057 & 19.014 & 30.959 \\
5 & 29.843 & 49.100 & 13.286 & 21.847 & 22.204 & 36.269 \\
6 & 19.545 & 32.157 & 19.124 & 31.501 & 15.035 & 24.619 \\
7 & 3.245 & 5.349 & 34.267 & 59.094 & 9.225 & 16.783 \\
8 & 82.442 & 135.577 & 55.654 & 90.869 & 52.205 & 85.763 \\
9 & 88.961 & 146.263 & 60.702 & 87.865 & 55.217 & 75.098 \\
10 & 168.029 & 275.229 & 166.942 & 263.349 & 147.067 & 226.895 \\
11 & 183.751 & 310.931 & 185.554 & 301.921 & 162.959 & 260.409 \\
12 & 220.703 & 369.010 & 204.107 & 330.578 & 239.920 & 381.613 \\
13 & 56.402 & 92.798 & 58.367 & 95.848 & 46.010 & 74.919 \\
14 & 38.591 & 63.493 & 15.873 & 26.091 & 14.971 & 24.409 \\
15 & 33.705 & 55.454 & 58.232 & 95.825 & 37.406 & 61.068 \\
16 & 136.536 & 223.772 & 112.243 & 177.518 & 135.685 & 210.124 \\
17 & 107.794 & 175.528 & 99.924 & 153.735 & 90.458 & 136.202 \\
18 & 97.415 & 151.960 & 89.800 & 133.391 & 80.566 & 116.612 \\
\hline
\end{tabular}


Table A. 25 Stress Values for specific points, for type of bone 3 at $70^{\circ}$

\begin{tabular}{ccccccc}
\hline \multirow{2}{*}{ Points } & \multicolumn{2}{c}{ FEM } & \multicolumn{2}{c}{ RPIM } & \multicolumn{2}{c}{ NNRPIM } \\
\cline { 2 - 7 } & $M 1$ & $M 2$ & $M 1$ & $M 2$ & $M 1$ & $M 2$ \\
\hline 1 & 75.330 & 123.515 & 51.319 & 72.121 & 46.819 & 60.744 \\
2 & 51.863 & 84.946 & 37.146 & 59.588 & 33.580 & 55.577 \\
3 & 3.034 & 4.987 & 30.846 & 55.220 & 6.661 & 12.891 \\
4 & 24.554 & 40.398 & 24.312 & 39.936 & 19.296 & 31.453 \\
5 & 31.761 & 52.256 & 14.046 & 23.103 & 23.549 & 38.478 \\
6 & 21.062 & 34.654 & 21.033 & 34.630 & 16.485 & 26.977 \\
7 & 2.468 & 4.067 & 22.328 & 37.920 & 6.452 & 11.435 \\
8 & 57.898 & 95.289 & 38.513 & 62.933 & 36.387 & 59.490 \\
9 & 57.907 & 95.292 & 39.435 & 57.659 & 35.876 & 49.589 \\
10 & 129.671 & 214.177 & 130.115 & 207.321 & 114.258 & 178.064 \\
11 & 141.668 & 241.114 & 144.553 & 237.104 & 126.372 & 203.705 \\
12 & 168.298 & 282.159 & 158.727 & 257.843 & 185.594 & 296.268 \\
13 & 55.243 & 90.891 & 61.052 & 100.321 & 43.978 & 71.717 \\
14 & 39.498 & 64.986 & 16.744 & 27.534 & 16.124 & 26.289 \\
15 & 39.164 & 64.436 & 60.957 & 100.305 & 37.435 & 61.199 \\
16 & 77.509 & 125.352 & 60.206 & 93.603 & 73.392 & 111.615 \\
17 & 60.279 & 96.166 & 52.457 & 78.120 & 48.303 & 70.237 \\
18 & 53.875 & 82.387 & 47.223 & 68.658 & 42.656 & 59.912 \\
\hline
\end{tabular}

Table A.26 Stress Values for specific points, for type of bone 3 at $80^{\circ}$

\begin{tabular}{ccccccc}
\hline \multirow{2}{*}{ Points } & \multicolumn{2}{c}{ FEM } & \multicolumn{2}{c}{ RPIM } & \multicolumn{2}{c}{ NNRPIM } \\
\cline { 2 - 7 } & $M 1$ & $M 2$ & $M 1$ & $M 2$ & $M 1$ & $M 2$ \\
\hline 1 & 43.491 & 71.240 & 29.480 & 40.995 & 26.978 & 34.444 \\
2 & 25.920 & 42.344 & 19.034 & 29.813 & 16.770 & 27.469 \\
3 & 2.286 & 3.754 & 18.792 & 33.895 & 3.879 & 7.443 \\
4 & 24.244 & 39.888 & 24.278 & 39.905 & 19.162 & 31.269 \\
5 & 32.952 & 54.216 & 14.520 & 23.886 & 24.386 & 39.853 \\
6 & 22.428 & 36.901 & 22.591 & 37.174 & 17.712 & 28.959 \\
7 & 1.888 & 3.108 & 10.593 & 17.081 & 3.686 & 6.046 \\
8 & 32.004 & 52.770 & 20.428 & 33.268 & 19.638 & 31.529 \\
9 & 25.624 & 42.310 & 17.184 & 26.119 & 15.699 & 23.057 \\
10 & 87.651 & 147.153 & 89.532 & 145.439 & 78.124 & 124.125 \\
11 & 95.647 & 164.563 & 99.359 & 165.431 & 86.112 & 141.093 \\
12 & 111.023 & 187.058 & 108.834 & 177.717 & 125.900 & 202.303 \\
13 & 52.763 & 86.811 & 62.730 & 103.131 & 41.837 & 68.322 \\
14 & 40.078 & 65.941 & 17.288 & 28.435 & 16.833 & 27.445 \\
15 & 44.457 & 73.145 & 62.681 & 103.123 & 38.302 & 62.643 \\
16 & 21.320 & 31.592 & 19.254 & 29.627 & 19.812 & 29.335 \\
17 & 20.121 & 32.778 & 14.844 & 26.604 & 12.687 & 21.385 \\
18 & 16.795 & 29.371 & 14.006 & 28.199 & 11.246 & 21.207 \\
\hline
\end{tabular}


Table A.27 Stress Values for specific points, for type of bone 3 at $90^{\circ}$

\begin{tabular}{ccccccc}
\hline \multirow{2}{*}{ Points } & \multicolumn{2}{c}{ FEM } & \multicolumn{2}{c}{ RPIM } & \multicolumn{2}{c}{ NNRPIM } \\
\cline { 2 - 7 } & $M 1$ & $M 2$ & $M 1$ & M2 & M1 & M2 \\
\hline 1 & 12.229 & 20.015 & 7.570 & 10.572 & 7.241 & 9.490 \\
2 & 9.687 & 15.974 & 5.312 & 6.369 & 4.869 & 5.247 \\
3 & 1.807 & 2.969 & 7.862 & 13.842 & 2.088 & 3.224 \\
4 & 23.518 & 38.694 & 23.694 & 38.968 & 18.624 & 30.422 \\
5 & 33.356 & 54.880 & 14.682 & 24.152 & 24.670 & 40.320 \\
6 & 23.518 & 38.694 & 23.694 & 38.968 & 18.624 & 30.422 \\
7 & 1.807 & 2.969 & 7.862 & 13.842 & 2.088 & 3.224 \\
8 & 9.687 & 15.974 & 5.312 & 6.369 & 4.869 & 5.247 \\
9 & 12.229 & 20.015 & 7.570 & 10.572 & 7.241 & 9.490 \\
10 & 44.079 & 77.637 & 46.971 & 80.657 & 40.184 & 67.491 \\
11 & 48.176 & 85.265 & 51.904 & 89.971 & 43.893 & 75.227 \\
12 & 51.482 & 87.732 & 56.802 & 93.841 & 63.468 & 103.687 \\
13 & 49.098 & 80.781 & 63.286 & 104.088 & 39.853 & 65.152 \\
14 & 40.279 & 66.270 & 17.473 & 28.742 & 17.073 & 27.836 \\
15 & 49.098 & 80.781 & 63.286 & 104.088 & 39.853 & 65.152 \\
16 & 51.482 & 87.732 & 56.802 & 93.841 & 63.468 & 103.687 \\
17 & 48.176 & 85.265 & 51.904 & 89.971 & 43.893 & 75.227 \\
18 & 44.079 & 77.637 & 46.971 & 80.657 & 40.184 & 67.491 \\
\hline
\end{tabular}

Table A.28 Stress Values for specific points, for type of bone 4 at $10^{\circ}$

\begin{tabular}{ccccccc}
\hline \multirow{2}{*}{ Points } & \multicolumn{2}{c}{ FEM } & \multicolumn{2}{c}{ RPIM } & \multicolumn{2}{c}{ NNRPIM } \\
\cline { 2 - 7 } & $M 1$ & $M 2$ & $M 1$ & $M 2$ & $M 1$ & $M 2$ \\
\hline 1 & 188.651 & 309.731 & 129.939 & 185.263 & 118.488 & 157.017 \\
2 & 150.715 & 247.401 & 104.881 & 169.523 & 96.814 & 158.696 \\
3 & 7.728 & 12.720 & 73.694 & 129.679 & 18.120 & 34.287 \\
4 & 18.993 & 31.249 & 15.214 & 24.875 & 13.192 & 21.335 \\
5 & 16.193 & 26.643 & 8.703 & 14.251 & 13.235 & 21.459 \\
6 & 16.585 & 27.288 & 12.385 & 20.279 & 10.921 & 17.696 \\
7 & 7.558 & 12.444 & 72.011 & 126.330 & 18.048 & 33.979 \\
8 & 151.518 & 248.802 & 105.007 & 169.993 & 97.194 & 159.305 \\
9 & 185.565 & 304.735 & 127.803 & 182.613 & 116.518 & 154.939 \\
10 & 266.609 & 428.968 & 258.987 & 398.948 & 229.260 & 344.361 \\
11 & 291.940 & 487.587 & 288.201 & 459.929 & 255.037 & 398.610 \\
12 & 356.158 & 591.762 & 317.268 & 509.272 & 376.667 & 592.318 \\
13 & 43.597 & 71.731 & 41.251 & 67.478 & 47.671 & 77.168 \\
14 & 33.923 & 55.815 & 14.808 & 24.184 & 2.611 & 4.198 \\
15 & 32.855 & 54.058 & 40.666 & 66.620 & 45.246 & 73.256 \\
16 & 339.107 & 562.374 & 298.668 & 478.294 & 355.645 & 557.732 \\
17 & 276.550 & 460.157 & 270.950 & 430.042 & 240.452 & 373.589 \\
18 & 252.294 & 403.953 & 243.375 & 372.605 & 215.826 & 322.082 \\
\hline
\end{tabular}


Table A.29 Stress Values for specific points, for type of bone 4 at $20^{\circ}$

\begin{tabular}{ccccccc}
\hline \multirow{2}{*}{ Points } & \multicolumn{2}{c}{ FEM } & \multicolumn{2}{c}{ RPIM } & \multicolumn{2}{c}{ NNRPIM } \\
\cline { 2 - 7 } & $M 1$ & $M 2$ & $M 1$ & $M 2$ & $M 1$ & $M 2$ \\
\hline 1 & 181.592 & 298.107 & 125.079 & 178.138 & 114.069 & 150.898 \\
2 & 143.428 & 235.399 & 100.026 & 161.532 & 92.198 & 151.126 \\
3 & 7.482 & 12.314 & 71.197 & 125.475 & 17.338 & 32.888 \\
4 & 20.478 & 33.693 & 17.214 & 28.159 & 14.701 & 23.797 \\
5 & 18.391 & 30.260 & 9.516 & 15.599 & 14.662 & 23.822 \\
6 & 16.072 & 26.444 & 12.227 & 20.071 & 10.639 & 17.302 \\
7 & 7.148 & 11.770 & 67.883 & 118.881 & 17.198 & 32.281 \\
8 & 145.012 & 238.159 & 100.274 & 162.457 & 92.946 & 152.326 \\
9 & 175.514 & 288.265 & 120.871 & 172.918 & 110.188 & 146.805 \\
10 & 261.714 & 422.120 & 255.090 & 394.144 & 225.609 & 339.964 \\
11 & 286.440 & 479.280 & 283.798 & 454.110 & 250.792 & 393.114 \\
12 & 348.539 & 579.632 & 312.235 & 501.757 & 370.135 & 582.818 \\
13 & 48.413 & 79.654 & 43.330 & 70.897 & 48.125 & 77.943 \\
14 & 34.536 & 56.823 & 14.563 & 23.793 & 3.749 & 6.071 \\
15 & 28.284 & 46.537 & 42.278 & 69.355 & 43.504 & 70.491 \\
16 & 314.951 & 521.740 & 275.598 & 440.737 & 328.726 & 514.692 \\
17 & 256.127 & 425.254 & 249.818 & 395.240 & 222.062 & 343.828 \\
18 & 233.518 & 372.851 & 224.339 & 342.260 & 199.147 & 296.082 \\
\hline
\end{tabular}

Table A.30 Stress Values for specific points, for type of bone 4 at $30^{\circ}$

\begin{tabular}{ccccccc}
\hline \multirow{2}{*}{ Points } & \multicolumn{2}{c}{ FEM } & \multicolumn{2}{c}{ RPIM } & \multicolumn{2}{c}{ NNRPIM } \\
\cline { 2 - 7 } & $M 1$ & $M 2$ & $M 1$ & $M 2$ & $M 1$ & $M 2$ \\
\hline 1 & 169.017 & 277.427 & 116.417 & 165.601 & 106.183 & 140.199 \\
2 & 131.796 & 216.264 & 92.137 & 148.633 & 84.784 & 138.962 \\
3 & 7.024 & 11.558 & 66.551 & 117.479 & 16.038 & 30.498 \\
4 & 21.894 & 36.023 & 19.196 & 31.427 & 16.174 & 26.215 \\
5 & 21.324 & 35.085 & 10.642 & 17.465 & 16.612 & 27.044 \\
6 & 16.198 & 26.652 & 13.065 & 21.496 & 11.085 & 18.098 \\
7 & 6.538 & 10.769 & 61.709 & 107.843 & 15.833 & 29.612 \\
8 & 134.110 & 220.298 & 92.500 & 149.986 & 85.877 & 140.716 \\
9 & 160.132 & 263.041 & 110.265 & 157.971 & 100.511 & 134.217 \\
10 & 248.884 & 402.488 & 243.453 & 377.403 & 215.109 & 325.259 \\
11 & 272.260 & 456.449 & 270.781 & 434.514 & 238.933 & 375.687 \\
12 & 330.334 & 549.890 & 297.732 & 479.021 & 352.366 & 555.623 \\
13 & 52.317 & 86.077 & 46.153 & 75.570 & 48.003 & 77.810 \\
14 & 35.453 & 58.332 & 14.178 & 23.179 & 5.015 & 8.144 \\
15 & 25.633 & 42.175 & 44.820 & 73.616 & 41.638 & 67.557 \\
16 & 281.239 & 465.267 & 244.189 & 389.840 & 291.842 & 456.046 \\
17 & 227.960 & 377.497 & 221.116 & 348.475 & 196.941 & 303.652 \\
18 & 207.678 & 330.493 & 198.510 & 301.586 & 176.431 & 261.129 \\
\hline
\end{tabular}


Table A.31 Stress Values for specific points, for type of bone 4 at $40^{\circ}$

\begin{tabular}{ccccccc}
\hline \multirow{2}{*}{ Points } & \multicolumn{2}{c}{ FEM } & \multicolumn{2}{c}{ RPIM } & \multicolumn{2}{c}{ NNRPIM } \\
\cline { 2 - 7 } & $M 1$ & $M 2$ & $M 1$ & $M 2$ & $M 1$ & $M 2$ \\
\hline 1 & 151.322 & 248.344 & 104.224 & 148.048 & 95.079 & 125.257 \\
2 & 116.186 & 190.602 & 81.461 & 131.231 & 74.806 & 122.585 \\
3 & 6.372 & 10.483 & 59.905 & 105.946 & 14.262 & 27.196 \\
4 & 23.099 & 38.005 & 20.960 & 34.344 & 17.462 & 28.343 \\
5 & 24.446 & 40.221 & 11.878 & 19.511 & 18.729 & 30.536 \\
6 & 16.936 & 27.866 & 14.642 & 24.121 & 12.132 & 19.857 \\
7 & 5.754 & 9.479 & 53.689 & 93.571 & 13.999 & 26.058 \\
8 & 119.159 & 195.785 & 81.928 & 132.970 & 76.211 & 124.840 \\
9 & 139.902 & 229.854 & 96.317 & 138.241 & 87.788 & 117.570 \\
10 & 228.531 & 370.704 & 224.450 & 349.264 & 198.095 & 300.719 \\
11 & 249.853 & 419.828 & 249.566 & 401.769 & 219.839 & 346.889 \\
12 & 302.123 & 503.482 & 274.225 & 441.793 & 323.928 & 511.600 \\
13 & 55.075 & 90.616 & 49.287 & 80.775 & 47.316 & 76.784 \\
14 & 36.547 & 60.131 & 13.692 & 22.404 & 6.226 & 10.122 \\
15 & 25.847 & 42.526 & 47.867 & 78.696 & 39.875 & 64.814 \\
16 & 239.029 & 394.725 & 205.435 & 327.214 & 246.154 & 383.640 \\
17 & 192.944 & 318.408 & 185.749 & 291.225 & 165.878 & 254.331 \\
18 & 175.594 & 278.232 & 166.704 & 251.887 & 148.394 & 218.334 \\
\hline
\end{tabular}

Table A.32 Stress Values for specific points, for type of bone 4 at $50^{\circ}$

\begin{tabular}{ccccccc}
\hline \multirow{2}{*}{ Points } & \multicolumn{2}{c}{ FEM } & \multicolumn{2}{c}{ RPIM } & \multicolumn{2}{c}{ NNRPIM } \\
\cline { 2 - 7 } & $M 1$ & $M 2$ & $M 1$ & $M 2$ & $M 1$ & $M 2$ \\
\hline 1 & 129.060 & 211.766 & 88.882 & 126.027 & 81.103 & 106.544 \\
2 & 97.093 & 159.228 & 68.337 & 109.871 & 62.579 & 102.507 \\
3 & 5.553 & 9.133 & 51.474 & 91.245 & 12.070 & 23.089 \\
4 & 23.988 & 39.466 & 22.366 & 36.677 & 18.464 & 30.010 \\
5 & 27.378 & 45.046 & 13.065 & 21.474 & 20.745 & 33.857 \\
6 & 18.129 & 29.829 & 16.592 & 27.341 & 13.534 & 22.172 \\
7 & 4.832 & 7.961 & 44.084 & 76.530 & 11.759 & 21.738 \\
8 & 100.633 & 165.397 & 68.892 & 111.943 & 64.251 & 105.193 \\
9 & 115.459 & 189.746 & 79.462 & 114.347 & 72.419 & 97.390 \\
10 & 201.297 & 327.776 & 198.677 & 310.622 & 175.102 & 267.120 \\
11 & 219.928 & 370.575 & 220.820 & 356.908 & 194.108 & 307.624 \\
12 & 264.788 & 441.860 & 242.456 & 391.246 & 285.713 & 452.130 \\
13 & 56.539 & 93.024 & 52.331 & 85.842 & 46.126 & 74.956 \\
14 & 37.676 & 61.989 & 13.155 & 21.549 & 7.296 & 11.870 \\
15 & 28.835 & 47.442 & 50.995 & 83.888 & 38.455 & 62.638 \\
16 & 189.657 & 312.336 & 160.590 & 254.874 & 193.117 & 299.778 \\
17 & 152.215 & 249.907 & 144.848 & 225.337 & 129.864 & 197.445 \\
18 & 138.301 & 217.782 & 129.943 & 194.801 & 115.930 & 169.087 \\
\hline
\end{tabular}


Table A.33 Stress Values for specific points, for type of bone 4 at $60^{\circ}$

\begin{tabular}{ccccccc}
\hline \multirow{2}{*}{ Points } & \multicolumn{2}{c}{ FEM } & \multicolumn{2}{c}{ RPIM } & \multicolumn{2}{c}{ NNRPIM } \\
\cline { 2 - 7 } & $M 1$ & $M 2$ & $M 1$ & $M 2$ & $M 1$ & $M 2$ \\
\hline 1 & 102.894 & 168.784 & 70.842 & 100.194 & 64.671 & 84.618 \\
2 & 75.104 & 123.104 & 53.160 & 85.189 & 48.470 & 79.320 \\
3 & 4.604 & 7.570 & 41.522 & 73.833 & 9.539 & 18.311 \\
4 & 24.492 & 40.296 & 23.322 & 38.275 & 19.111 & 31.103 \\
5 & 29.874 & 49.152 & 14.091 & 23.169 & 22.476 & 36.707 \\
6 & 19.567 & 32.195 & 18.604 & 30.649 & 15.051 & 24.652 \\
7 & 3.822 & 6.299 & 33.212 & 57.272 & 9.190 & 16.793 \\
8 & 79.095 & 130.060 & 53.787 & 87.529 & 50.358 & 82.355 \\
9 & 87.536 & 143.920 & 60.201 & 87.005 & 54.862 & 74.288 \\
10 & 168.000 & 275.002 & 166.904 & 262.641 & 146.813 & 225.467 \\
11 & 183.387 & 310.173 & 185.399 & 301.268 & 162.506 & 259.063 \\
12 & 219.439 & 366.847 & 203.375 & 328.890 & 238.858 & 378.980 \\
13 & 56.637 & 93.184 & 54.964 & 90.236 & 44.541 & 72.494 \\
14 & 38.708 & 63.686 & 12.629 & 20.714 & 8.176 & 13.306 \\
15 & 33.582 & 55.252 & 53.849 & 88.606 & 37.594 & 61.359 \\
16 & 134.641 & 220.617 & 111.108 & 175.166 & 134.398 & 207.092 \\
17 & 107.103 & 174.256 & 99.713 & 152.954 & 90.029 & 134.822 \\
18 & 97.010 & 151.180 & 89.408 & 132.294 & 80.062 & 115.023 \\
\hline
\end{tabular}

Table A.34 Stress Values for specific points, for type of bone 4 at $70^{\circ}$

\begin{tabular}{ccccccc}
\hline \multirow{2}{*}{ Points } & \multicolumn{2}{c}{ FEM } & \multicolumn{2}{c}{ RPIM } & \multicolumn{2}{c}{ NNRPIM } \\
\cline { 2 - 7 } & $M 1$ & $M 2$ & $M 1$ & $M 2$ & $M 1$ & $M 2$ \\
\hline 1 & 73.660 & 120.773 & 50.675 & 71.376 & 46.302 & 60.197 \\
2 & 50.978 & 83.479 & 36.438 & 57.982 & 32.951 & 53.766 \\
3 & 3.586 & 5.894 & 30.401 & 54.309 & 6.777 & 13.044 \\
4 & 24.576 & 40.435 & 23.773 & 39.042 & 19.364 & 31.554 \\
5 & 31.765 & 52.262 & 14.875 & 24.465 & 23.794 & 38.876 \\
6 & 21.046 & 34.627 & 20.453 & 33.678 & 16.492 & 26.994 \\
7 & 2.824 & 4.654 & 21.525 & 36.580 & 6.409 & 11.428 \\
8 & 55.277 & 90.972 & 37.114 & 60.514 & 34.989 & 57.052 \\
9 & 57.054 & 93.890 & 39.153 & 57.115 & 35.689 & 49.044 \\
10 & 129.717 & 214.107 & 130.146 & 206.881 & 114.127 & 177.100 \\
11 & 141.418 & 240.585 & 144.429 & 236.625 & 126.037 & 202.750 \\
12 & 167.513 & 280.808 & 158.239 & 256.722 & 184.852 & 294.469 \\
13 & 55.362 & 91.087 & 56.944 & 93.555 & 42.722 & 69.648 \\
14 & 39.529 & 65.037 & 12.184 & 20.007 & 8.829 & 14.371 \\
15 & 39.002 & 64.170 & 56.147 & 92.391 & 37.439 & 61.193 \\
16 & 75.996 & 122.856 & 59.190 & 91.628 & 72.327 & 109.282 \\
17 & 59.598 & 94.934 & 52.224 & 77.399 & 47.963 & 69.184 \\
18 & 53.509 & 81.699 & 46.855 & 67.764 & 42.246 & 58.766 \\
\hline
\end{tabular}


Table A.35 Stress Values for specific points, for type of bone 4 at $80^{\circ}$

\begin{tabular}{ccccccc}
\hline \multirow{2}{*}{ Points } & \multicolumn{2}{c}{ FEM } & \multicolumn{2}{c}{ RPIM } & \multicolumn{2}{c}{ NNRPIM } \\
\cline { 2 - 7 } & $M 1$ & $M 2$ & $M 1$ & $M 2$ & $M 1$ & $M 2$ \\
\hline 1 & 42.371 & 69.402 & 29.045 & 40.578 & 26.617 & 34.183 \\
2 & 25.858 & 42.238 & 18.864 & 29.255 & 16.667 & 26.739 \\
3 & 2.614 & 4.293 & 18.617 & 33.500 & 3.991 & 7.588 \\
4 & 24.232 & 39.869 & 23.690 & 38.934 & 19.205 & 31.334 \\
5 & 32.939 & 54.195 & 15.364 & 25.274 & 24.616 & 40.228 \\
6 & 22.395 & 36.846 & 21.980 & 36.171 & 17.722 & 28.979 \\
7 & 2.057 & 3.387 & 10.069 & 16.280 & 3.653 & 6.045 \\
8 & 30.193 & 49.793 & 19.552 & 31.865 & 18.748 & 30.145 \\
9 & 25.310 & 41.794 & 17.118 & 25.918 & 15.670 & 22.812 \\
10 & 87.765 & 147.228 & 89.624 & 145.265 & 78.113 & 123.644 \\
11 & 95.485 & 164.224 & 99.257 & 165.117 & 85.894 & 140.539 \\
12 & 110.712 & 186.521 & 108.573 & 177.152 & 125.471 & 201.353 \\
13 & 52.776 & 86.833 & 58.104 & 95.519 & 40.870 & 66.732 \\
14 & 40.055 & 65.903 & 11.884 & 19.531 & 9.230 & 15.025 \\
15 & 44.318 & 72.917 & 57.691 & 94.915 & 38.015 & 62.166 \\
16 & 20.056 & 29.533 & 18.209 & 28.090 & 18.668 & 27.718 \\
17 & 19.186 & 31.197 & 14.360 & 25.787 & 12.298 & 20.731 \\
18 & 16.577 & 28.990 & 13.781 & 27.869 & 11.060 & 20.985 \\
\hline
\end{tabular}

Table A.36 Stress Values for specific points, for type of bone 4 at $90^{\circ}$

\begin{tabular}{ccccccc}
\hline \multirow{2}{*}{ Points } & \multicolumn{2}{c}{ FEM } & \multicolumn{2}{c}{ RPIM } & \multicolumn{2}{c}{ NNRPIM } \\
\cline { 2 - 7 } & $M 1$ & $M 2$ & $M 1$ & $M 2$ & $M 1$ & $M 2$ \\
\hline 1 & 11.583 & 18.960 & 7.341 & 10.545 & 7.033 & 9.552 \\
2 & 9.115 & 15.031 & 5.263 & 6.435 & 4.790 & 5.204 \\
3 & 1.958 & 3.217 & 7.806 & 13.796 & 2.149 & 3.347 \\
4 & 23.487 & 38.643 & 23.082 & 37.959 & 18.647 & 30.458 \\
5 & 33.338 & 54.850 & 15.531 & 25.549 & 24.895 & 40.688 \\
6 & 23.487 & 38.643 & 23.082 & 37.959 & 18.647 & 30.458 \\
7 & 1.958 & 3.217 & 7.806 & 13.796 & 2.149 & 3.347 \\
8 & 9.115 & 15.031 & 5.263 & 6.435 & 4.790 & 5.204 \\
9 & 11.583 & 18.960 & 7.341 & 10.545 & 7.033 & 9.552 \\
10 & 44.229 & 77.795 & 47.093 & 80.696 & 40.275 & 67.465 \\
11 & 47.978 & 84.924 & 51.781 & 89.748 & 43.763 & 75.023 \\
12 & 51.524 & 87.843 & 56.655 & 93.674 & 63.251 & 103.462 \\
13 & 49.022 & 80.656 & 58.361 & 95.985 & 39.224 & 64.116 \\
14 & 40.237 & 66.202 & 11.779 & 19.364 & 9.365 & 15.245 \\
15 & 49.022 & 80.656 & 58.361 & 95.985 & 39.224 & 64.116 \\
16 & 51.524 & 87.843 & 56.655 & 93.674 & 63.251 & 103.462 \\
17 & 47.978 & 84.924 & 51.781 & 89.748 & 43.763 & 75.023 \\
18 & 44.229 & 77.795 & 47.093 & 80.696 & 40.275 & 67.465 \\
\hline
\end{tabular}


Table A.37 Stress Values for specific points, for type of bone 5 at $10^{\circ}$

\begin{tabular}{ccccccc}
\hline \multirow{2}{*}{ Points } & \multicolumn{2}{c}{ FEM } & \multicolumn{2}{c}{ RPIM } & \multicolumn{2}{c}{ NNRPIM } \\
\cline { 2 - 7 } & $M 1$ & $M 2$ & $M 1$ & $M 2$ & $M 1$ & $M 2$ \\
\hline 1 & 178.395 & 292.883 & 126.030 & 179.904 & 115.710 & 152.746 \\
2 & 137.225 & 225.126 & 96.765 & 153.567 & 89.105 & 141.616 \\
3 & 12.433 & 20.452 & 69.244 & 121.344 & 18.633 & 34.963 \\
4 & 19.694 & 32.403 & 15.592 & 25.457 & 13.730 & 22.151 \\
5 & 16.919 & 27.838 & 10.339 & 16.908 & 14.511 & 23.476 \\
6 & 17.473 & 28.750 & 12.943 & 21.169 & 11.566 & 18.706 \\
7 & 12.104 & 19.915 & 67.372 & 117.752 & 18.435 & 34.517 \\
8 & 137.240 & 225.231 & 96.524 & 153.582 & 89.085 & 141.887 \\
9 & 175.603 & 288.368 & 124.029 & 177.284 & 113.844 & 150.590 \\
10 & 265.553 & 426.355 & 258.090 & 394.256 & 227.184 & 335.741 \\
11 & 289.355 & 482.438 & 287.052 & 455.701 & 252.175 & 390.356 \\
12 & 346.735 & 575.812 & 312.296 & 498.442 & 369.543 & 575.642 \\
13 & 44.881 & 73.844 & 43.202 & 70.587 & 45.680 & 73.771 \\
14 & 35.277 & 58.044 & 26.259 & 42.865 & 15.322 & 24.698 \\
15 & 34.378 & 56.565 & 41.133 & 67.267 & 43.783 & 70.736 \\
16 & 329.429 & 546.035 & 293.535 & 467.197 & 348.450 & 540.924 \\
17 & 273.814 & 454.786 & 269.793 & 425.811 & 237.620 & 365.376 \\
18 & 251.039 & 401.051 & 242.307 & 367.747 & 213.639 & 313.423 \\
\hline
\end{tabular}

Table A.38 Stress Values for specific points, for type of bone 5 at $20^{\circ}$

\begin{tabular}{ccccccc}
\hline \multirow{2}{*}{ Points } & \multicolumn{2}{c}{ FEM } & \multicolumn{2}{c}{ RPIM } & \multicolumn{2}{c}{ NNRPIM } \\
\cline { 2 - 7 } & $M 1$ & $M 2$ & $M 1$ & $M 2$ & $M 1$ & $M 2$ \\
\hline 1 & 171.654 & 281.782 & 121.279 & 173.011 & 111.365 & 146.863 \\
2 & 130.955 & 214.799 & 92.469 & 146.541 & 85.047 & 135.002 \\
3 & 12.049 & 19.819 & 67.045 & 117.643 & 17.895 & 33.606 \\
4 & 21.022 & 34.588 & 17.373 & 28.382 & 15.151 & 24.466 \\
5 & 18.963 & 31.202 & 11.141 & 18.242 & 15.785 & 25.597 \\
6 & 16.934 & 27.863 & 12.640 & 20.729 & 11.252 & 18.276 \\
7 & 11.403 & 18.764 & 63.358 & 110.570 & 17.504 & 32.727 \\
8 & 130.984 & 215.006 & 91.994 & 146.570 & 85.007 & 135.536 \\
9 & 166.154 & 272.887 & 117.339 & 167.849 & 107.689 & 142.617 \\
10 & 260.805 & 419.767 & 254.318 & 389.744 & 223.683 & 331.756 \\
11 & 284.038 & 474.459 & 282.700 & 450.066 & 248.042 & 385.209 \\
12 & 339.668 & 564.597 & 307.559 & 491.538 & 363.362 & 566.959 \\
13 & 49.493 & 81.433 & 44.760 & 73.158 & 45.992 & 74.317 \\
14 & 35.730 & 58.789 & 25.534 & 41.692 & 15.454 & 24.946 \\
15 & 29.745 & 48.943 & 40.932 & 67.022 & 42.381 & 68.546 \\
16 & 305.578 & 505.938 & 270.603 & 429.993 & 321.813 & 498.570 \\
17 & 253.426 & 419.992 & 248.703 & 391.189 & 219.371 & 336.003 \\
18 & 232.217 & 369.927 & 223.230 & 337.534 & 197.002 & 287.796 \\
\hline
\end{tabular}


Table A.39 Stress Values for specific points, for type of bone 5 at $30^{\circ}$

\begin{tabular}{ccccccc}
\hline \multirow{2}{*}{ Points } & \multicolumn{2}{c}{ FEM } & \multicolumn{2}{c}{ RPIM } & \multicolumn{2}{c}{ NNRPIM } \\
\cline { 2 - 7 } & $M 1$ & $M 2$ & $M 1$ & $M 2$ & $M 1$ & $M 2$ \\
\hline 1 & 159.696 & 262.118 & 112.842 & 160.862 & 103.635 & 136.525 \\
2 & 120.718 & 197.964 & 85.370 & 135.066 & 78.409 & 124.287 \\
3 & 11.313 & 18.606 & 62.821 & 110.385 & 16.622 & 31.239 \\
4 & 22.272 & 36.645 & 19.118 & 31.261 & 16.533 & 26.740 \\
5 & 21.725 & 35.745 & 12.267 & 20.115 & 17.558 & 28.542 \\
6 & 16.941 & 27.874 & 13.195 & 21.699 & 11.605 & 18.935 \\
7 & 10.371 & 17.068 & 57.434 & 100.051 & 16.051 & 29.956 \\
8 & 120.760 & 198.267 & 84.674 & 135.108 & 78.352 & 125.068 \\
9 & 151.656 & 249.115 & 107.081 & 153.318 & 98.262 & 130.319 \\
10 & 248.148 & 400.461 & 242.828 & 373.425 & 213.390 & 317.710 \\
11 & 270.105 & 452.088 & 269.763 & 430.769 & 236.376 & 368.367 \\
12 & 322.281 & 536.221 & 293.486 & 469.712 & 346.143 & 541.052 \\
13 & 53.171 & 87.483 & 46.397 & 75.888 & 45.825 & 74.122 \\
14 & 36.412 & 59.911 & 24.379 & 39.825 & 15.654 & 25.321 \\
15 & 26.811 & 44.114 & 41.361 & 67.824 & 40.865 & 66.206 \\
16 & 272.449 & 450.472 & 239.472 & 379.755 & 285.409 & 441.086 \\
17 & 225.365 & 372.484 & 220.072 & 344.715 & 194.469 & 296.446 \\
18 & 206.367 & 327.630 & 197.391 & 297.130 & 174.392 & 253.466 \\
\hline
\end{tabular}

Table A.40 Stress Values for specific points, for type of bone 5 at $40^{\circ}$

\begin{tabular}{ccccccc}
\hline \multirow{2}{*}{ Points } & \multicolumn{2}{c}{ FEM } & \multicolumn{2}{c}{ RPIM } & \multicolumn{2}{c}{ NNRPIM } \\
\cline { 2 - 7 } & $M 1$ & $M 2$ & $M 1$ & $M 2$ & $M 1$ & $M 2$ \\
\hline 1 & 142.899 & 234.510 & 100.982 & 143.843 & 92.764 & 122.057 \\
2 & 106.836 & 175.154 & 75.690 & 119.503 & 69.402 & 109.807 \\
3 & 10.250 & 16.855 & 56.707 & 99.803 & 14.857 & 27.940 \\
4 & 23.318 & 38.366 & 20.651 & 33.803 & 17.739 & 28.739 \\
5 & 24.695 & 40.631 & 13.522 & 22.198 & 19.515 & 31.784 \\
6 & 17.494 & 28.783 & 14.451 & 23.807 & 12.529 & 20.507 \\
7 & 9.046 & 14.890 & 49.790 & 86.531 & 14.126 & 26.293 \\
8 & 106.890 & 175.543 & 74.797 & 119.557 & 69.328 & 110.810 \\
9 & 132.565 & 217.798 & 93.577 & 134.147 & 85.857 & 114.082 \\
10 & 227.987 & 369.060 & 223.988 & 345.825 & 196.635 & 294.057 \\
11 & 248.000 & 416.042 & 248.656 & 398.430 & 217.549 & 340.370 \\
12 & 295.124 & 491.584 & 270.528 & 433.661 & 318.435 & 498.748 \\
13 & 55.691 & 91.630 & 47.918 & 78.451 & 45.196 & 73.207 \\
14 & 37.232 & 61.259 & 22.884 & 37.408 & 15.897 & 25.774 \\
15 & 26.534 & 43.659 & 42.351 & 69.546 & 39.417 & 64.001 \\
16 & 231.078 & 381.370 & 201.121 & 318.066 & 240.382 & 370.275 \\
17 & 190.517 & 313.767 & 184.800 & 287.854 & 163.695 & 247.951 \\
18 & 174.308 & 275.509 & 165.605 & 247.827 & 146.522 & 211.523 \\
\hline
\end{tabular}


Table A.41 Stress Values for specific points, for type of bone 5 at $50^{\circ}$

\begin{tabular}{ccccccc}
\hline \multirow{2}{*}{ Points } & \multicolumn{2}{c}{ FEM } & \multicolumn{2}{c}{ RPIM } & \multicolumn{2}{c}{ NNRPIM } \\
\cline { 2 - 7 } & $M 1$ & $M 2$ & $M 1$ & $M 2$ & $M 1$ & $M 2$ \\
\hline 1 & 121.786 & 199.822 & 86.069 & 122.485 & 79.090 & 103.915 \\
2 & 89.751 & 147.093 & 63.737 & 100.341 & 58.310 & 92.015 \\
3 & 8.899 & 14.631 & 48.901 & 86.236 & 12.661 & 23.818 \\
4 & 24.067 & 39.598 & 21.849 & 35.799 & 18.669 & 30.296 \\
5 & 27.503 & 45.252 & 14.740 & 24.218 & 21.400 & 34.904 \\
6 & 18.480 & 30.406 & 16.117 & 26.565 & 13.814 & 22.638 \\
7 & 7.480 & 12.316 & 40.678 & 70.453 & 11.794 & 21.862 \\
8 & 89.816 & 147.556 & 62.674 & 100.406 & 58.222 & 93.210 \\
9 & 109.477 & 179.916 & 77.248 & 110.937 & 70.863 & 94.421 \\
10 & 200.958 & 326.557 & 198.389 & 307.818 & 173.943 & 261.542 \\
11 & 218.421 & 367.457 & 220.039 & 354.063 & 192.151 & 302.096 \\
12 & 259.047 & 432.079 & 239.405 & 384.516 & 281.104 & 441.370 \\
13 & 56.918 & 93.648 & 49.159 & 80.566 & 44.164 & 71.659 \\
14 & 38.085 & 62.662 & 21.178 & 34.654 & 16.151 & 26.247 \\
15 & 29.020 & 47.748 & 43.750 & 71.923 & 38.229 & 62.225 \\
16 & 182.768 & 300.800 & 156.777 & 246.895 & 188.155 & 288.378 \\
17 & 150.001 & 245.729 & 144.008 & 222.428 & 128.025 & 192.067 \\
18 & 137.075 & 215.266 & 128.891 & 191.247 & 114.277 & 163.330 \\
\hline
\end{tabular}

Table A.42 Stress Values for specific points, for type of bone 5 at $60^{\circ}$

\begin{tabular}{ccccccc}
\hline \multirow{2}{*}{ Points } & \multicolumn{2}{c}{ FEM } & \multicolumn{2}{c}{ RPIM } & \multicolumn{2}{c}{ NNRPIM } \\
\cline { 2 - 7 } & $M 1$ & $M 2$ & $M 1$ & $M 2$ & $M 1$ & $M 2$ \\
\hline 1 & 96.984 & 159.082 & 68.545 & 97.425 & 63.019 & 82.646 \\
2 & 69.986 & 114.641 & 49.873 & 78.156 & 45.471 & 71.442 \\
3 & 7.312 & 12.019 & 39.645 & 70.102 & 10.109 & 19.007 \\
4 & 24.459 & 40.243 & 22.630 & 37.114 & 19.257 & 31.303 \\
5 & 29.905 & 49.202 & 15.800 & 25.974 & 23.032 & 37.602 \\
6 & 19.729 & 32.460 & 17.909 & 29.514 & 15.236 & 24.968 \\
7 & 5.747 & 9.466 & 30.397 & 52.341 & 9.141 & 16.815 \\
8 & 70.059 & 115.163 & 48.673 & 78.229 & 45.372 & 72.791 \\
9 & 83.083 & 136.601 & 58.579 & 84.388 & 53.726 & 71.933 \\
10 & 167.872 & 274.234 & 166.795 & 260.549 & 145.988 & 221.139 \\
11 & 182.252 & 307.785 & 184.762 & 298.988 & 160.936 & 254.681 \\
12 & 215.116 & 359.462 & 201.043 & 323.739 & 235.257 & 370.617 \\
13 & 56.788 & 93.434 & 49.995 & 82.022 & 42.828 & 69.628 \\
14 & 38.870 & 63.953 & 19.439 & 31.848 & 16.386 & 26.684 \\
15 & 33.416 & 54.979 & 45.361 & 74.623 & 37.473 & 61.133 \\
16 & 128.990 & 211.198 & 107.846 & 168.497 & 130.342 & 197.930 \\
17 & 105.112 & 170.565 & 98.976 & 150.532 & 88.572 & 130.569 \\
18 & 95.868 & 148.920 & 88.422 & 129.326 & 78.674 & 110.487 \\
\hline
\end{tabular}


Table A.43 Stress Values for specific points, for type of bone 5 at $70^{\circ}$

\begin{tabular}{ccccccc}
\hline \multirow{2}{*}{ Points } & \multicolumn{2}{c}{ FEM } & \multicolumn{2}{c}{ RPIM } & \multicolumn{2}{c}{ NNRPIM } \\
\cline { 2 - 7 } & $M 1$ & $M 2$ & $M 1$ & $M 2$ & $M 1$ & $M 2$ \\
\hline 1 & 69.282 & 113.588 & 48.960 & 69.470 & 45.061 & 58.947 \\
2 & 48.217 & 78.911 & 34.563 & 53.674 & 31.315 & 48.751 \\
3 & 5.568 & 9.150 & 29.264 & 51.955 & 7.312 & 13.697 \\
4 & 24.465 & 40.252 & 22.946 & 37.666 & 19.465 & 31.693 \\
5 & 31.729 & 52.203 & 16.614 & 27.323 & 24.283 & 39.666 \\
6 & 21.057 & 34.645 & 19.607 & 32.293 & 16.613 & 27.201 \\
7 & 3.979 & 6.557 & 19.380 & 32.943 & 6.295 & 11.372 \\
8 & 48.296 & 79.473 & 33.270 & 53.753 & 31.209 & 50.210 \\
9 & 54.241 & 89.266 & 38.167 & 55.380 & 35.003 & 47.388 \\
10 & 129.795 & 213.794 & 130.212 & 205.547 & 113.656 & 174.143 \\
11 & 140.655 & 238.942 & 143.941 & 234.952 & 124.890 & 199.629 \\
12 & 164.713 & 276.006 & 156.662 & 253.255 & 182.337 & 288.715 \\
13 & 55.309 & 91.001 & 50.349 & 82.681 & 41.330 & 67.329 \\
14 & 39.499 & 64.988 & 17.896 & 29.363 & 16.576 & 27.036 \\
15 & 38.656 & 63.601 & 46.979 & 77.305 & 37.269 & 60.899 \\
16 & 71.651 & 115.681 & 56.362 & 86.147 & 69.123 & 102.400 \\
17 & 57.715 & 91.516 & 51.508 & 75.313 & 46.868 & 66.056 \\
18 & 52.459 & 79.689 & 45.927 & 65.405 & 41.150 & 55.591 \\
\hline
\end{tabular}

Table A.44 Stress Values for specific points, for type of bone 5 at $80^{\circ}$

\begin{tabular}{ccccccc}
\hline \multirow{2}{*}{ Points } & \multicolumn{2}{c}{ FEM } & \multicolumn{2}{c}{ RPIM } & \multicolumn{2}{c}{ NNRPIM } \\
\cline { 2 - 7 } & $M 1$ & $M 2$ & $M 1$ & $M 2$ & $M 1$ & $M 2$ \\
\hline 1 & 39.619 & 64.889 & 27.957 & 39.608 & 25.816 & 33.709 \\
2 & 25.426 & 41.522 & 18.448 & 27.848 & 16.445 & 24.781 \\
3 & 3.809 & 6.258 & 18.206 & 32.541 & 4.471 & 8.199 \\
4 & 24.083 & 39.623 & 22.775 & 37.420 & 19.280 & 31.441 \\
5 & 32.864 & 54.071 & 17.124 & 28.167 & 25.064 & 40.957 \\
6 & 22.303 & 36.695 & 21.051 & 34.645 & 17.804 & 29.117 \\
7 & 2.538 & 4.183 & 8.699 & 14.153 & 3.554 & 6.018 \\
8 & 25.505 & 42.088 & 17.137 & 27.929 & 16.337 & 26.286 \\
9 & 24.110 & 39.825 & 16.774 & 25.159 & 15.431 & 21.965 \\
10 & 88.024 & 147.333 & 89.844 & 144.691 & 78.001 & 122.126 \\
11 & 95.035 & 163.246 & 98.900 & 164.042 & 85.182 & 138.727 \\
12 & 109.458 & 184.358 & 107.719 & 175.357 & 124.049 & 198.289 \\
13 & 52.554 & 86.467 & 50.184 & 82.480 & 39.841 & 65.022 \\
14 & 39.903 & 65.653 & 16.813 & 27.620 & 16.698 & 27.262 \\
15 & 43.926 & 72.272 & 48.414 & 79.657 & 37.650 & 61.557 \\
16 & 16.726 & 24.126 & 15.403 & 24.061 & 15.611 & 23.532 \\
17 & 16.716 & 27.068 & 13.074 & 23.691 & 11.276 & 19.151 \\
18 & 15.823 & 27.750 & 13.210 & 27.126 & 10.639 & 20.651 \\
\hline
\end{tabular}


Table A.45 Stress Values for specific points, for type of bone 5 at $90^{\circ}$

\begin{tabular}{ccccccc}
\hline \multirow{2}{*}{ Points } & \multicolumn{2}{c}{ FEM } & \multicolumn{2}{c}{ RPIM } & \multicolumn{2}{c}{ NNRPIM } \\
\cline { 2 - 7 } & $M 1$ & $M 2$ & $M 1$ & $M 2$ & $M 1$ & $M 2$ \\
\hline 1 & 10.254 & 16.802 & 6.866 & 10.641 & 6.654 & 9.877 \\
2 & 8.082 & 13.329 & 5.256 & 6.806 & 4.765 & 5.387 \\
3 & 2.446 & 4.021 & 7.773 & 13.833 & 2.412 & 3.831 \\
4 & 23.343 & 38.406 & 22.131 & 36.393 & 18.715 & 30.564 \\
5 & 33.249 & 54.705 & 17.298 & 28.455 & 25.330 & 41.396 \\
6 & 23.343 & 38.406 & 22.131 & 36.393 & 18.715 & 30.564 \\
7 & 2.446 & 4.021 & 7.773 & 13.833 & 2.412 & 3.831 \\
8 & 8.082 & 13.329 & 5.256 & 6.806 & 4.765 & 5.387 \\
9 & 10.254 & 16.802 & 6.866 & 10.641 & 6.654 & 9.877 \\
10 & 44.568 & 78.135 & 47.391 & 80.760 & 40.479 & 67.335 \\
11 & 47.541 & 84.151 & 51.452 & 89.100 & 43.415 & 74.407 \\
12 & 51.566 & 87.987 & 56.256 & 93.183 & 62.689 & 102.811 \\
13 & 48.680 & 80.094 & 49.519 & 81.441 & 38.554 & 63.006 \\
14 & 40.043 & 65.883 & 16.421 & 26.990 & 16.741 & 27.341 \\
15 & 48.680 & 80.094 & 49.519 & 81.441 & 38.554 & 63.006 \\
16 & 51.566 & 87.987 & 56.256 & 93.183 & 62.689 & 102.811 \\
17 & 47.541 & 84.151 & 51.452 & 89.100 & 43.415 & 74.408 \\
18 & 44.568 & 78.135 & 47.391 & 80.760 & 40.479 & 67.335 \\
\hline
\end{tabular}




\section{Appendix 4}

In this appendix it is presented the graphs where it is possible to observe how stress varies in function of the value of the angles. The numbers of the title of each graphic correspond to the numbers from the points mentioned in section 6.1. 
1

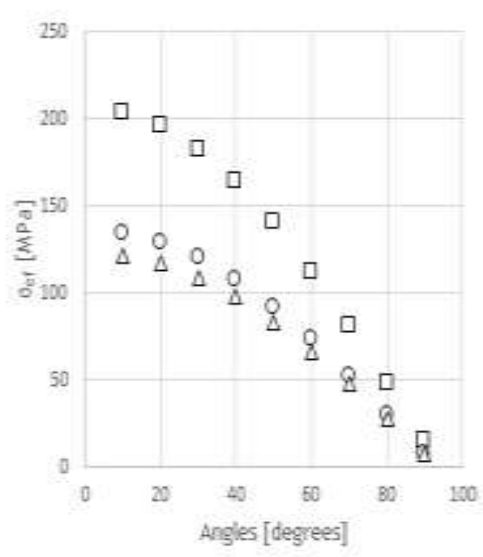

口FEM ORPM $\triangle$ NKRPM

4

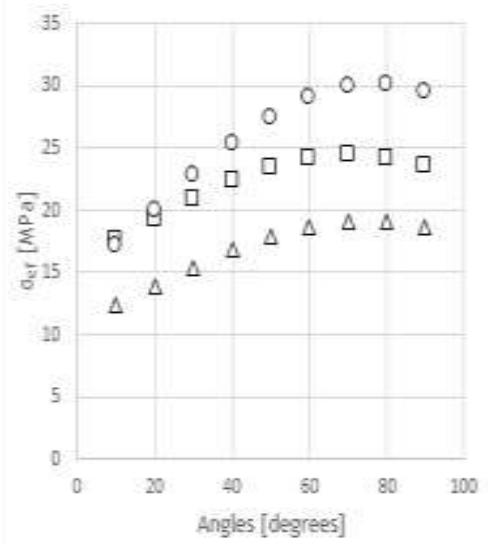

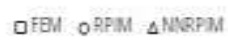

7

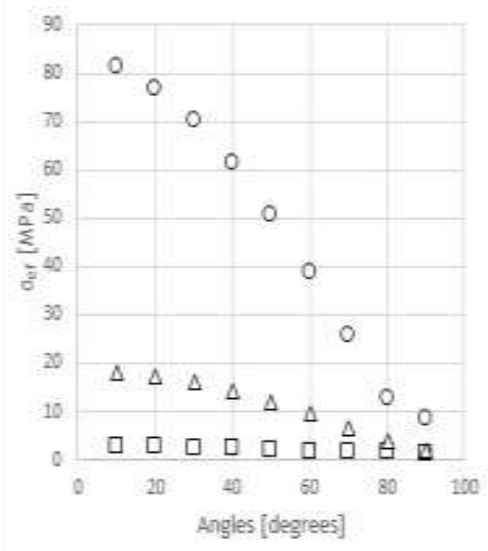

口FEU ORFM A NKEPM
2

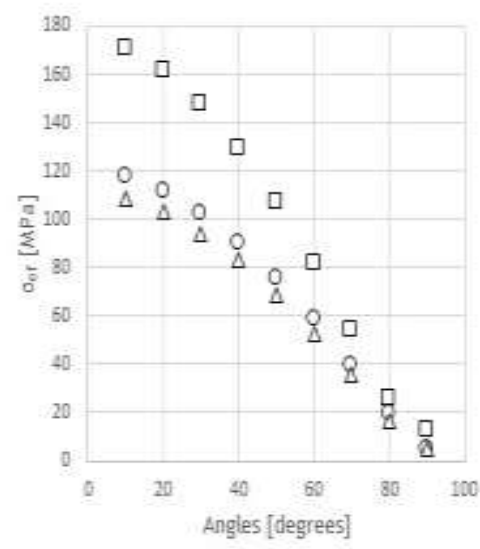

DFEM ORFM ANWRPM

5

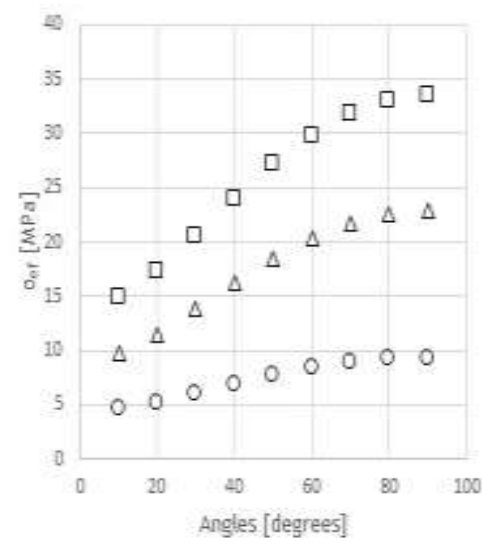

口FEM ORPM $\triangle$ NNAPM

8

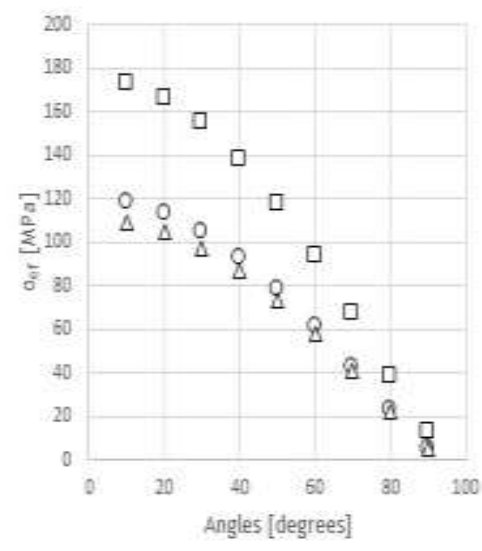

口FEM ORPM ANREPM
3

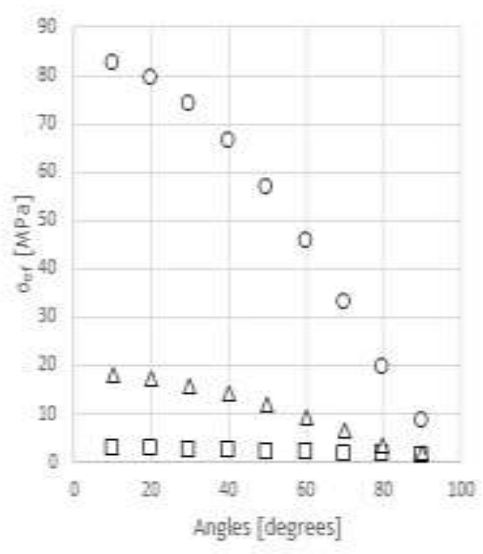

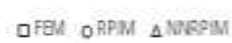

6

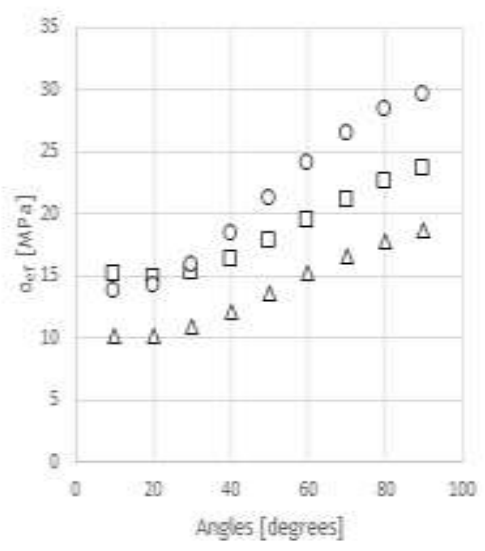

DFEM OBPM A AWEOM

9

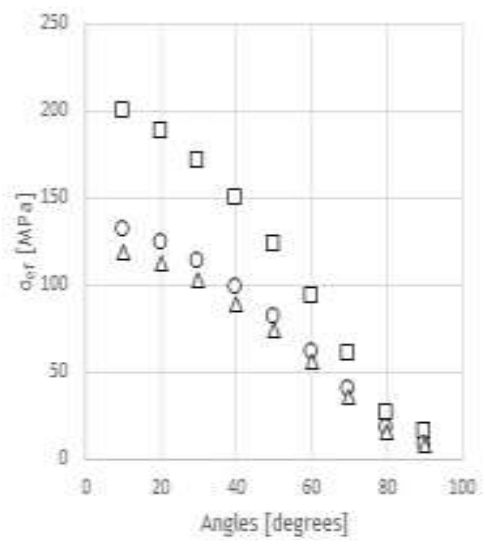

口FEM OREM AXTEPM

Figure A.31 Discrete stress values for type of bone 1, 'Model 1' and from bone side 
10

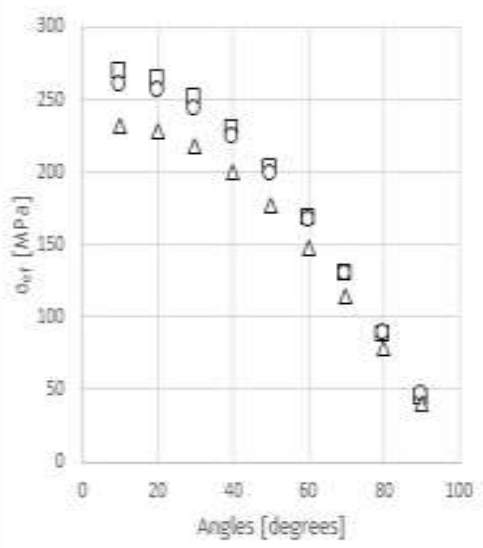

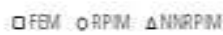

13

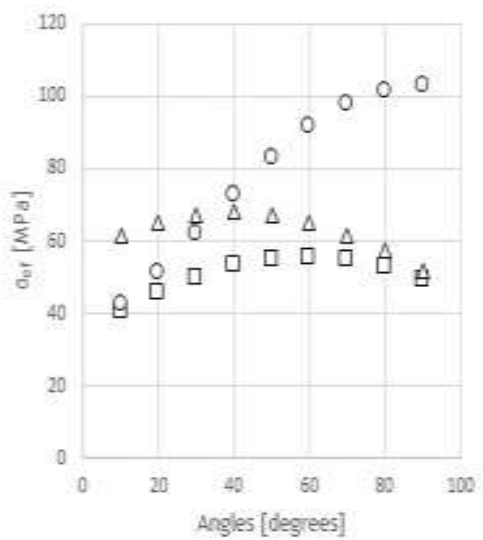

口FEU OROM A Mreaim

16

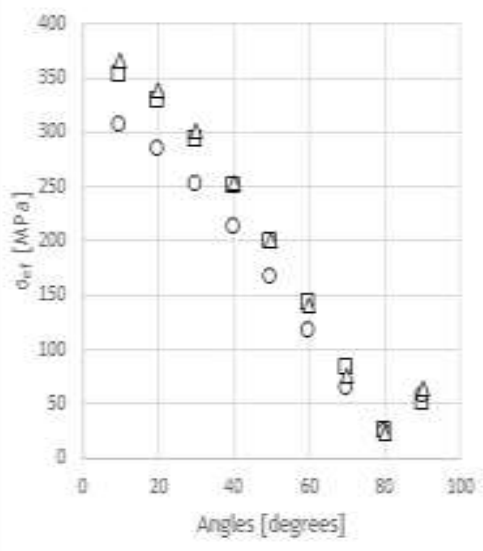

QFEU ORPM ANVOM
11

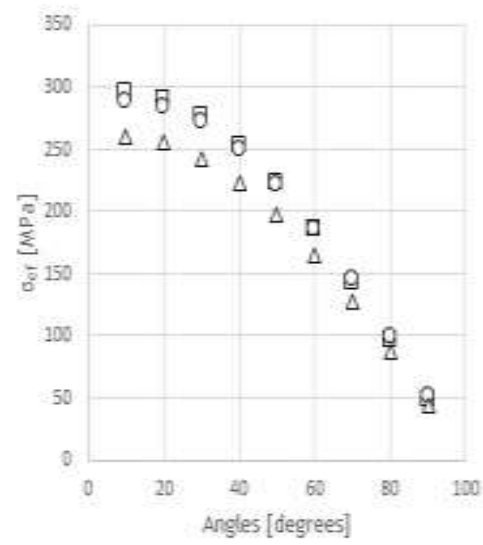

DFEM OPPM $\triangle$ NRAPN

14

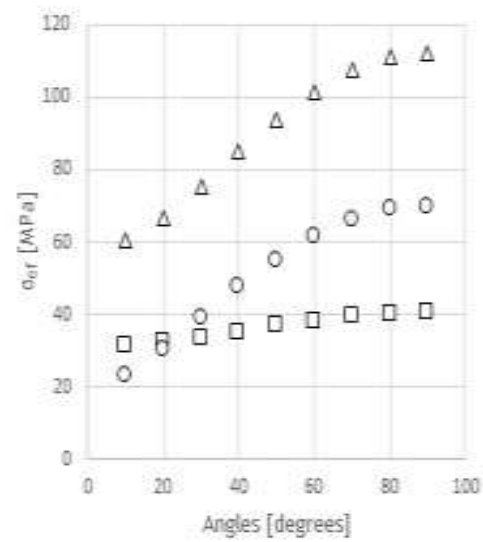

口FEM OPFMM $\triangle$ NREPW

17

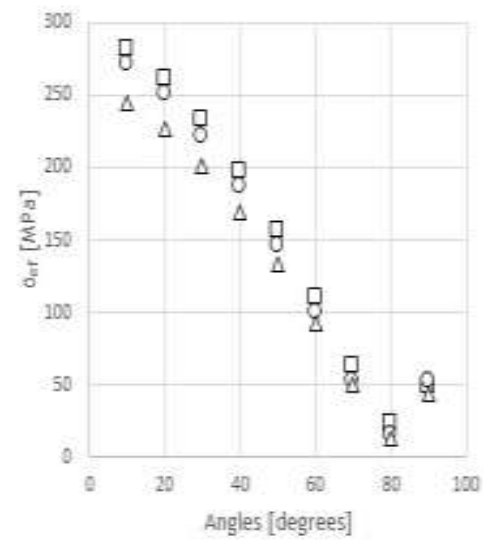

口FEM ORPM $\triangle N$ NAPM
12

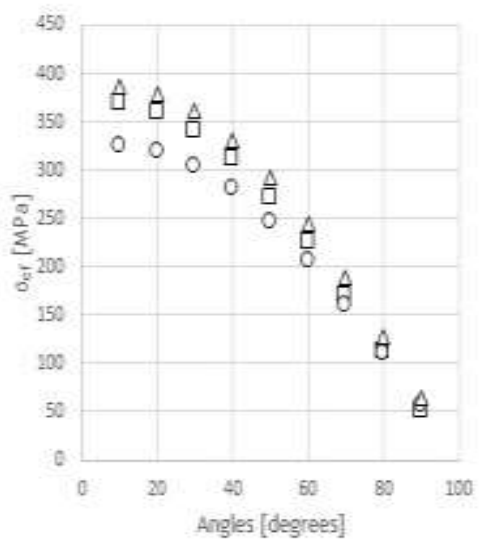

QFEU ORPM $\triangle$ ANAPM

15

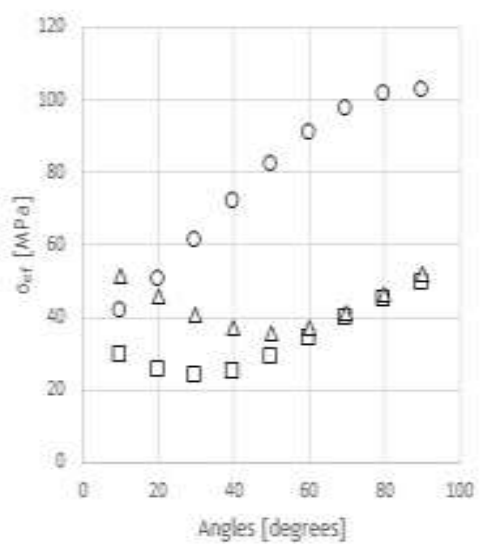

aFEM ORFM $\triangle N$ NAPM

18

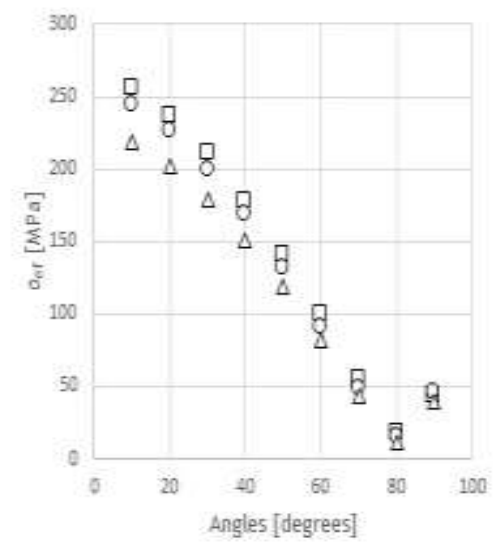

口FEM OBPM $\triangle$ NIRPM

Figure A.32 Discrete stress values for type of bone 1, for 'Model 1' and from implant side 
1

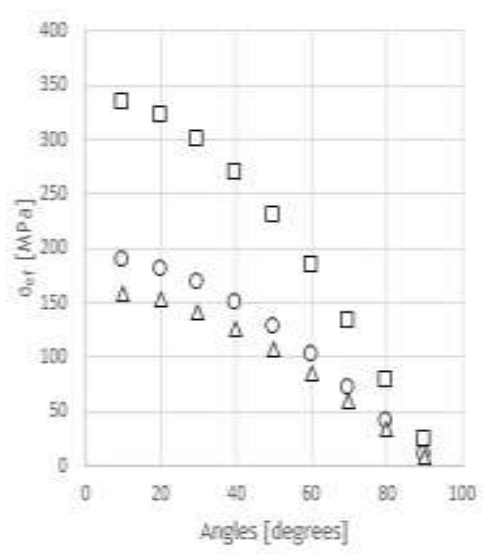

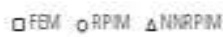

4

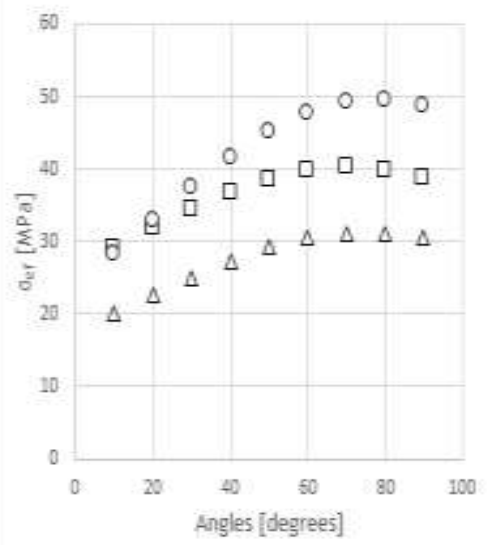

口FAU ORPM ANBPM

7

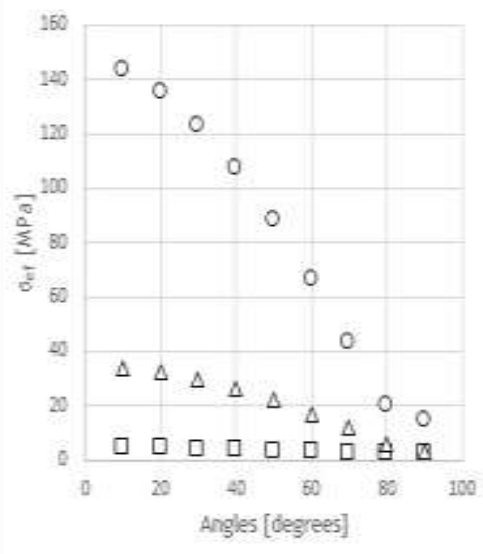

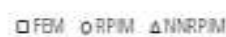

2

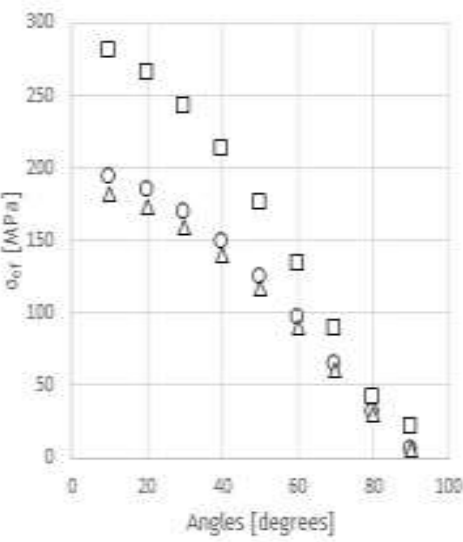

DFEM OPFM ANNRPM

5

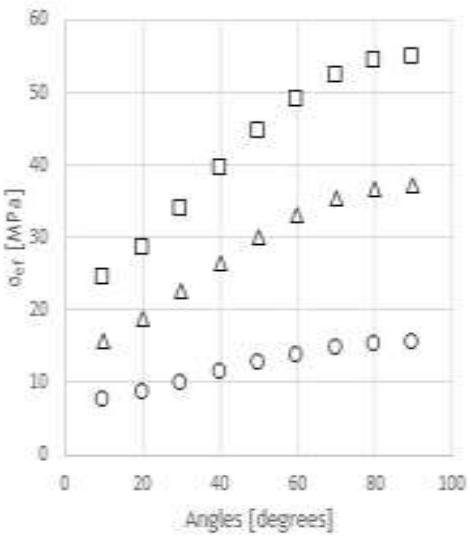

DFAM OPPM ANGSM

8

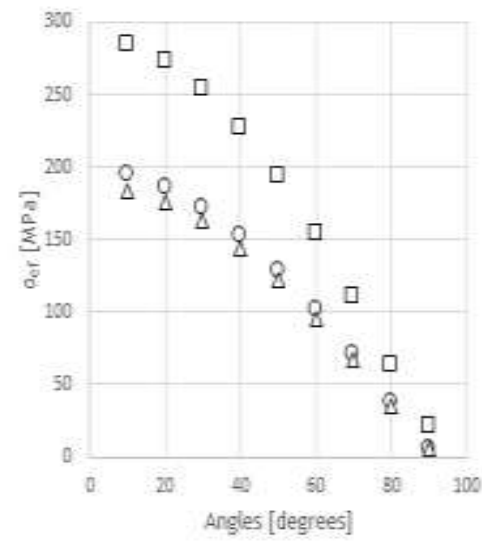

DFEM ORPM SINPFM
3

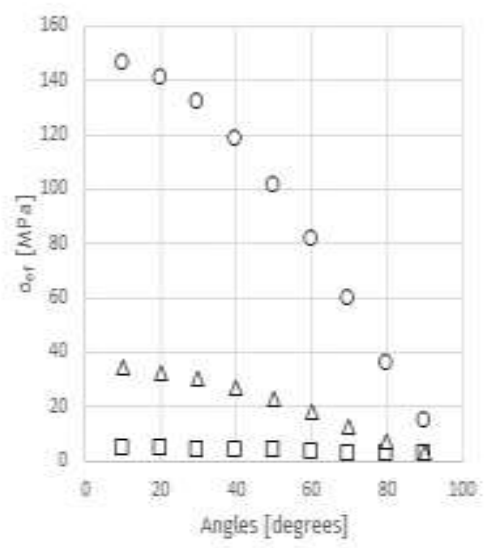

口FEM OAPM $\triangle$ NGEMM
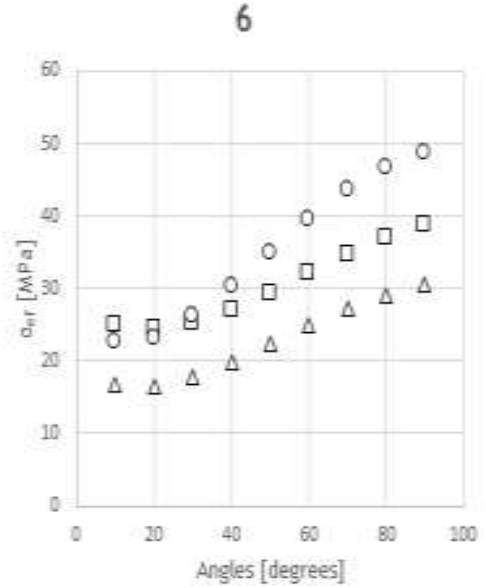

DEEM ORPM ANRES

9

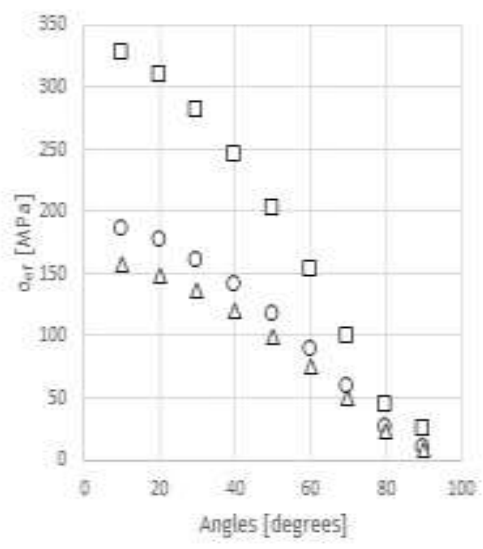

口FEMI ORPM SNREPM

Figure A.33 Discrete stress values for type of bone 1, 'Model 2' and from bone side 
10

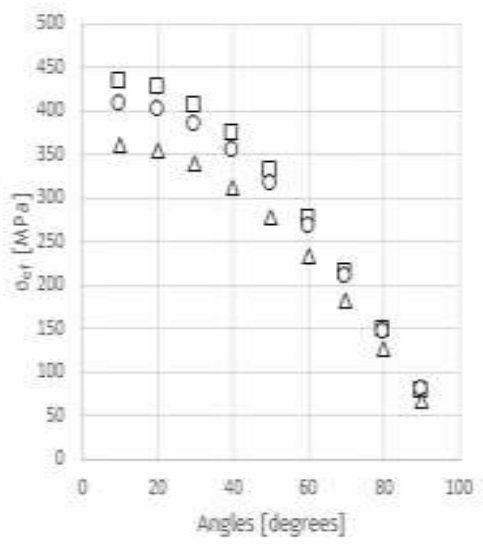

QFEM OAPM $\triangle$ NMPPM

13

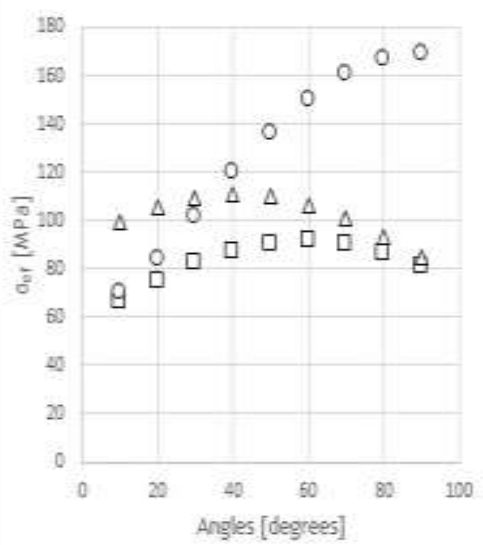

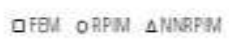

16

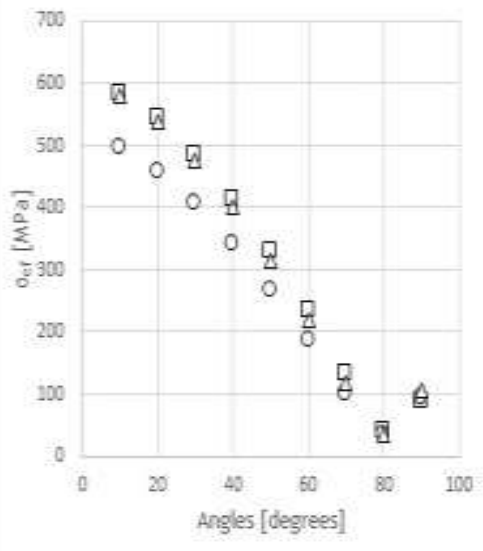

口FGU ORPM ANIRPM
11

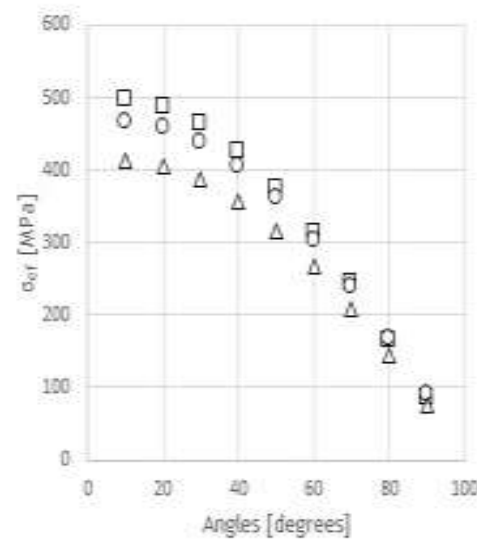

DFEM OPFM $\triangle$ NGPPM

14

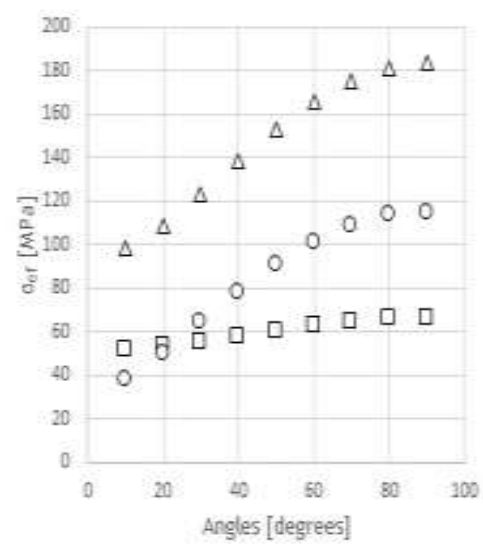

DFEM OPFM SNGPM

17

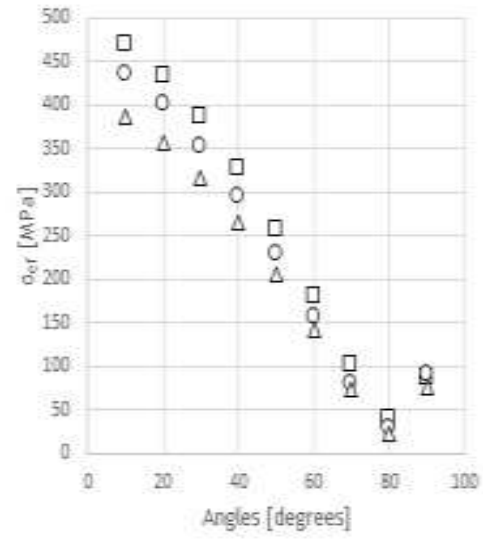

DFEM OPPM ARDPM
12

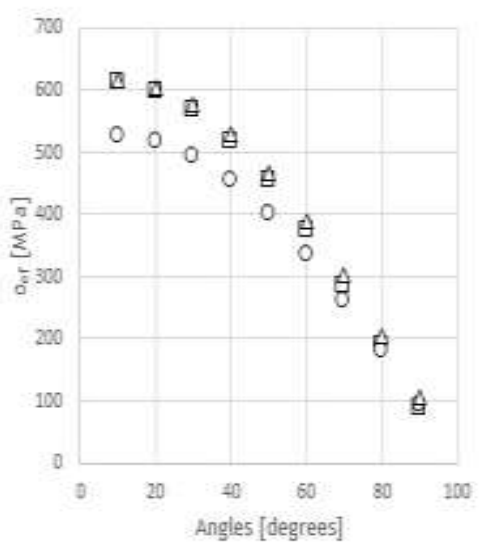

口FEM ORPM $\triangle$ NWRPM

15

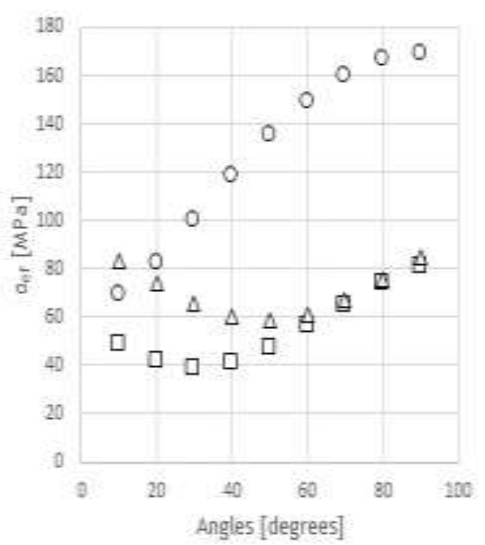

口FEM ORPM ANTEPM

18

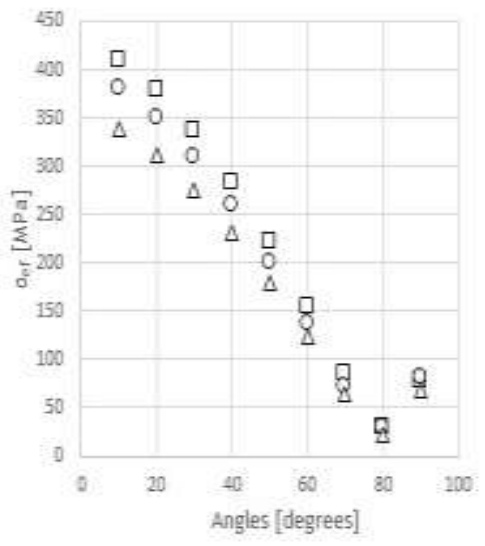

口FEM ORPMI $\triangle$ NThPM

Figure A.34 Discrete stress values for type of bone 1, for 'Model 2' and from implant side 
1

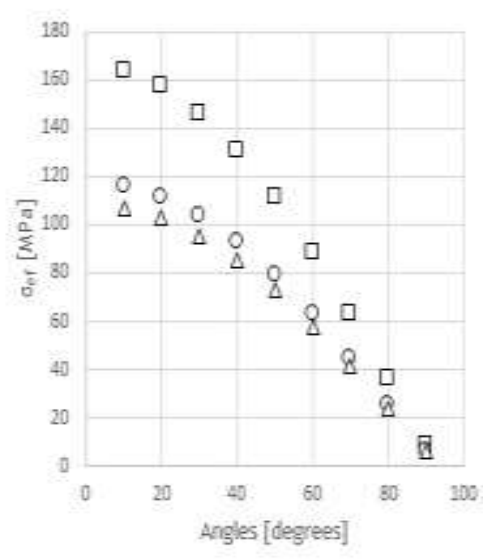

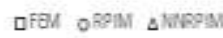

4

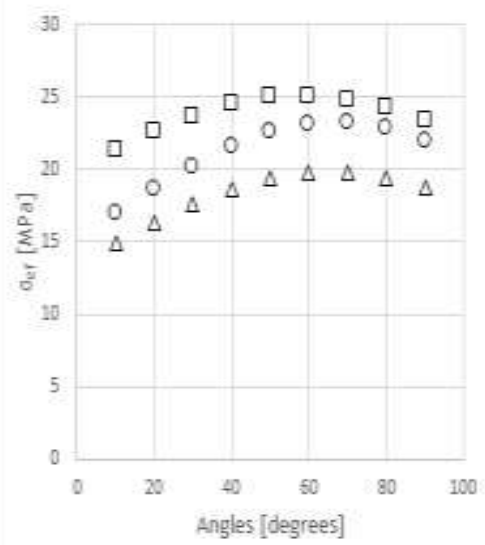

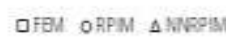

7

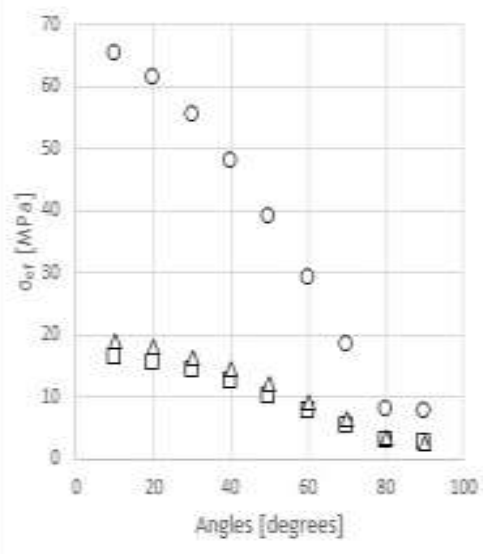

QFEU ORPM $\triangle$ MVOMM
2

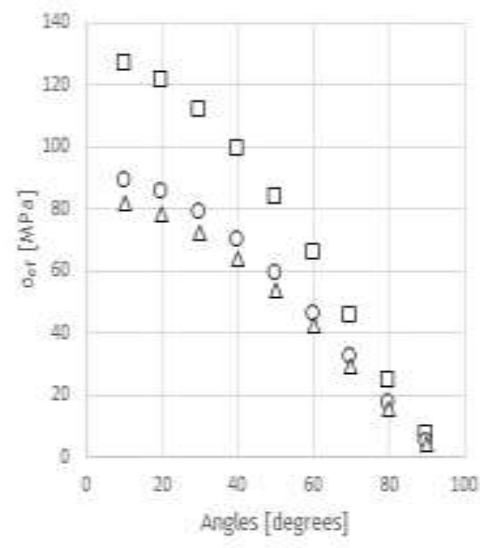

口FEM ORPM $\triangle$ NRAPM

5

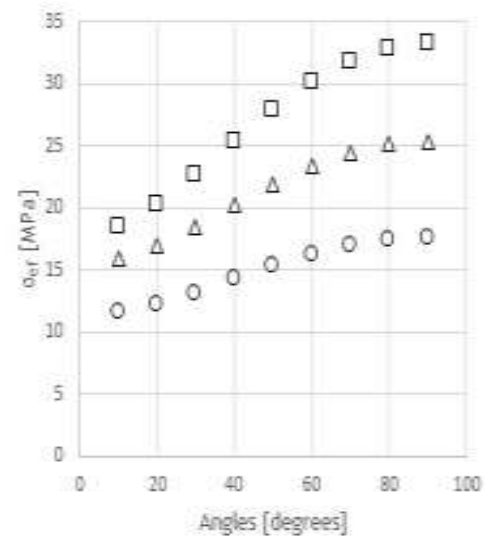

口FEA ORPM $\triangle$ NIAPIM

8

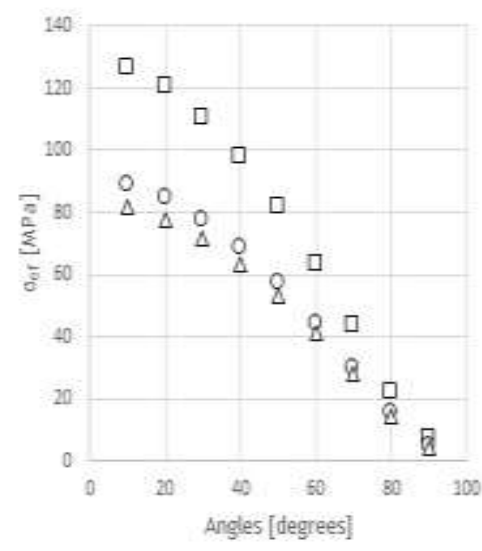

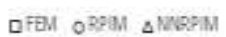

3

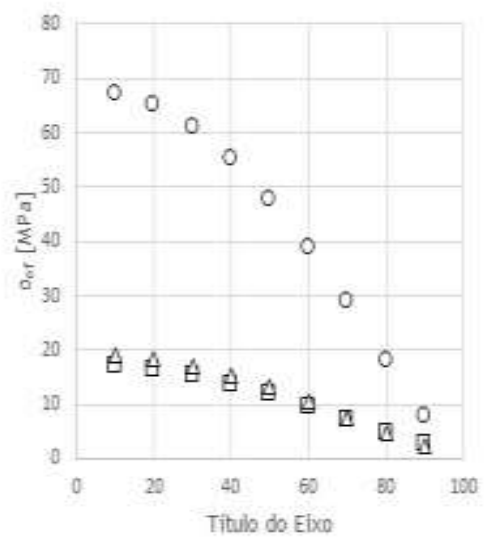

口FEM OBPM $\triangle$ NIAPM

6

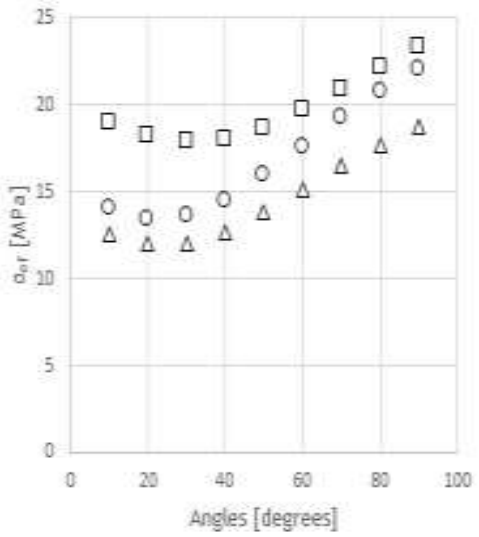

口FEM ORPM $\triangle$ NNRPM

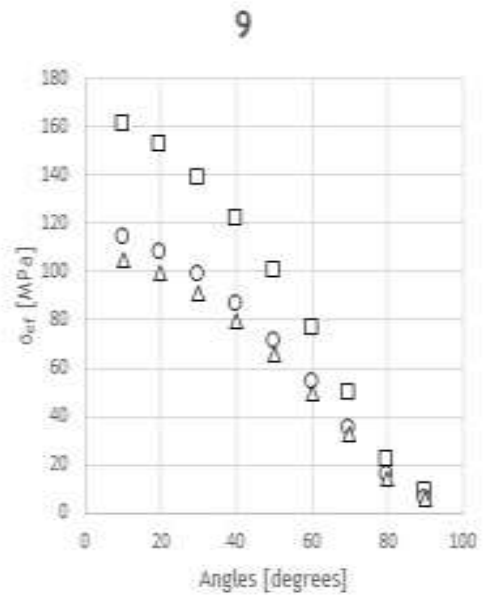

DFEM ORPM ANMAPM

Figure A.35 Discrete stress values for type of bone 2, 'Model 1' and from bone side 
10

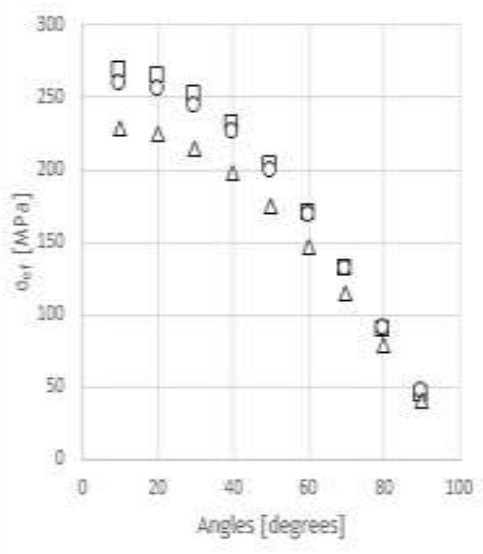

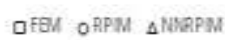

13

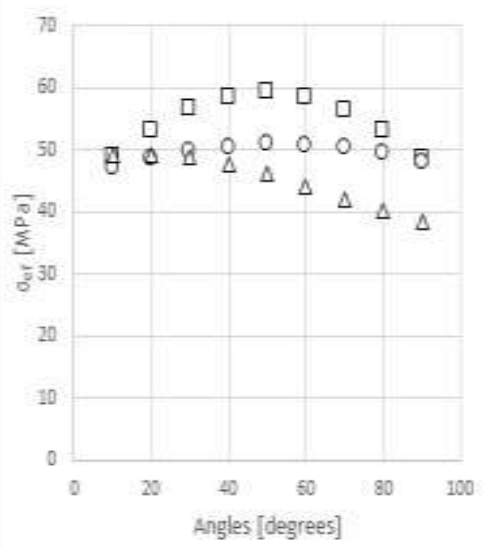

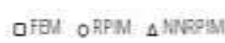

16

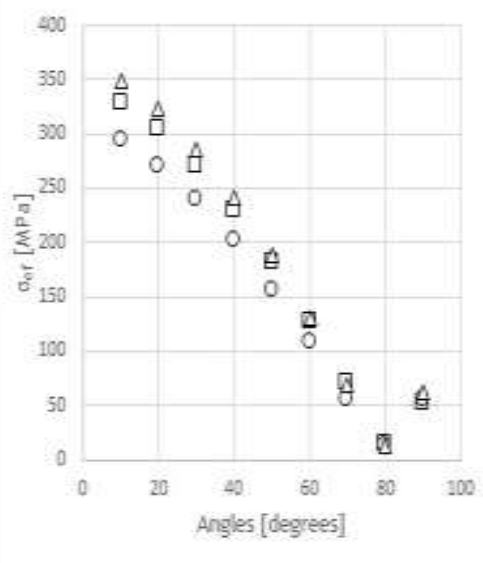

口FeU ORPM A IrTegM
11

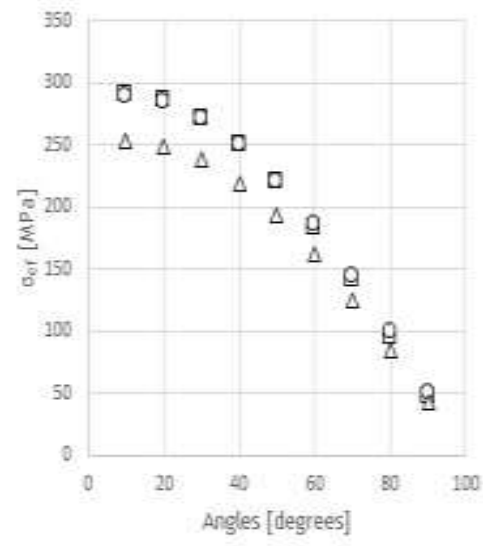

口FEM OPPM $\triangle$ NIAPM

14

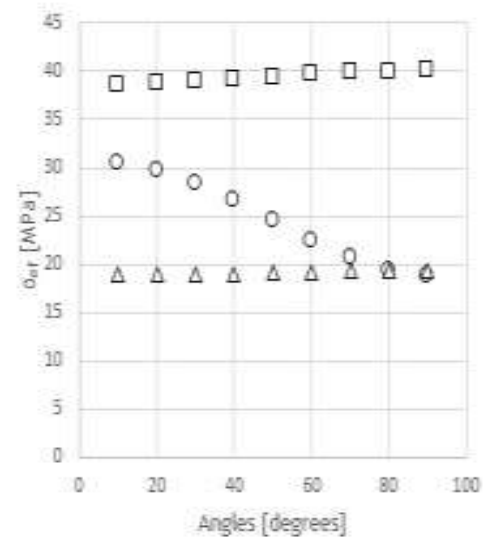

口FEM ORPM ANTAPIM

17

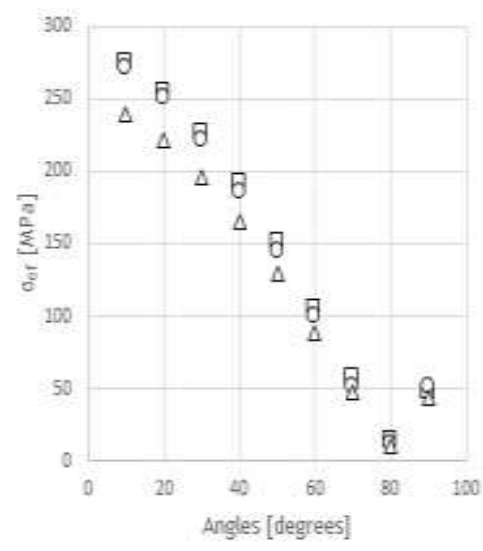

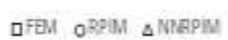

12

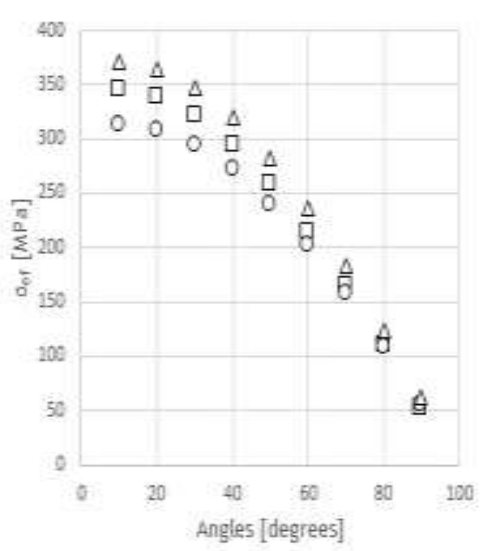

口FEM OAPM $\triangle$ MNAPM

15

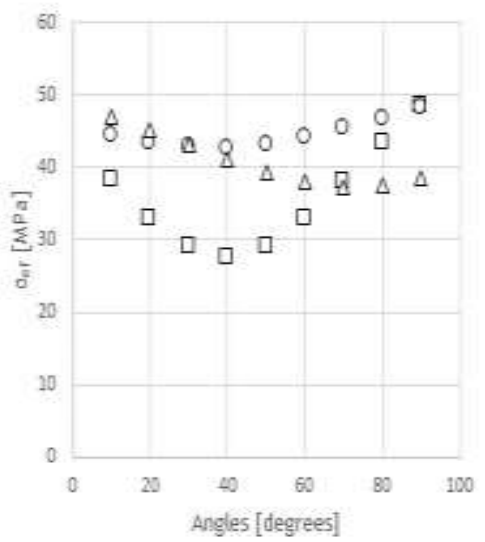

口FEM ORPM $\triangle$ NNRPM

18

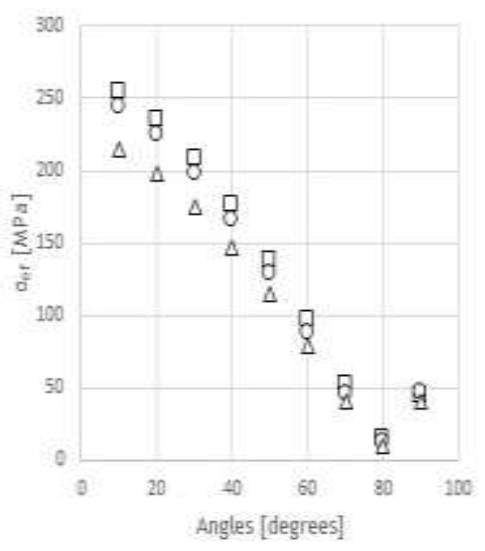

口EEM ORPMT $\triangle$ NMAPM

Figure A.36 Discrete stress values for type of bone 2, 'Model 1 ' and from implant side 
1

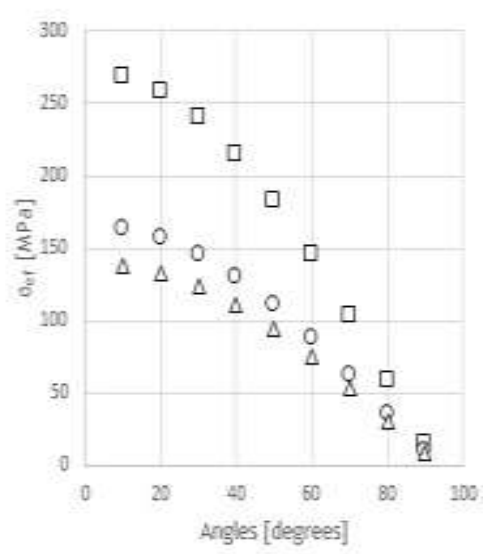

aFEM OAPM $\triangle$ Xapos

\section{4}

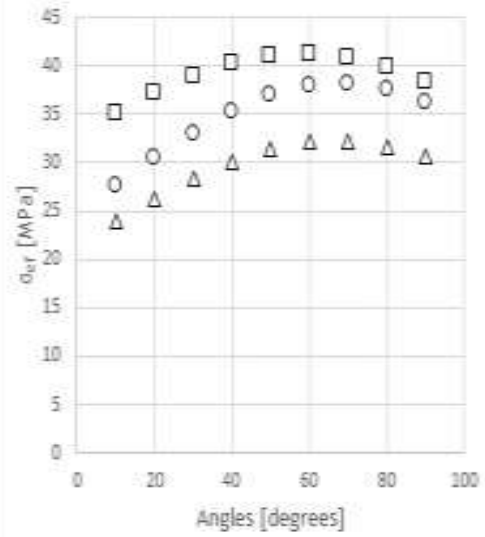

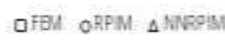

7

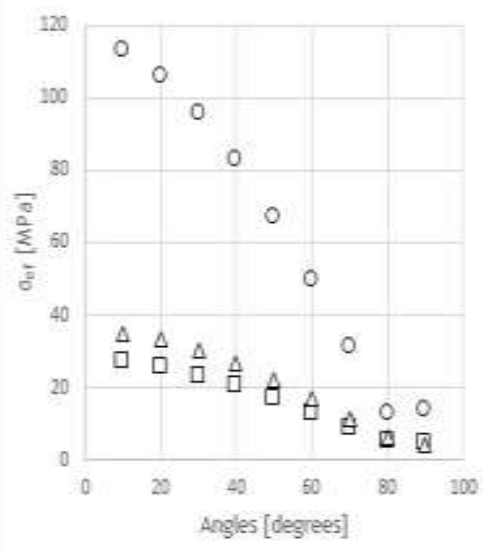

口FEU ORPM $\triangle$ WREDIN
2

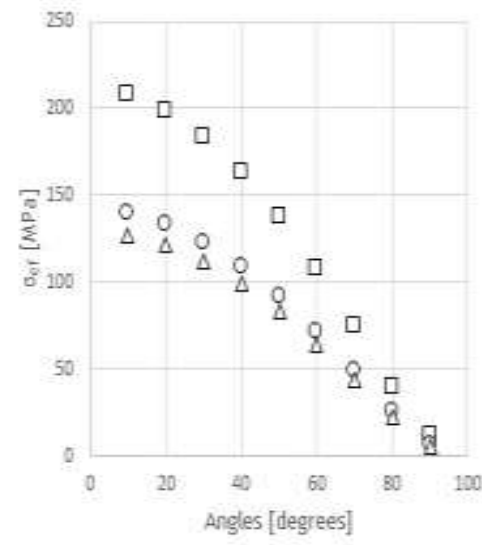

DFEM OPPM $\triangle$ NRAPM

5

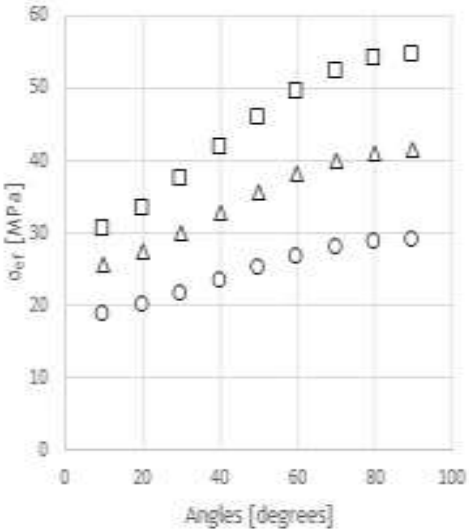

口FAM ORPM ANGSM

8

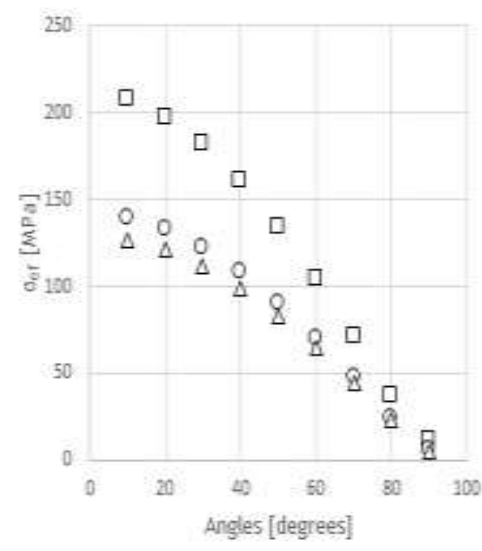

DFEM OPPAM $\triangle$ NGPM
3

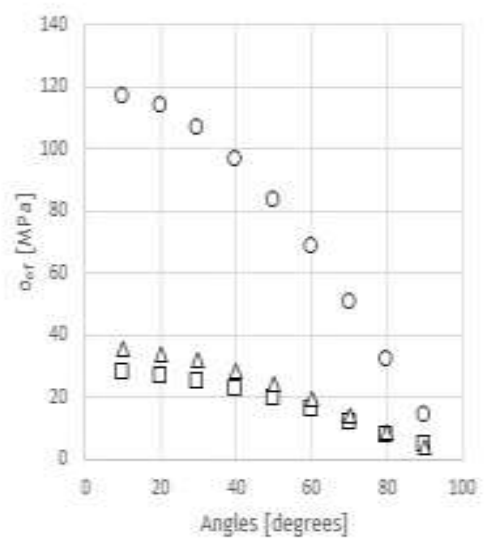

口FEM ORPM $\triangle$ NTRPAM

6

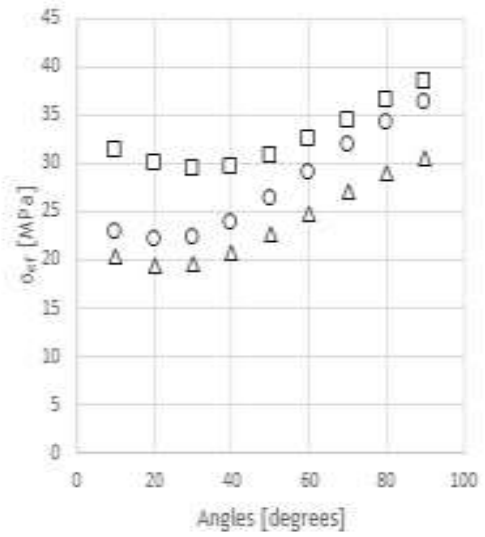

QFEM ORPM $\triangle$ MNRPM

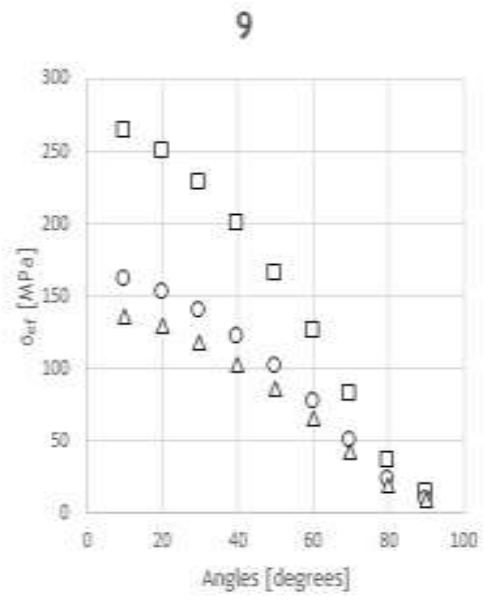

口FEM ORPM ANMAPM

Figure A.37 Discrete stress values for type of bone 2, 'Model 2' and from bone side 
10

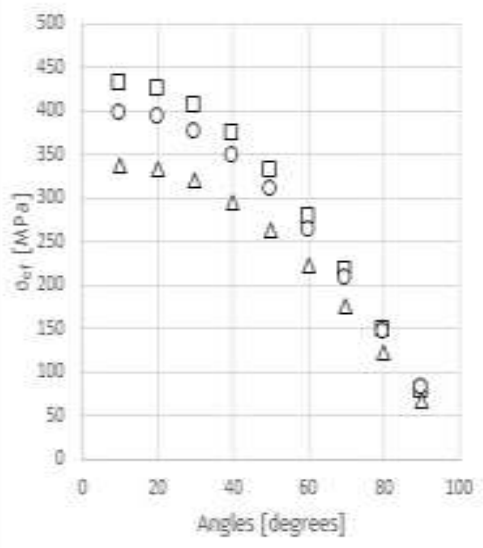

QFEM OAPM $\triangle$ NMPPM

13

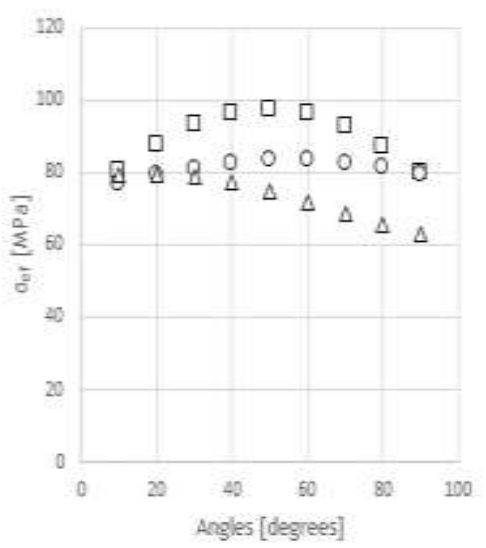

aFEU OPPM $\triangle$ NREAM

16

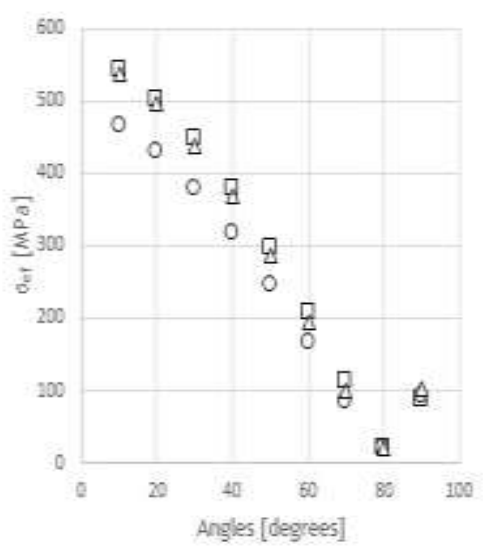

QFEM ORPM $\triangle$ WMPM
11

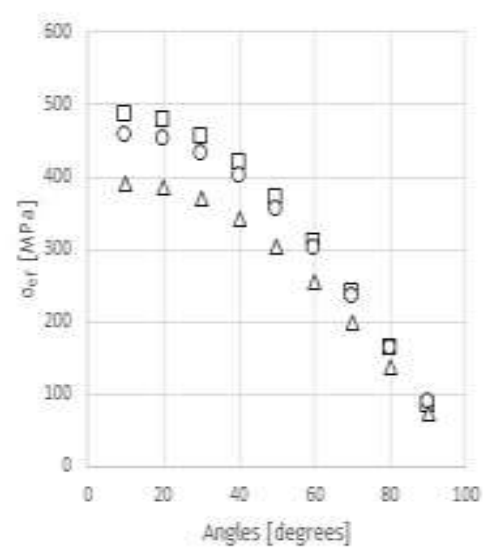

口FAM OPRM ANRAPIN

14

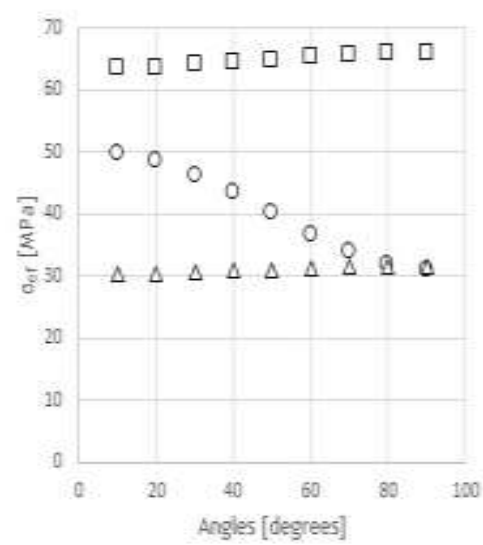

DFEM OPSM $\triangle$ NREPN

17

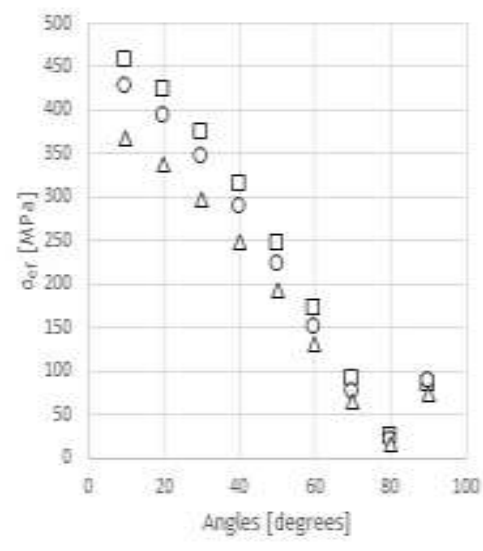

口FEA ORPM DNRAPM
12

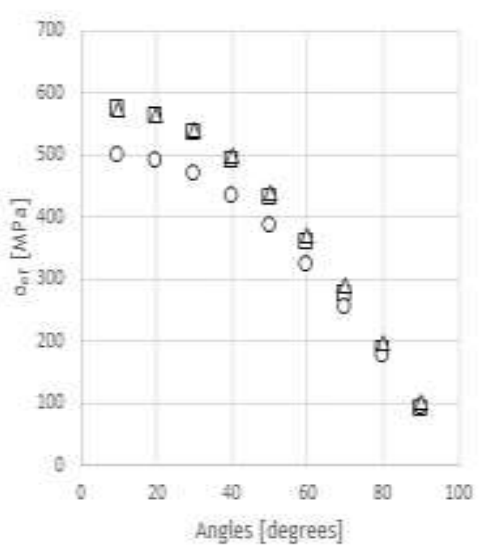

QFEM ORPM $\triangle$ NMPPM

15

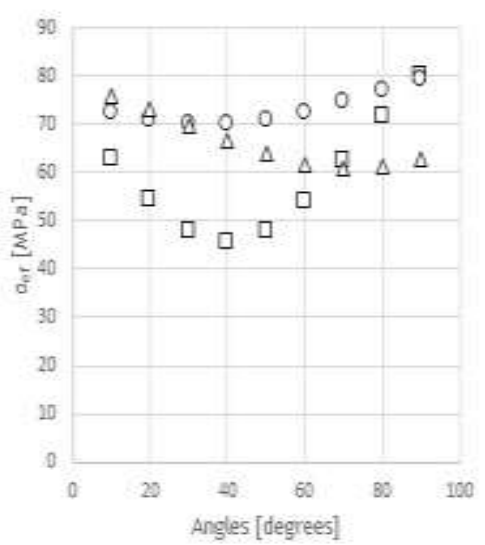

DFEM OAPM D NHAPM

18

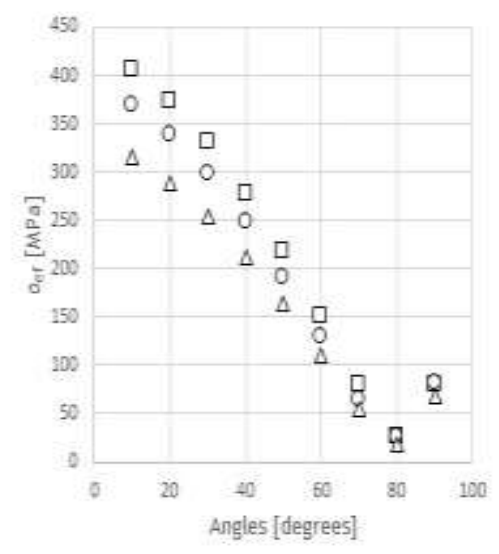

口FEM OBPM $\triangle$ NIRPM

Figure A.38 Discrete stress values for type of bone 2, 'Model 2' and from implant side 
1

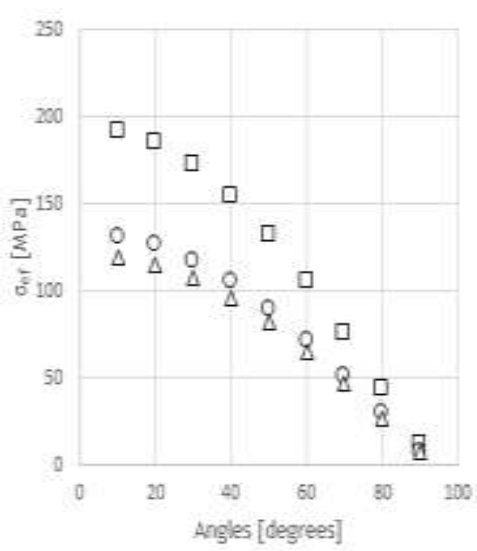

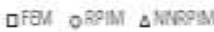

4

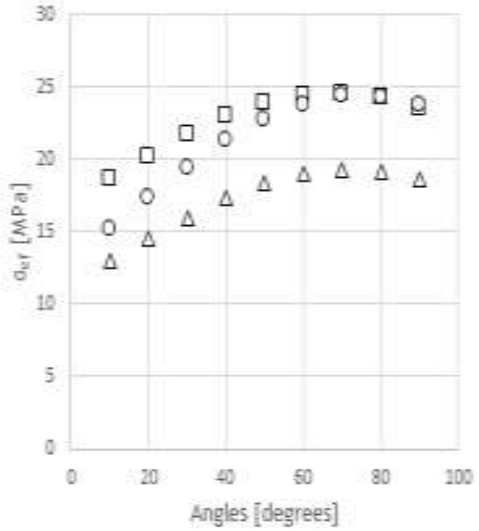

aFPU OAPM A Mageis

7

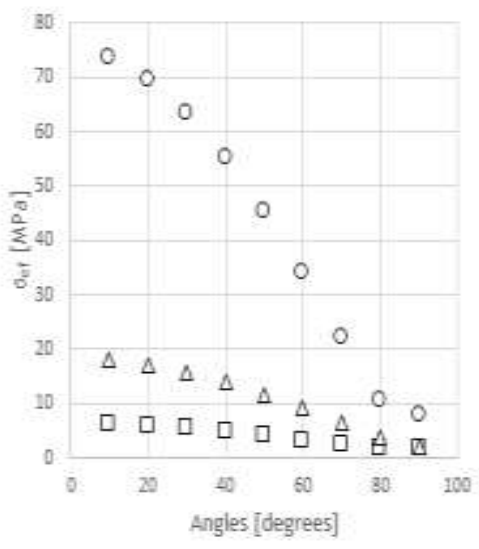

口FEU OPPM $\triangle$ NWVOM
2

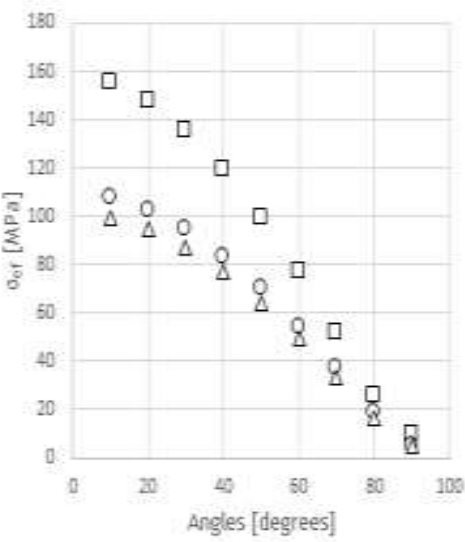

DFEM OPPM $\triangle$ NNQPM

5

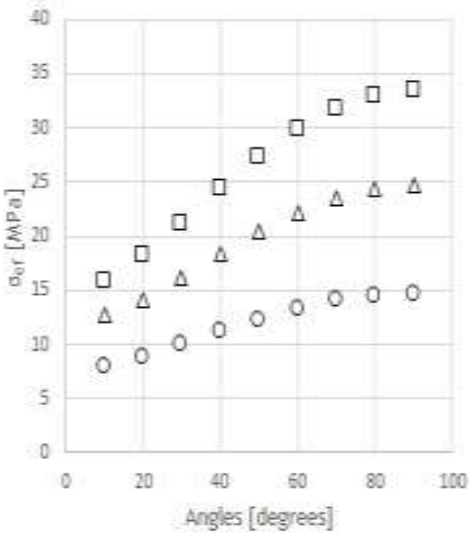

DFEM ORPM ANREPIN

8

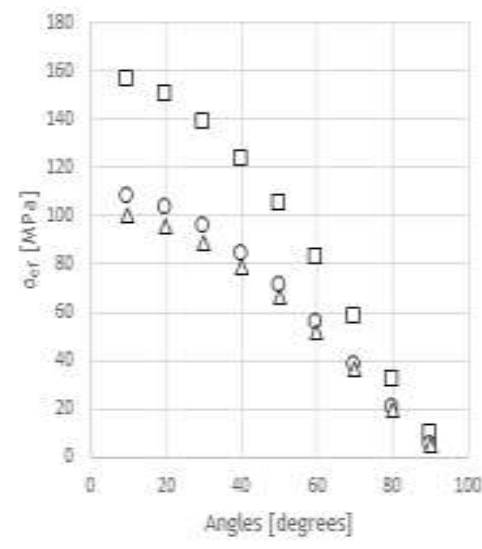

DFEM ORPM $\triangle$ NIRPM
3

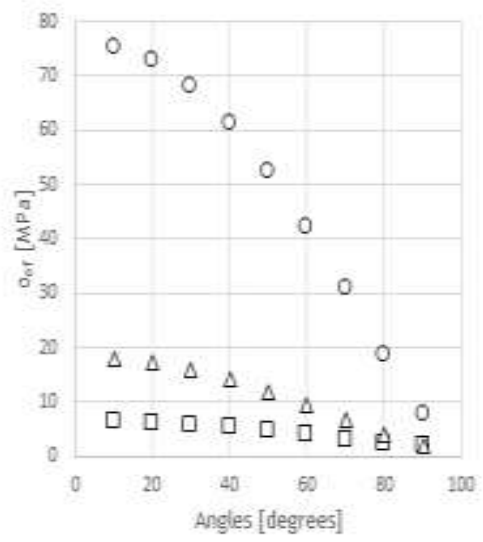

口FEM ORPM $\triangle$ HIRPM

6

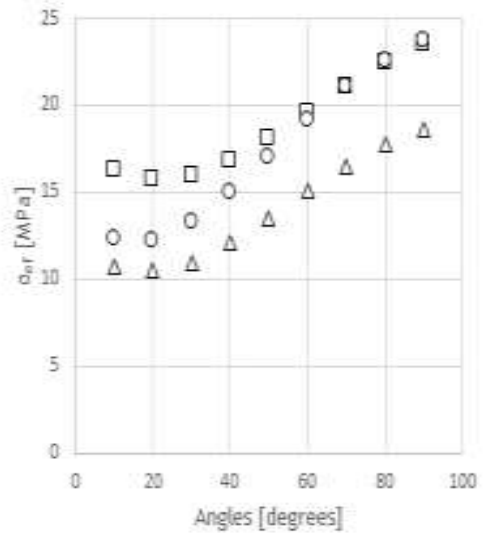

DEEM OFPM $\triangle$ NNRPM

9

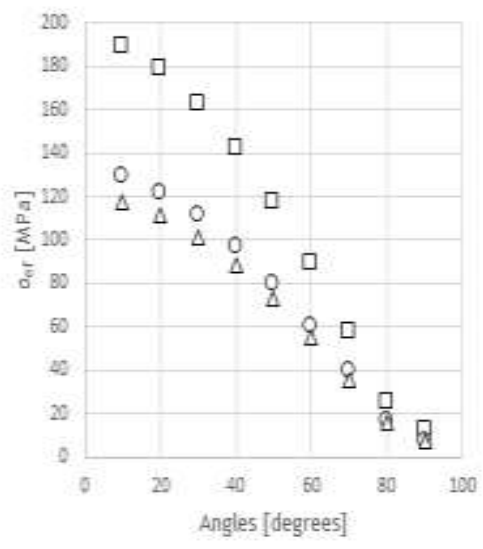

口FEM OBPM $\triangle$ NIRPM

Figure A.39 Discrete stress values for type of bone 3, 'Model 1' and from bone side 
10

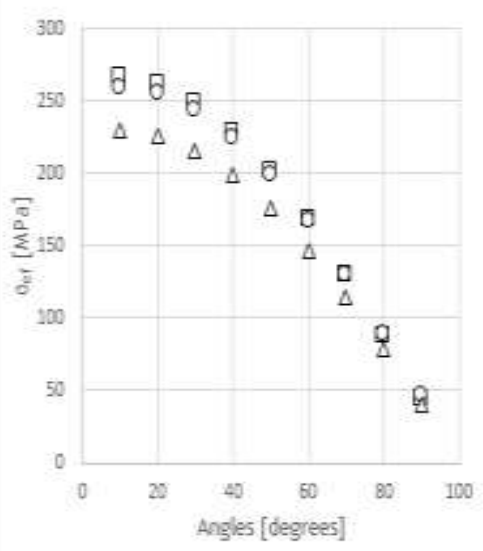

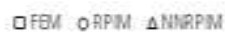

13

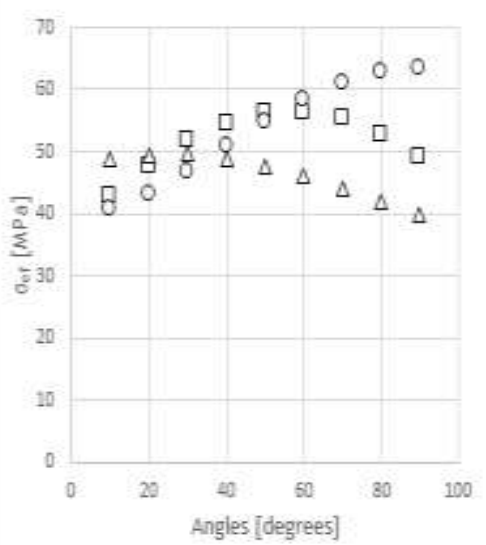

口FEU OPPM AINRPM

16

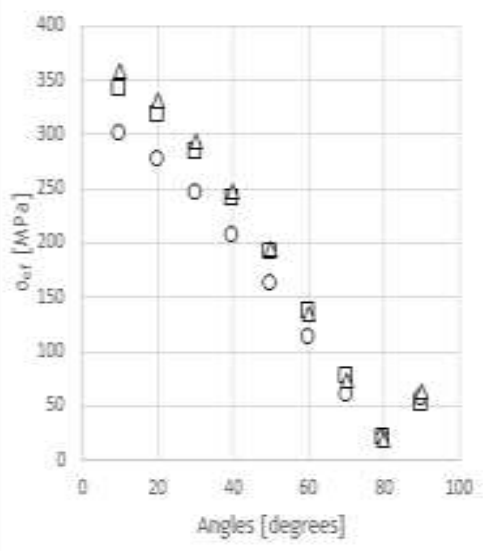

口FEA ORPM $\triangle$ WWGPM
11

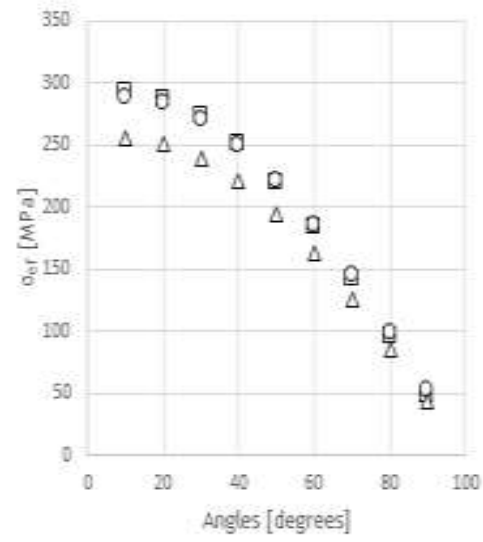

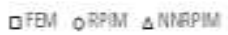

14

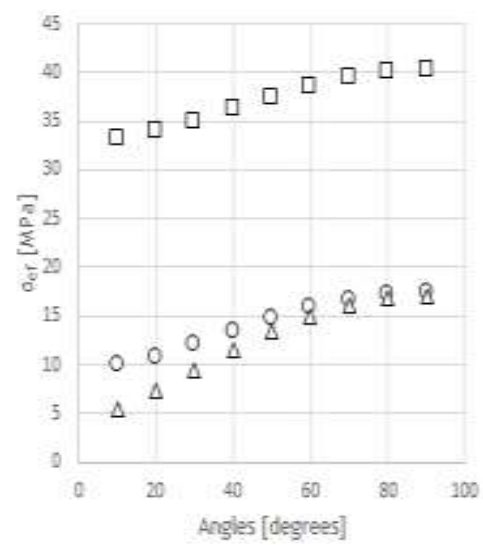

DFEM OBPM $\triangle$ NREPIN

17

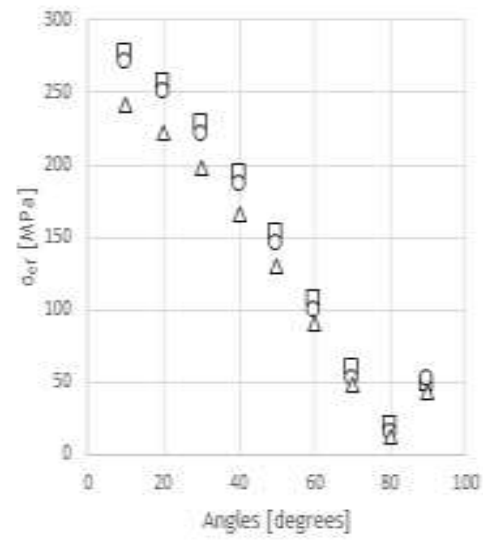

DFEM OPPIM $\triangle$ NNAPN
12

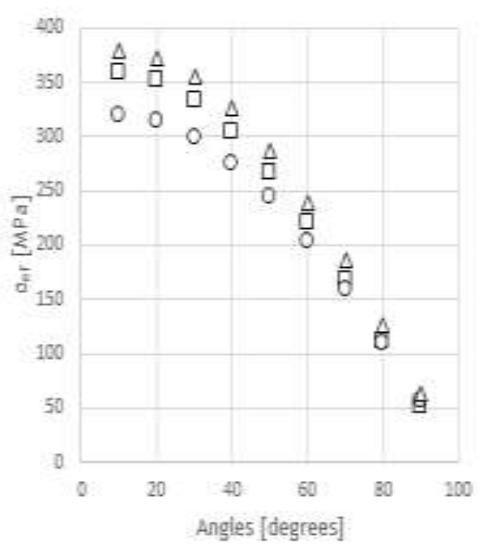

口FEM ORPM $\triangle$ NNRPM

15

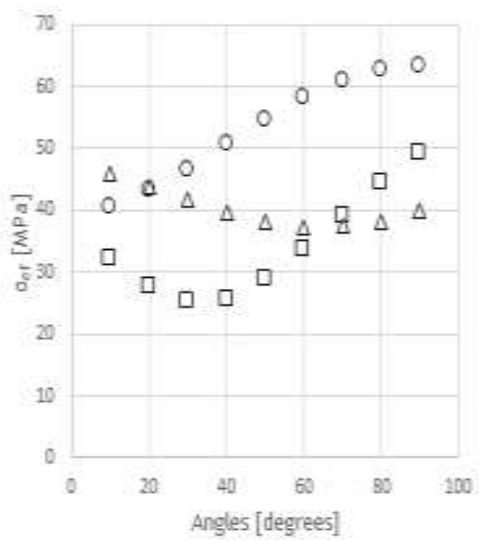

DFEM ORPM ANREPM

18

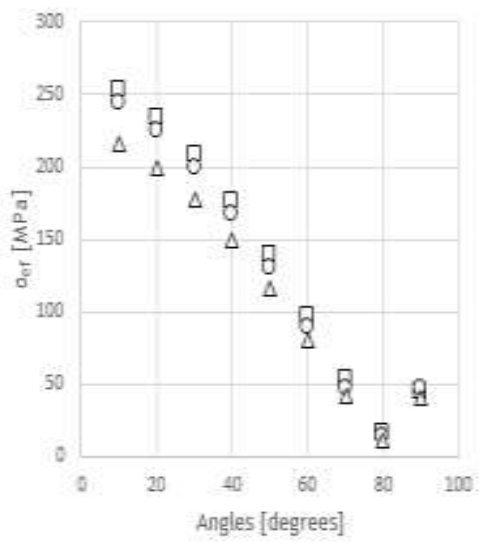

口FEM ORPMI $\triangle$ NNRPM

Figure A.40 Discrete stress values for type of bone 3, 'Model 1' and from implant side 
1

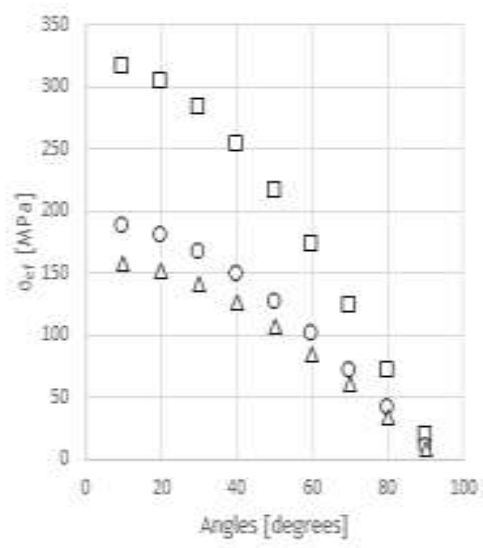

口FEM OPPM $\triangle$ NWEPM

4

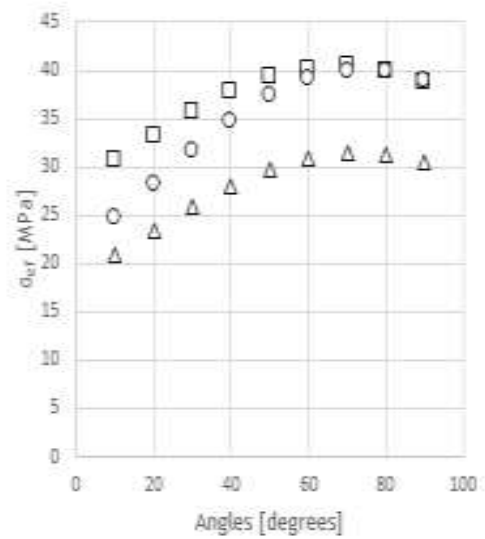

QFEM ORPM $\triangle$ MAPM

7

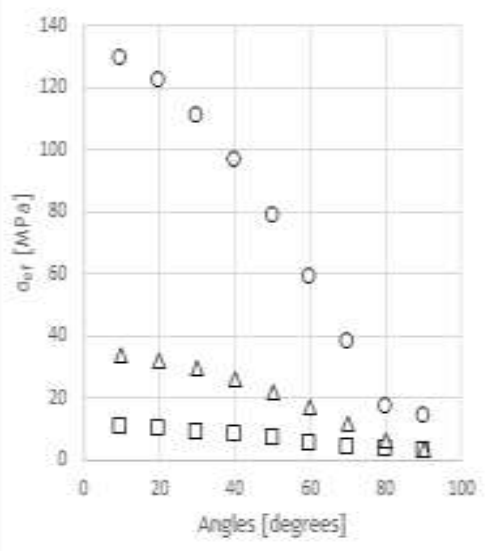

口FEU ORPM $\triangle$ NTEOIN
2

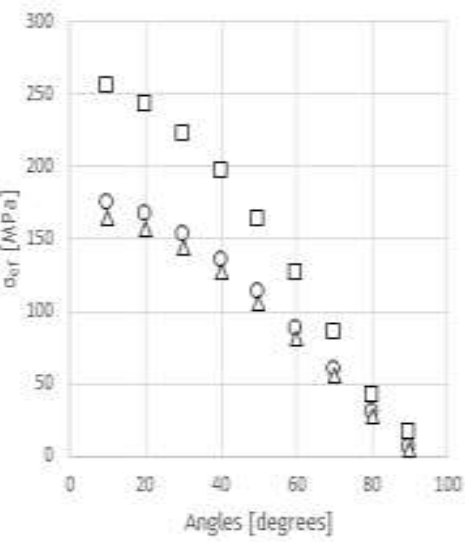

DFEM OPEM $\triangle$ MNAPM

5

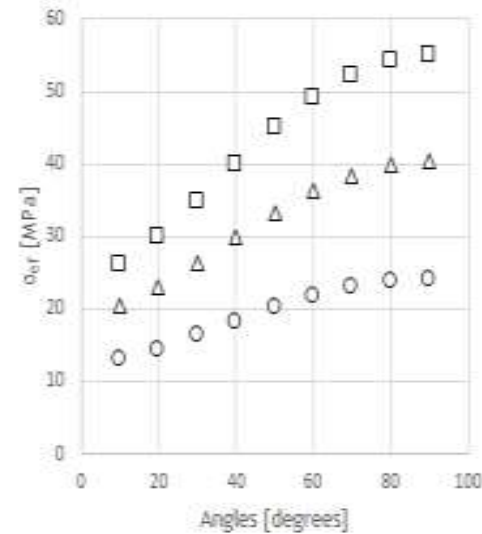

GFEM ORPM ANIEPIU

8

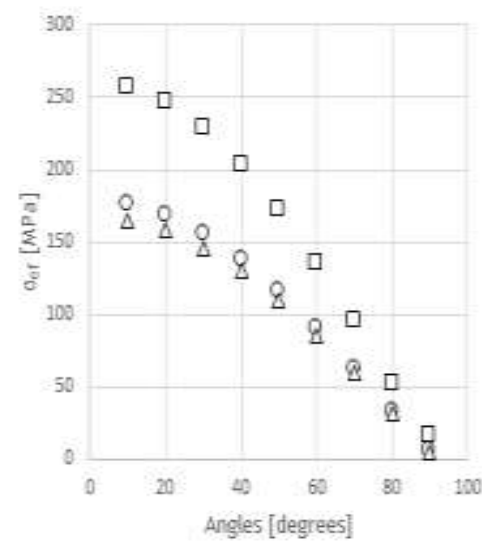

口FEM OPFM $\triangle$ NRAPIN
3

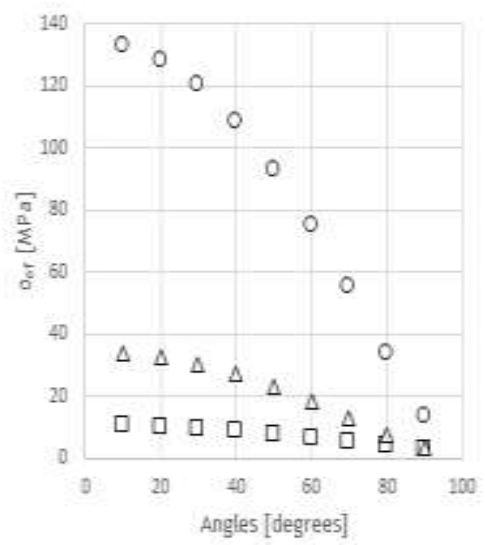

口FEM ORPM $\triangle$ NTRPM

6

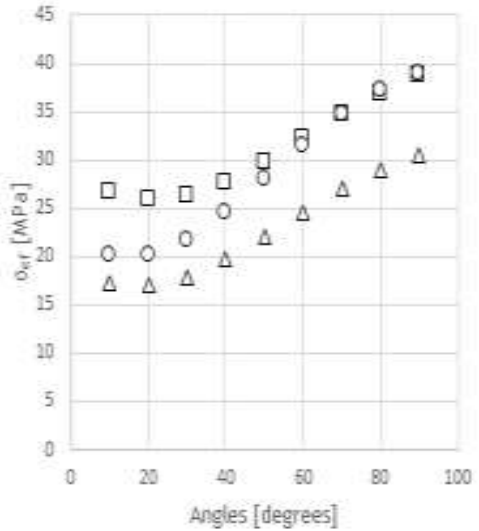

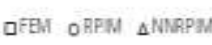

9

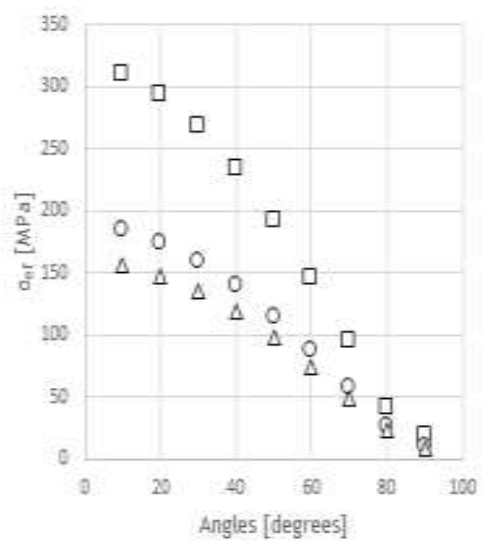

GFEM ORPM $\triangle$ NHPPU

Figure A.41 Discrete stress values for type of bone 3, 'Model 2' and from bone side 
10

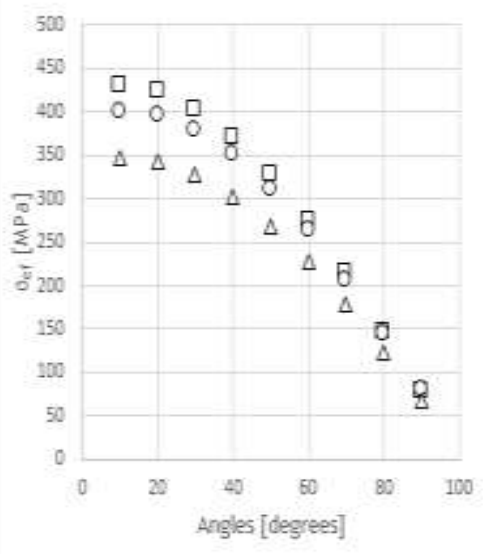

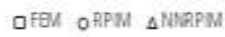

13

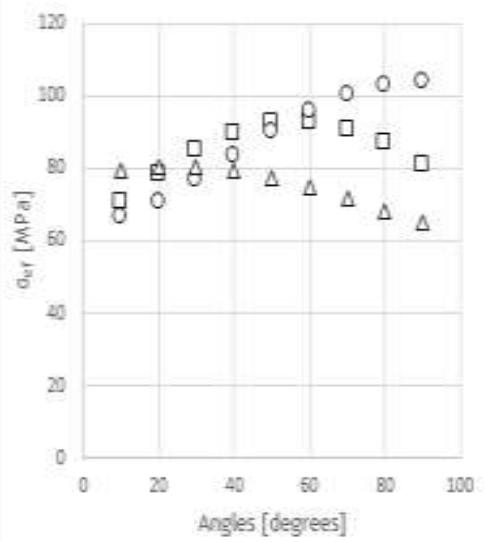

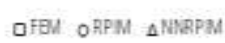

16

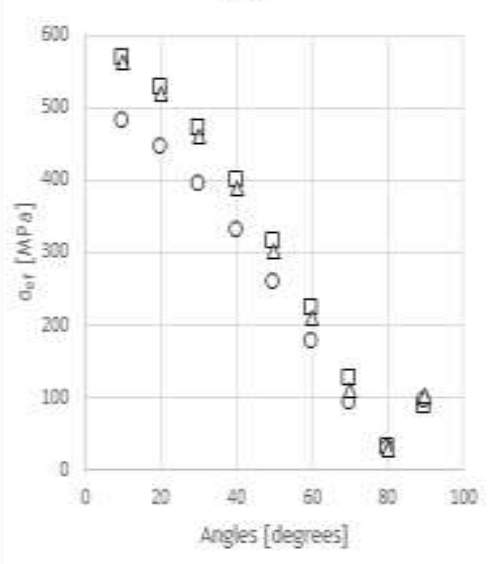

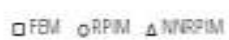

11

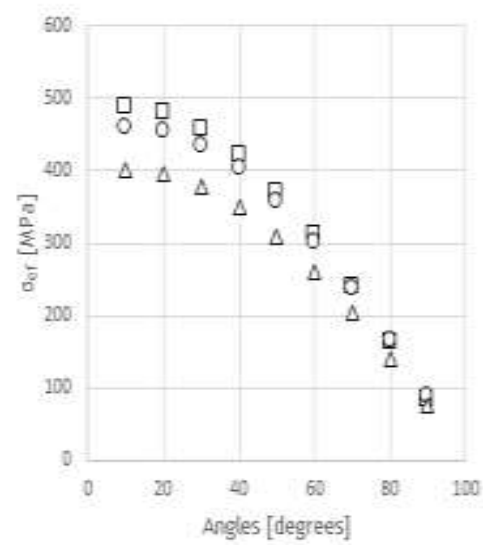

QFEM ORFM $\triangle$ NNAPM

14

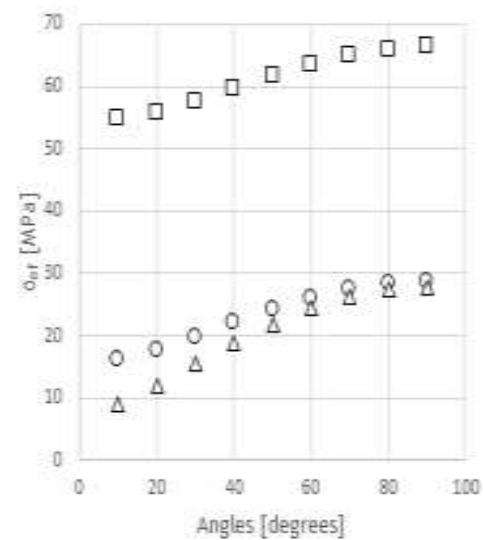

口FEM OPRM ANIAPIU

17

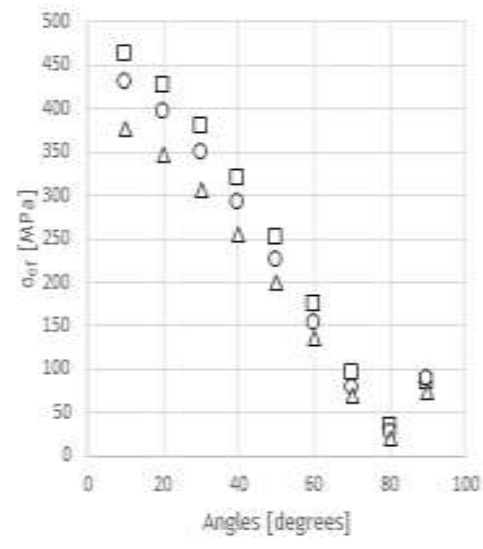

口FEM OPFM $\triangle$ NPEPIN
12

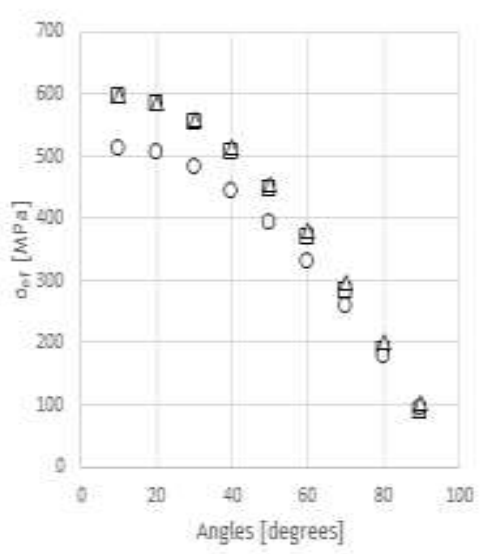

口FEM ORPM $\triangle$ NIRPM

15

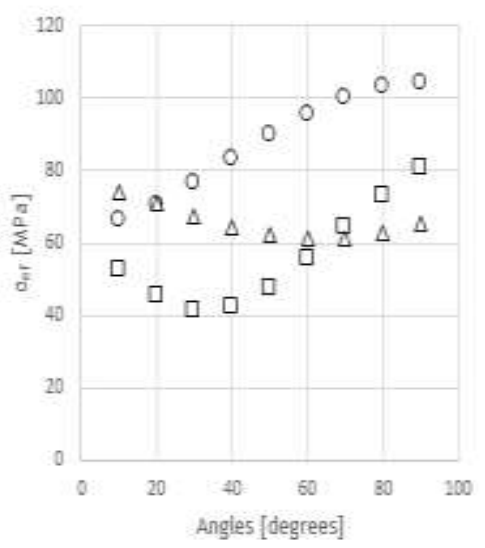

口FEM ORPM ANREPM

18

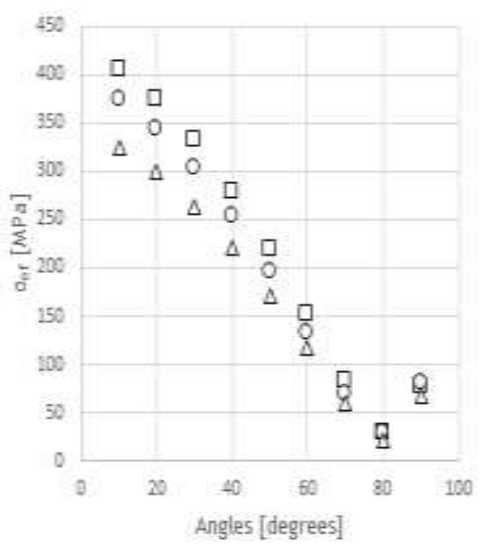

QFEM ORPM $\triangle$ NMPPM

Figure A.42 Discrete stress values for type of bone 3, 'Model 2' and from implant side 
1

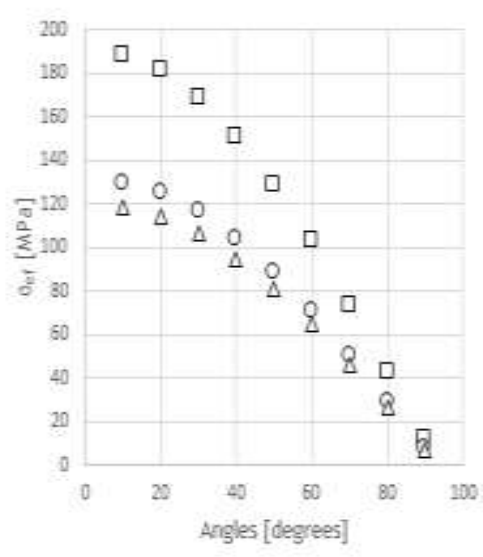

口FAM OAPM $\triangle$ NWEPSI

4

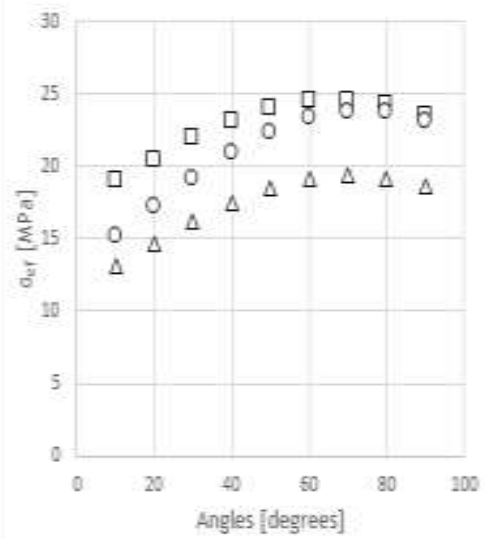

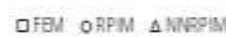

7

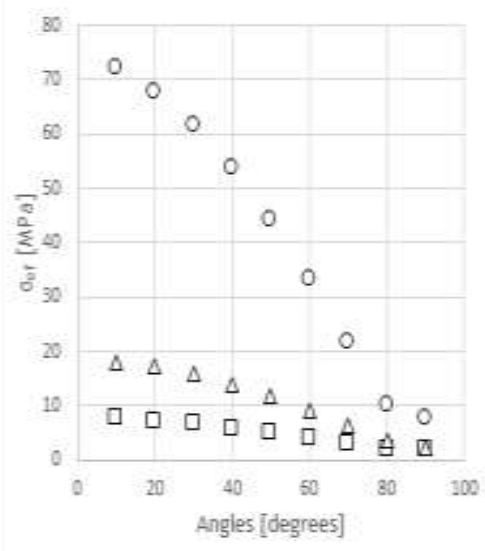

口FEU ORPM $\triangle$ MVPIM
2

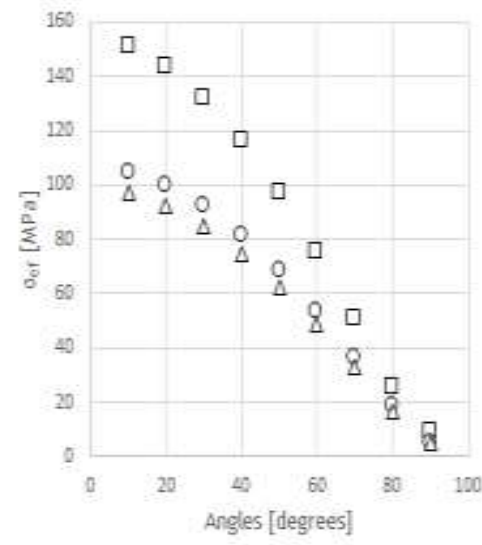

口FEM ORPIN $\triangle$ NIRPM

5

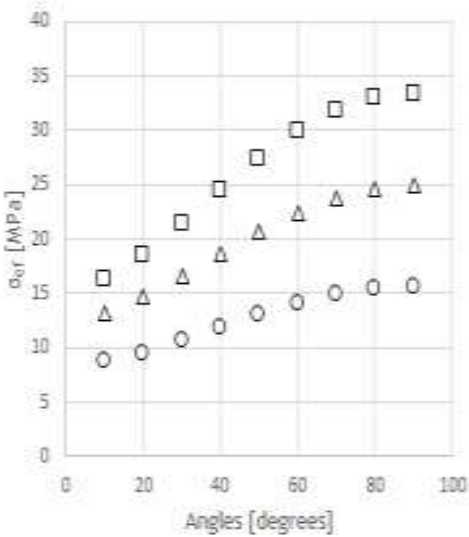

DFEM OPRM $\triangle$ NRAPM

8

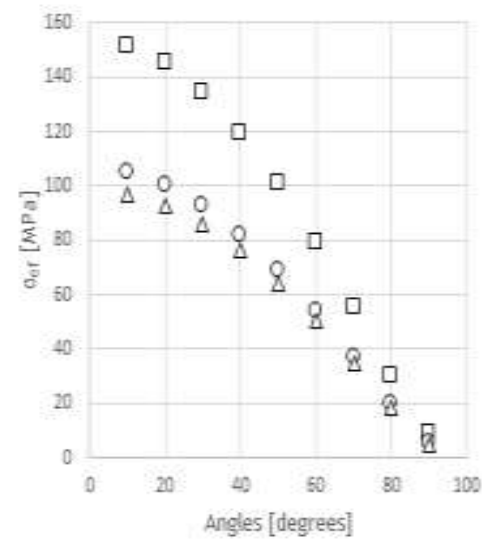

口FEM OPPAM $\triangle$ WNPM
3

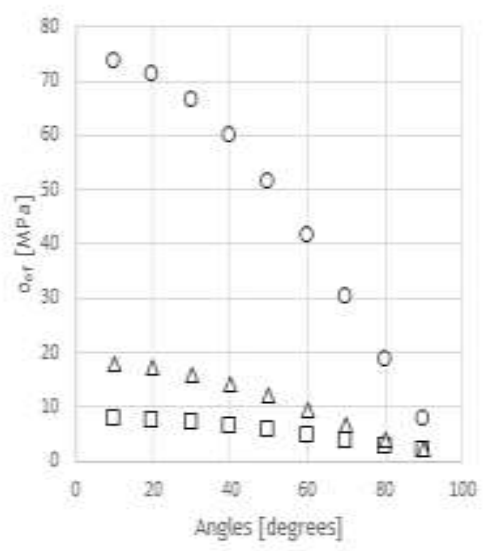

口FEM ORPM $\triangle$ HIRPM

\section{6}

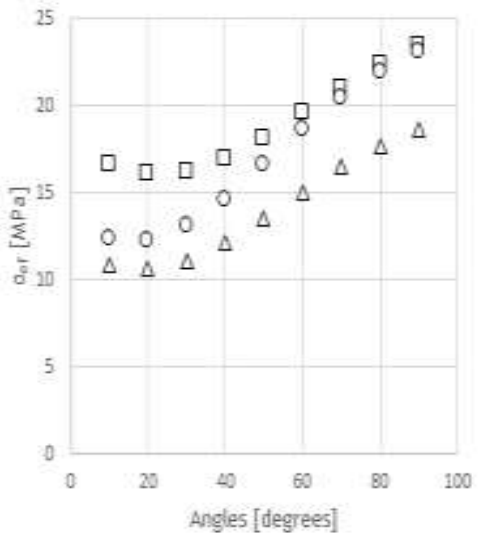

口FEM ORPM ANNRPM

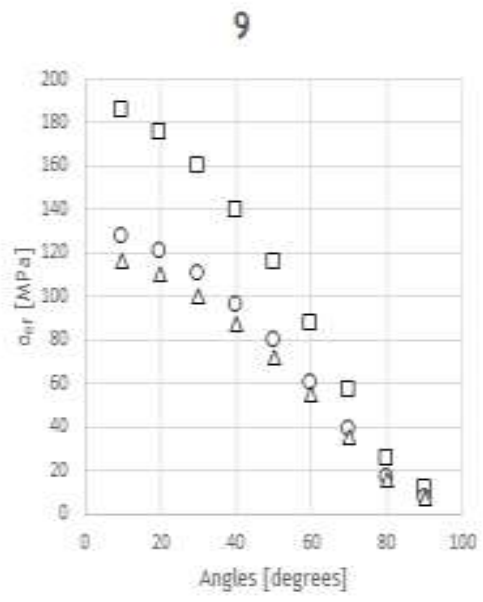

DFEM OBPM $\triangle$ NKAPUA

Figure A.43 Discrete stress values for type of bone 4, 'Model 1' and from bone side 
10

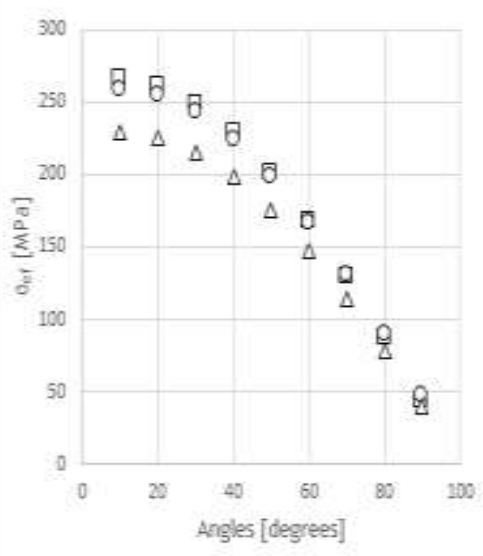

口FOM OPPM $\triangle$ NWEPM

13

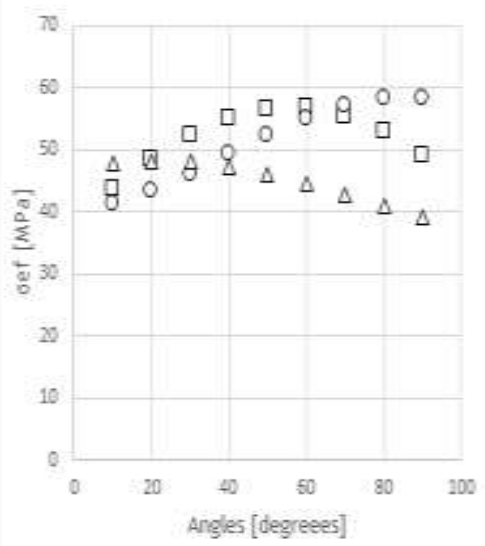

aFAM OPPM $\triangle$ MNEPM

16

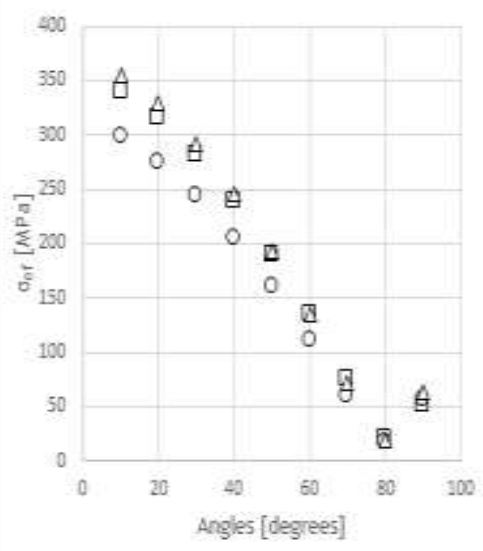

口FEU ORPM $\triangle$ NTregiM
11

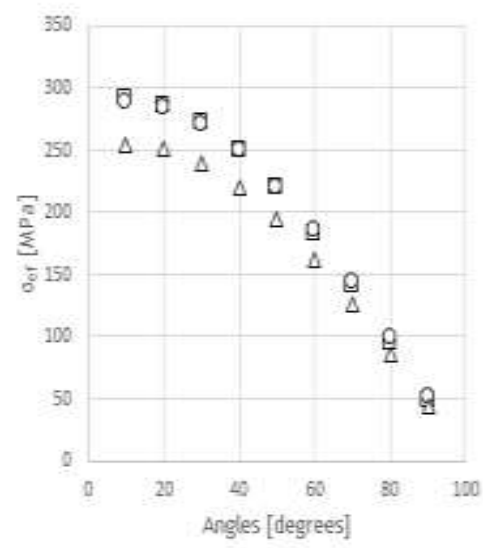

DFEM OPFM $\triangle$ NRAPM

14

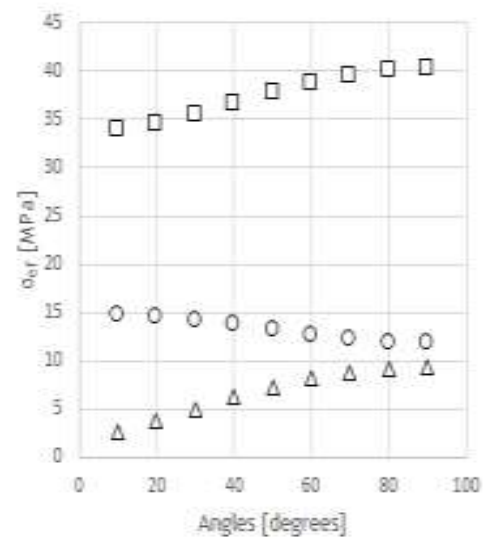

口FEM OPRM ANIAPIU

17

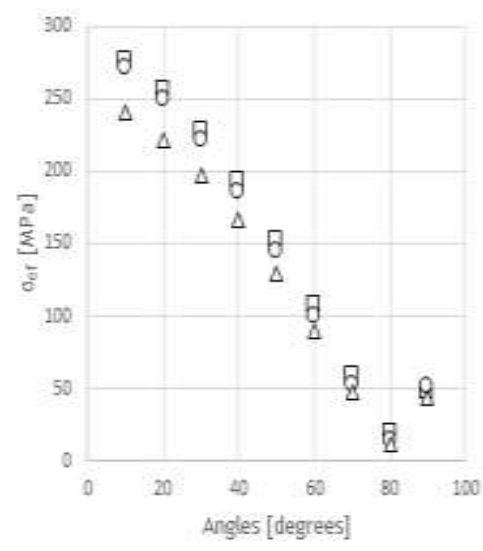

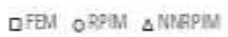

12

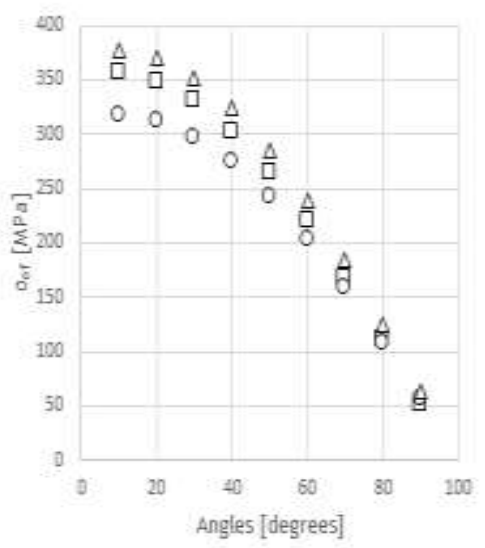

口EEM OAPM $\triangle$ NNRPM

15

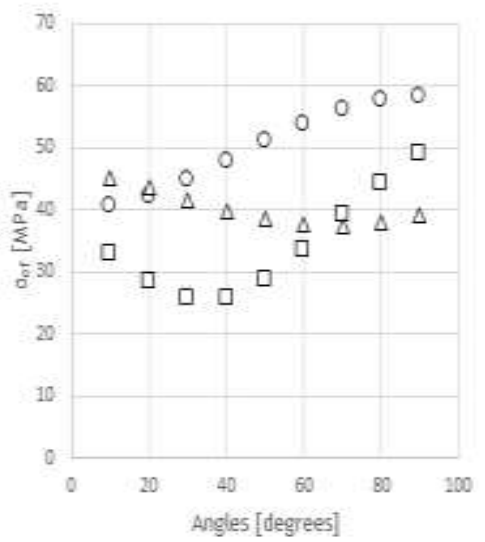

口FEM ORPM ANREPM

18

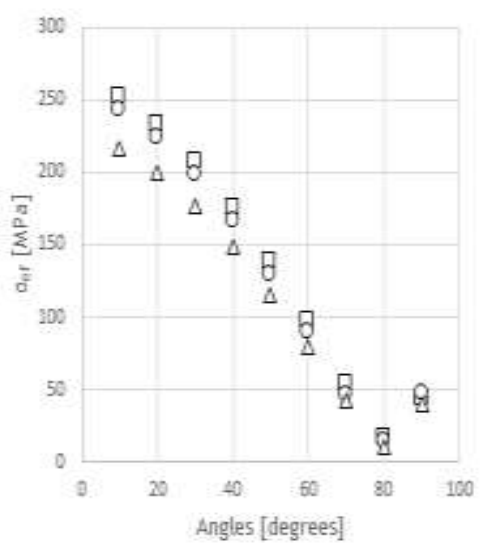

口EEM ORPM $\triangle$ NMPPM

Figure A.44 Discrete stress values for type of bone 4, 'Model 1 ' and from implant side 
1

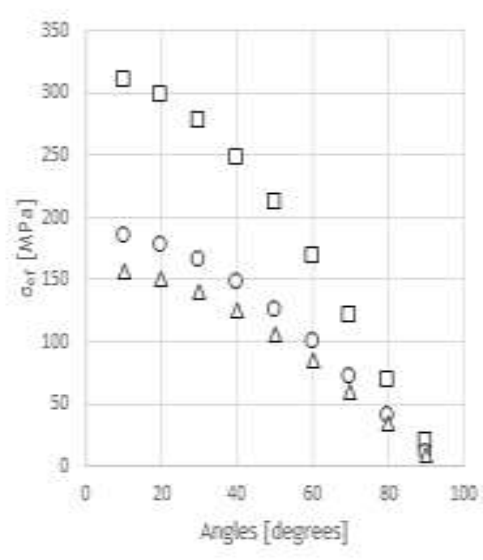

afan opelm $\Delta$ xweps

4

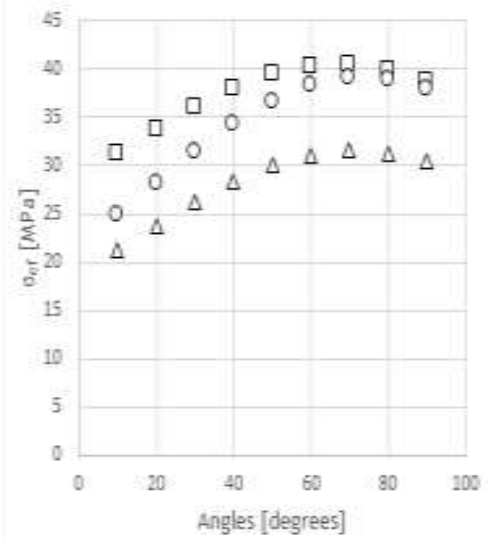

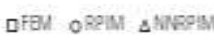

7

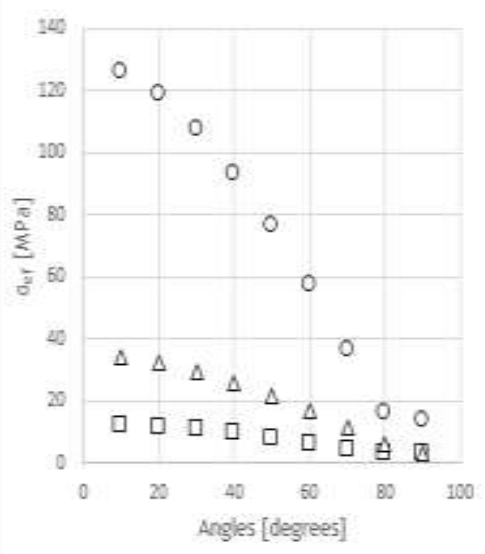

口FOU ORPM ANOEPI
2

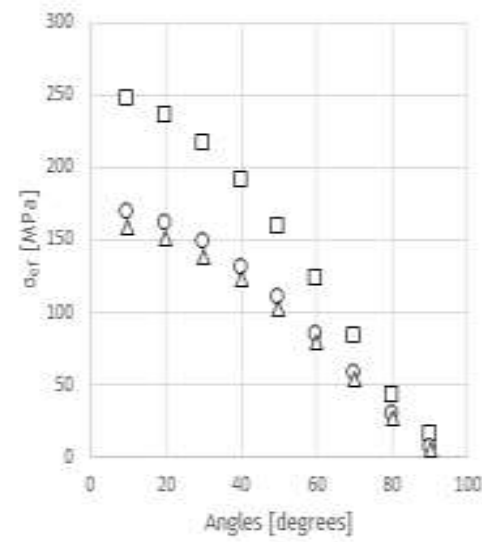

DFEM ORFM $\triangle$ NRAPM

5

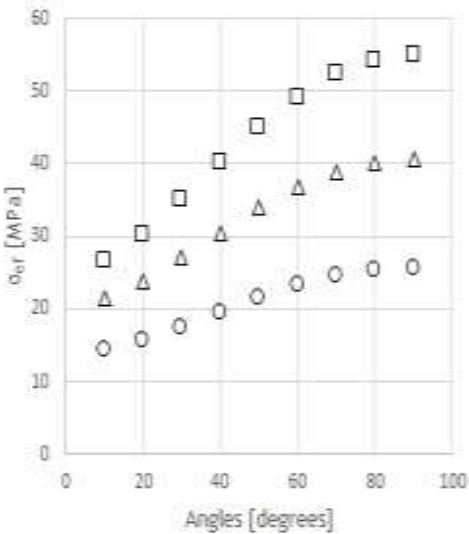

DFEM OPPM $\triangle$ MNAPM

8

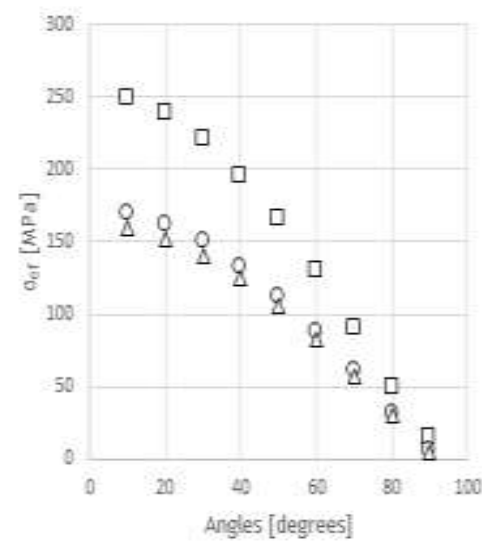

DFEM OPPAM $\triangle$ NMAPIM
3

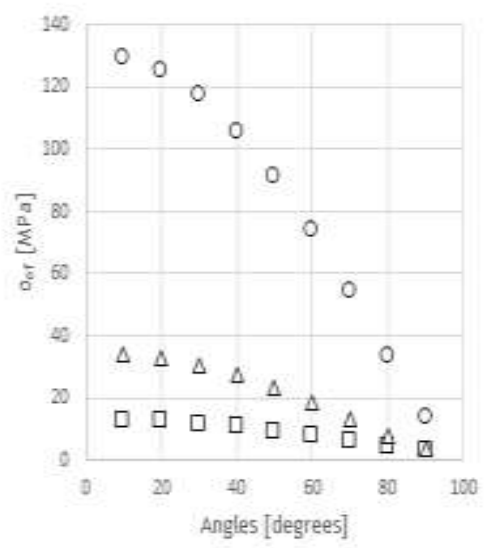

DFEM ORPM $\triangle$ MLPPM

\section{6}

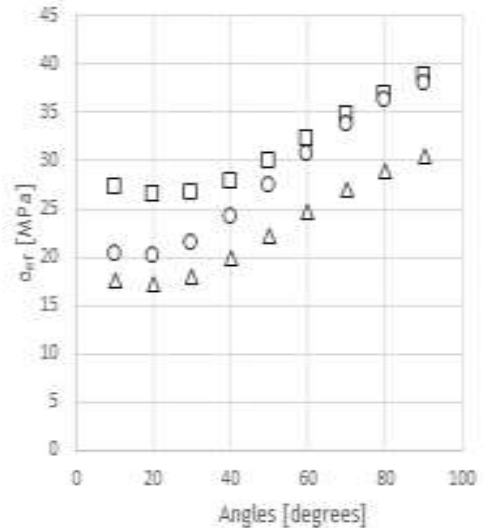

口FEM OKPM $\triangle$ NNRPM

9

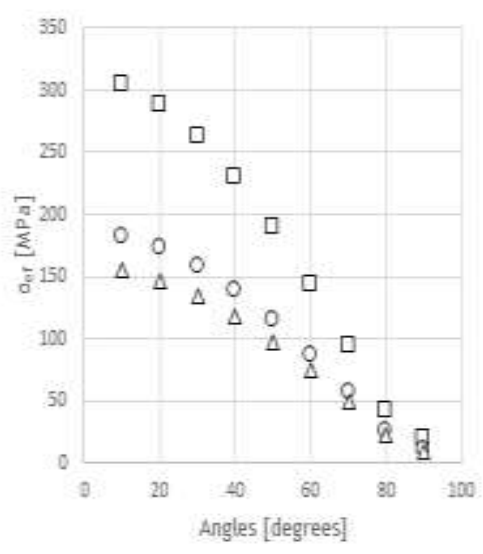

口FEM OBPM $\triangle$ NKAPUA

Figure A.45 Discrete stress values for type of bone 4, 'Model 2' and from bone side 
10

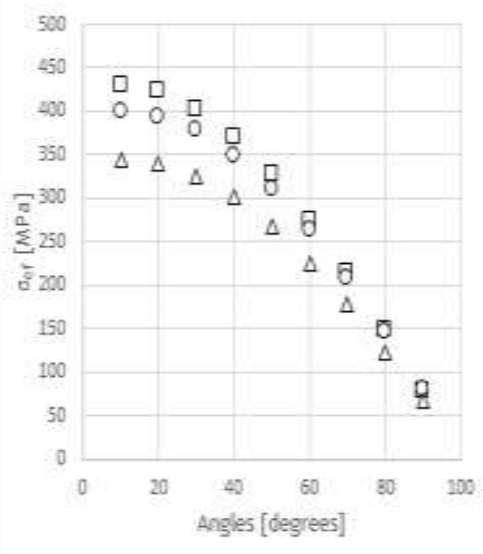

afeM opgM siwepM

13

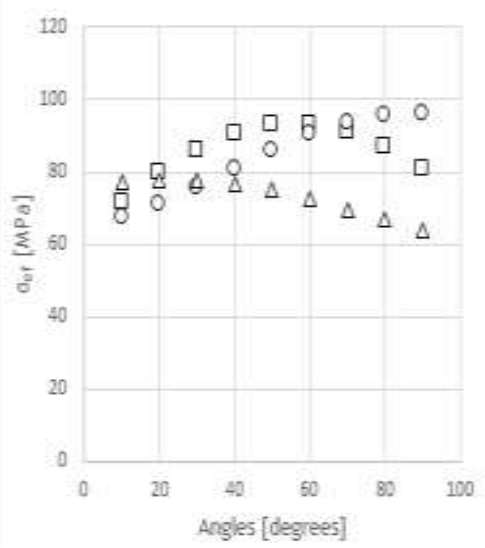

口FEU OPPM $\triangle$ NMPPM

16

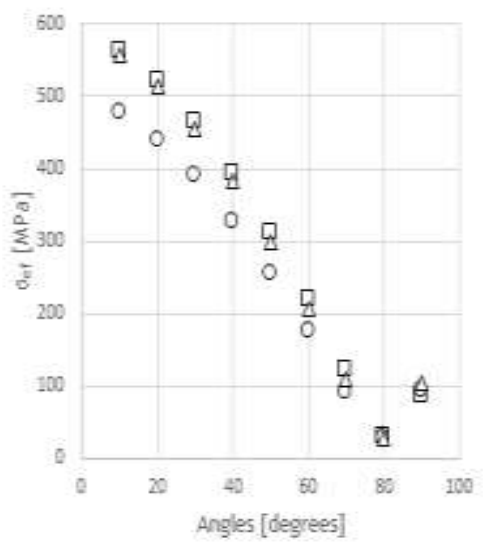

QFEM ORPM $\triangle$ NMRPM
11

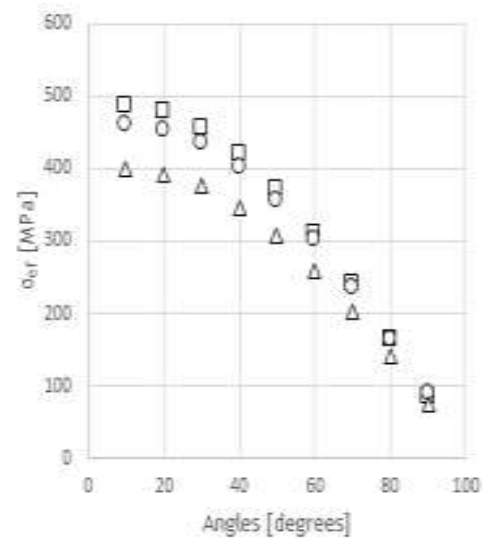

口FEM OPRM $\triangle$ NTEPIU

\section{4}

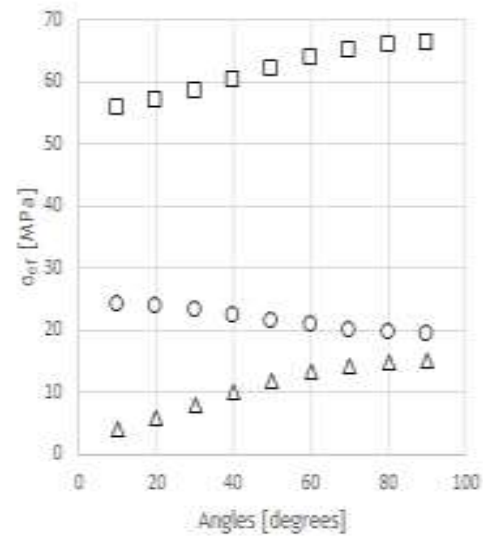

DFEM OPFM $\triangle$ NPEPIN

17

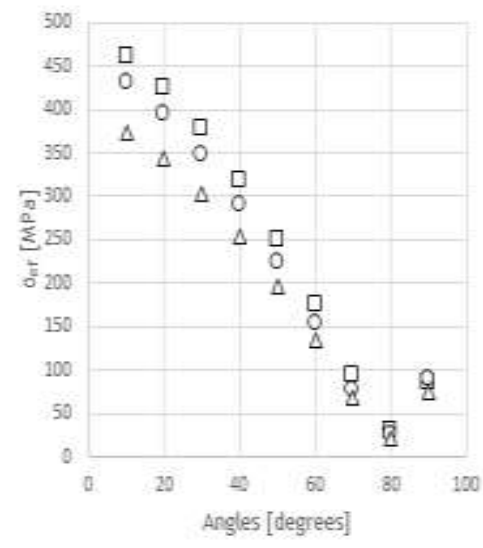

口FEG ORPM ANRAPM
12

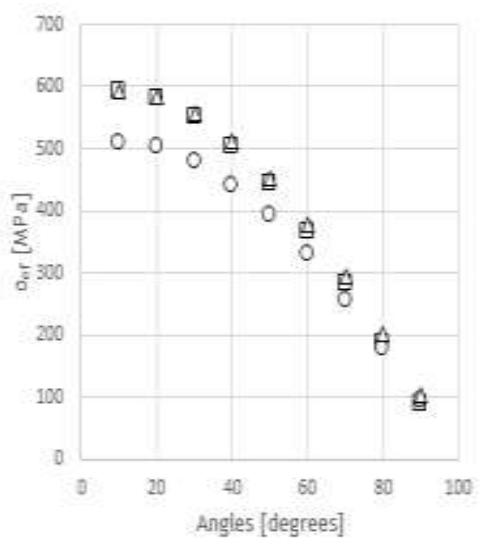

口FEM ORPM AHAPPM

15

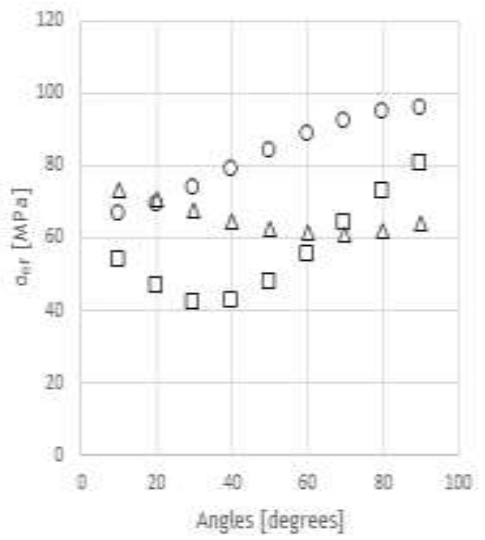

口FEM OBPM $\triangle$ NIRPM

18

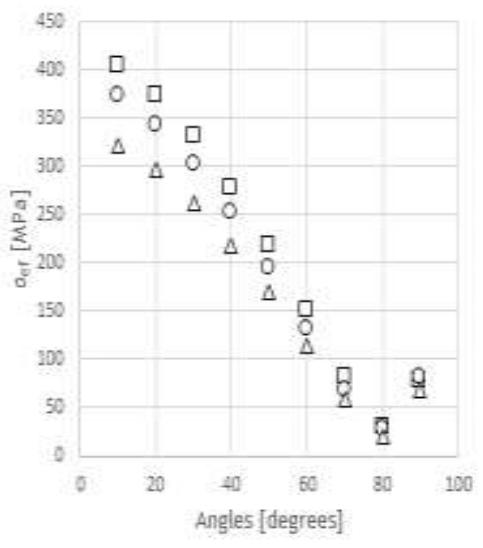

口FEM ORPM $\triangle$ NIRPM

Figure A.46 Discrete stress values for type of bone 4, 'Model 2' and from implant side 
1

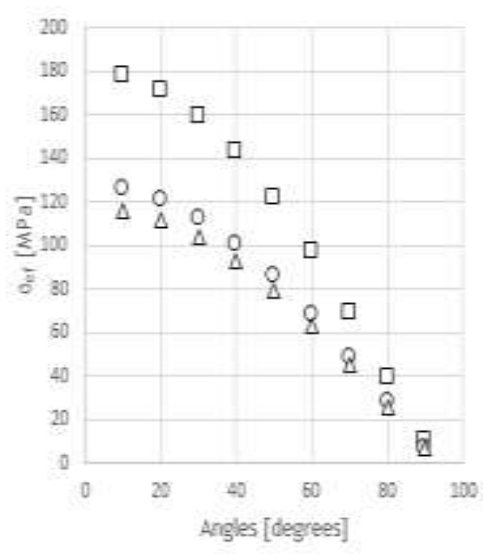

口FAM OAPM $\triangle$ NWEPM

4

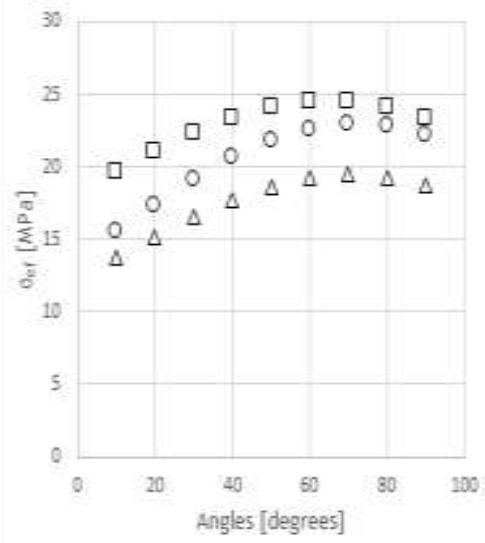

afen opeM skwege

7

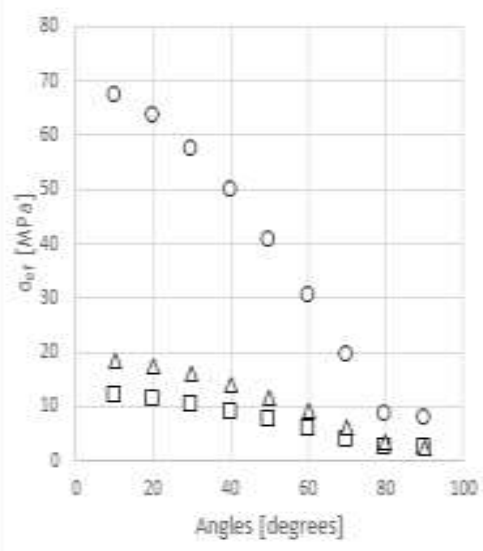

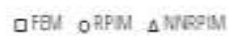

2

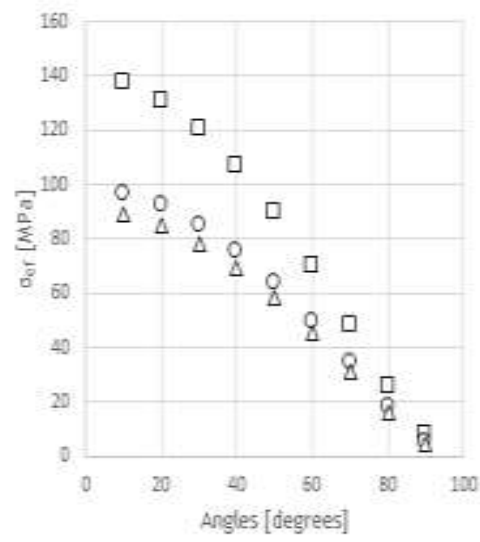

DFEM OPRM $\triangle$ NRAPM

5

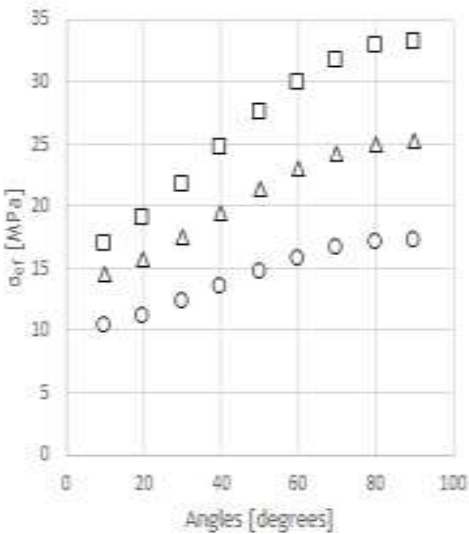

口FEM ORPM ANRAPM

8

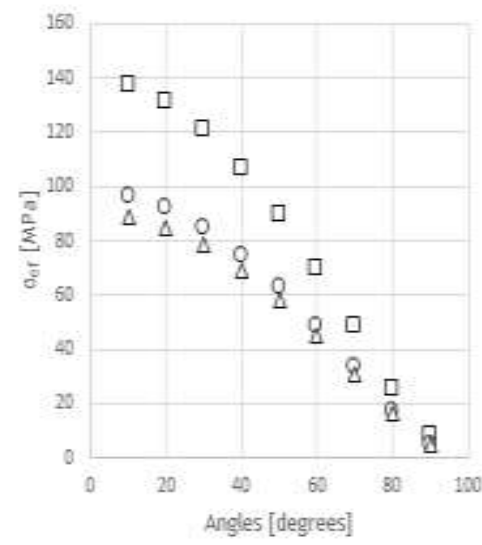

口FEM OPPW ANREPIW
3

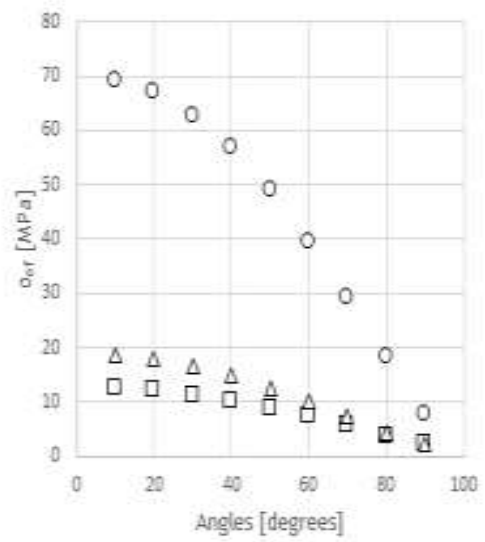

DFEM ORPM AWIRPM

6

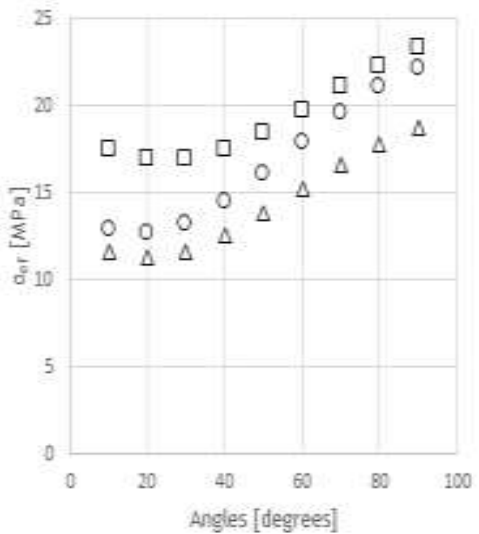

口FEM OKPM $\triangle$ NNAPM

9

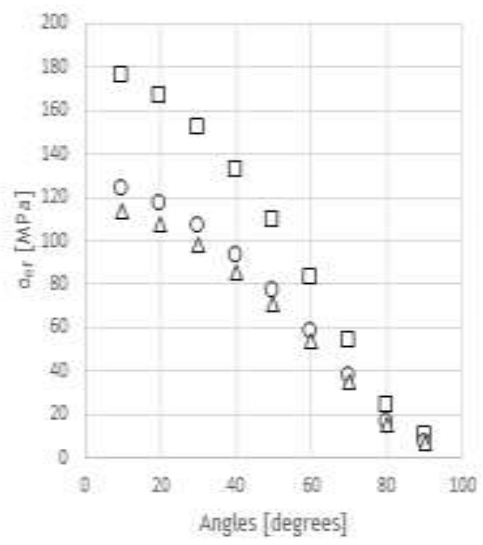

口FEM OBPM $\triangle$ NKAPHU

Figure A.47 Discrete stress values for type of bone 5, 'Model 1' and from bone side 
10

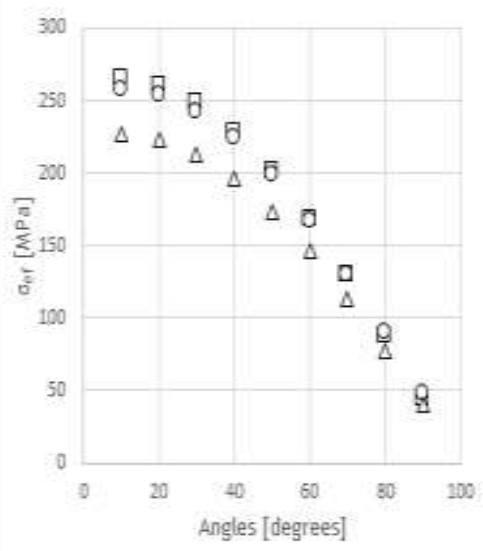

DFEM OPOM ANWEM

13

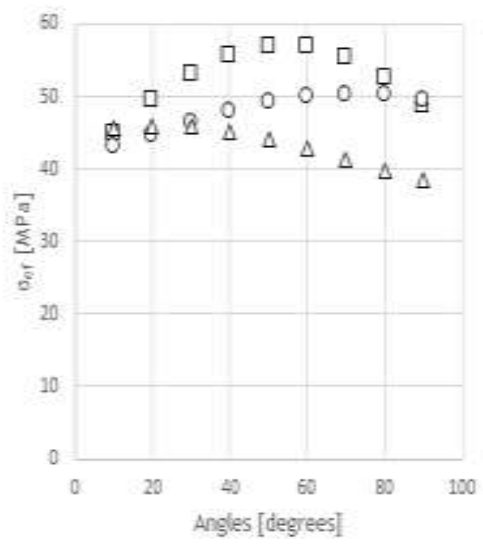

GFEM ORPM ANIRPM

16

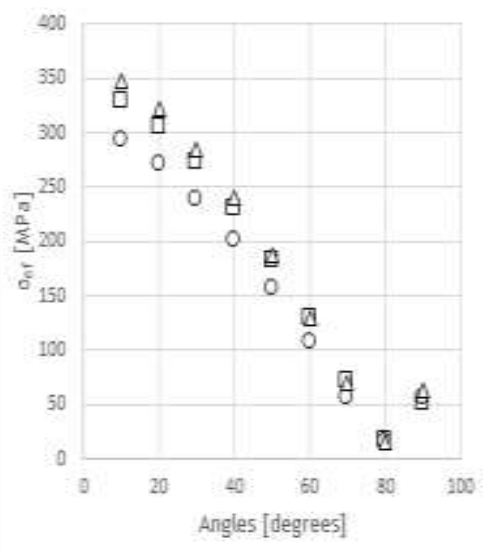

口FEM OPPM A NWEOM
11

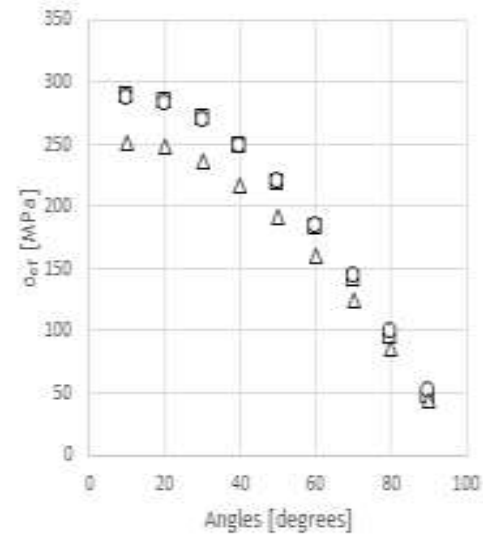

口FEM ORPM A NRPM

14

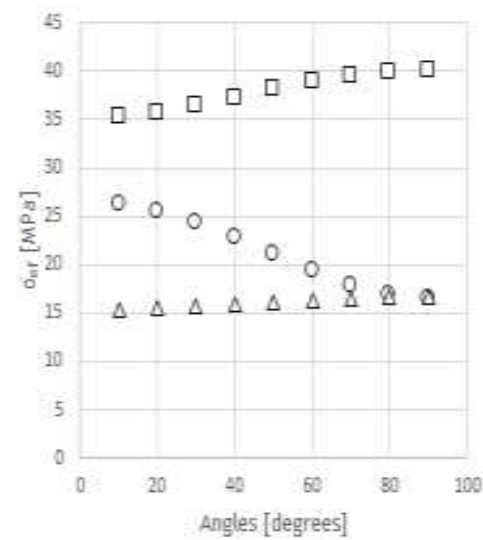

口FEM OPPW $\triangle$ MNPPM

17

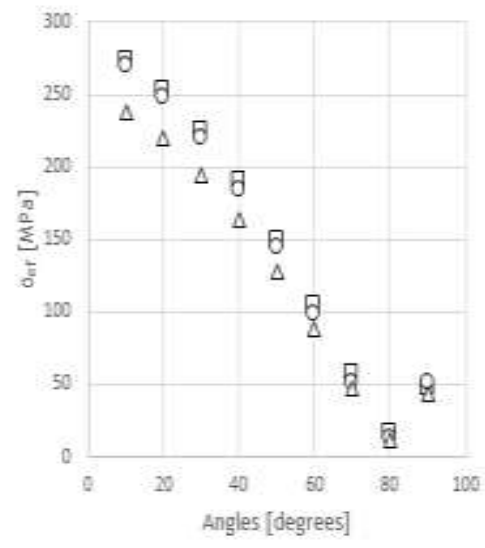

DFEM ORFM $\triangle$ MMPPM
12

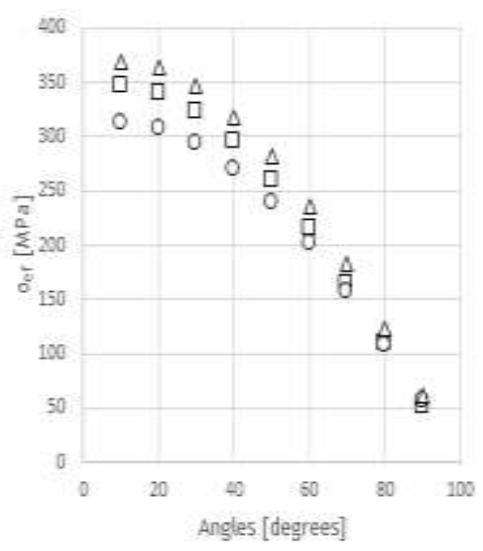

DFEM OPaM ANWRM

15

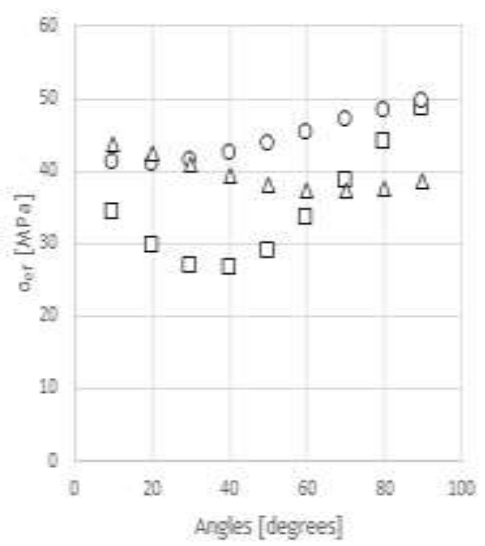

aFEM OREM AMVRM

18

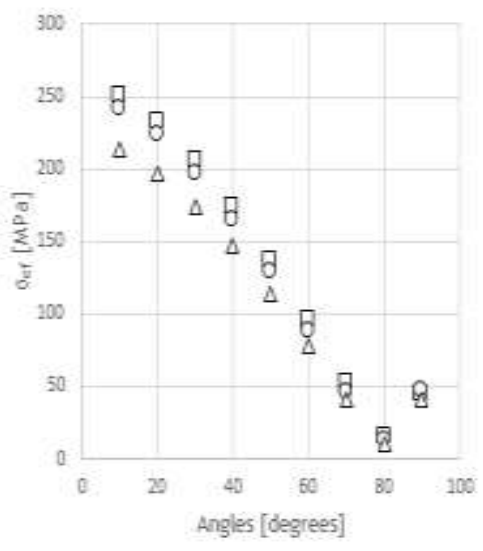

口FEL ORPM $\triangle$ NWPAM

Figure A.48 Discrete stress values for type of bone 5, 'Model 1' and from implant side 
1

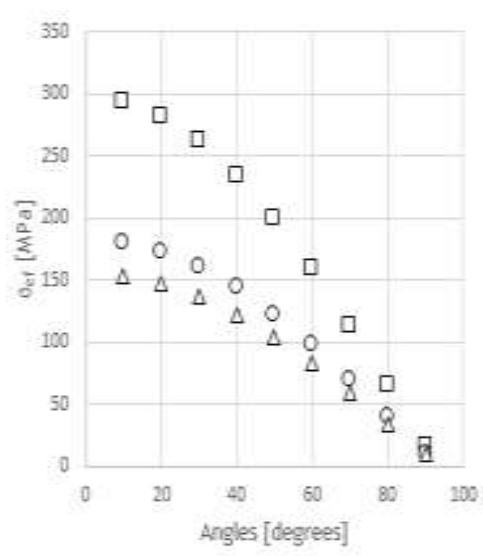

aFAM OAPM AKNePS

4

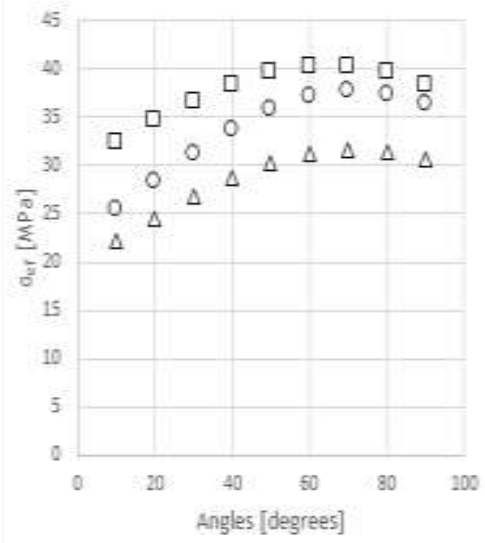

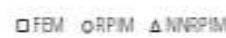

7

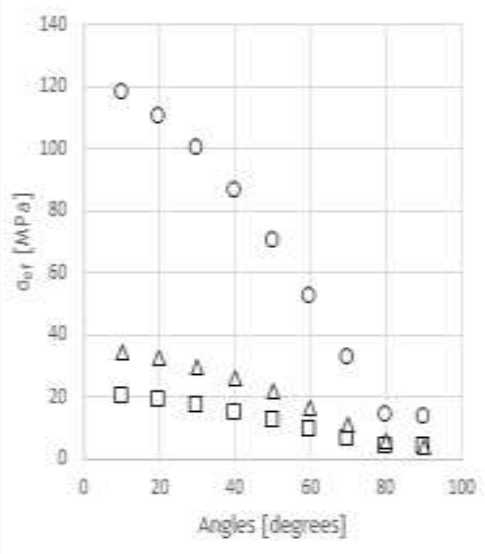

口FPU OBPM A STERIM
2

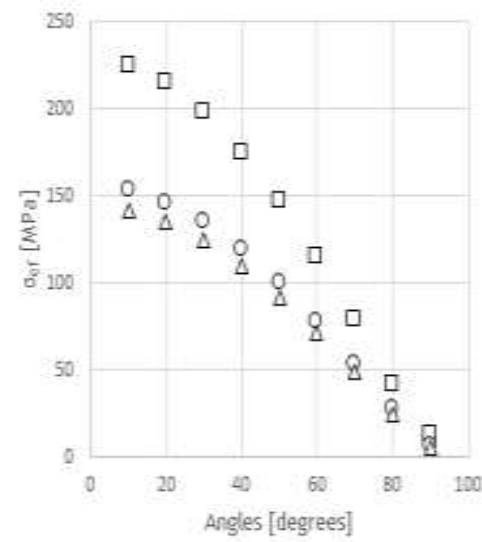

口FEM ORPM $\triangle$ NNAPM

5

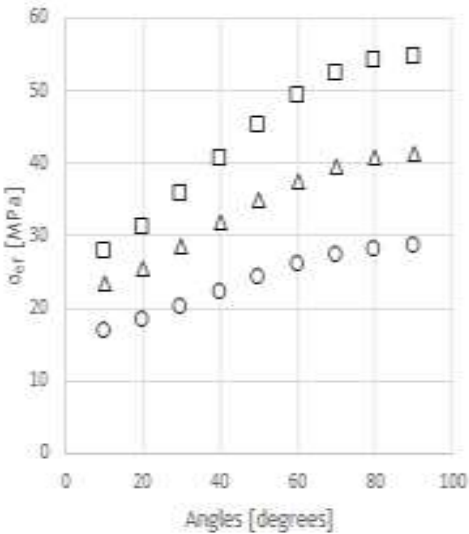

口FEM ORPM $\triangle$ NIEPIM

8

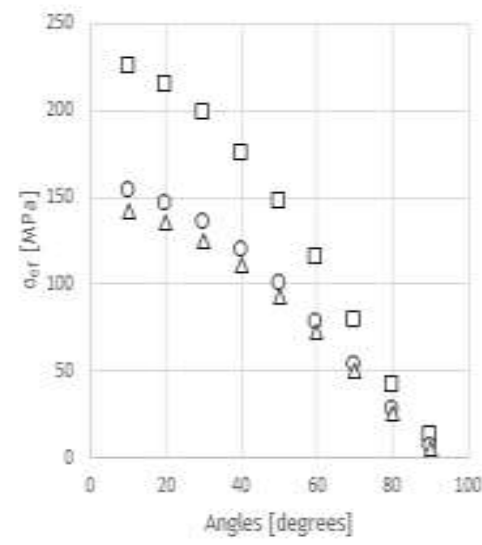

口FEM ORPM $\triangle$ NRAPIM
3

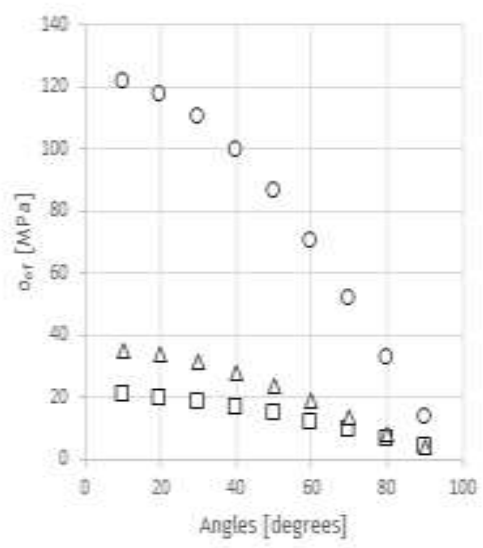

DFEM ORPM AWIRPM

\section{6}

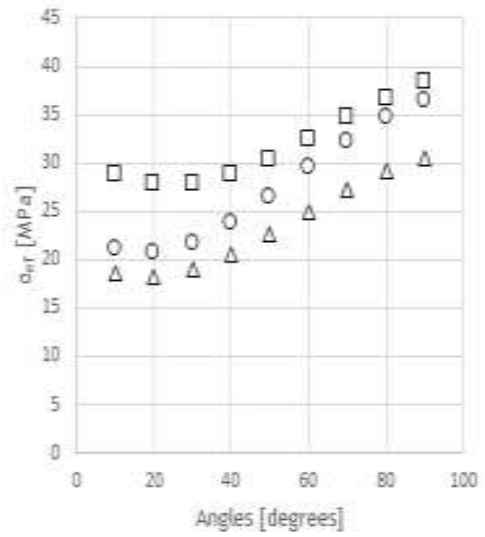

口FEM ORPM ANNRPM

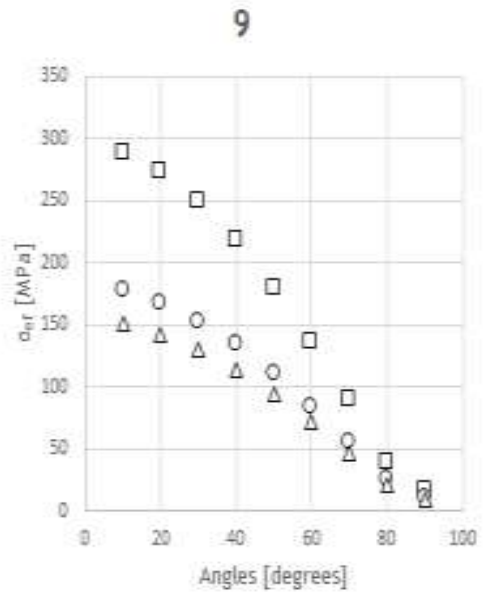

DFEM ORPM $\triangle$ NHAPM

Figure A.49 Discrete stress values for type of bone 5, 'Model 2' and from bone side 
10

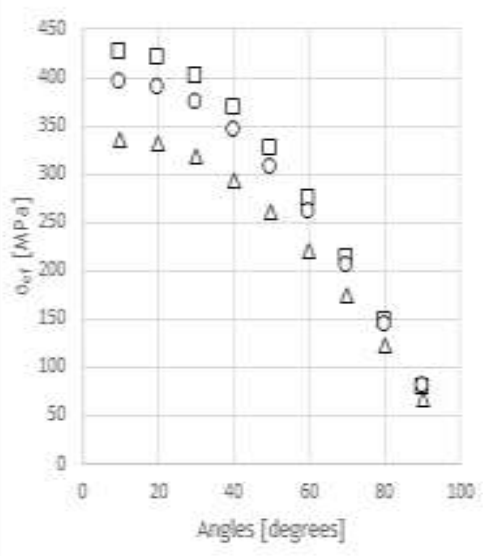

口FOM OPPM $\triangle$ NWEPM

13

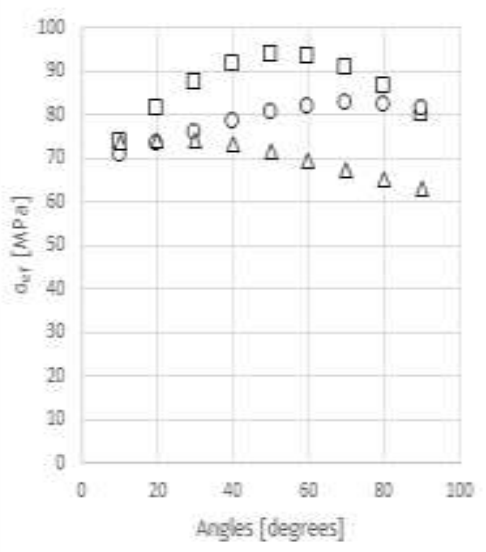

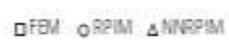

16

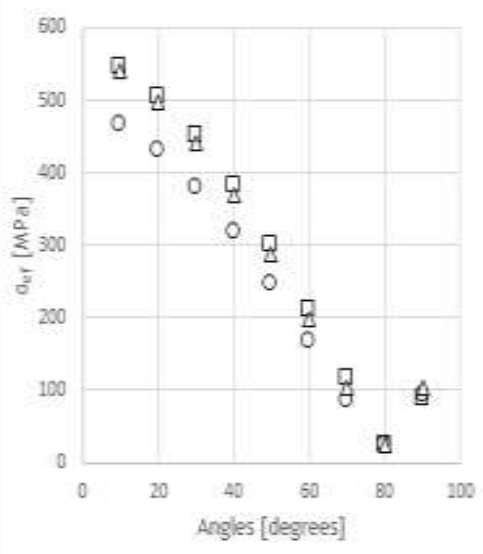

口FAU OAPM ANEPM
11

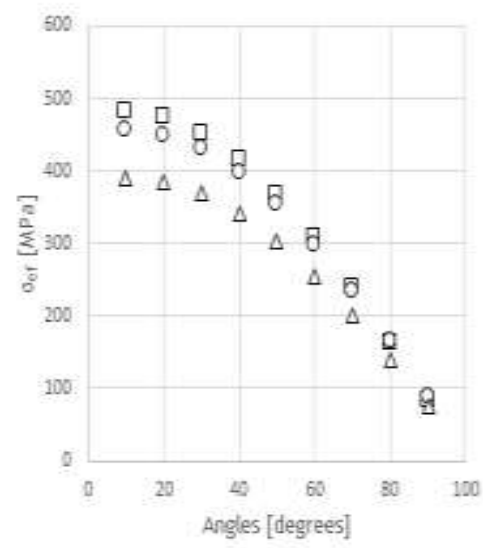

DFEM OPFM $\triangle$ NRAPM

14

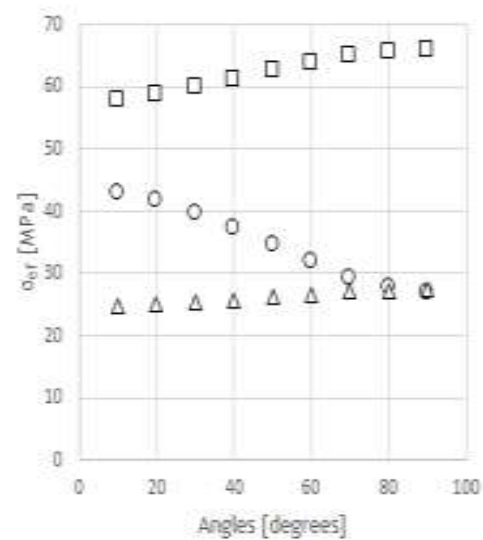

口FEM ORPM ANIAPIU

17

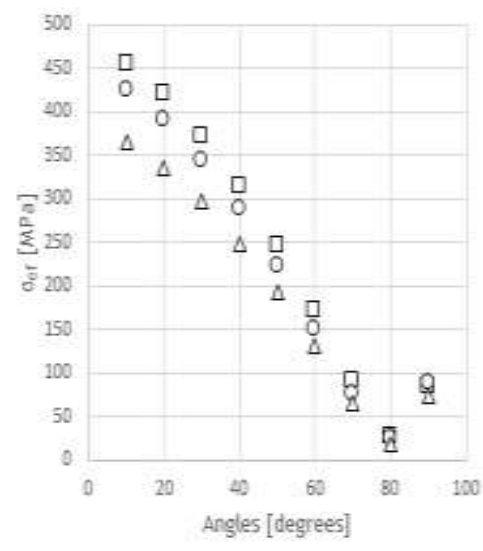

口FEM ORPIU ANRAPIU
12

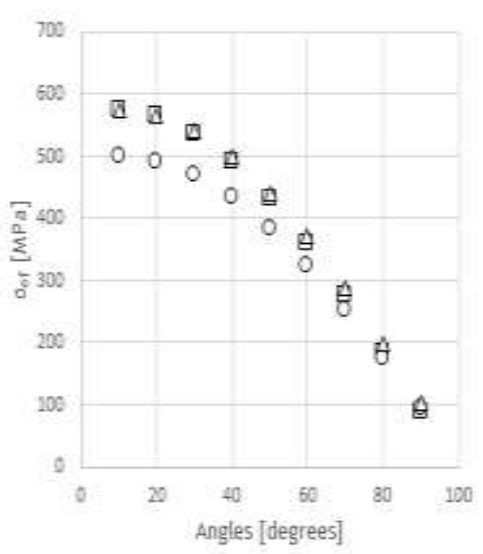

QFEM ORPM $\triangle N$ NPM

15

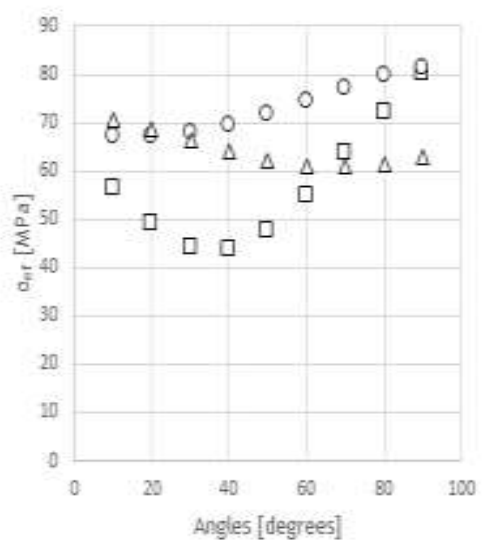

口FEM ORPM $\triangle$ NNRPM

18

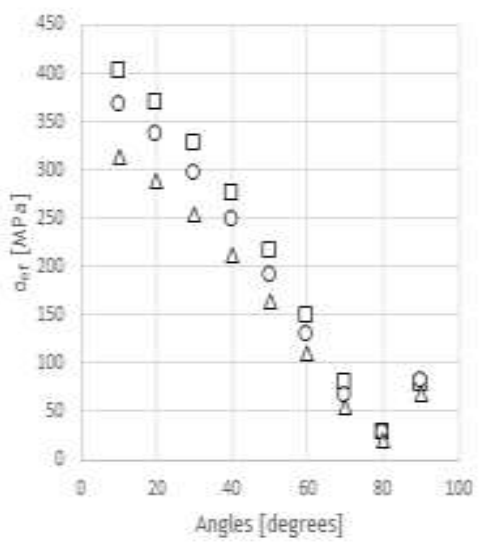

DFEM ORPM ANMPMU

Figure A.50 Discrete stress values for type of bone 5, 'Model 2' and from implant side 